\title{
MOTIVATION, CULTURAL VALUES, LEARNING PROCESSES, AND LEARNING IN CHINESE STUDENTS
}

by

\author{
Li Ouyang \\ A thesis submitted to the Faculty of Education \\ in conformity with the requirements for \\ the degree of Master of Education
}

Queen's University

Kingston, Ontario, Canada

July, 2008

Copyright CLi Ouyang, 2008 


\begin{abstract}
The purpose of this study was: (a) to examine the predictive utility of the achievement goal and Student Approaches to Learning (SAL) frameworks for characterizing Chinese students' motivation and achievement, and (b) to investigate how Confucian-heritage culture (CHC) may combine with achievement goals or SAL to generate different learning processes and outcomes and to promote optimal motivation. A questionnaire was conducted during a two-week period with over 700 first-year students who took both of the two courses - college English classes for non-English majors and advanced mathematics classes for science students - at a university in northern China. The questionnaire consisted of students' self-reported demographic information and the instrument that was designed to measure: (a) goal orientations, (b) attitudes towards the specified CHC values, (c) SAL constructs, and (d) two variables widely used in research in this field - metacognitive strategy and school well-being. Exploratory factor analyses were conducted to examine the consistency of the extracted factor solutions with the four goal constructs postulated by the $2 \times 2$ conceptualization, the two SAL contructs posited by the SAL framework, and the five cultural value contructs derived from the literature review. Standard analysis procedures were used to calculate the reliability of the scales and to determine which items should be retained for further analyses. Then regression analyses were employed to examine the relationship of the goal orientation framework and SAL framework to cultural values, school well-being, metacognitive strategies, and grades. Results indicated that the $2 \times 2$ achievement goal framework was an appropriate model for characterizing the types of achievement goals these Chinese students pursued
\end{abstract}


and for predicting a number of achievement-relevant processes and outcomes, as was the revised two-factor SAL framework for characterizing the different ways students approached their learning and for predicting these learning processes and outcomes. The results supported Chinese students' multiple goal pursuit in an additive goal pattern, an interactive goal pattern, or a specialized goal pattern to promote their optimal motivation and achievement. The results also provided evidence that $\mathrm{CHC}$ values combined with achievement goals or SAL either in an additive or interactive pattern to facilitate Chinese students' learning processes and outcomes. 


\section{ACKNOWLEDGEMENTS}

In acknowledging those who have made important contributions to the completion of this thesis, I must first extend my heartfelt thanks and gratitude to my supervisor and committee members, Nancy Hutchinson, John Kirby, and Liying Cheng, for their unwavering emotional and academic support and guidance throughout my master's program and thesis completion. They went far above and beyond their role, galvanizing me into hard work all the way with their trust, care, and enthusiasm. Without their professional help and constant encouragement, the completion of this research would not have been a reality.

I am extremely grateful to the students, teachers, and staff of the participating university. It is only through their cooperation and support that this study could be made possible.

I am indebted to my friends, Longhua Wang, Jing Liang, Cunhui Shang, for their assistance during the pilot and main study.

I owe many thanks to Lee Fabrigar for offering relevant information concerning statistics, and to Andrew J. Elliot for providing suggestions during the questionnaire design. My deepest appreciation is also extended to the instructors in the Faculty of Education for enriching my master's pursuit with their expertise and instigating my desire to join their ranks someday; to Marlene Sayers and Erin Wicklam for their enthusiastic help; and, to all my fellow students in the Faculty of Education at Queen's University for their sincere support. 
Finally, I would like to dedicate this thesis to my father for his boundless and unselfish love, and to my mother, brothers, and sister for their understanding and support in every way they could provide. 


\section{TABLE OF CONTENTS}

ABSTRACT

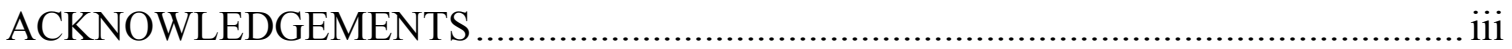

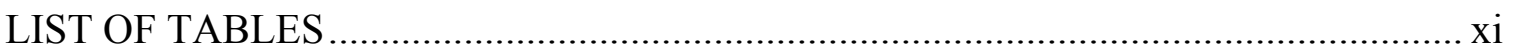

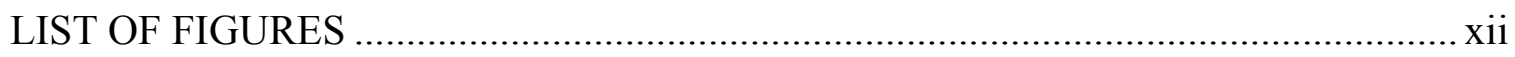

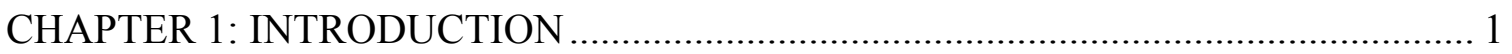

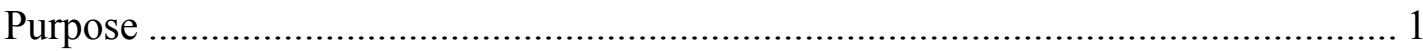

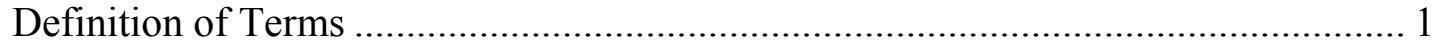

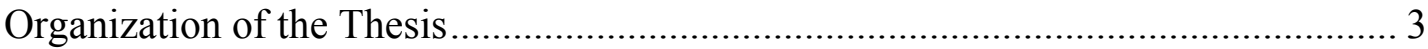

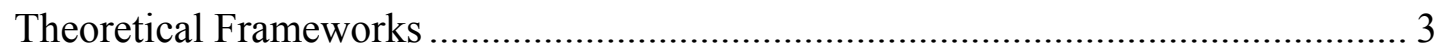

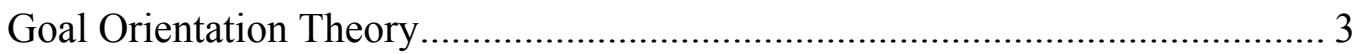

Dichotomous Framework ……………................................................. 4

Trichotomous Framework ………………………………………..... 5

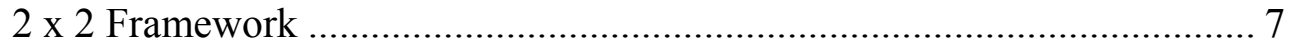

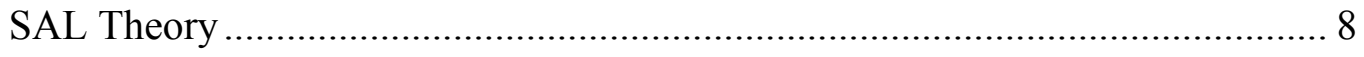

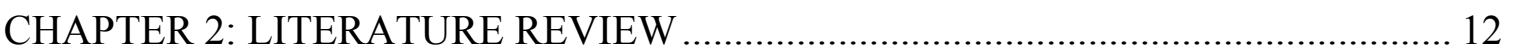

Confucian-heritage Culture Values .......................................................................... 12

Achievement Goal Orientation, Cultural Values, and Chinese Students .................. 13

Applicability of Achievement Goal Theory to Chinese Students ....................... 13

Empirical Work with Western Students....................................................... 13

Empirical Research with Chinese Students................................................ 16

2 x 2 Conceptualization and Chinese Students .......................................... 19

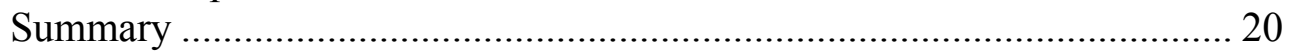

Goal Orientations, Cultural Values, and Chinese Students' Learning Processes and Academic Achievement ............................................................................. 21

Confucian-heritage Cultural Values, Goal Orientations, and Learning

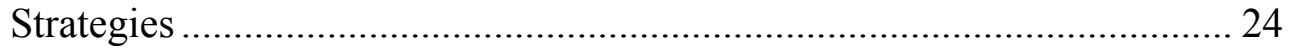

Confucian-heritage Cultural Values, Goal Orientations, and School Well-

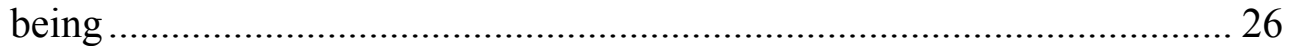

Confucian-heritage Cultural Values, Goal Orientations, and Academic

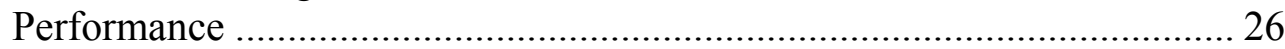

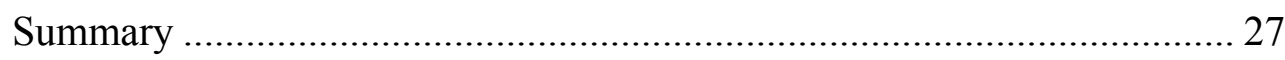

Multiple Goals and Chinese Students........................................................... 28 


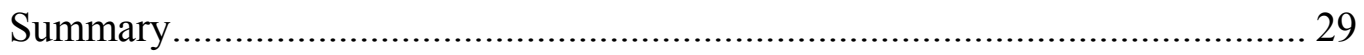

SAL, Cultural Values, and Chinese Students ......................................................... 29

Applicability of SAL Theory to Chinese Students............................................. 29

Empirical Work with Western Students...................................................... 30

Empirical Research with Chinese Students................................................... 34

SAL, Cultural Values, and Chinese Students' Motivational and Cognitive Processes and Outcomes................................................................................. 35

Confucian-heritage Cultural Values, SAL, and Use of Metacognitive Strategies ................................................................................................ 37

Confucian-heritage Cultural Values, SAL, and School Well-being ............ 38

Confucian-heritage Cultural Values, SAL, and Academic Performance.... 38

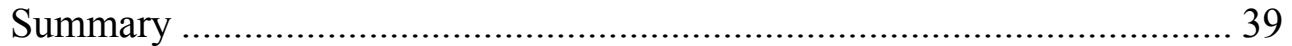

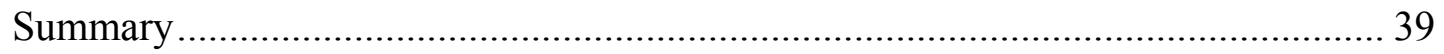

CHAPTER 3: METHOD, HYPOTHESES, AND ANALYSES ....................................... 41

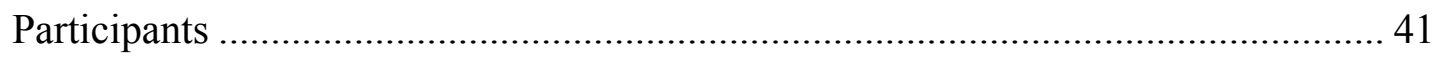

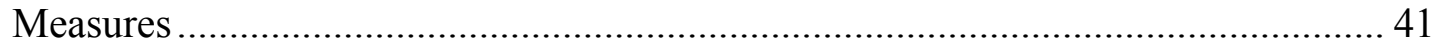

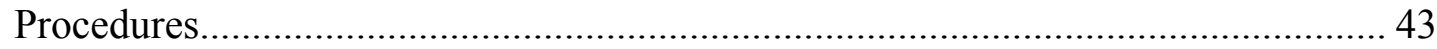

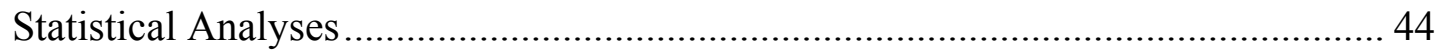

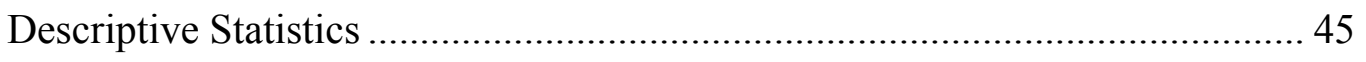

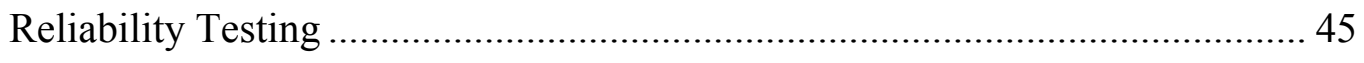

Hypotheses and Major Statistical Analyses ....................................................... 46

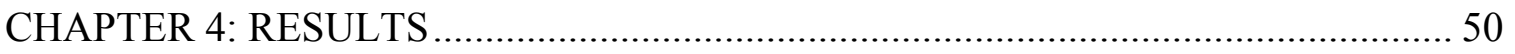

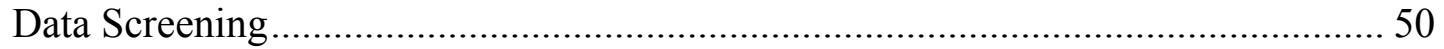

Accuracy of Data File................................................................................... 50

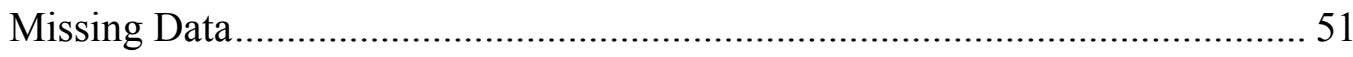

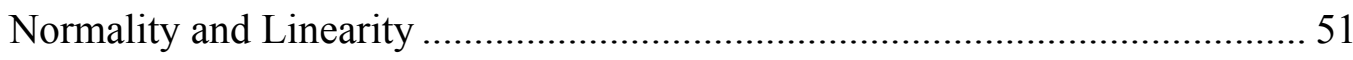

Univariate and Multivariate Outliers among Cases........................................... 53

Exploratory Factor Analysis ............................................................................ 55

Factor Analyses of Cultural Value, Achievement Goal, and SAL Items ........... 55

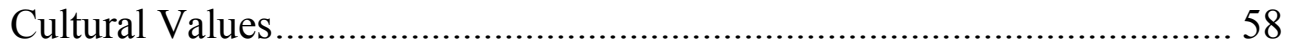

Goal Orientations in College English Classes.............................................. 61

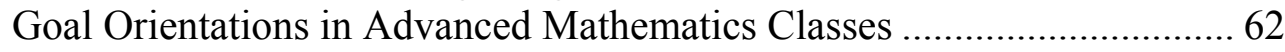

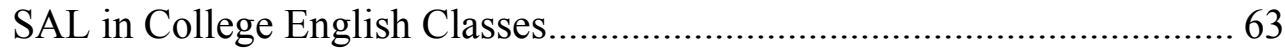

SAL in Advanced Mathematics Classes ..................................................... 63 
Factor Analyses of Metacognitive Strategy and School Well-being Items........ 64

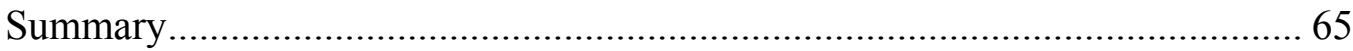

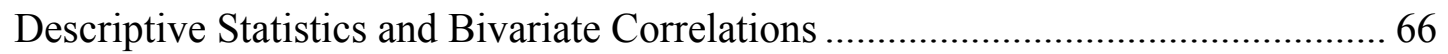

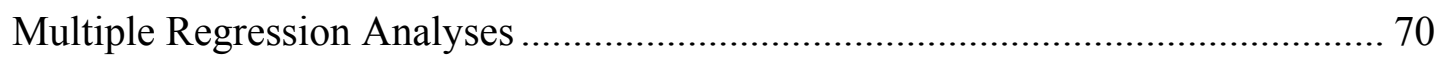

Goal Orientation Framework and Learning Process and Outcome Variables ... 71

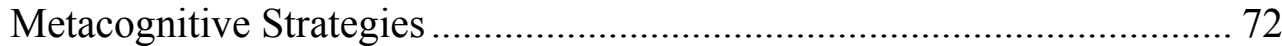

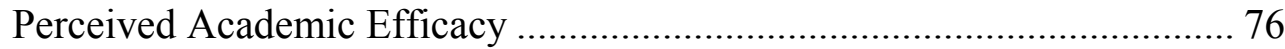

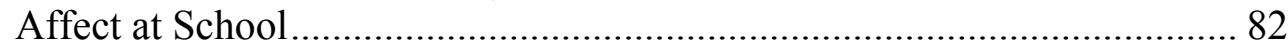

Academic Performance ......................................................................... 84

SAL Framework and Learning Process and Learning Outcome Variables ....... 85

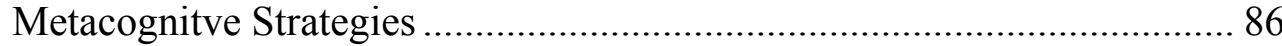

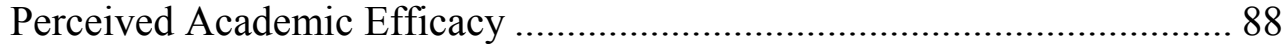

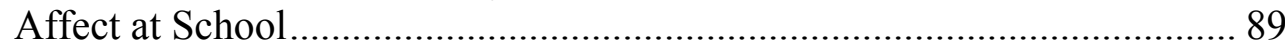

Academic Performance .................................................................... 91

CHC Values and the Goal Orientation Framework ....................................... 92

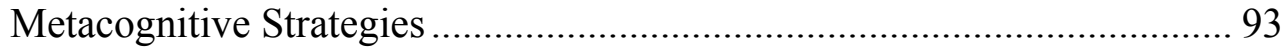

Perceived Academic Efficacy ............................................................... 96

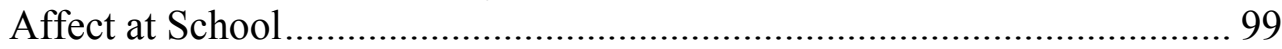

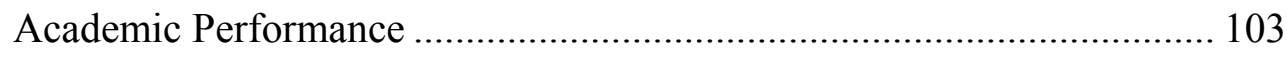

$\mathrm{CHC}$ values and the SAL Framework .................................................... 105

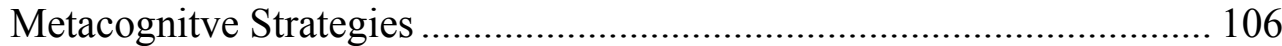

Perceived Academic Efficacy ............................................................ 108

Affect at School............................................................................... 110

Academic Performance ..................................................................... 113

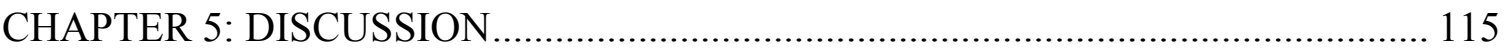

To What Extent Do Chinese Students Pursue the CHC Values? ........................... 115

To What Extent Do Chinese Students Endorse Achievement Goal Orientations as Postulated by the 2 x 2 Conceptualization?

To What Extent Do Chinese Students Adopt the Approaches to Learning as Posited by the SAL Framework?

To What Extent Does Chinese Students' Achievement Goal Endorsement Differentially Predict Their Learning Processes and Outcomes?

To What Extent Do Achievement Goals Combine to Facilitate Learning Processes and Outcomes for Chinese Students?

To What Extent Do Chinese Students' Approaches to Learning Differentially Predict Their Learning Processes and Outcomes? 
To What Extent Do Chinese Students' Attitude Towards CHC Values and Their Achievement Goal Pursuit Interact to Impact Their Learning Processes and Outcomes?

To What Extent Do Chinese Students' Attitude Towards CHC Values and their Adoption of Approaches to Learning Interact to Affect Their Learning Processes and Outcomes? 136

Research Implications 137

Implications for Educational Research on CHC Students............................ 138

Implications for Achievement Goal Theory and SAL Theory Research ......... 139

Limitations and Avenues for Future Research ................................................ 141

REFERENCES 143

APPENDIX A 157

Table A1: Primary and Secondary Factor Loadings for Cultural Value Items (ordered by size of loadings in which variables contribute to factors) and Intercorrelations among Factors

Table A2: Internal Consistency Reliability Coefficient of Cultural Value Scales (Ordered by size of loadings in which variables contribute to factors)

Table A3: Zero-Order Correlations among the Cultural ValueVariables 162

Table A4: Internal Consistency Reliability Coefficient of CHC Value Scale (ordered by size of loadings in which variables contribute to the factor) 163

Table A5: Primary and Secondary Factor Loadings for Goal Orientation Items in College English Classes (ordered by size of loadings in which variables contribute to factors) and Intercorrelations among Factors

Table A6: Internal Consistency Reliability Coefficient of Goal Orientation Scales (ordered by size of loadings in which variables contribute to factors) in College English Classes

Table A7: Primary and Secondary Factor Loadings for Goal Orientation Items in Advanced Mathematics Classes (ordered by size of loadings in which variables contribute to factors) and Intercorrelations among Factors

Table A8: Internal Consistency Reliability Coefficient of Goal Orientation Scales (order by size of loadings in which variables contribute to factors) in Advanced Mathematics Classes.

Table A9: Primary and Secondary Factor Loadings for SAL Items in College English Classes (ordered by size of loadings in which variables contribute to factors) ....... 172 
Table A10: Internal Consistency Reliability Coefficient of SAL Scales (Ordered by size of loadings in which variables contribute to factors) in College English Classes

Table A11: Primary and Secondary Factor Loadings for SAL Items in Advanced Mathematics Classes (ordered by size of loadings in which variables contribute to factors)

Table A12: Internal Consistency Reliability Coefficient of SAL Scales (ordered by size of loadings in which variables contribute to factors) in Advanced Mathematics Classes

Table A13: Factor Loadings for Metacognitive Strategy Items in College English Classes (ordered by size of loadings in which variables contribute to factors) ....... 180

Table A14: Factor Loadings for Metacognitive Strategy Items in Advanced Mathematics Classes (ordered by size of loadings in which variables contribute to factors)

Table A15: Factor Loadings for Perceived Academic Efficacy Items in College English Classes (ordered by size of loadings in which variables contribute to factors)

Table A16: Factor Loadings for Perceived Academic Efficacy Items in Advanced Mathematics Classes (ordered by size of loadings in which variables contribute to factors)

Table A17: Factor Loadings for Affect at School Items in College English Classes (ordered by size of loadings in which variables contribute to factors)....

Table A18: Factor Loadings for Affect at School Items in Advanced Mathematics Classes (ordered by size of loadings in which variables contribute to factors)....... 185

Table A19: Internal Consistency Reliability Coefficient of Metacognitive Strategy and School Well-being Scales (Ordered by size of loadings in which variables contribute to factors) in College English Classes and Advanced Mathematics Classes

Table A20: Descriptive Statistics for All Variables

Table A21: Zero-Order Correlations among the Cultural Value, Achievement Goal Orientation, SAL, Metacognitive Strategy and School Well-being, and Achievement Variables 188

Table A22: Summary of Hierarchical and Simultaneous Regression Analysis for Achievement Goal Variables Predicting Metacognitive Strategies, Perceived Academic Efficacy, Affect at School, and Academic Performance in College English Classes 190

Table A23: Summary of Hierarchical and Simultaneous Regression Analysis for Achievement Goal Variables Predicting Metacognitive Strategies, Perceived 
Academic Efficacy, Affect at School, and Academic Performance in Advanced Mathematics Classes.

Table A24: Summary of Hierarchical and Simultaneous Regression Analysis for SAL Variables Predicting Metacognitive Strategies, Perceived Academic Efficacy, Affect at School, and Academic Performance in College English Classes

Table A25: Summary of Hierarchical and Simultaneous Regression Analysis for SAL Variables Predicting Metacognitive Strategies, Perceived Academic Efficacy, Affect at School, and Academic Performance in Advanced Mathematics Classes. 195

Table A26: Summary of Hierarchical and Simultaneous Regression Analysis for CHC Values and Goal Orientation Variables Predicting Metacognitive Strategies, Perceived Academic Efficacy, Affect at School, and Academic Performance in College English Classes.

Table A27: Summary of Hierarchical and Simultaneous Regression Analysis for CHC Values and Goal Orientation Variables Predicting Metacognitive Strategies, Perceived Academic Efficacy, Affect at School, and Academic Performance in Advanced Mathematics Classes

Table A28: Summary of Hierarchical and Simultaneous Regression Analysis for CHC Values and SAL Predicting Metacognitive Strategies, Perceived Academic Efficacy, Affect at School, and Academic Performance in College English Classes

Table A29: Summary of Hierarchical and Simultaneous Regression Analysis for CHC Values and SAL Predicting Metacognitive Strategies, Perceived Academic Efficacy, Affect at School, and Academic Performance in Advanced Mathematics

Classes

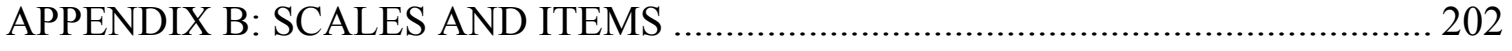

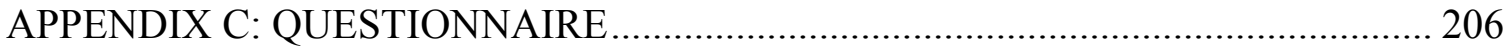

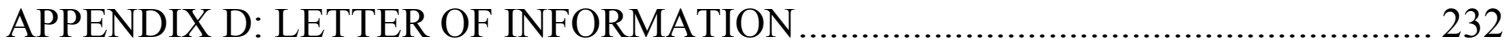

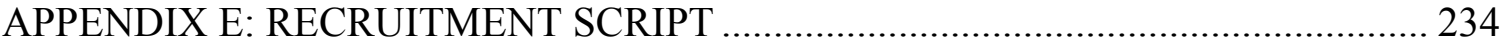




\section{LIST OF TABLES}

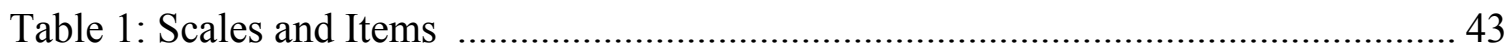

Table 2: Mehalanobis $\mathrm{D}^{2}$ Scores and Their Probability for Cases Located as Multivariate

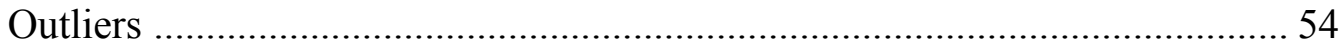

Table 3: The Prediction of Achievement Goals for Learning Processes and Outcomes 121

Table 4: The Prediction of SAL for Learning Processes and Outcomes ...................... 130

Table 5: The Way CHC Values Combine with Achievement Goals to Influence Learning Processes and Outcomes .................................................................... 132

Table 6: The Way CHC Values Combine with SAL to Influence Learning Processes and

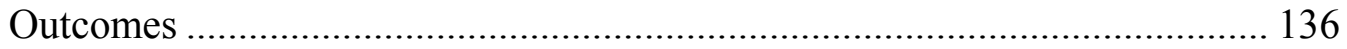




\section{LIST OF FIGURES}

Figure 1: Pap $\times$ Pav Interaction Effect on Metacognitive Strategy in College English Classes

Figure 2: Map $\times$ Mav Interaction Effect on Metacognitive Strategy in Advanced Mathematics....

Figure 3: Map $\times$ Mav Interaction Effect on Perceived Academic Efficacy in College English Classes 78

Figure 4: Pap $\times$ Pav Interaction Effect on Perceived Academic Efficacy in College English Classes

Figure 5: Map $\times$ Pav Interaction Effect on Perceived Academic Efficacy in Advanced Mathematics Classes

Figure 6: Mav $\times$ Pap Interaction Effect on Perceived Academic Efficacy in Advanced Mathematics Classes

Figure 7: Mav $\times$ CHC Value Interaction Effect on Metacognitive Strategies in College English Classes

Figure 8: Mav $\times$ CHC Value Interaction Effect on Perceived Academic Efficacy in College English Classes

Figure 9: Map $\times$ CHC Value Interaction Effect on Affect at School in College English Classes.

Figure 10: Pav $\times$ CHC Value Interaction Effect on Affect at School in College English Classes.

Figure 11: Dap $\times$ CHC Value Interaction Effect on Metacognitive Strategies in College English Classes

Figure 12: Dap $\times$ CHC Value Interaction Effect on Affect at School in College English Classes. 


\section{CHAPTER 1}

\section{INTRODUCTION}

Purpose

In the past two decades, a considerable amount of research has been conducted with university students in an attempt to understand their motivation in academic settings. One prominent framework that has been used to guide research in the North American context is achievement goal orientation theory (Pintrich \& Schunk, 2002). This theory has evolved from two (dichotomous framework) through three (trichotomous framework) to four factors (often called the 2 × 2 framework) (Elliot \& McGregor, 2001). Another well-known theory that has been employed to understand the motivation and strategy use of university students in many contexts, including Asian contexts, is the Student Approaches to Learning (SAL) framework (Biggs, 1993; Biggs, Kember, \& Leung, 2001). The general purpose of this study is to investigate the relationships among motivation, cultural values, learning processes, and learning in Chinese university students. The investigation was undertaken using measures developed within each of these two theoretical frameworks - the $2 \times 2$ goal orientation framework and the SAL framework. Specifically, this research is aimed to: (a) investigate the predictive utility of each of the goal orientation framework and the SAL framework for characterizing Chinese students' motivation and achievement; (b) investigate how Confucian-heritage culture may combine with each of achievement goals and SAL to generate different learning processes and outcomes and to promote optimal motivation.

\section{Definition of Terms}


This study employs two theoretical frameworks in motivation. In the $2 \times 2$ framework, motivation refers to goal orientations, which are differentiated on two fundamental dimensions: according to how competence is defined (mastery-performance dimension) and according to how competence is valenced (approach-avoidance dimension) (Elliot \& Thrash, 2001). In the SAL framework, motivation refers to different ways students may approach their learning - the deep and surface approaches (Biggs, 1993; Biggs \& Kirby, 1984; Entwistle \& Waterston, 1988), i.e., the manner in which students utilize motives and corresponding strategies to fulfill the diverse intentions of studying. Cultural values that are focused on in this study are those notions emphasized in Confucian-heritage cultures (Confucius, 479 B.C.; Hong, 2001; Lee, 1999; Salili, 1995, 1999; Salili, Chiu, \& Lai, 2001; Tweed \& Lehman, 2002; Watkins \& Biggs, 2001), including perception of learning as a primary and moral duty, utility value or perceived instrumentality of current school success to attainment of personally valued future goals, and endorsement of group goals (family-oriented goals, peer-oriented goals, and teacheroriented goals). In this study, learning processes refers to the metacognitive strategies students utilize to control their learning and to facilitate their self-regulation and includes school well-being, while learning is interpreted in terms of students' academic achievement, with grades representing the most obvious and universally accepted indicator in academic settings. In the literature review for this research, the term Chinese students is used to refer to individuals who are influenced by the Confucian-heritage cultures; however, in this study the term is delimited as students who are now pursuing their schooling at a university in China. 
Organization of the Thesis

In general, the focus of this thesis is on: (a) the predictive utility of each of the $2 \mathrm{x}$ 2 framework and the revised two-factor SAL framework for characterizing Chinese students' motivation and achievement; (b) the way Confucian-heritage culture and achievement goals or SAL may combine to generate different learning processes and outcomes and promote optimal motivation. This thesis is presented in five chapters. Chapter one presents the purpose, lays out the definitions of terms, and introduces the theoretical frameworks. Chapter two presents a review of the literature on Confucianheritage cultural values, achievement goal theory, and SAL theory. Chapter three details the methodology for this study, describing the participants, measures, data collection procedures, and methods of statistical analysis. Chapter four reports the results of analysis following eight research questions. In the final chapter, research findings are summarized and discussed. This chapter also presents the implications of this study for education research and its limitations with avenues for future research indicated.

Theoretical Frameworks

This section contains a brief description of the two theoretical frameworks of goal orientations and students' approaches to learning.

\section{Goal Orientation Theory}

Three frameworks of achievement goal theory have emerged since its inception in the late 1970 s and early 1980 s. The dichotomous framework reflects the definition dimension of competence (mastery-performance distinction) and the trichotomous conceptualization stems from the incorporation of the valence dimension (approach- 
avoidance distinction) into performance goals. The $2 \times 2$ matrix of four distinct factors "represents a further revision of the mastery-performance dichotomy and an extension of the trichotomous framework" (Elliot \& McGregor, 2001, p. 501).

\section{Dichotomous Framework}

Within the dichotomous framework, mastery goals orient the student toward learning and understanding, the development of skills and competence, and selfimprovement using either self-referenced and intrapersonal standards of competence or task-referenced and absolute standards of competence. Performance goals, however, focus the student on demonstrations of competence, recognition of high competence, selfworth protection, and attempts to surpass others using normative standards based on social comparisons (Elliot \& Church, 1997; Elliot \& Thrash, 2001; Pintrich, 2003).

Mastery goals have been regularly associated with a positive and adaptive constellation of motivational, cognitive, behavioural, and affective outcomes and processes, such as effort attribution for success and failure (Ames, 1992), higher selfefficacy (Wolters, Yu, \& Printrich, 1996), more intrinsic motivation (Harackiewicz, Barron, Tauer, \& Elliot, 2002), effort and persistence (Elliot, McGregor, \& Gable, 1999), challenge seeking (Dweck \& Leggett, 1988), adaptive help seeking (Ryan, Pintrinch \& Midgley, 2001), use of deep learning strategies (Wolter et al., 1996), positive attitude (Roeser, Midgley, \& Urdan, 1996), and well-being (Kaplan \& Maehr, 1999). These data are usually collected with self-report instruments. But the relation of mastery goal orientation to academic achievement appears less clear-cut, with some findings showing positive relations (e.g., Kaplan \& Maehr, 1999) and others demonstrating none of this 
pattern (e.g., Harackiewicz, Barron, Tauer, Carter, \& Elliot, 2000). Kaplan and Maerhr (2007) suggest a moderating mastery goal effect of task type on academic achievement: Mastery goals might be more predictive of achievement on open-ended tasks but less predictive of objective tasks such as multiple-choice tests.

In contrast to mastery goals, performance goals, generally considered maladaptive, have been linked to some negative motivational and cognitive outcomes and processes, such as ability attributions for success and failure (Dweck \& Leggett, 1988), increased test anxiety (Skaalvik, 1997), use of superficial and effort-minimizing learning strategies (Meece, Blumenfeld, \& Hoyle, 1988), less adaptive help seeking (Ryan \& Pintrinch, 1997), and negative affect (Ames, 1992). However, there are some mixed and ambiguous empirical findings with regard to the linear relations between performance goals and selfefficacy, intrinsic motivation, and especially GPA (e.g. Elliot, 1999; Pintrinch \& Schunk, 2002; Roeser, Midgley, \& Urdan, 1996). These empirical inconsistencies, combined with the historical significance and theoretical utility of the approach-avoidance distinction, led Elliot and Harackiewiez and their colleagues to reformulate the dichotomous achievement goal theory framework (Elliot, 1999; Elliot \& Church, 1997; Elliot \& Harackiewicz, 1996).

\section{Trichotomous Framework}

Within the trichotomous framework, the conventional performance goal is bifurcated into independent approach and avoidance components, while the mastery goal construct is left intact. Performance approach goals focus on doing better than others, demonstrating competence, and attaining favourable judgments of competence. Under 
this type of goal, students are thought to be positively motivated to outperform others and demonstrate their competence. Since this type of goal is seen as focused on the possibilities of a positive normative outcome (Elliot \& Harackiewicz, 1996) or on the need for achievement combined with fear of failure and with high competence expectancies (Elliot, 1999), the relevant motivational profiles are not as consistent as those associated with the other two goal types. What is most prominent in the relationship between this type of goal orientation and its motivational and cognitive processes and outcomes is its positive and significant correlation with better GPA (Elliot et al., 1999; Harackiewicz, Barron, \& Elliot, 1998). Other correlation studies and their experimental counterparts have also indicated that performance approach goals have either null or positive associations with adaptive processes and outcomes, such as scales measuring higher self-efficacy (Anderman \& Midgley, 1997), more intrinsic motivation (Elliot \& Church, 1997), and use of more learning strategies (Middleton \& Midgley, 1997). Performance approach goals are also demonstrated to have no or negative correlations with maladaptive processes and outcomes, such as test anxiety (e.g., Skaalvik, 1997; Wolters et al., 1996).

In contrast, performance avoidance goals focus on not looking less able than others, striving not to demonstrate incompetence, and trying to avoid unfavorable judgments of competence. Under this type of performance goal, students are considered to be negatively motivated to avoid failure. This type of performance goal is focused on the possibilities of a negative normative outcome (Elliot \& Harackiewicz, 1996) or on fear of failure coupled with low competence expectancies (Elliot, 1999). Research is 
consistent in providing evidence of negative and maladaptive processes and outcomes associated with performance avoidance goals, such as low self-efficacy (Skaalvik, 1997), low intrinsic motivation (Church, Elliot \& Gable, 2001), high test-anxiety (Middleton \& Midgley, 1997), poor performance, and use of more surface processing strategies (Elliot et al., 1999).

\section{$2 \times 2$ Framework}

Within the recently proposed $2 \times 2$ conceptualization, mastery avoidance goals have been added. There is little research on this new type of goals, which focuses on striving to avoid falling short of task mastery and on avoiding misunderstanding or not learning the material. Three studies (Elliot \& McGregor, 2001) have investigated the $2 \mathrm{x}$ 2 goal framework with emphasis on the mastery avoidance construct.

In study 1 , an exploratory factor analysis was conducted with 180 undergraduates on 12 achievement goal items using principal-components extraction with varimax rotation. The analysis yielded four factors (eigenvalue $>1.0$ ), with the factor solution accounting for $81.5 \%$ of the total variance. Factor 1 comprised the 3 performance approach items (eigenvalue $=4.37 ; \alpha=.92$ ), accounting for $36.4 \%$ of the variance with factor loadings ranging from .89 to .93 . Factor 2 consisted of the 3 mastery avoidance items (eigenvalue $=2.56 ; \alpha=.89$ ), accounting for $21.3 \%$ of the variance with factor loadings ranging from .84 to .90 . Factor 3 comprised the 3 mastery approach items (eigenvalue $=1.79 ; \alpha=.87$ ), explaining $14.9 \%$ of the variance with factor loadings varying from .80 to .91 , and factor 4 consisted of the 3 performance avoidance goal items (eigenvalue $=1.06 ; \alpha=.83$ ), accounting for $8.8 \%$ of the variance with factor loadings 
ranging from .74 to .87 . None of the secondary loadings exceeded .35. In study 2 , confirmatory factor analyses (CFA) were performed with 148 undergraduates to replicate the study 1 findings. The results from the first CFA strongly supported the independence of the 4 achievement goal constructs, with each fit statistic meeting the conventional criteria for a good fitting model. Additional CFAs that examined the fit of alternative models revealed that the $2 \times 2$ framework provided a better fit than any of the alternative models. Moreover, the four resultant goal indexes derived from averaging item scores for each factor evidenced good reliability, with Cronbach $\alpha$ ranging from .83 to .94 . Research was further conducted in study 2 and 3 using regression analyses to investigate important antecedents and consequences of achievement goal endorsement within the $2 \times 2$ framework. The findings revealed distinct empirical profiles for the 4 achievement goals, with each not only linked to a distinct set of antecedent variables but also predictive of a distinct pattern of achievement-relevant processes and outcomes. The pattern for mastery avoidance goals was shown to be more negative than that for mastery approach goals and more positive than that for performance avoidance goals.

\section{SAL Theory}

The conceptual framework known as Student Approaches to Learning or SAL theory is derived from the powerful idea of "approaches to learning" that Marton and Saljo developed when studying how students perceived a particular reading task and proceeded to learn it (1976a, 1976b). According to Diseth and Martinsen (2003), approaches to learning refer to "individual differences in intentions and motives when facing a learning situation, and the utilization of corresponding strategies" (p. 195), 
which reflect different levels of processing. Researchers originally identified three different ways students could approach their learning: the deep, surface, and achieving/strategic approaches (Biggs, 1993; Biggs \& Kirby, 1984; Entwistle \& Waterston, 1988). Each consists of two components: a motive that indicates the reason for approaching a task and a strategy that indicates the way to approach a task.

Students who adopt the deep approach to learning are those who are intrinsically motivated by an interest in the subject matter, have an intention to understand the learning material, and relate the task to their personal experience or prior knowledge. The motive underlying the deep approach is intrinsic motivation or curiosity, while the strategies focus on the use of evidence and relating of ideas for the purpose of maximizing understanding, which contributes to a high level of cognitive processes (Biggs, 1993).

Those with the surface approach to learning are extrinsically motivated, have an intention to reproduce learning material, and focus on test-oriented strategies. The motive underlying the surface approach is extrinsic motivation or fear of failure, while the strategies involve different forms of rote learning or reproduction without understanding, which lead to a low level of cognitive processes (Biggs, 1993).

The achieving/strategic approach refers to the student's intention to attain the highest grades possible by adapting to the assessment demands. This intent is achieved by employing organized study methods and effective time management in line with the perceived criteria for high grades. The motive in this type of approach is competition with others. With regard to strategy, the achieving/strategic approach is not associated 
with any distinct learning strategy; actually students who adopt the achieving/strategic approach will use whatever strategy serves the purpose of achieving success, such as time and space organizing, study monitoring, planning, and being alert to assessment criteria (Biggs, 1993). In consequence, the achieving or strategic approach is distinct from the other two types, because "the strategies employed in the deep and surface approaches describe ways in which students engage the content of the task, whereas achieving strategies describe ways in which students organize the context of the task" (Evans, Kirby, \& Fabrigar, 2003, p. 509). The achieving/strategic approach, therefore, may be combined with strategies associated with either the deep or surface approach to learning, while the latter two are contradictory and mutually exclusive.

The Study Process Questionnaire (SPQ) was designed to measure these three approaches to learning (Biggs, 1978, 1987). But the achieving/strategic approach was found in many cases to be associated with the deep approach and occasionally with the surface approach, as evidenced by the confirmatory factor analytic work on the SPQ (Kember \& Leung, 1998) where achieving/strategic motive and strategy subscales loaded on both deep and surface factors. Given this consideration, Biggs, Kember, and Leung (2001) developed a revised two-factor - deep and surface — study process questionnaire, which was employed to measure students' motivation in this study.

The interpretation of SPQ responses and scores entails an understanding of the teaching/learning system in which "an educational event is located, as schematized in the Presage-Process-Product (3 P) model," because students' approaches to learning are conceived as constituting part of the total system (Biggs et al., 2001). In this three-stage 
model, student factors, the factors on the side of the teaching context, on-going approaches to learning, and the learning outcomes, all interact with one another as parts of a dynamic system.

Presage factors refer to those that exist before students engage themselves in learning, including student factors (such as prior knowledge, ability, preferred approach to learning) and the factors on the side of the teaching context (such as subject area, teaching method, assessment, school climate). The process stage results from the interplay between student factors and teaching context factors. It is manifested in students' approaches to learning-focused activities (deep or surface), which are defined by both their motives and strategies for learning. This stage plays a critical role in the teaching/learning system, because the learning activities at this level determine the performance at the product level, i.e., the learning outcome (Biggs \& Kirby, 1984). Thus SPQ scores, as "a function of both individual characteristics and the teaching context," reflect the form of students' approaches to learning, the nature of the relationship among student, context, and task (Biggs et al., 2001).

This brief section has introduced the two theoretical frameworks that were used in this study. A thorough review of the relevant databases suggests that no researcher has collected data on the instruments from these two frameworks within one study on a common group of subjects. Thus the current study enabled a comparison of the ability of these two frameworks to account for the data from a sample of Chinese university students. As the literature review in the next section shows, only one of these frameworks, SAL, has been used extensively to conduct research with Chinese populations. 


\section{CHAPTER 2}

\section{LITERATURE REVIEW}

The literature review consists of three parts. The first part addresses briefly the Confucian-heritage cultural components relevant to academic settings. The second part focuses on the relationships among achievement goal orientations, cultural values, and learning processes and academic achievement, while the third part concerns the relationships among students' approaches to learning, cultural values, and learning processes and achievement.

\section{Confucian-heritage Culture Values}

Confucius and his philosophy, Confucianism, have been well established and entrenched in the cultures and civilizations in China, Korea, Singapore, and Japan for thousands of years. It is believed that these deep-rooted and long-standing Confucian doctrines pervade the attitude toward life, the pattern of living, the social values, the political theory and institutions, and, most importantly, education. Writers have argued that in academic settings, such a Confucian-heritage culture $(\mathrm{CHC})$ is primarily characterized by: (a) emphasis on effort consistent with the perception of learning as a primary and moral obligation, (b) stress on pragmatic outcomes manifested in utility value or perceived instrumentality of current school success to personally valued future goals, and (c) collectivism in nature embodied in emphasis on group responsibilities and socially oriented goals (Confucius, 479 B.C./1979; Ho, 2001; Hong, 2001; Lee, 1996; Salili, 1995, 1999; Salili et al., 2001; Shi et al., 2001; Tweed \& Lehman, 2002; Watkins \& Biggs, 2001). In the current study, scales were used to measure students' attitudes 
toward each of these values - effort, utility, and socially-oriented goals (the last with three scales, one for each of family-, peer-, and teacher-oriented goals). The first research question focuses on determining to what extent Chinese students pursue the $\mathrm{CHC}$ values by endorsing socially oriented goals (family-, peer-, and teacher-oriented goals), following a sense of learning duty, and practicing utility value.

Achievement Goal Orientation, Cultural Values, and Chinese Students This part addresses three topics. The first topic deals with the applicability of achievement goal theory to Chinese students. The second topic addresses the influence of the CHC values on Chinese students' motivational and cognitive processes and outcomes, and the third topic is devoted to the recent findings on multiple goals and the impact of the CHC on Chinese students' multiple goal pursuit.

\section{Applicability of Achievement Goal Theory to Chinese Students}

In an attempt to address the applicability of achievement goal theory to Chinese students, I begin by briefly describing the findings of the empirical work with North American students, continue with the three studies conducted with Chinese students, and end with the research concerning the relationship between the $\mathrm{CHC}$ values and avoidance goals.

\section{Empirical Work with Western Students}

Much empirical research has been conducted with Western students to examine the relationship of achievement goal pursuit to the motivational and cognitive processes and outcomes regarding attributional patterns, intrinsic motivation, use of learning strategies, school well-being, and academic performance. 
Goal orientations and attributional patterns. In general, the research demonstrates that mastery goals are linked to a positive and adaptive pattern of attributions, whereas performance goals are linked to a maladaptive and helpless pattern of attributions (Ames, 1992; Dweck \& Leggett, 1988). Central to mastery goals is an attribution belief that effort and outcome covary, which maintains achievement-directed behaviour over time (Weiner, 1979). Thus students operating under mastery goals are more likely to see a positive link between effort and ability and to make effort attributions for success and failure. In contrast, central to performance goals is a focus on one's ability and sense of self-worth, and ability is evidenced by doing better than others or by attaining success with the least effort possible (Covington, 1984). When operating under performance goals, students tend to see an inverse link between effort and ability and to make ability attributions, which are maladaptive and can lead to learned helplessness patterns of behaviour.

Goal orientations and learning strategies. Research has consistently shown that mastery goal oriented students tend to report using various cognitive strategies for learning in general, but less surface processing strategies and more deep processing strategies in particular (Ames \& Archer, 1988; Elliot et al., 1999; Kaplan \& Midgley, 1997; Wolters et al., 1996). In addition, when operating under mastery goals, students are more likely to report use of metacognitive and self-regulatory strategies, such as selfmonitoring their cognition and seeking ways to become aware of their understanding and learning (Ames \& Archer, 1988; Dweck \& Leggett, 1988; Middleton \& Midgley, 1997; Wolters et al., 1996). In contrast to mastery goals, the recent research within the 
trichotomous framework reveals that there are null or positive correlations between performance approach goals and reported use of learning strategies (Elliot et al., 1999; Middleton \& Midgley, 1997; Wolters et al., 1996; Wolters, 2004), whereas null or negative associations have been found between performance avoidance goals and reports of strategy use (Elliot et al., 1999; Middleton \& Midgley, 1997; Wolters, 2004). Within the $2 \times 2$ framework, Elliot and McGregor (2001) revealed a differential profile of strategy use for the four factors. Mastery approach goals were found to be a positive predictor of deep processing; performance approach goals a marginally significant positive predictor of surface processing; mastery avoidance goals a positive predictor of disorganization; and performance avoidance goals a marginally significant negative predictor of deep processing, and a positive predictor of surface processing and disorganization.

Goal orientations and school well-being. A series of hierarchical multiple regressions (Kaplan \& Maehr, 1999) examined whether goal orientations might impact well-being and how. Mastery goal pursuit was found to be a significant positive predictor for all self-reported measures of well-being (emotional tone, peer relationship, impulse control, affect at school, and perceived academic efficacy) and a significant negative predictor for students' perceptions of disruptive behaviour. In contrast, performance goal endorsement was found to be a significant negative predictor for emotional tone, impulse control, and affect at school, but to have a null relationship to peer relationship, perceived academic efficacy, and disruptive behaviour. 
Goal orientations and academic achievement. The research in experimental settings has shown that mastery goal oriented students usually perform at higher levels (Dweck \& Leggett, 1988). Given the positive and adaptive patterns of motivational, affective, cognitive outcomes associated with endorsement of mastery goals, it would be expected that mastery goals would also lead to higher levels of achievement. However, some of the classroom studies have indicated that mastery goals are not related to or predictive of academic performance (Elliot \& Church, 1997; Elliot et al., 1999; Harackiewicz et al., 2000; Harackiewicz et al., 2002; Wolters, 2004). In contrast, performance approach goals are consistently evidenced to be associated with better grades or higher GPA (Elliot \& Church, 1997; Elliot et al., 1999; Harackiewicz et al., 2000; Harackiewicz et al., 2002; Wolters, 2004).

Summary. In summary, the numerous studies conducted with Western students reveal that achievement goals differentially predict attributional patterns, use of learning strategies, school well-being, and academic achievement (Ames, 1992; Church, Elliot, \& Gable, 2001; Dweck \& Leggett, 1988; Elliot et al., 1999; Elliot \& Church, 1997; Harackiewicz et al., 2000; Harackiewicz et al., 2002; Kaplan \& Maehr, 1999; Middleton \& Midgley, 1997; Wolters, 2004 ).

\section{Empirical Research with Chinese Students}

Three studies (Salili et al., 2001; Shi et al., 2001; Woodrow \& Chapman, 2002) have investigated Chinese students' motivational profile within the achievement goal theoretical framework. All of them have supported the generalizability of achievement 
goal theory to Chinese students and provided evidence for the conceptual importance and utility of the achievement goal theoretical framework across cultures.

In one of these studies, Shi et al. (2001) assessed the individual achievement goals among students aged 14-19 years in China with the Patterns of Adaptive Learning Survey (PALS) (Midgley, Maehr \& Urdan, 1993). The PALS assesses constructs commonly assessed in the studies of motivation and learning from a goal theory perspective. The Individual Achievement Goals Scale in the final questionnaire measured 6 facets: (a) extrinsic (reward) performing goal, (b) ability comparison goal, (c) effort avoidance goal, (d) adult approval goal, (e) peer approval goal, and (f) task-focused goal. Confirmatory factor analysis demonstrated two major goals: the task (mastery) goal and the performance goal (including all goals except the task-focused goal). Research findings provided support for the applicability of goal conceptions and measures in China in spite of the "radically different cultural context from US" (Shi et al., 2001, p. 267). However, the results also demonstrated some distinct motivational profiles for Chinese students. For example, some items such as those concerning the ability-comparison goal were evaluated as negative by US subjects, but as positive by Chinese students. The researchers suggested this could not be fully explained except from the perspective of culture.

Another study (Woodman \& Chapman, 2002) compared the motivational goal orientations of international students of English for academic purpose (EAP) in Australia. Participants had been in Australia from 1 to 42 months and had spent from 1 to 12 months studying at the language center. Out of 275 students, 69 originated from 
Mainland China, 15 from Taiwan, 7 from Hong Kong, 37 from Korea, 33 from Thailand, 27 from Europe, 25 from Indonesia, 20 from Japan, 18 from Vietnam, and 14 from South America. Research findings supported the applicability of the trichotomous framework of achievement goal theory for $\mathrm{CHC}$ students, but indicated likewise that $\mathrm{CHC}$ learners have different motivational profiles from their European and South American counterparts. For example, participants from Chinese-speaking countries (China, Hong Kong, Taiwan) scored higher on performance approach goals than their South American, European and, surprisingly, Vietnamese counterparts. Other Asian participants scored in between. As for performance avoidance goals, participants from Chinese-speaking countries, along with Thai and Indonesian participants, scored higher than their European counterparts, with Vietnamese, South American and Japanese participants' scores in between. Furthermore, since the Confucian cultures lay emphasis on group responsibilities, this may lead to higher academic pressure and emphasis on performance in collectivistic cultures; and Woodman and Chapman suggested that this cultural influence could "manifest itself through the adoption of both mastery goals and performance avoidance goals" (p. 10).

Of the three studies, the only attempt that has been made to investigate the role of the Confucian-heritage culture in students' achievement and motivation was by Salili et al. (2001), using the dichotomous framework. In their study, Salili and his colleagues measured effort expenditure, but failed to study the role of the emphasis on efforts, that is characteristic of the Confucian cultures, in students' motivation and learning; however, they examined the relationship of students' attitudes towards the endorsement of group goals (family-, teacher-, and peer-oriented goals) to their motivation and learning. The 
findings revealed the impact of culture and context of learning on students' motivational orientation and achievement. For example, with multiple regression analyses used to identify significant predictors of academic performance for Hong Kong Chinese, Chinese Canadian, and European Canadians, it was found that performance goal was the most important predictor of academic performance among Hong Kong Chinese, while familyoriented goal was an important predictor of high marks for Canadian Chinese students. But the limitation of their study is that it failed to make the approach-avoidance distinction while characterizing students' goal orientations. As well, this study did not have data on the utility value of education, the third $\mathrm{CHC}$ value included in the present study.

\section{$2 \times 2$ Conceptualization and Chinese Students}

Culture plays an integral and formative role in developing an individual's cognitive, affective, and motivational processes, while socialization provides people with an interpretive framework that establishes their construal of self in the world (Elliot, Chirkov, Kim, \& Sheldon 2001). Elliot and his colleagues (2001) argued that the individualistic emphasis on standing out with its independent self-construal and the collectivisitic emphasis on fitting in with its interdependent self-construal differentially promote approach and avoidance motivational processes. In order to examine the relationship between avoidance goals and individualism-collectivism, the individualismcollectivism distinction was represented by psychological construal (interdependent or independent self-construals), ethnic category (Asian Americans versus non-Asian Americans, and Asian Americans versus Caucasian Americans), and country (United 
States versus South Korea, and United States versus Russia) in four studies. Empirical findings provided support for the primary hypothesis that the pursuit of avoidance goals (mastery avoidance or performance avoidance goals) varies as a function of individualism-collectivism (across representations of this distinction). This concordance of avoidance goals with collectivism makes it essential to consider the approachavoidance distinction in the analysis of motivational data for $\mathrm{CHC}$ Chinese students. Among the three frameworks, the $2 \times 2$ conceptualization is the only one that fully incorporates the approach-avoidance distinction, and for this reason it may better characterize Chinese students' motivational profiles.

Meanwhile, Confucianism highlights the importance of understanding one's roles within a hierarchy and the importance of fulfilling group responsibilities, which in turn leads to "the emphasis on improving the self toward consensually shared standards" and an enhanced concern for role perfection (Heine et al., 2001, p. 601). Since those high in perfectionism may be prime candidates for the adoption of mastery avoidance goals (Elliot, 1999; Elliot \& Thrash, 2001), this is another reason why the 2 x 2 conceptualization with its mastery avoidance goals may be appropriate as a theoretical framework for interpreting CHC students' motivation and learning in academic settings.

\section{Summary}

Given that the three published studies on the topic suggest achievement goal theory may apply to Chinese students (Salili et al., 2001; Shi et al., 2001; Woodrow \& Chapman, 2002) and the potential appropriateness of applying the 2 x 2 achievement goal framework to CHC Chinese students, this study's two research questions are respectively 
concerned with determining: (a) to what extent Chinese students pursue achievement goal orientations as postulated by the $2 \times 2$ framework, and (b) to what extent their goal endorsement is linked to a differential set of learning processes (i.e., use of metacognitive strategies and school well-being) and to academic achievement. The cultural differences, however, make it necessary to assess to what extent the relationships between achievement goals and academic achievement for Chinese students are similar to these relationships for North American students.

Goal Orientations, Cultural Values, and Chinese Students' Learning Processes and Academic Achievement

This topic in the literature review introduces $\mathrm{CHC}$ values to explore the way culture and achievement goal endorsement may interact to produce different achievement-relevant processes and outcomes and to promote optimal motivation.

Generally, CHC students tend to view effort as "central to the learning process" (Tweed \& Lehman, 2002, p. 89), which is reflected not only in a culturally inherent emphasis on effort and the attendant perception of learning as a primary and moral duty, as discussed already, but also in the salience of attribution of success and failure to effort instead of to inherent ability. In one study, Heine et al. (2001) developed a six-item Beliefs in Incremental Abilities (BIA) Scale $(\alpha=.68)$ measuring the extent to which students think success depends on effort as opposed to inherent ability. The results indicated that both Asian American and Japanese students reported higher level of beliefs in the utility of effort than did their Western counterparts. A similar result concerning effort attribution was demonstrated with Chinese students as well by Hau and Salili 
(1991). In another study, Hess and his colleagues (1987) found that Chinese mothers cited lack of effort as the predominant cause of their child's failure in mathematics, whereas American mothers were more likely to attribute failure to inherent ability, training, luck, and effort equally. Similarly, Stevenson and his associates (1990) showed that Chinese parents and students are more likely than their American counterparts to make effort attributions in academic achievement. Based on these empirical findings as well as a host of research in America that shows effort attribution is linked to a more mastery oriented achievement pattern (Hong, 2001), the possibility arises that culturally inherent emphasis on effort marked by the culturally invested sense of learning duty may encourage both effort attribution and mastery goal oriented motivation and learning processes and outcomes.

On the other hand, in CHC dominated societies, the sense of self involves "significant others" (Salili, 1996), and academic success is perceived as a source of pride and failure as a source of stigma for the whole concerned group (Salili, 1996; Watkins \& Biggs, 2001). This conceptualization of success and failure can make group goals and responsibilities salient and promote a mastery goal oriented pattern if the $\mathrm{CHC}$ students identify with the personal importance of an action; in the meanwhile, this collectivistic value may evoke more academic pressure and make a performance goal oriented pattern salient as well.

Hong (2001) observed that among Chinese students prevalence of effort attribution and superior achievement coexist with higher levels of test anxiety, lower selfefficacy, and vulnerability to the learned helplessness pattern, which can be partly 
accounted for from this perspective of culture. Chinese students might, on the one hand, exhibit a mastery goal oriented motivational pattern associated with emphasis on effort and group responsibilities, and on the other hand, experience more academic pressure and other negative aspects of performance goal oriented coping that is associated with collectivistic values.

Not only emphasis on effort and collectivistic values, but also utility value may elicit mastery goal oriented learning processes and outcomes (Miller \& Brickman, 2004). Empirical work with Western students (Brickman \& Miller, 1998; DeBacker \& Nelson, 1999; Greene, DeBacker, Ravindran, \& Krows, 1999; DeVolder \& Lens, 1982; Miller, DeBacker, \& Greene, 1999; Miller, Greene, Montalvo, Ravindran, \& Nichols, 1996; Raynor, 1970; Schutz, 1997; Schutz \& Lanehart, 1994) has provided support for the relationship between utility value and intrinsic valuing, extrinsic valuing, use of selfregulation strategies, deep-processing study strategies, cognitive engagement, and academic performance.

In addition to the aforementioned mastery-performance dimension, the influence of Confucian-heritage culture on achievement goal oriented learning processes and outcomes may also be manifested in the approach-avoidance facet. Elliot et al. (2001) revealed that avoidance goals were found to be a negative predictor of subjective wellbeing in individualistic (the United States), but not collectivistic (South Korea and Russia), countries.

Given the potential impact of these cultural values on achievement goal oriented learning processes and outcomes, of particular interest for this study is the research 
question addressing how the $\mathrm{CHC}$ values and achievement goal endorsement may interact to influence achievement-relevant processes and outcomes, such as use of metacognitive strategies, school well-being, and academic performance.

Confucian-heritage Cultural Values, Goal Orientations, and Learning Strategies

There is a limited amount of research within the achievement goal framework addressing the relationship between cultural values and the use of learning strategies among CHC Chinese students. To emphasize the influence of cultural context on Chinese students' motivation and learning, Biggs and Watkins stated that for Chinese students the adoption of more and improved learning strategies can be activated by "a head of mixed motivational steam: personal ambition, family face, peer support, material reward, and, yes, possibly even interest” (Biggs \& Watkins, 1996, p. 273).

To date few studies could be identified that have specifically investigated the impact of culturally inherent emphasis on effort and collectivistic values on students' use of learning strategies. But as mentioned before, the likelihood is that a sense of learning duty evokes mastery goal oriented processes and outcomes, while socially oriented goals encourage both mastery and performance goal oriented patterns.

Regarding the impact of utility value on students' use of learning strategies, a body of research has been undertaken with Western students that demonstrates a positive relationship. Miller and Brickman (2004) pointed out that the research on the relation of achievement goal adoption and use of learning strategies and self-regulation has only focused on "short-term (proximal) motivational and self-regulatory issues and excluded potentially important personally valued, distant goals in their analysis (p. 10)". In order to 
address this problem, they presented a theoretical model of future-oriented motivation and self-regulation complementary to the proximal model. They inferred that since proximal tasks with utility value have greater overall incentive value than those without, engagement in those tasks should be more vigorous than that found for noninstrumental tasks. To support this claim, a body of research has been identified. The research conducted by Schutz (1997) and by Schutz and Lanehart (1994) indicated that long-term educational goals were positively correlated with students' reports of self-regulation and strategy use. Similarly, in a pair of studies, Miller and his colleagues (1996) found that high school mathematics students' utility value of course performance to future goal attainment was positively correlated with deep-processing cognitive strategies, metacognitive strategies, effort, and persistence. Even when controlling for students' achievement goals and competence perception in math, this utility value was still capable of predicting both use of metacognitive strategies and deep-processing cognitive strategies. Another study (Brickman \& Miller, 1998) that examined the effect of utility value on learning strategy use showed that utility value positively predicted metacognitive strategy use $(\beta=.46, p<.05)$, deep processing cognitive strategy use ( $\beta$ $=.42, \mathrm{p}<.05)$, surface processing $(\beta=.33, \mathrm{p}<.05)$, and persistence $(\beta=.23, \mathrm{p}<.05)$ when controlling for variations in importance of future goals in a regression analysis. In view of the potential influence of $\mathrm{CHC}$ value components on achievement goal oriented use of learning strategies, this study includes a focus on determining how $\mathrm{CHC}$ values interact with achievement goals to promote optimal use of learning strategies. 
Confucian-heritage Cultural Values, Goal Orientations, and School Well-being

Kaplan and Maehr (1999) demonstrated an association between mastery goals and positive psychological well-being and between performance goals and negative psychological well-being in their empirical work with Western students. However, no research has been undertaken concerning the relationship of achievement goal pursuit and cultural values to school well-being among $\mathrm{CHC}$ Chinese students. Considering the potential impact of the three cultural values on achievement goal oriented learning processes and outcomes, as argued above, this study also focused on determining how $\mathrm{CHC}$ values combine with achievement goals to influence Chinese students' school wellbeing.

In addition, owing to the impact of interdependent self-construals typical of a collectivistic culture, it has been found that avoidance personal goals are a negative predictor of subjective well-being in individualistic, but not collectivistic countries (Elliot et al., 2001). This study, hence, also tested the hypothesis that the relationships between achievement avoidance goals and school well-being for Chinese students would not be in agreement with those postulated by achievement goal theory for Western students. Confucian-heritage Cultural Values, Goal Orientations, and Academic Performance

Although little research can be identified that has investigated the impact of utility value on Chinese students' motivation and achievement, some studies have been conducted with Western students, providing support for the facilitating role of utility value in academic performance. Steinberg, Dornbusch, and Brown (1992) revealed in their large-scale study of adolescents that the highest achieving group reported the 
highest utility value of current school success to attainment of future goals. Elliot, Shell, Henry, and Maier (2005) examined the effect of achievement goals on academic achievement and the moderating role of utility value, i.e., what they termed "performance contingencies." They found that performance avoidance goals undermined academic achievement compared to mastery goals and performance approach goals, whether in the absence or in the presence of a performance contingency. In the absence of a performance contingency, performance approach goals were as positive as mastery goals for achievement, but in the presence of a performance contingency, performance approach goals were shown to have a more positive effect than mastery goals. Furthermore, the presence of a performance contingency was shown to accentuate the effects of performance approach and performance avoidance goals on achievement but to have little impact on the effect of mastery goals on academic achievement.

Given the potential influence of cultural values on achievement goal oriented processes and outcomes, this study set out to determine how $\mathrm{CHC}$ values and achievement goals might interact to impact Chinese students' academic performance.

\section{Summary}

In view of the potential impact of the three $\mathrm{CHC}$ value components - a sense of learning duty, socially oriented goals (family-, teacher-, peer-oriented goals), and utility value - on achievement goal oriented learning processes and outcomes, the present study is conducted to determine to what extent the $\mathrm{CHC}$ values work together with achievement goals to influence Chinese students' metacognitive strategies, school well-being (perceived academic efficacy and affect at school), and academic performance. 


\section{Multiple Goals and Chinese Students}

Using survey methods, researchers consistently find that measures of mastery and performance goals are either unrelated or even positively correlated (see Harackiewicz et al, 1998, for a review). They proposed that mastery goals and performance goals are not mutually exclusive and that the endorsement of these two goals to varying degrees can facilitate adaptive patterns of certain motivational and learning processes and outcomes (Barron, \& Harackiewicz, 2001; Elliot \& Church, 1997; Harackiewicz et al., 1998; Harackiewicz et al., 2002; Midgley, Kaplan, \& Middleton, 2001; Pintrinch, 2000). The effects of multiple goals are assessed by using person-centered analyses (using median splits and clustering procedures) or variable-centered analyses (testing goal interactions in regression analyses). In view of the agreement that has been consistently arrived at about the detrimental effects of performance avoidance goals, the multiple goal perspective is intended to explore the potential of a facilitative role for a combination of mastery goals and performance approach goals for academic achievement and motivation. In a number of survey-based studies, the most facilitative pattern has been documented to be the endorsement of a low level of performance approach goals with a high level of mastery goals (Meece \& Holt, 1993; Pintrich \& Garcia, 1991; Wolters et al., 1996).

In order to determine how different types of achievement goals may combine to promote optimal motivation and achievement, Barron and Harackiewicz (2001) have identified four possible patterns for describing how two achievement goals may interact, including: (a) an additive goal pattern, where two goals have independent positive effect on a particular educational outcome, resulting in positive main effects for both goals; (b) 
an interactive goal pattern, where two goals interact, resulting in a positive goal interaction effect on a single outcome measure; (c) a specialized goal pattern, where two goals have positive effects on different outcomes; (d) a selective goal pattern, where individuals focus on the achievement goal that is most relevant at a particular time.

Given the potential multiple goal endorsement for Chinese students, one research question focuses on testing the first three patterns (additive, interactive, and specialized) and determining how achievement goals may interact to influence Chinese students' use of learning strategies, school well-being, and academic achievement in an attempt to reveal the most facilitative pattern of goal combinations for Chinese students.

\section{Summary}

This section has reviewed the literature to make a case for investigating the relationships among goal orientation as an approach to motivation, $\mathrm{CHC}$ cultural values, learning processes, and academic achievement of Chinese university students in one study. The next section makes a similar argument for focusing on this set of relationships for SAL, as an approach to motivation.

\section{SAL, Cultural Values, and Chinese Students}

This section is composed of two parts. The first part concerns the applicability of SAL theory to Chinese students. The second part focuses on the impact of the CHC values on Chinese students' learning processes and outcomes.

Applicability of SAL Theory to Chinese Students 
To address the applicability of SAL theory to Chinese students, I first briefly describe the findings of the empirical work with Western students, and then focus on some studies conducted with Chinese students.

\section{Empirical Work with Western Students}

A host of research has been conducted to investigate the relationship of students' approaches to learning to their use of metacognitive strategies and academic performance.

SAL and Use of Metacognitive Strategies. Schoenfeld (1987) compared selfregulation to a management role. He argued that expert learners are more likely to execute a management and self-regulation role during problem-solving (such as planning, monitoring, and resource allocating), in contrast to inexpert learners who tend to use whatever strategy occurs to them. He drew an analogy between the deep approach and expert problem solving and between the surface approach and inexpert problem solving.

Bouffard and his colleagues (1995) identified three major components of selfregulation: cognitive strategies used for learning, memorizing, and understanding; metacognitive strategies used to oversee and supervise cognition; and motivation which determines effort expenditure. They found that self-regulating students were interested in the increase in knowledge and intrinsically motivated to learn, which coincides with Biggs's (1987) description of students' deep approach to learning and suggests that students adopting the deep approach are more likely to use self-regulating strategies.

Other researchers (Winne, 1995; Vermetten, Lodewijks, \& Vermunt, 2001) have also found that self-regulation of learning is linked to deep learning strategies while external regulation is associated with surface strategies. Cantwell and Moore (1996) 
identified three levels of self-regulation according to degrees of proficiency among learners: adaptive control, which stands for flexible planning and monitoring of cognitive strategies during self-regulated learning; irresolute control, which represents confusion and uncertainty in strategic behaviours during unsuccessful self-regulation; and inflexible control, which reflects a predisposition to use an inflexible strategy during unsuccessful self-regulatory processes.

Evans, Kirby, and Fabrigar (2003) reviewed the aforementioned theories concerning self-regulation and pointed out that these theories suggested that there were similarities among the deep approach, need for cognition, and adaptive control (aspects of self-regulated learning); and similarities among the surface approach, and inflexible and irresolute control (aspects of ineffective approaches to learning). Based on the responses from 226 Canadian military college students to the Study Process Questionnaire (Biggs, 1978), the Need for Cognition Scale (Cacioppo \& Petty, 1982), and the Strategic Flexibility Questionnaire (Cantwell \& Moore, 1996), these researchers conducted a series of confirmatory factor analyses to explore the relationships among approaches to learning (deep, surface), need for cognition, and three types of control of learning (adaptive, inflexible, irresolute). Results supported the identification of the six scale factors. Second order confirmatory factor analysis revealed that in contrast to one- or two-factor models, three factors accounted adequately for the data and represented constructs underlying the 6 factors. One of the three factors, self-regulating learning, consisted of the deep approach to learning, need for cognition, and adaptive control of learning; the second 
factor consisted of irresolute control, the surface approach, and negative need for cognition; and the third factor included inflexible and negative adaptive control.

Generally, students who report using the deeper approach to learning also use more, and more effective, learning and metacognitive strategies.

SAL and Academic Performance. Some studies (Diseth, 2002; Diseth, 2003; Diseth \& Martinsen, 2003) have been conducted to examine the relationship between approaches to learning and academic achievement.

Diseth (2002) examined the relationships among intelligence, approaches to learning, and academic achievement. There was a significant negative correlation between the surface approach and academic achievement $(r=-.20, p<.05)$ but no relationship between general intelligence and approaches to learning. The study revealed a significant curvilinear relationship between the surface approach and examination grades, showing that the highest level of achievement was linked to a low or a moderate level of the surface approach and achievement became gradually worse as the level of the surface approach increased.

Diseth and Martinsen (2003) investigated the relationship between approaches to learning, cognitive style (assimilator and explorer style), motives (motive for success, motive to avoid failure, and need for cognition), and academic achievement among 192 undergraduate psychology students. The results indicated that the deep approach along with the motive for success, the need for cognition, and the assimilator and explorer style, unexpectedly, did not predict achievement, whereas the surface approach, as expected, was a significant negative predictor of achievement. The missing relationship between 
the deep approach and achievement, in line with the findings from research on medical students (Newble \& Hejka, 1991), was attributed to the examination procedure, the nature of the curriculum, and the pressure to achieve.

In an investigation of the relationship between personality, approaches to learning, and academic achievement, Diseth (2003) revealed a significant negative correlation between the surface approach and academic achievement among 151 undergraduate psychology students, and a positive significant correlation between the deep approach and academic achievement among 164 examen philosophicum students. These findings, that the surface approach was associated with lower examination grades and the deep approach was linked to higher achievement, are compatible with previous findings; they are also in line with the theoretical assumption that the surface approach impairs performance and the deep approach is beneficial when the examination procedure demands understanding. The authors suggested that the reasons for the sample specific difference between approaches to learning and academic achievement had to do with learning environment and examination procedures.

Generally, when students report using the deep approach to learning, this is associated with higher academic achievement than when students report using the surface approach to learning.

SAL and School Well-being. Few studies have examined the relationship between students' approaches to learning and their school well-being. However, Evans, Kirby, and Fabrigar (2003) inferred that there are similarities between mastery goals and the deep approach and between performance goals and the surface approach; on the other hand, 
Kaplan and Maehr (1999) demonstrated an association between mastery goals and positive psychological well-being and between performance goals and negative psychological well-being in their empirical work with Western students. It can be expected that the deep approach, like mastery goals, facilitates school well-being whereas the surface approach debilitates school well-being.

Summary. In sum, the deep approach has been found to be positively linked to the use of metacognitive strategies, whereas the surface approach is negatively associated with the use of metacognitive strategies. The deep approach has also been found to be positively linked to achievement and the surface approach negatively linked to achievement, when the examination procedures demand understanding and exploration of learning materials. Meanwhile, it can be hypothesized that the deep approach is positively linked to school well-being while the surface approach may be negatively linked to school well-being. With an interest in investigating the predictive relationship between the SAL framework and learning process and learning outcome variables among Chinese students, the research question in this part focuses on determining the predictive utility of the deep and surface approaches for metacognitve strategies, school well-being, and academic performance.

\section{Empirical Research with Chinese Students}

A host of studies, qualitative (e.g. Kember \& Gow, 1990) or quantitative (e.g., Biggs, Kember, \& Leung, 2001; see Watkins, 1999, for a review), have examined students' motivational profile in Hong Kong within the SAL theoretical framework. They have provided evidence for the applicability of SAL theory to Chinese students and 
supported the predictive utility of this motivational theoretical framework for characterizing CHC Chinese students' learning processes and outcomes.

In the interviews with students in Hong Kong, Kember and Gow (1990) found evidence of both deep and surface approaches to learning in the forms in which they have been characterized in studies conducted with Western students.

Watkins (1999) reviewed the studies conducted with students from Australia, Hong Kong, Brunei, Indonesia, Malaysia, Nepal, and Philipines, strongly arguing for the cross-cultural validity of SAL constructs and measuring instruments. The review demonstrated that the SAL theory, although developed to account for how students learn in Western cultures, is applicable for studying learning from a cross-cultural point of view. In this quantitative review of the studies where the frequently used SAL instruments, such as Learning Process Questionnaire (LPQ) (Biggs, 1987), SPQ (Biggs, 1987), and Approaches to Studying Inventory (ASI) (Entwistle \& Ramsden, 1983), were completed by students in schools from a wide range of countries, it was found that these questionnaires are moderately reliable, the underlying factors reflect the deep and surface approaches to learning, and these scales correlate with academic performance, selfesteem, and locus of control in generally predictable ways. Although no data from mainland China were involved in this review, the responses from the students in Hong Kong provided strong support for the within- and between-construct validities of these SAL questionnaires for use with CHC Chinese students.

SAL, Cultural Values, and Chinese Students' Motivational and Cognitive Processes and

Outcomes 
This topic in the literature review examines $\mathrm{CHC}$ values to suggest the way culture and student approaches to learning may combine to yield different learning processes and outcomes and to promote optimal motivation.

Besides effort attribution (Hau \& Salili, 1991; Heine et al., 2001; Stevenson et al., 1990), the culturally inherent emphasis on effort with its attendant perception of learning as a primary and moral duty has also been documented to be associated with a belief in human perfectability or malleability of fundamental abilities (Tweed \& Lehman, 2002). In fact, human perfectability, learning, rationality, effort, and will power are "so closely interrelated" in the Confucian tradition that "they are sometimes inseparable" (Lee, 1999). These culturally inherent notions invest education in the Confucian tradition with an intrinsic value - education is meaningful only when it leads to perfection of the self. This self in the Confucian tradition, however, is subject to the cult of restraint within the family (Lee, 1999) and group responsibilities and goals rooted in collectivistic values (Heine et al., 2001). It is because of this emphasis on self-cultivation or self-improvement towards consensually shared standards regarding one's role within a hierarchy and of fulfilling obligations to in-group members that education in the Confucian tradition is considered important for its intrinsic value. From this point of view, both the culturally inherent emphasis on effort and collectivistic values may encourage intrinsically motivated learning and influence the motivational and cognitive processes and outcomes associated with the deep approach to learning.

Likewise, another component of the $\mathrm{CHC}$ values - utility value or the perceived instrumentality of current school success to personally valued future goals - may also 
evoke intrinsic motivation and encourage learning processes and outcomes associated with the deep approach to learning. As reviewed above, empirical work with western students (Brickman \& Miller, 1998; DeBacker \& Nelson, 1999; Greene, DeBacker, Ravindran, \& Krows, 1999; DeVolder \& Lens, 1982; Miller, DeBacker, \& Greene, 1999; Miller, Greene, Montalvo, Ravindran, \& Nichols, 1996; Raynor, 1970; Schutz, 1997; Schutz \& Lanehart, 1994) has supported the relationship between utility value and each of intrinsic valuing, extrinsic valuing, use of self-regulation strategies, deep-processing study strategies, cognitive engagement, and academic performance.

Given the potential impact of these cultural values on the SAL affected learning processes and outcomes, one research question focuses on determining to what extent the CHC values and SAL may combine to influence Chinese students' achievement-relevant processes and outcomes, such as use of metacognitive strategies, school well-being, and academic performance.

Confucian-heritage Cultural Values, SAL, and Use of Metacognitive Strategies

On the one hand, the culturally inherent emphasis on effort and collectivistic values may encourage intrinsically motivated learning; on the other hand, self-regulation of learning demands effort and students are less likely to engage in it unless they are intrinsically motivated to learn. Therefore, it can be expected that these two cultural values may work as the deep approach to predispose Chinese students to use of adaptive metacognitive strategies. Besides, another $\mathrm{CHC}$ value component—utility value-has also been demonstrated to be associated with intrinsic motivation (DeBacker \& Nelson, 1999; Miller et al., 1999) and with the use of deep-processing cognitive strategies and 
metacognitivex strategies (Brickman \& Miller, 1998; Miller, et al., 1996). Hence, it can be argued that utility value would predispose Chinese students to the use of adaptive metacognitive strategies. Given that all of these three $\mathrm{CHC}$ values may encourage the use of adaptive metacognitive strategies that proved to be associated with the deep approach (e.g., Evans, Kirby, \& Fabrigar, 2003), the research was concerned with determining how CHC values combine with SAL to influence Chinese students' use of metacognitive strategies.

\section{Confucian-heritage Cultural Values, SAL, and School Well-being}

From the above, all of the three $\mathrm{CHC}$ value components may encourage intrinsic motivation and evoke mastery oriented patterns; on the other hand, Kaplan and Maehr (1999) demonstrated an association between mastery goals and positive psychological well-being and between performance goals and negative psychological well-being in their empirical work with Western students. It can be expected, therefore, that $\mathrm{CHC}$ values would facilitate Chinese students' school well-being.

Given that all of the three $\mathrm{CHC}$ values may predispose Chinese students to positive school well-being, which may be predicted also by the deep approach, the study was concerned with determining how $\mathrm{CHC}$ values and SAL combine to influence Chinese students' school well-being.

\section{Confucian-heritage Cultural Values, SAL, and Academic Performance}

Bouffard et al. (1995) argued that intrinsic motivation suggests higher engagement and self-regulation, which in turn were found to be the best predictor of academic performance among their sample of university students. Since the emphasis on 
effort, utility value, and group responsibilities and group goals may predispose Chinese students to intrinsic motivation, it can be expected that $\mathrm{CHC}$ values may predispose Chinese students to better performance.

Given that both $\mathrm{CHC}$ values and the deep approach may influence academic performance, the study focused on determining to what extent $\mathrm{CHC}$ values and SAL combine to influence their academic performance.

\section{Summary}

Considering that the three cultural values may exert an influence on the SAL affected motivational and cognitive processes and outcomes, the research question concerns the investigation of the combined influence of $\mathrm{CHC}$ values and SAL on use of metacognitive strategies, school well-being, and academic performance for Chinese students.

Summary

Empirical work conducted with Western students has demonstrated the conceptual importance and predictive utility of each of achievement goal and SAL frameworks for characterizing the learning processes and outcomes. Research with Chinese students suggests the potential applicability of these two theoretical frameworks to Chinese students. In the meanwhile, $\mathrm{CHC}$ values may exert their influence on achievement goal oriented or SAL affected learning processes and outcomes. Give these, the research focuses on determining: (a) to what extent Chinese students' achievement goal endorsement or SAL adoption differentially predict their learning processes and 
outcomes and (b) to what extent $\mathrm{CHC}$ values may combine with achievement goals or SAL to influence Chinese students' motivation and achievement. 


\section{CHAPTER 3}

\section{METHOD, HYPOTHESES, AND ANALYSES}

For the purpose of this research, one comprehensive questionnaire was used to examine the applicability of the $2 \times 2$ framework and SAL framework to CHC Chinese students and to investigate how Confucian-heritage culture and achievement goals or SAL may combine to generate different learning processes and outcomes and promote optimal motivation. This chapter describes the participants, measures, procedures, and methods of statistical analysis.

\section{Participants}

The participants were 721 first-year science students who took both of the two courses - college English classes for non-English majors and advanced mathematics classes for science students - at a large university in Xi' an, Northern China. Both college English and advanced mathematics are compulsory courses for this group of university students. These two classes (known as Big Classes designed for compulsory courses) are typically composed of 120-150 students from approximately 5 specialty classes (known as Small Classes). Students take their courses together in these Big Classes each academic year under the management of the department.

\section{Measures}

The questionnaire for this study consisted of two parts: (a) students' demographic information, including major, gender, location of middle school (urban or rural), and permission for English and mathematics course grades to be used in this research, and (b) the scales to measure the constructs involved. All the items (except the demographic 
items and the request for students' permission to obtain their grades from the university) were answered on a Likert-type 7-point scale, the anchors ranging from strongly disagree (1) to strongly agree (7) with higher scores indicating higher levels of the construct being measured.

For goal orientations, 5 items measured each of mastery approach, mastery avoidance, performance approach, and performance avoidance (Elliott \& McGregor, 2001) (20 items in all). For the SAL framework, all measures were drawn from Biggs et al. (2001). Deep motive was measured with 5 items $(\alpha=.62)$ and surface motive with 5 items $(\alpha=.72)$, while deep strategy was measured with 5 items $(\alpha=.63)$ and surface strategy with 5 items $(\alpha=.57)$ ( 20 items in all). For cultural values, 5 items I designed measured the sense of learning duty, while 5 items with $\alpha=.91$ measured utility value (Miller et al., 1999), and 5 items based on Salili et al. (2001) measured each of familyoriented goals, peer-oriented goals, and teacher oriented goals (25 items in all). I also included the scales for school well-being and metacognitive strategies that are widely used in research in this field. For school well-being, two scales were drawn from Kaplan and Maehr (1999): affect at school (7 items, with $\alpha=.82$ ) and perceived academic efficacy (6 items, $\alpha=.84)$ (13 items in all). And 6 items from Yong (2005) measured metacognitive strategies (see Table 1). The total number of Likert-type items each student completed was 143 (because the scales for goal orientation, SAL, and metacognitive strategies were completed with reference to each course, English and mathematics). Students usually required approximately 40 minutes to complete the scales in Chinese. 
Table 1

Scales and Items

\begin{tabular}{|c|c|}
\hline Scales & Number of Items \\
\hline \multicolumn{2}{|l|}{ Cultural values } \\
\hline Sense of learning duty & 5 \\
\hline Utility value & 5 \\
\hline \multicolumn{2}{|l|}{ Socially oriented goals } \\
\hline Family-oriented goals & 5 \\
\hline Teacher-oriented goals & 5 \\
\hline Peer-oriented goals & 5 \\
\hline \multicolumn{2}{|l|}{ Achievement goal orientations } \\
\hline Mastery approach & 5 \\
\hline Mastery avoidance & 5 \\
\hline Performance approach & 5 \\
\hline Performance avoidance & 5 \\
\hline \multicolumn{2}{|l|}{ SAL } \\
\hline \multicolumn{2}{|l|}{ Deep approach } \\
\hline Deep motive & 5 \\
\hline Deep strategy & 5 \\
\hline \multicolumn{2}{|l|}{ Surface approach } \\
\hline Surface motive & 5 \\
\hline Surface strategy & 5 \\
\hline \multicolumn{2}{|l|}{ Learning processes } \\
\hline Metacognitive strategy & 6 \\
\hline \multicolumn{2}{|l|}{ School well-being } \\
\hline Perceived academic efficacy & 6 \\
\hline Affect at school & 7 \\
\hline
\end{tabular}

Procedures

The process of questionnaire design begins with identifying what needs to be known and why (Gray \& Guppy, 1999). Scales were used for the major constructs in this study. Most of the scale items were drawn from existing instruments with acceptable reliability and validity, while some were self-created (e.g. cultural value scale) for this study. Caution was taken in the process of item writing and creating to ensure that each question did not lead the respondents to a desired response nor contain bias and that the 
wordings of the items reflected terminology familiar to the respondents. Considering that people's attitudes and beliefs are much more fluid than their knowledge about specific facts, the measurement error can be large (Salant \& Dillman, 1994). To minimize the measurement error, multiple questions related to the same belief were employed which were collapsed during the analysis stage to provide one indicator reflecting a specific belief.

Before the administration of the survey, the draft questionnaire was back translated and pilot tested to ensure the reliability and validity of the items in the Chinese version. Following receipt of ethics clearance, pilot work was conducted with volunteers, Chinese students at Queen's University, using the same Letter of Information that was used for research participants. In October 2007 I made presentations to the university in China to explain the rationale, underlying theoretical framework, potential significance of this study for education, and the procedures for collecting data and protecting the confidentiality of the students, the departments, and the university. On receiving approval of the study, using a recruitment script consistent with the Letter of Information, I recruited 721 first-year students who took both of the two courses - college English for non-English majors and advanced mathematics for science students. The Letter of Information was distributed to whole classes (Big Classes) that were randomly selected, and the questionnaire was administered to all the consenting students in a class at the same time.

Statistical Analyses 
After the data were collected and entered into SPSS, the data were checked for accuracy and completeness. The data set was screened for incomplete responses and only the questionnaires that were at least $60 \%$ complete remained in the data set. Outliers were identified and removed. Missing values were replaced by means. Dummy coding was employed to represent such variables as students' gender, major, and location of middle school (urban or rural). Negatively worded items were reversed and totals for items in each scale were calculated. Standard analysis procedures were used to calculate the internal consistency of the scales in this study (Cronbach's $\alpha$ ) and to determine which items should be retained for further analyses.

\section{Descriptive Statistics}

Descriptive statistics for the final data set included variability in responses, and the measures of central tendency, symmetry, and peakness. According to Fink (2002, p. 29 ), ordinal scales typically are seen in questions that call for ratings of quality (from excellent to very poor) or agreement (from strongly agree to strongly disagree). It is argued that the ordinal scale is robust enough to confidently state, for example, that an excellent response is higher or greater than a very good response. Thus, descriptive statistics reserved for interval data, such as means and standard deviations, can be performed on an ordinal scale.

\section{Reliability Testing}

The internal consistency coefficient alpha was calculated for each scale to determine whether the items in a scale were all measuring the same underlying construct. 
The higher the Cronbach's coefficient alpha, the more reliable the scale. The items were retained if their deletion made Cronbach's $\alpha$ decrease.

\section{Hypotheses and Major Statistical Analyses}

Exploratory factor analyses (EFAs) and regression analyses were conducted to meet the purposes of the study. EFAs were performed to examine the consistency of the extracted factor solutions with the four goal constructs as postulated by the $2 \times 2$ achievement goal framework, the two SAL contructs posited by the SAL framework, and the five cultural value constructs (effort as an obligation, utility value of outcomes, and collectivism in nature embodied in emphasis on three kinds of group responsibilities and socially oriented goals) as discussed in the literature review. EFAs were also conducted on the five extracted cultural constructs, the metacognitive strategy items, the perceived academic efficacy items, and affect at school items to examine if each of them represented a unitary construct.

Then regression analyses were employed to test hypotheses, extrapolated from the small existing literature, on the relationship between the goal orientation framework and cultural values, school well-being, metacognitive strategies, and grades. Similarly, regression analyses were used to test hypotheses on the relationship between SAL and cultural values, school well-being, metacognitive strategies, and grades. Results for the two frameworks were compared.

Research question 1: To what extent do Chinese students pursue the Confucianheritage cultural values (CHC values)? The hypothesis is that Chinese students would pursue the $\mathrm{CHC}$ values by endorsing socially oriented goals (family-, peer-, and teacher- 
oriented goals), following a sense of learning, and practicing utility value, in agreement with those derived from literature review.

This question entails the examination of the extent to which Chinese students endorse socially oriented goals (family-, peer-, and teacher-oriented goals), follow a sense of learning duty (the perception of learning as a primary and moral obligation), and practice utility value (perceived instrumentality of current school success to personally valued future goals). It is hypothesized that Chinese students would pursue the five Confucian-heritage cultural value constructs, which are presumed to be components of the high-order unitary $\mathrm{CHC}$ value construct.

Research question 2: To what extent do Chinese students endorse achievement goal orientations as postulated by the $2 \times 2$ achievement goal framework? The hypothesis is that Chinese students would pursue mastery approach, mastery avoidance, performance approach, and performance avoidance goals in agreement with the $2 \times 2$ conceptualization.

Research question 3: To what extent do Chinese students adopt the approaches to learning as posited by the SAL framework? The hypothesis is that Chinese students would adopt the deep and surface approaches to learning in agreement with the SAL framework.

Research question 4: To what extent does Chinese students' achievement goal endorsement differentially predict their learning processes and outcomes? The hypothesis is that Chinese students' goal pursuit within the $2 \times 2$ framework would predict a distinct pattern of metacognitive strategy use, school well-being (perceived academic efficacy 
and affect at school), and academic performance, with the patterns for mastery avoidance and performance approach goals more negative and maladaptive than that for mastery approach goals, but more positive and adaptive than that for performance avoidance goals.

Research question 5: To what extent do achievement goals combine to facilitate learning processes and outcomes for Chinese students? With regard to these multiple goal benefits, three of the four hypotheses suggested by Barron and Harackiewicz (2001) were tested to examine the way multiple goal pursuit promoted achievement outcomes: (a) if the four achievement goals have their own independent, positive effects on a particular learning process and outcome (an additive goal pattern); (b) if different types of achievement goals interact above and beyond their independent effects in achieving a particular learning process and outcome (an interactive goal pattern); and (c) if the four achievement goals have specialized effects on different outcomes (a specialized goal pattern). Since Confucian heritage cultures are thought to predispose Chinese students to interpret performance and avoidance goals differently, we hypothesized that a multiple goal pursuit of high-level mastery goals (mastery approach or mastery avoidance goals) and high-level performance approach goals would be the most adaptive pattern for Chinese students.

Research question 6: To what extent do Chinese students' approaches to learning differentially predict their learning processes and outcomes? The hypothesis is that Chinese students' adoption of deep and surface approaches within the SAL framework would be linked to a distinct predictive profile, with the former positively related to use of metacognitive strategies, school well-being, and academic performance (when 
examination procedures demand understanding), whereas the latter would be negatively associated with these outcome variables.

Research question 7: To what extent do Chinese students' attitudes towards CHC values and their achievement goal pursuit interact to impact their learning processes and outcomes? It is hypothesized that $\mathrm{CHC}$ values would facilitate the effect of achievement goal pursuit on metacognitive strategy use, school well-being, and academic performance either in an additive or interactive pattern.

Research question 8: To what extent do Chinese students' attitudes towards CHC values and their adoption of approaches to learning interact to impact their learning processes and outcomes? Our hypothesis is that Chinese students' attitude towards CHC values would facilitate the effect of the deep approach to learning on metacognitive strategy use, school well-being, and academic performance either in an additive or interactive pattern.

The next chapter reports the results of the analyses that addressed the eight research questions. 


\section{CHAPTER 4}

\section{RESULTS}

The results of the data analyses are presented in four parts. First, data screening procedures are described, followed by the results of the exploratory factor analyses conducted to examine the consistency of the extracted factor solutions with the four goal constructs postulated by the $2 \times 2$ achievement goal framework, the two SAL contructs posited by the SAL framework, and the five cultural value contructs derived from the literature review. Next, descriptive statistics and bivariate correlations for the cultural value scales, achievement goal orientation scales, SAL scales, metacognitive strategy scale, school well-being scales, and grades are presented. Fourth, the results of regression analyses employed to examine the relationship of the goal orientation framework and SAL framework to cultural values, school well-being, metacognitive strategies, and grades are reported.

\section{Data Screening}

Data screening prior to analysis was performed through various programs within SPSS (version 16.0). Responses of 721 students to the instruments (i.e., 5 cultural value scales, 4 achievement goal orientation scales, 2 SAL scales, 1 metacognitive strategy scale, 2 school well-being scales) and their academic performances were examined for accuracy of data entry, missing data, outliers among cases, and the fit between their distributions and the assumptions of normality and linearity.

Accuracy of Data File 
To ensure the accuracy of the data file that was based on sound measurement and relatively free of coding errors, the data set was examined through the descriptive program of SPSS FREQUENCIES for means, standard deviations, and out-of-bounds entries beyond the expected range.

\section{Missing Data}

Before missing value analysis was conducted and decisions were made on the way to handle missing data, recoding was performed on four negatively worded Affect at School items for each of college English classes and advanced mathematics classes.

Missing data analysis was subsequently performed through SPSS MVA (Missing Value Analysis) on students' responses to the 143 quantitative instrument variables and their academic performances in college English classes and advanced mathematics classes.

All of the 145 variables had their missing values below $2 \%$ of cases, except one with missing values at $2.6 \%$, one at $3.2 \%$, and one at $8.9 \%$. The only one variable with missing values above 5\% of the total 721 participants, the grades for college English classes, was retained given that it is of vital interest for this study. Out of this sample of 721,708 participants had missing values below $5 \%$ of survey items, 9 had missing values ranging from $5 \%$ to $11 \%$, and 5 above $40 \%$. The five cases with missing values for over $40 \%$ of the survey items were removed from the data set, making the total sample 716. All the missing values on the 145 survey item variables of the 716 cases were replaced by the variable means.

Normality and Linearity 
Screening continuous variables for normality is an important early step in almost every multivariate analysis (Tabachnick \& Fidell, 2007). A check on normality was assessed through SPSS EXPLORE. Both normality plots (normal Q-Q plots and detrended normal Q-Q plots) and the statistical tests of normality (Kolmogorov-Smirnov and Shapiro-Wilk staticstics) indicated the departure from normality for each of the 145 variables.

According to Tabachnick and Fidell (2007), the null hypothesis of these statistical tests of normality is likely to be rejected with large samples even if there are only minor deviations from normality, because the standard errors for both skewness and kurtosis decrease with larger numbers in the sample; furthermore, a variable with statistically significant skewness in a large sample often does not deviate enough from normality to make a substantive difference in the analysis. Out of the 145 variables, 125 had skewness values ranging from +1.00 to -1.00 and the remaining 20 from \pm 1.00 to \pm 1.50 . With no extremely high skewness values identified, the 145 variables were believed to suffer no severe deviation from normality in the subsequent analysis. With regard to the impact of kurtosis on data analysis, Waternaux (1976) pointed out that underestimates of variance associated with positive kurtosis disappear with samples of 100 or more cases; with negative kurtosis, underestimation of variance disappears with samples of 200 or more. Out of the 145 variable, 138 had kurtosis values ranging from -1.50 to $+1.50,3$ from +1.50 to $+2.00,3$ from +2.00 to +2.50 , and 1 from +3.00 to +4.00 . Given that in large samples the significance level of skewness is not as important as its actual size and the 
impact of departure from zero kurtosis also diminishes (Tabachnick \& Fidell, 2007), all of the 145 variables were retained in the data set for further analysis.

Due to the large number of variables involved in the study, it would be burdensome to screen all possible pairs of variables for linearity. Statistics on skewness were used to screen only pairs that were likely to depart from linearity. Five cultural value variables picked as worst cases with the greatest deviation from normality, CV1 $\left(\gamma_{1}=-1.391\right), \operatorname{CV} 8\left(\gamma_{1}=-1.480\right), \operatorname{CV} 10\left(\gamma_{1}=-1.352\right), \operatorname{CV} 15\left(\gamma_{1}=-1.331\right)$, and CV17 $\left(\gamma_{1}=-\right.$ 1.397), were examined for a linear relationship with the variables of interest in the study, achievement goal and SAL items.

Although it has been suggested that the scatterplot is an effective way to examine linearity among items, the scatterplots between pairs of variables were not very revealing and defied interpretation in this study as a consequence of there being only seven choices for each of the items. SPSS COMPARE MEANS, instead, was used to examine the five variables for linearity. The tests for linearity showed a significant linear relationship between each of these five variables and the aforementioned variables of interest.

Given the normality and linearity of the variables involved in the study, there is no evident necessity for any of the 145 variables to undergo transformation.

\section{Univariate and Multivariate Outliers among Cases}

The test for univariate outliers among cases was performed through SPSS DESCRIPTIVES. Univariate outliers among the 716 cases were detected using the standardized scores of their responses in excess of $3.29(\mathrm{p}<.01$, two-tailed test) (Tabachnick \& Fidell, 2007). One case who had extremely low z-scores on four of the 
five survey items of the family-oriented goal scale (z-scores of -3.84 on CV1, -3.64 on CV5, -3.54 on CV19, -3.52 on CV21) and a low z-score on the other item (z-score of 2.92 on CV17) was located as an univariate outlier in this examination.

According to Tabachnick and Fidell (2007), outliers have a profound impact on the value of the correlation coefficient, which will influence those multivariate procedures based on correlation (or covariance) among variables, such as factor and regression analyses. Tabachnick and Fidell suggested four approaches to reducing the influence of outliers. One of the options is to retain the case but change the value on the offending variables so that the case no longer has as much impact. In compliance with the strategy, this one outlier was assigned raw scores on the four offending variables that is one unit larger than the next most extreme score in the distribution.

The 716 cases were then screened for multivariate outliers through SPSS REGRESSION using the criterion of Mahalanobis distance at $\mathrm{p}<.001$ (Tabachnick \& Fidell, 2007). For the four parts of cultural values, goal orientations, SAL, and metacognitive strategies and school well-being, none of the cases had their Mahalanobis distances at $\mathrm{p}<.001$ across all of the four parts in college English classes; for college English classes, no case was identified as a multivariate outlier. In contrast, two cases, located through Mahalanobis distance as multivariate outliers with $\mathrm{p}<.001$ in advanced mathematics classes, were deleted from the data set, making the sample size 714 (see Table 2).

Table 2

Mehalanobis $D^{2}$ Scores and Their Probability for Cases Located as Multivariate Outliers 


\begin{tabular}{|l|c|c|l|l|l|l|}
\hline Classes & Student\# & $\begin{array}{l}\text { Type of } \\
\text { statistics }\end{array}$ & CV & GO & SAL & MS \\
\hline \multirow{2}{*}{$\begin{array}{l}\text { Advanced } \\
\text { mathematics }\end{array}$} & 062017 & $\chi^{2}$ & 61.652 & 62.679 & 57.837 & 45.980 \\
\cline { 3 - 7 } & 062768 & $\mathrm{p}$ & .0000 & .0000 & .0000 & .0005 \\
\cline { 3 - 7 } & & $\chi^{2}$ & 68.175 & 63.994 & 48.895 & 44.726 \\
\cline { 3 - 7 } & $\mathrm{p}$ & .0000 & .0000 & .0003 & .0007 \\
\hline
\end{tabular}

Note: $\mathrm{CV}=$ Cultural values. $\mathrm{GO}=$ Goal orientations. $\mathrm{SAL}=$ Student approaches to learning. $\mathrm{MS}=$ Metacognitive strategies and school well-being.

\section{Exploratory Factor Analysis}

Principal components analysis (PCA) is useful as an initial step in factor analysis (FA) where it reveals a great deal about maximum number and nature of factors (Tabachnick \& Fidell, 2007, p.635).

Factor Analyses of Cultural Value, Achievement Goal, and SAL Items

Following Tabachnick and Fidell's suggestion, a preliminary PCA with varimax rotation was performed through SPSS DATA REDUCTION on 5 correlation matrices: one containing the 25 cultural value variables, one including 20 goal orientation variables for each of college English classes and advanced mathematics classes, and one consisting of 20 SAL variables for each of the two classes.

These five correlation matrices were shown well factorable by: (a) numerous bivariate correlations well in excess of .30, (b) many significant correlations of pairs of variables, (c) significant Bartlett's tests of spherity, (d) mostly small values among the off-diagonal elements of the anti-image matrices, and (e) all of the five Kaiser-MeyerOlkin measures of sampling adequacy over .86 , with values of .60 and above required for good FA (Tabachnick \& Fidell, 2007).

When questionnaires were first administered in college English classes, some students reported being confused about one of the five mastery avoidance goal items, the 
10th achievement goal item: 有时我害怕自己可能并没一像自己希望地那样一透彻理 解学习的内容 (Sometimes I'm afraid that I may not understand the content of this class as thoroughly as I'd like), which was clarified orally before its administration in advanced mathematics classes. The adverbial clause of comparison "as thoroughly as I'd like” in the English version was rendered as a parenthesis in Chinese “像自己希望地那 样”, sandwiched between "sometimes I'm afraid that I may not" and "understand the content of this class" by a dash in pairs to explain the meaning of the main clause. Correct interpretation of this item entails sufficient knowledge of the function of the punctuation mark dash used in pairs; otherwise, students are unable to interpret the parts outside the pair of dashes as what is intended to impart in the main clause while the part between is a parenthesis for further explanation. Caution, therefore, was given to this mastery avoidance goal item within the initial solution in college English classes. Examination of the rotated solution for the 20 goal orientation items in college English classes indicated that this mastery avoidance goal item was found not only to load (r $=.455)$ on the construct of mastery approach goal but also to load highly at .435 on performance avoidance goal factor. In an attempt to make the factor solutions comparable, this variable was therefore deleted from all the subsequent analyses in both classes.

The two most commonly used approaches, the Kaiser criterion of "eigenvalue greater than 1" and Cattell's scree test, were used to determine the optimal number of factors for the subsequent runs of principal factors extraction. By the "eigenvalue greater than 1" rule, it was shown that the cultural value correlation matrix of 25 variables had 6 factors, the goal orientation in college English classes 4 factors, the goal orientation in 
advanced mathematics 4 factors, and the SAL both in college English classes and advanced mathematics classes 4 factors. However, in numerous studies involving both principal components and common factors, this best known procedure in selecting the number of factors "has been demonstrated to lead to substantial overfactoring and occasionally to underfactoring" (Fabrigar, Wegener, MacCallum, \& Strahan, 1999). Cattell's scree test was then used to further examine the number of factors, the number of eigenvalues prior to the last substantial drop in the magnitude of the eigenvalues (the number of eigenvalues above the "break") (Fabrigar, et al., 1999). The scree tests indicated 5 factors underlying the cultural value variable matrix, 4 factors for the goal orientation variable matrix both in college English classes and advanced mathematics classes, 2 factors for the SAL variable matrix in college English classes, and 2 or 3 factors for the SAL variable matrix in advanced mathematics classes.

Combining the results from the above two procedures, principal factors analysis (PFA) specifying the suggested number of factors ( 5 or 6 for the cultural value variables, 4 factors for the goal orientation variables both in college English classes and advanced mathematics classes, 2 or 4 factors for the SAL variables in college English classes, 2, 3, or 4 factors for the SAL variables in advanced mathematics classes) was respectively performed to find the optimal number of factors for each correlation matrix.

Oblique rotation would seem more reasonable than its orthogonal counterpart, because the use of correlated factors seems more likely in the study of sociobehavioral phemomena (Tabachnick \& Fidell, 2007). Each of the principal axis factoring extractions was performed first with oblique rotation so that decisions could be made about rotation 
based on the examination of the factor correlation matrix. Any factor correlation in excess of .32 warrants oblique rotation (Tabachnick \& Fidell, 2007). Each of the subsequent PFA with the specified number of factors on cultural value items and goal orientation items revealed sufficient factor correlations that defied further runs with orthogonal rotation. During the interpretation of factors, "only variables with loadings of .32 and above are interpreted" (Tabachnick \& Fidell, 2007, p. 649).

\section{Cultural Values}

For the 25 cultural value variables, the principal factor analysis with oblique rotation of 6 factors yielded a poorly defined factor (the $6^{\text {th }}$ one) on which only two variables loaded. The correlation between these two variables was only .396 $(\mathrm{p}<.001)$. Moreover, one of them was significantly correlated as highly as .300 and the other .325 with one of the three variables that formed the second extracted factor. According to Tabachnick and Fidell (2007), even in the most exploratory factor analysis the interpretation of factors defined by only two variables is hazardous, and the factor defined by two variables may be reliable only when the two variables are highly correlated with each other $(r>.70)$ but relatively uncorrelated with other variables. In contrast to this less satisfactory pattern, the PFA with 5 factors yielded an interpretable factor solution that accounted for $48.374 \%$ of the total variance and demonstrated a cleaner factor structure: item loadings on the primary factor above .32 , no or few item crossloadings, and no factors with fewer than three items (see Appendix A: Table A1) Examination of items within the extracted factor patterns indicated a result consistent with the hypothesis that Chinese students pursue socially oriented goals 
(family-, peer-, and teacher-oriented goals), follow a sense of learning duty (the perception of learning as a primary and moral obligation), and practice utility value (perceived instrumentality of current school success to personally valued future goals), as derived from literature review: factor one comprised the five teacher-oriented goal items, factor two consisted of the five peer-oriented goal items; factor three was made up of the five family-oriented goal items; factor four comprised the three utility value items; and factor five was composed of the four sense of learning duty items.

Three items, one from the sense of learning duty scale and two from the utility value scale, failed to load onto any of the five factors, and so were deleted. Deletion of the one from the originally designed five-item sense of learning scale made the scale internal consistency reliability coefficient (Cronbach's $\alpha$ ) decrease from .732 to .718 , while exclusion of the two from the originally designed five-item utility value scale made the Cronbach's $\alpha$ of the scale increase from .657 to .689 . The family-oriented goal, peeroriented goal, family-oriented goal, utility value, and sense of learning duty measures were constructed by averaging the items on each factor, and all five resultant reliability coefficents evidenced acceptable to high levels of internal consistency ranging from .665 to .907 (see Appendix A: Table A2). Since Cronbach's alphas of .50 or higher are judged adequate for research purposes (Nunnally, 1967), in this study the scales with an internal consistency reliability coefficient meeting this standard were retained for subsequent analyses.

The five extracted cultural value factors were then subjected to correlation and exploratory factor analyses to examine their defining features as a component of the 
higher-order unitary $\mathrm{CHC}$ value construct and the construct validity of the $\mathrm{CHC}$ values. The $\mathrm{CHC}$ value measure was to be used in regression analyses to investigate its relationship to the two motivational frameworks and to the learning process and outcome variables.

The bivariate correlation (see Appendix A: Table A3) among the five cultural value measures indicated that teacher-oriented goals, family-oriented goals, utility value, and sense of learning duty were positively associated with one another at $\mathrm{p}<.01$. Peeroriented goals, however, seemed to be different from the aforementioned four correlated cultural values: They were very weakly correlated with teacher-oriented goals $(r=.098, p$ $<.01$ ), and unrelated to all the other cultural values. Consistently, exploratory factor analyses on these 5 cultural value measures yielded two factors, with the first one composed of the four correlated measures and the second comprising only peer-oriented goals. Given this pronounced distinction between peer-oriented goals and the other four cultural values, it was decided that peer-oriented goals would be deleted from further analysis as a component of the higher-order unitary $\mathrm{CHC}$ value construct.

The PCA conducted on the four remaining cultural value measures of teacheroriented goals, family-oriented goals, sense of learning duty, and utility value yielded a single factor with an eigenvalue greater than 1(see Appendix A: Table A4), which was consistent with what the scree test suggested.

The $\mathrm{CHC}$ value measure was constructed by averaging the four underlying cultural values. That this single factor was well defined by the four cultural values was validated by the fact that this scale reliability coefficient evidenced an acceptable level of 
internal consistency $(\alpha=.721)$. The deletion of any one of the four scores would make the Cronbach's $\alpha$ of the unitary cultural value measure decrease.

\section{Goal Orientations in College English Classes}

Principal factor extraction with oblique rotation of 4 factors on the 19 retained goal orientation variables in college English classes produced a factor solution in which the 5 items that loaded on factors 2 included one crossloaded item and one relatively lowloading item. Each of the other three extracted factors, however, was defined by a subset of measured variables that had large loadings relative to the other measured variables, and on only one of these three factors did each measured variable load highly.

Examination of the 5 items that loaded on factor 2 revealed that the crossloaded item loaded on factor 2 at .384 , but on another factor at .320; the low-loading item loaded on factor 2 at .266 , but on all other three below .129. Considering the difference in their loadings on factor 2 and the loadings on other factors on the one hand and on the other hand the reduction of the scale's internal consistency resulting from deletion of either of them, it were decided that these two items were retained to make the factor solutions comparable for further analysis.

Inspection of items within the extracted factor patterns provided evidence for the hypothesis that Chinese students endorse achievement goal orientations in agreement with those postulated by the $2 \times 2$ achievement goal framework: factor one was composed of the four mastery avoidance goal items; factor two comprised the five performance avoidance goal items; factor three consisted of the five performance approach goal items; and factor four was made up of the five mastery approach goal 
items (see Appendix A: Table A5). This rotated solution accounted for $41.195 \%$ of the total variance.

Mastery approach goal, mastery avoidance goal, performance approach, and performance avoidance goal measures were constructed by averaging the items on each factor, and the resultant reliability coefficients had acceptable to moderate levels of internal consistency (see Appendix A: Table A6).

\section{Goal Orientations in Advanced Mathematics Classes}

A principal factor analysis with oblique rotation of 4 factors on the 19 retained goal orientation variables in advanced mathematics classes produced a factor solution marked by a clean factor pattern. Examination of items within the extracted factor patterns provided evidence for the hypothesis that Chinese students endorse achievement goal orientations and that these achievement goals are consistent with the $2 \times 2$ achievement goal framework: factor one was composed of the four mastery avoidance goal items; factor two comprised the five performance avoidance goal items; factor three consisted of the five performance approach goal items; and factor four was made up of the five mastery approach goal items. This rotated solution accounted for $46.479 \%$ of the total variance (see Appendix A: Table A7).

Inspection of the internal consistency for each scale indicated that exclusion of item 17 from the mastery avoidance goal construct made the scale's Cronbach's $\alpha$ increase from a low internal consistency coefficient of .669 to a moderate level of .741. It was decided to drop this item from the mastery avoidance goal scale. Each of the four goal orientation factor scores was constructed by averaging the items on each factor, and 
the resultant indices evidenced acceptable to moderate levels of internal consistency (see Appendix A: Table A8).

\section{SAL in College English Classes}

Principal factor extraction with oblique rotation of 4 factors yielded no interpretable and theoretically plausible solution in contrast to the PFA with 2 factors. Examination of the factor correlation matrix indicated a low correlation between the two extracted factors $(\mathrm{r}=-.170)$, which justified orthogonal rotation. The orthogonal rotated factor solution with 2 factors presented the property of simple structure, i.e., "high within-factor variability in loadings" but "low factorial complexity in defining variables" (Fabrigar, et al., 1999). Examination of items within the extracted factor patterns indicated a result consistent with the hypothesis that Chinese students adopted the deep and surface approaches to learning: factor one consisted of the five deep motive items and five deep strategy items, and factor two comprised the five surface motive items and four surface strategy items, with one surface strategy item loading on neither of the two factors (see Appendix A: Table A9). The rotated solution accounted for $31.394 \%$ of the total variance.

Each of the two SAL measures (deep approach and surface approach) was constructed by averaging the items on each factor, and the resultant indices evidenced moderate levels of internal consistency (see Appendix A: Table A10).

\section{SAL in Advanced Mathematics Classes}

The PFA with oblique rotation of 3 and 4 factors on the 20 SAL items in advanced mathematics classes produced no interpretable factor solutions, whereas the 
extraction with 2 factors yielded a solution marked by high within-factor variability in loadings and low factorial complexity in defining variables. Since the factor correlation matrix suggested a low correlation $(\mathrm{r}=-.289)$ between the two extracted factors, a principal factor analysis was subsequently conducted with orthogonal rotation of 2 factors. Examination of items within the extracted factor patterns suggested a result consistent with the hypothesis that Chinese students adopted the deep and surface approaches to learning: factor one consisted of five deep motive items and five deep strategy items, and factor two comprised of five surface motive items and five surface strategy items (see Appendix A: Table A11). The rotated solution accounted for $34.868 \%$ of the total variance.

Each of the two SAL measures (deep approach and surface approach) was constructed by averaging the items on each factor, and the resultant indices evidenced moderate levels of internal consistency (see Appendix A: Table A12).

\section{Factor Analyses of Metacognitive Strategy and School Well-being Items}

Principal components analyses were conducted respectively on the 6 metacognitive strategy items, 6 perceived academic efficacy items, and 7 affect-at-school items in each of the college English classes and advanced mathematics classes to determine whether each of them represented a single construct. If more than one construct were identified in any solution, principal factors analysis with oblique rotation would be performed subsequently to examine the underlying factor pattern.

The PCA conducted on the metacognitive strategy and perceived academic efficacy items in college English classes and advanced mathematics classes respectively 
yielded a single factor with an eigenvalue greater than 1, which was consistent with what the scree tests suggested (see Appendix A: Table A13, 14, 15, and 16).

The PCA on the affect-at-school items in each of the college English classes and advanced mathematics classes yielded two factors with eigenvalues over 1 , while the scree tests indicated 1 construct underlying these 7 items in each of the two classes. The trial PFA run with oblique rotation of 2 factors for each of the two classes yielded 2 eigenvalues greater than 1 among unrotated factors, but the eigenvalue for the $2^{\text {nd }}$ factor in each of the two classes was below 1 after rotation. It was decided that the number of underlying factor (s) for the affect-at-school items in each of the two classes was one (see Appendix A: Table A17 and 18). That this single factor was well defined by the seven items in each of the two classes was confirmed by the affect-at-school scale internal consistency reliability coefficient of Cronbach's $\alpha$ at .818 in college English classes and .846 in advanced mathematics classes.

Each of the metacognitive strategy and school well-being measures in college English and advanced mathematics classes was constructed by averaging the items on each factor, and the resultant indices evidenced moderate levels of internal consistency (see Appendix A: Table A19).

\section{Summary}

The EFA and reliability data provided evidence for: (a) the $\mathrm{CHC}$ values as a highorder unitary construct of socially oriented goals, a sense of learning duty, and utility value, when the peer-oriented goals were removed, (b) Chinese students' endorsement of 
achievement goals consistent with the goal constructs of the $2 \times 2$ framework, and (c) the Chinese students' adoption of the deep and surface approaches to learning.

\section{Descriptive Statistics and Bivariate Correlations}

The descriptive statistics are presented in Appendix A: Table A20 for the CHC value, goal orientation, SAL, metacognitive strategy, school well-being, and academic achievement measures, including their means (M), standard deviations (SD), minimum and maximum values, and distributional indices (skewness and kurtosis).

The means for $\mathrm{CHC}$ values, four achievement goal orientations, and the deep approach were above the scale midpoint of these scales, indicating a general endorsement by Chinese students of the constructs these scales were intended to measure. The mean for the $\mathrm{CHC}$ value measure was far higher than the scale midpoint, evidencing its prevalance among Chinese students. Among the achievement goal orientations, the mean for mastery approach goals was the highest, followed by those for mastery avoidance goals and performance approach goals, with that for performance avoidance goals consistently ranking last, whether in college English classes or advanced mathematics classes. This signified the way the four achievement goal orientations tended to vary in salience in these academic settings: Chinese students tended to pursue mastery approach goals first, mastery avoidance goals second, performance approach goals next, and performance avoidance goals last, with mastery approach goals most salient in college English classes and both mastery approach and mastery avoidance goals most prevalent in advanced mathematics classes. With regard to the SAL measures, participants tended 
to adopt the deep approach to learning rather than the surface approach in the two classes, which is in agreement with expectation.

Students' reports of their use of metacognitive strategy, perceived academic efficacy, and affect at school were also above the scale midpoint values both for college English classes and advanced mathematics classes, which suggested a high orientation towards the contructs these scales were intended to measure.

Given the impact of a large sample size on the statistical test of normality, an inspection of the distributional indices for the 21 measures was more of an examination of the size of skewness and kurtosis values (Tabachnick \& Fidell, 2007). No extreme skewness and kurtosis values were found, although caution might be given to the grades in advanced mathematics classes $\left(\gamma_{1}=-1.03\right)$.

Appendix A: Table A21 presents the zero-order correlations among CHC values, achievement goal orientation, SAL, metacognitive strategy and school well-being, and academic achievement measures.

As expected, the cultural values were not only associated with achievement goal orientation and SAL constructs in the anticipated direction, but also linked to metacognitive strategy and school well-being measures. As a unitary measure of the cultural values, $\mathrm{CHC}$ value was positively and significantly correlated with each of the four goal orientations, the deep approach to learning, metacognitive strategy, and school well-being, but were unrelated (in college English classes) or slightly negatively associated (in advanced mathematics classes) with the surface approach. 
In agreement with the previous empirical results obtained by Elliot and McGregor (2001) in the bivariate analysis of the achievement goal measures, the four goal orientions were mostly positively correlated with one another because of the overlap either in mastery-performance or approach-avoidance dimensions. As surprisingly as in Elliot and McGregor's findings (2001), mastery avoidance goals were positively associated with performance approach goals $(\mathrm{r}=.39, \mathrm{p}<.01$ in college English classes; $\mathrm{r}$ $=.38, \mathrm{p}<.01$ in advanced mathematics classes) in spite of their distinction in both mastery-performance and approach-avoidance dimensions, which makes a combination of mastery avoidance and performance approach goals in a multiple goal pursuit possible. In contrast, mastery approach goals were, as expected, either unrelated to (in college English classes $)$ or negatively associated with $(r=-.17, \mathrm{p}<.01$ in advanced mathematics classes) performance avoidance goals. Furthermore, it is noteworthy that among these positive associations found for the achievement goals among Chinese students, the correlation between mastery avoidance and performance approach goals as mentioned above was far higher than the association found between mastery avoidance and performance avoidance goals $(\mathrm{r}=.20, \mathrm{p}<.01$ in college English classes; $\mathrm{r}=.11, \mathrm{p}<.01$ in advanced mathematics classes) even though the latter pair overlapped in terms of approach-avoidance dimension. Besides the intercorrelations among achievement goal constructs as described above, the bivariate analysis also indicated that the associations found between these goal orientations and metacognitive strategy, school well-being, and academic achievement variables were generally consistent with expectations based on achievement goal theory: with metacognitive strategy and school well-being, mastery 
approach goals showed the strongest positive correlation, mastery avoidance and performance approach goals displayed a progressively weaker association, and performance avoidance goals demonstrated a negative link; with course grades, mastery approach goals showed a positive correlation $(r=.10, p<.01$ in college English classes; $r$ $=.15, \mathrm{p}<.01$ in advanced mathematics classes), but performance avoidance goals a negative association $(r=-.14, p<.01$ in college English classes; $r=-.18, p<.01$ in advanced mathematics classes). Surprisingly, performance approach goals, a consistent predictor of academic performance, demonstrated the strongest positive association with the course grades in college English classes $(\mathrm{r}=.13, \mathrm{p}<.01)$, but presented a null correlation in advanced mathematics classes $(\mathrm{r}=.05, \mathrm{p}=.16)$.

The correlations concerning the SAL were in agreement with the anticipated pattern for the deep approach and surface approach based on SAL theory. The two approaches were negatively associated in college English classes $(r=-.26 \mathrm{p}<.01)$ and in advanced mathematics classes $(\mathrm{r}=-.28, \mathrm{p}<.01)$. The deep approach presented a positive correlation with metacognitive strategy, perceived academic efficacy, and affect at school in both classes, while the surface approach had a negative link to each of them. The surface approach was negatively related to course grades in college English classes $(r=$ $.19, \mathrm{p}<.01)$ and advanced mathematics classes $(\mathrm{r}=-.21, \mathrm{p}<.01)$. In contrast, the deep approach was positively associated with course grades in advanced mathematics classes $(\mathrm{r}=.16, \mathrm{p}<.01)$, but unrelated in college English classes $(\mathrm{r}=-.01, \mathrm{p}=.71)$.

Examination of the correlations between achievement goal orientations and the SAL constructs indicated positive associations between each of mastery approach and 
mastery avoidance goals and the deep approach but negative relations between each of these two goals and the surface approach, weak positive links between performance approach goals and each of the deep and surface approaches, null or negative association between performance avoidance goals and the deep approach but a positive link between performance avoidance goals and the surface approach in the two classes.

In sum, the measures of CHC values, achievement goals, SAL, metacognitive strategy, academic efficacy, affect at school, and academic performance were generally correlated with each other in the expected direction.

\section{Multiple Regression Analyses}

A series of combinations of sequential and standard multiple regression was exployed to examine the predictive relationships between each of the $2 \times 2$ goal orientation framework and the SAL framework and Chinese university students' use of metacognitive strategies, school well-being (perceived academic efficacy and affect at school), and academic performance. The regression was hierarchical over blocks, but simultaneous within blocks. Furthermore, these regression combinations were also used to investigate the way these students' attitudes towards the $\mathrm{CHC}$ values influenced the impact of each of the two motivation frameworks on their metacognitive strategies, school well-being (perceived academic efficacy and affect at school), and academic performance.

The basic regression model used in all of the analyses contained student background information and relevant main effect and interaction effect variables. In Step 1, students' demographic variables including gender (females $=-1$, males $=1$ ) and 
location of middle school (rural area $=-1$, urban area $=1$ ) were included as predictors in order to control for any gender and geographical effect. In Step 2, the main effect terms were contained in the regression model to test for the unique predictive utility of independent variables of interest. In Step 3, the interaction product terms between the goal orientation main effects were included to test for all the possible two-way interactive effects.

Following the strategy suggested by Aiken and West (1991), the independent variables were centered (put in mean-deviated score form), and all the two-way interaction product terms were constructed using these mean-deviated main effects. Significant two-way interaction effects were subjected to simple slope analyses with one variable $(X)$ at 3 levels of the other variable $(Z), Z_{\text {Low }}\left(1 \mathrm{SD}\right.$ below the mean), $Z_{\text {Moderate }}$ (at the mean), and $\mathrm{Z}_{\mathrm{High}}(1 \mathrm{SD}$ above the mean), to determine the nature of the interaction effects.

\section{Goal Orientation Framework and Learning Process and Outcome Variables}

Given that not only the motivational profiles associated with a single goal adoption but also with multiple goal adoption are of central conceptual interest for the study, the regression was conducted to: (a) investigate the independent main effects of the four achievement goals to provide evidence for the additive goal pattern of the multiple goal (Harackiewicz, et al., 2002), and (b) examine the two-way interaction effects to provide evidence for the interactive goal pattern of the multiple goal perspective (Harackiewicz, et al., 2002) (Note: No extant literature revealed three- and four-way interaction effects for the achievement goal orientations.). In addition, different learning 
process and learning outcome variables were used in the study, which may provide evidence for the specialized pattern of the multiple goal perspective (Harackiewicz, et al., 2002).

Apart from students' background information, the independent variables within the regression model tested on each learning process and learning outcome contained: (a) the main effect terms of mastery approach (Map), mastery avoidance (Mav), performance approach (Pap), and performance avoidance (Pav) goals, thereby affording a test of each goal's unique predictive utility, and (b) all possible two-way interaction product terms between the four goal orientation main effects.

\section{Metacognitive Strategies}

Regressing metacognitive strategies on the basic model yielded a significant effect for the overall model in college English classes, $F(12,692)=17.052, \mathrm{p}<.001, \mathrm{R}^{2}$ $=.228$, and in advanced mathematics classes, $F(12,692)=29.454, \mathrm{p}<.001, \mathrm{R}^{2}=.338$.

College English classes. In Step 1, with the multiple correlation coefficient being not significantly different from zero, $F(2,702)=.318, \mathrm{p}=.728, \mathrm{R}^{2}=.001$, there was no evidence for any gender and geographical effects on metacognitive strategies. When the 4 achievement goal main effect terms and 6 interaction terms were added to the prediction, there were significant increases in the squared multiple correlation in Step 2, $F_{\text {inc }}(4,698)$ $=46.987, \mathrm{p}<.001, \Delta \mathrm{R}^{2}=.212$ and in Step 3, $F_{\text {inc }}(6,692)=2.296, \mathrm{p}<.05, \Delta \mathrm{R}^{2}=.015$.

In Step 2, regressing metacognitive strategies on gender, location of middle school, and 4 achievement goal main effect terms revealed that mastery approach goals were a positive predictor of metacognitive strategies $(\beta=.335, \mathrm{p}<.001)$, and mastery 
avoidance goals also positively but less strongly predicted metacognitive strategies ( $\beta$ $=.179, \mathrm{p}<.001)$.

In Step 3, regressing metacognitive strategies on the 6 interaction effect terms and the aforementioned 6 predictors revealed not only a significant positive main effect for mastery approach goals $(\beta=.354, \mathrm{p}<.001)$ and mastery avoidance goals $(\beta=.168, \mathrm{p}$ $<.001$ ), but also a significant positive unique predictive utility of performance approach goal $($ Pap $) \times$ performance avoidance goal $($ Pav) interaction effect $(\beta=.090, p<.05)$. Simple slope analysis for the significant Pap $\times$ Pav interaction indicated that the negative effect of performance avoidance goals on metacognitive strategies tended to be weakended with the increase of performance approach goals $\left(\beta_{\mathrm{Pav}}=-.209, \mathrm{p}<.001\right.$, $\beta_{\text {PapLow }}=.209, \mathrm{p}<.001 ; \beta_{\text {Pav }}=. .080, \mathrm{p}<.05, \beta_{\text {PapModerate }}=.209, \mathrm{p}<.001 ; \beta_{\text {Pav }}=.049, \mathrm{p}$ $\left.=.343, \beta_{\text {PapHigh }}=.209, \mathrm{p}<.001\right)$, suggesting that increases in performance avoidance goals led to large decreases in metacognitive strategies when performance approach goals were low (see Figure 1). None of the other variables attained significance (see Appendix A: Table A22).

Figure 1

Pap $\times$ Pav Interaction Effect on Metacognitive Strategy in College English Classes Plotted from Simple Regression Equations $\mathrm{Y}=\left(-0.070+0.103 Z_{\text {Pap }}\right) \mathrm{X}_{\text {Pav }}+\left(0.166 Z_{\text {Pap }}+4.587\right)$ $\mathrm{S}_{\text {Pap }}=1.097, \mathrm{~S}_{\text {Pav }}=0.990$

At $Z_{\text {PapHigh }}=1.097: \quad Y=0.043 X_{\text {Pav }}+4.769$

At $Z_{\text {PapModerate }}=0.000: \quad \mathrm{Y}=-0.070 \mathrm{X}_{\mathrm{Pav}}+4.587$

At $Z_{\text {PapLow }}=-1.097: \quad Y=-0.183 X_{\text {Pav }}+4.405$ 
Simple Regression Analysis of Pap x Pav Interaction on Metacognitive Strategies

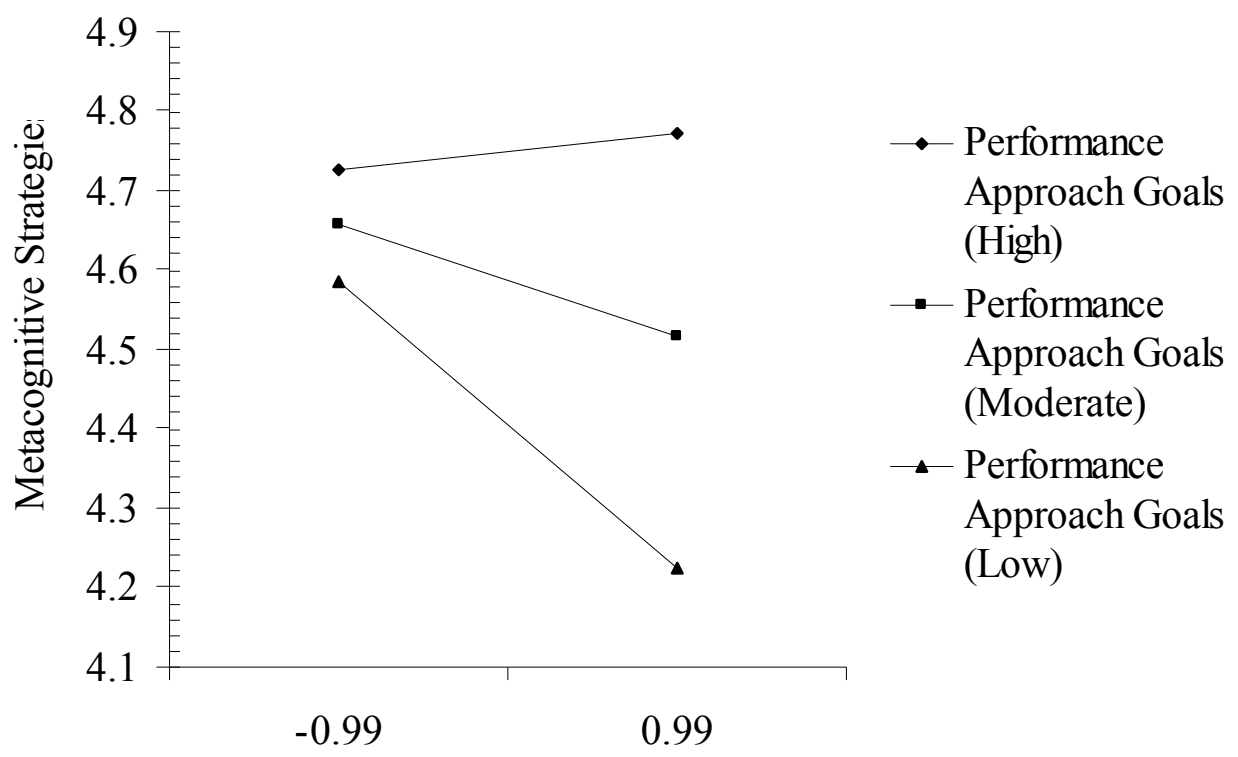

Performance Avoidance Goals

Advanced mathematics classes. In Step 1, the null hypothesis that the multiple correlation coefficient is not significantly different from zero was rejected, $F(2,702)=$ $3.266, \mathrm{p}<.05, \mathrm{R}^{2}=.009$. The regression of metacognitive strategies revealed a significant effect for gender $(\beta=-.078, \mathrm{p}<.05)$, but this gender effect on metacognitive strategies was not significant in Step $2(\beta=-.054, \mathrm{p}=.085)$ and Step $3(\beta=-.050, \mathrm{p}$ $=.111)$. With achievement goal variables and their two-way interaction terms added to the model, the change in squared multiple correlation was significant in Step 2, $F_{\text {inc }}$ (4, $698)=80.891, \mathrm{p}<.001, \Delta \mathrm{R}^{2}=.314$ and in Step $3, F_{\text {inc }}(6,692)=2.622, \mathrm{p}<.05, \Delta \mathrm{R}^{2}$ $=.015$.

In Step 2, regressing metacognitive strategies on gender, location of middle school, and 4 achievement goal main effect terms revealed that both mastery approach 
goals and mastery avoidance goals positively predicted metacognitive strategies, with the effect of the former $(\beta=.414, \mathrm{p}<.001)$ more than twice as strong as that of the latter $(\beta$ $=.199, \mathrm{p}<.001)$.

In Step 3, regressing metacognitive strategies on the 6 interaction effect terms and the aforementioned 6 predictors revealed that besides a significant main effect for mastery approach goals $(\beta=.388, \mathrm{p}<.001)$ and mastery avoidance goals $(\beta=.194, \mathrm{p}$ $<.001)$, there was a significant negative unique predictive utility of mastery approach goal $($ Map $) \times$ mastery avoidance goal $($ Mav) interaction effect $(\beta=-.100, p<.01)$. Simple slope analysis for the Map $\times$ Mav interaction $\left(\beta_{\text {Map }}=.468, p<.001, \beta\right.$ MavLow $=.215, p$ $<.001 ; \beta$ Map $=.403, \mathrm{p}<.001, \beta$ MavModerate $=.215, \mathrm{p}<.001 ; \beta_{\mathrm{Map}}=.338, \mathrm{p}<.001$, $\left.\beta_{\text {MavHigh }}=.215, \mathrm{p}<.001\right)$ indicated that the positive effect of mastery approach goals tended to be weakened with the increase of mastery avoidance goals, suggesting that increases in mastery approach goals led to large increases in metacognitive strategies when mastery avoidance goals were low (see Figure 2). None of the other variables were significant predictors (see Appendix A: Table A23).

Figure 2

$$
\begin{aligned}
& \text { Map } \times \text { Mav Interaction Effect on Metacognitive Strategy in Advanced Mathematics } \\
& \text { Classes Plotted from Simple Regression Equations } \\
& \mathrm{Y}=\left(0.365-0.059 \mathrm{Z}_{\mathrm{Mav}}\right) \mathrm{X}_{\mathrm{Map}}+\left(0.192 \mathrm{Z}_{\mathrm{Mav}}+4.956\right) \\
& \mathrm{S}_{\text {Mav }}=0.991, \mathrm{~S}_{\text {Map }}=0.978 \\
& \text { At } Z_{\text {MavHigh }}=0.991: \quad Y=0.307 X_{\text {Map }}+5.146 \\
& \text { At } \mathrm{Z}_{\text {MavModerate }}=0.000: \quad \mathrm{Y}=0.365 \mathrm{X}_{\text {Map }}+4.956 \\
& \text { At } Z_{\text {MavLow }}=-0.991: \quad Y=0.423 X_{\text {Map }}+4.766
\end{aligned}
$$




\section{Simple Regression Analysis of Map x Mav Interaction on}

Metacognitive Strategies

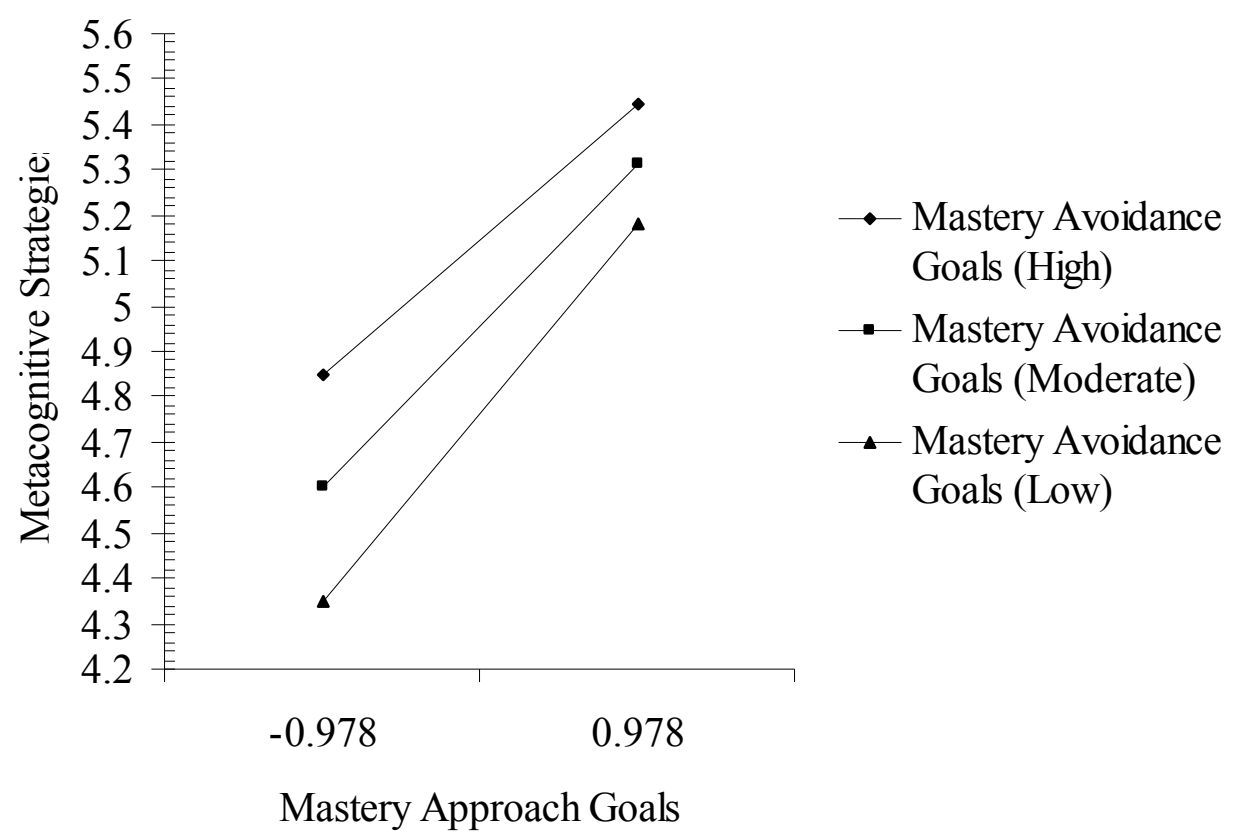

Perceived Academic Efficacy

Regressing perceived academic efficacy on the basic model yielded a significant effect for the overall model in college English classes, $F(12,692)=12.802, \mathrm{p}<.001, \mathrm{R}^{2}$ $=.182$, and in advanced mathematics classes, $F(12,692)=21.725, \mathrm{p}<.001, \mathrm{R}^{2}=.274$.

College English classes. In Step 1, the multiple correlation coefficient was significantly different from zero, $F(2,702)=3.190, \mathrm{p}<.05, \mathrm{R}^{2}=.009$. The regression indicated a significant effect of location of middle school on perceived academic efficacy $(\beta=.089, \mathrm{p}<.05)$. This location effect continued to be significant with achievement goal effects added to prediction in Step $2(\beta=.076, \mathrm{p}<.05)$ and Step $3(\beta=.072, \mathrm{p}<.05)$, indicating that the students whose middle schools were located in urban areas were more likely to have higher perceived academic efficacy in college English classes. When the 
achievement goal variables and their interaction terms were added to the prediction, the change in the squared multiple correlation was significant in Step $2, F_{\text {inc }}(4,698)=$ $30.744, \mathrm{p}<.001, \Delta \mathrm{R}^{2}=.148$ and in Step $3, F_{\text {inc }}(6,692)=3.414, \mathrm{p}<.01, \Delta \mathrm{R}^{2}=.024$.

In Step 2, regressing perceived academic efficacy on gender, location of middle school, and 4 achievement goal main effect terms revealed that mastery approach goals positively predicted perceived academic efficacy $(\beta=.276, \mathrm{p}<.001)$, twice as strong a positive predictor as performance approach goals $(\beta=.121, \mathrm{p}<.01)$, whereas performance avoidance goals were a negative predictor $(\beta=-.142, \mathrm{p}<.001)$.

In Step 3, regressing perceived academic efficacy on the 6 interaction effect terms and the aforementioned 6 predictors revealed not only a significant main effect for mastery approach goals $(\beta=.313, \mathrm{p}<.001)$, performance approach goals $(\beta=.140, \mathrm{p}$ $<.01)$, and performance avoidance goals $(\beta=-.138, \mathrm{p}<.001)$, but also a significant positive unique predictive utility of the Map $\times$ Mav interaction $(\beta=.149, \mathrm{p}<.01)$ and Pap $\times$ Pav interaction $(\beta=.091, \mathrm{p}<.05)$. Simple slope analysis for the Map $\times$ Mav interaction $\left(\beta_{\text {Map }}=.276, \mathrm{p}<.001, \beta_{\text {MavLow }}=.055, \mathrm{p}=.184 ; \beta_{\text {Map }}=.367, \mathrm{p}<.001\right.$, $\left.\beta_{\text {MavModerate }}=.055, \mathrm{p}=.184 ; \beta_{\text {Map }}=.457, \mathrm{p}<.001, \beta_{\text {MavHigh }}=.055, \mathrm{p}=.184\right)$ indicated that the positive effect of mastery approach goals tended to be strengthened with the increase of mastery avoidance goals, suggesting that increases in mastery approach goals led to large increases in perceived academic efficacy when mastery avoidance goals were high (see Figure 3). Simple slope analysis for performance approach goal $\times$ performance avoidance goal interaction $\left(\beta_{\text {Pav }}=-.279, \mathrm{p}<.001, \beta_{\text {PapLow }}=.248, \mathrm{p}<.001 ; \beta_{\text {Pav }}=-.177, \mathrm{p}\right.$ $\left.<.001, \beta_{\text {PapModerate }}=.248, \mathrm{p}<.001 ; \beta_{\text {Pav }}=-.075, \mathrm{p}=.141, \beta_{\text {PapHigh }}=.248, \mathrm{p}<.001\right)$ 
indicated that the negative effect of performance avoidance goals on perceived academic efficacy tended to be weakened with the increase of performance approach goals, suggesting that increases in performance avoidance goals led to large decreases in perceived academic efficacy when performance approach goals were low (see Figure 4).

No other achievement goal variables attained significance (see Appendix A: Table A22).

Figure 3

Map $\times$ Mav Interaction Effect on Perceived Academic Efficacy in College English Classes Plotted from Simple Regression Equations

$\mathrm{Y}=\left(0.356+0.084 \mathrm{Z}_{\mathrm{Mav}}\right) \mathrm{X}_{\mathrm{Map}}+\left(0.049 \mathrm{Z}_{\mathrm{Mav}}+5.101\right)$

$\mathrm{S}_{\mathrm{Mav}}=1.052, \mathrm{~S}_{\mathrm{Map}}=0.959$

At $Z_{\text {MavHigh }}=1.052: \quad \mathrm{Y}=0.444 \mathrm{X}_{\mathrm{Map}}+5.153$

At $Z_{\text {MavModerate }}=0.000: \quad \mathrm{Y}=0.356 \mathrm{X}_{\text {Map }}+5.101$

At $Z_{\text {MavLow }}=-.1 .052: \quad Y=0.268 X_{\text {Map }}+5.049$

Simple Regression Analysis of Map x Mav Interaction on

Perceived Academic Efficacy

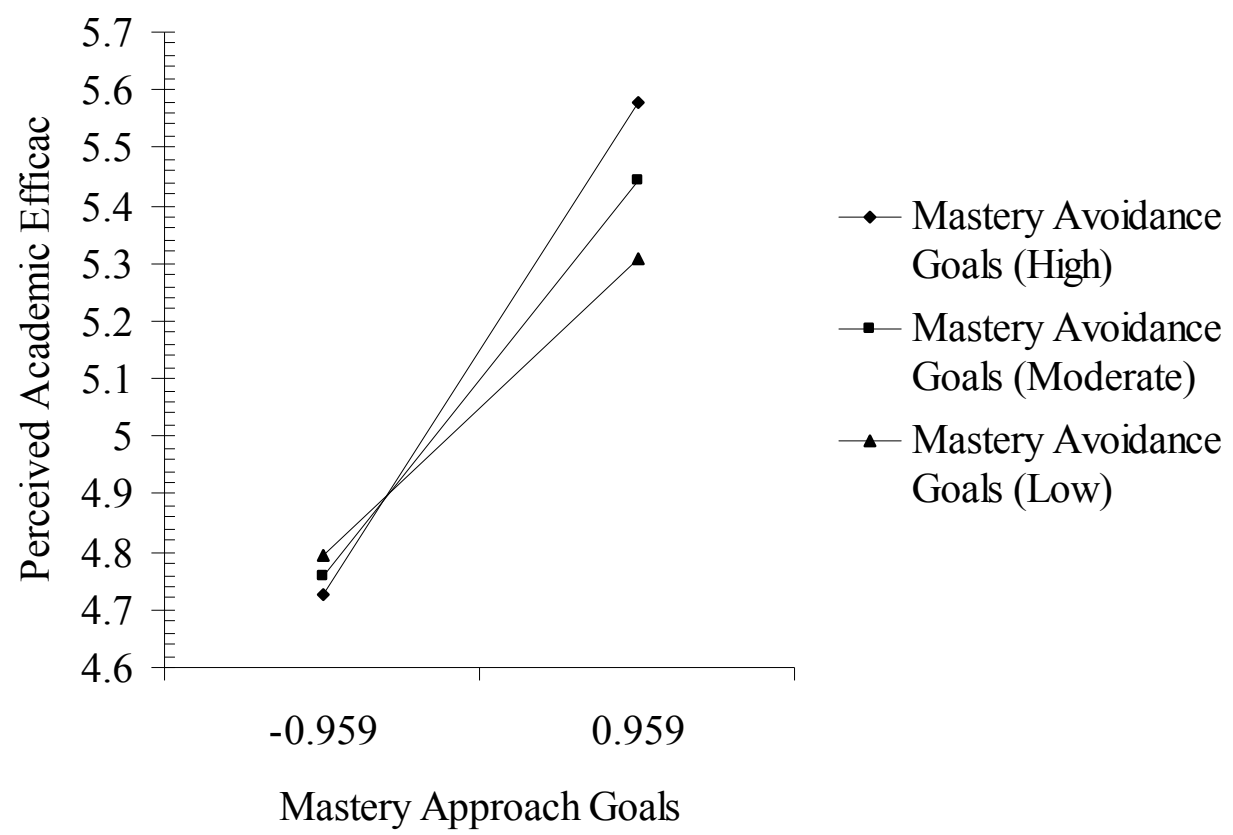

Figure 4 
Pap $\times$ Pav Interaction Effect on Perceived Academic Efficacy in College English Classes Plotted from Simple Regression Equations

$$
\begin{aligned}
& \mathrm{Y}=\left(-0.166+0.087 \mathrm{Z}_{\text {Pap }}\right) \mathrm{X}_{\text {Pav }}+\left(0.211 \mathrm{Z}_{\text {Pap }}+5.114\right) \\
& \mathrm{S}_{\text {Pap }}=1.097, \mathrm{~S}_{\text {Pav }}=.990 \\
& \text { At } \mathrm{Z}_{\text {PapHigh }}=1.097: \quad \mathrm{Y}=-0.071 \mathrm{X}_{\text {Pav }}+5.346 \\
& \text { At } \mathrm{Z}_{\text {PapModerate }}=0.000: \mathrm{Y}=-0.166 \mathrm{X}_{\text {Pav }}+5.114 \\
& \text { At } \mathrm{Z}_{\text {PapLow }}=-1.097: \quad \mathrm{Y}=-0.261 \mathrm{X}_{\text {Pav }}+4.883
\end{aligned}
$$

Simple Regression Analysis of Pap x Pav Interaction on

Perceived Academic Efficacy

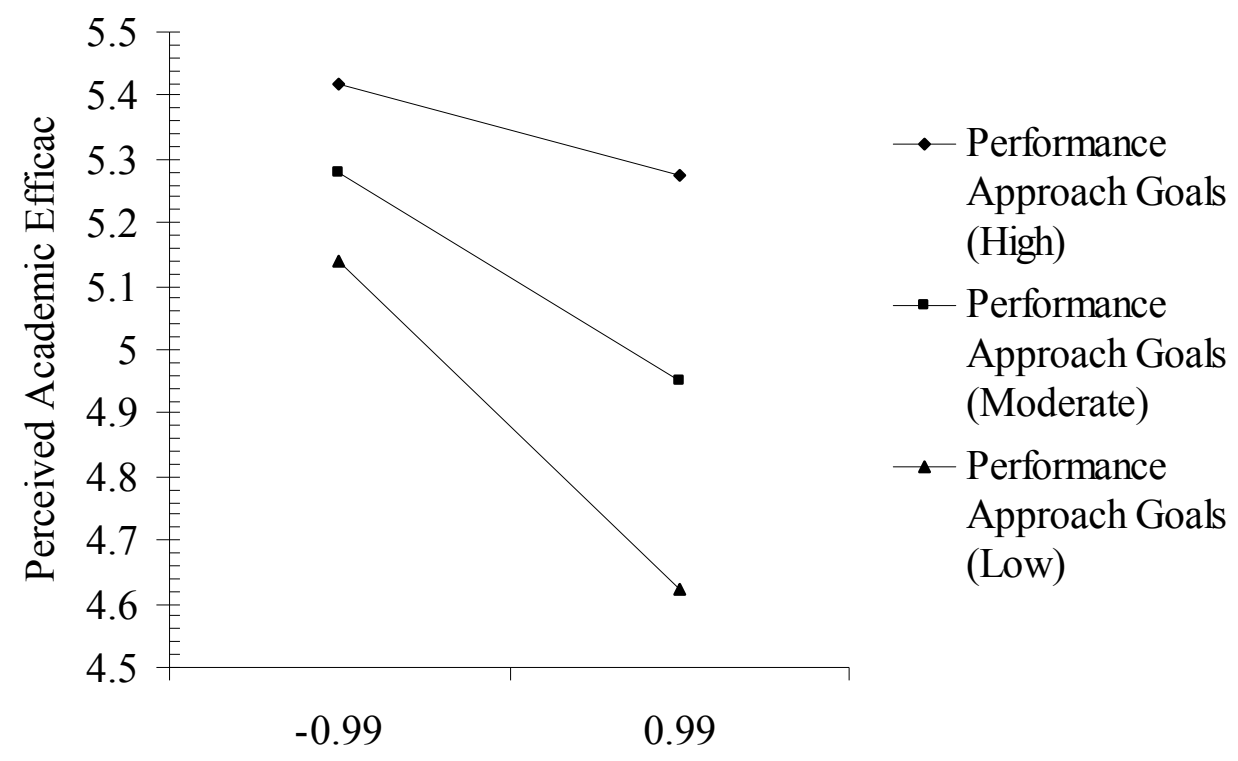

Performance Avoidance Goals

Advanced mathematics classes. In Step 1, the multiple correlation coefficient was not significantly different from zero, $F(2,702)=.048, \mathrm{p}=.954, \mathrm{R}^{2}=.000$, indicating the absence of gender and geographical effects on students' perceived academic efficacy. When the achievement goal main effect and interaction effect terms were added to the model, the change in squared multiple correlation was significant in Step $2, F_{\text {inc }}(4,698)$ $=59.667, \mathrm{p}<.001, \Delta \mathrm{R}^{2}=.255$ and in Step $3, F_{\text {inc }}(6,692)=2.975, \mathrm{p}<.01, \Delta \mathrm{R}^{2}=.019$. 
In Step 2, the regression of perceived academic efficacy revealed that performance approach goals were a positive predictor $(\beta=.224, \mathrm{p}<.001)$, as were mastery approach goals $(\beta=.334, \mathrm{p}<.001)$, whereas performance avoidance goals were a negative predictor $(\beta=-.191, \mathrm{p}<.001)$.

In Step 3, regressing perceived academic efficacy on gender, location of middle school, achievement goal main effect terms, and their two-way interaction effect terms revealed not only a significant main effect for mastery approach goals $(\beta=.321, \mathrm{p}<.001)$, performance approach goals $(\beta=.238, \mathrm{p}<.001)$, and performance avoidance goals $(\beta=$ $.181, \mathrm{p}<.001)$, but also a significant unique predictive utility of the Map $\times \operatorname{Pav}(\beta=-.099$, $\mathrm{p}<.05)$ and Mav $\times$ Pap interaction $(\beta=.114, \mathrm{p}<.05)$. Simple slope analysis for the Map $\times$ Pav interaction $\left(\beta_{\text {Map }}=.490, \mathrm{p}<.001, \beta_{\text {PavLow }}=-.073, \mathrm{p}<.05 ; \beta_{\text {Map }}=.450, \mathrm{p}<.001\right.$, $\left.\beta_{\text {PavModerate }}=-.073, \mathrm{p}<.05 ; \beta_{\text {Map }}=.410, \mathrm{p}<.001, \beta_{\text {PavHigh }}==-.073, \mathrm{p}<.05\right)$ indicated that the positive effect of mastery approach goals tended to be weakened with the increase of performance avoidance goals, suggesting that increases in performance approach goals led to great increase in perceived academic efficacy when performance avoidance goals were low (see Figure 5). Simple slope analysis for the Mav $\times$ Pap interaction $\left(\beta_{\text {Mav }}=.148, \mathrm{p}<.01, \beta_{\text {PapLow }}=.155, \mathrm{p}<.001 ; \beta_{\text {Mav }}=.252, \mathrm{p}<.001, \beta_{\text {PapModerate }}\right.$ $\left.=.155, \mathrm{p}<.001 ; \beta_{\mathrm{Mav}}=.357, \mathrm{p}<.001, \beta_{\text {PapHigh }}=.155, \mathrm{p}<.001\right)$ indicated that the positive effect of mastery avoidance goals tended to be strengthened with the increase of performance approach goals, suggesting that increases in mastery avoidance goals led to large increase in perceived academic efficacy when performance approach goals were 
high (see Figure 6). None of the other variables were significant predictors (See Appendix A: Table A23).

Figure 5

Map $\times$ Pav Interaction Effect on Perceived Academic Efficacy in Advanced Mathematics Classes Plotted from Simple Regression Equations

$\mathrm{Y}=\left(0.421-0.035 Z_{\text {Pav }}\right) \mathrm{X}_{\text {Map }}+\left(-0.063 Z_{\text {Pav }}+5.415\right)$

$\mathrm{S}_{\mathrm{Pav}}=1.069, \mathrm{~S}_{\mathrm{Map}}=0.978$

At $Z_{\text {PavHigh }}=1.069: \quad \mathrm{Y}=0.384 \mathrm{X}_{\mathrm{Map}}+5.348$

At $Z_{\text {PavModerate }}=0.000: \quad \mathrm{Y}=0.421 \mathrm{X}_{\text {Map }}+5.415$

At $Z_{\text {PavLow }}=-1.069: \quad Y=0.458 X_{\text {Map }}+5.482$

Simple Regression Analysis of Map x Pav Interaction on

Perceived Academic Efficacy

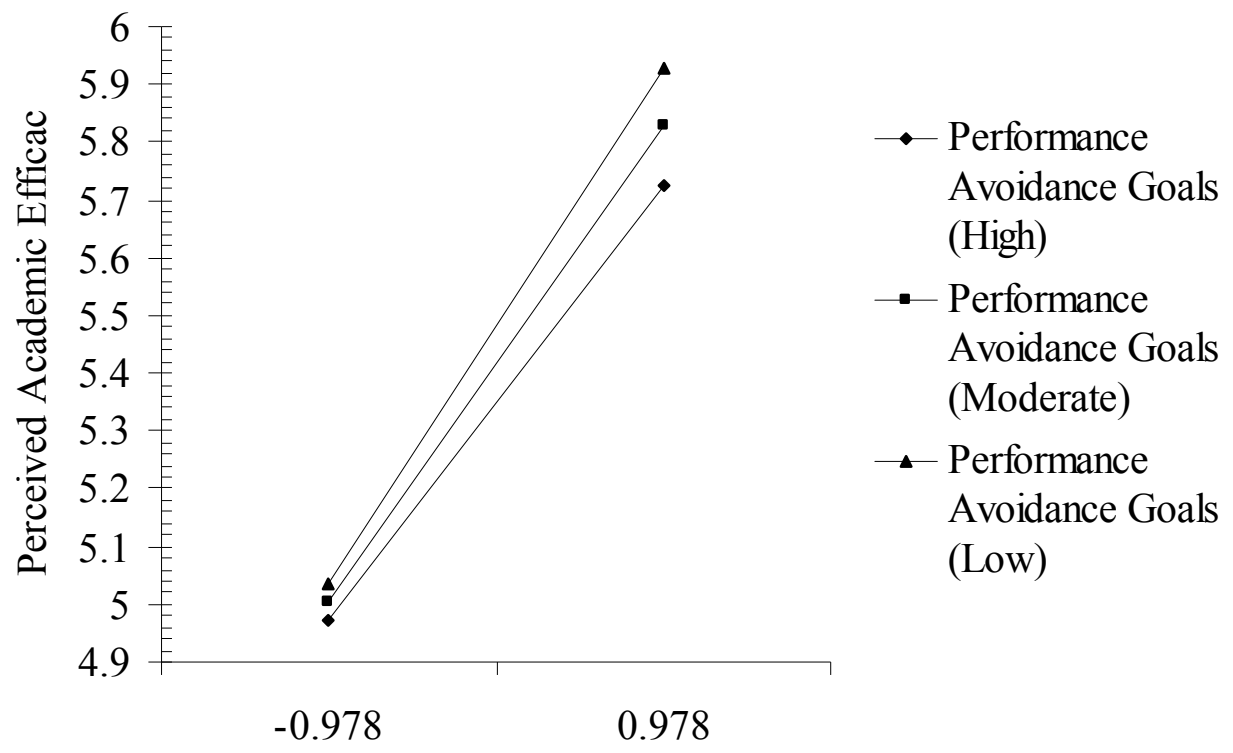

Mastery Approach Goals

Figure 6

Mav $\times$ Pap Interaction Effect on Perceived Academic Efficacy in Advanced Mathematics Classes Plotted from Simple Regression Equations

$\mathrm{Y}=\left(0.233+0.083 Z_{\text {Pap }}\right) \mathrm{X}_{\text {Mav }}+\left(0.123 Z_{\text {Pap }}+5.385\right)$

$\mathrm{S}_{\text {Pap }}=1.155, \mathrm{~S}_{\text {Mav }}=0.991$

At $Z_{\text {PapHigh }}=1.155: \quad \mathrm{Y}=0.329 \mathrm{X}_{\mathrm{Mav}}+5.527$

At $Z_{\text {PapModerate }}=0.000: Y=0.233 \mathrm{X}_{\mathrm{Mav}}+5.385$ 
At $Z_{\text {PapLow }}=-1.155: \quad \mathrm{Y}=0.137 \mathrm{X}_{\mathrm{Mav}}+5.243$

Simple Regression Analysis of Mav x Pap Interaction on

Perceived Academic Efficacy

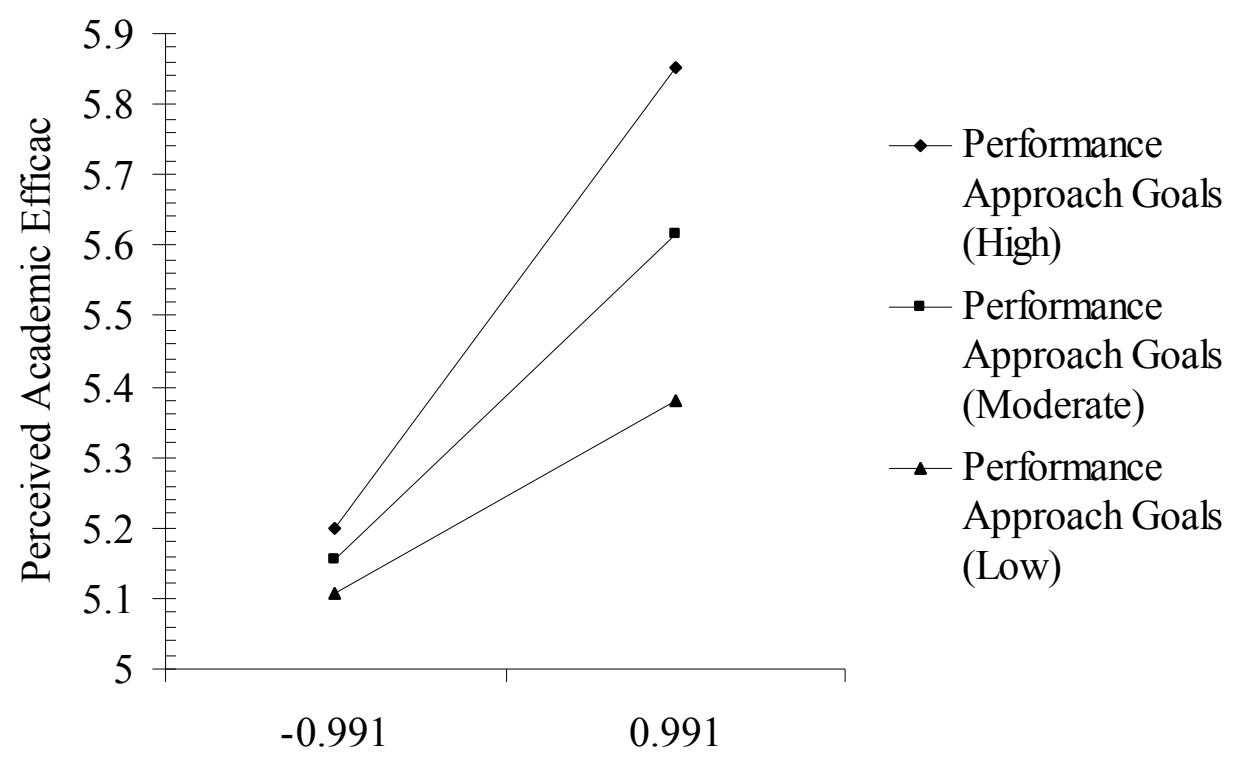

Mastery Avoidance Goals

Affect at School

Regressing affect at school on the basic model yielded a significant effect for the overall model in college English classes, $F(12,692)=9.716, \mathrm{p}<.001, \mathrm{R}^{2}=.144$, and in advanced mathematics classes, $F(12,692)=15.523, \mathrm{p}<.001, \mathrm{R}^{2}=.212$.

College English classes. In Step 1, the multiple correlation was significantly different from zero, $F(2,702)=3.198, \mathrm{p}<.05, \mathrm{R}^{2}=.009$. The regression of affect at school at this stage revealed a significant gender effect, which, however, turned out to be nonsignicant when the achievement goal effects were entered in Steps 2 and 3. When the achievement goal variables were added to the prediction, the change in squared multiple 
correlation was significant in Step $2, F_{\text {inc }}(4,698)=25.306, \mathrm{p}<.001, \Delta \mathrm{R}^{2}=.126$, but not significant in Step 3, $F_{\text {inc }}(6,692)=1.302, \mathrm{p}=.254, \Delta \mathrm{R}^{2}=.010$.

In Step 2, the regression of affect at school revealed a significant positive main effect for mastery approach goals $(\beta=.253, \mathrm{p}<.001)$ and mastery avoidance goals $(\beta$ $=.108, \mathrm{p}<.05)$, but a significant negative main effect for performance avoidance goals $(\beta=-.159, \mathrm{p}<.001)$

In Step 3, the regression yielded a significant effect for the overall model in spite of no significant change of squared multiple correlation between Step 2 and Step 3. The regression at this stage revealed a significant effect for mastery approach goals $(\beta=.290$, $\mathrm{p}<.001)$, mastery avoidance goals $(\beta=.102, \mathrm{p}<.05)$, and performance avoidance goals $(\beta=-.162, p<.001)$. No other variables attained significance (see Appendix A: Table A22).

Advanced mathematics classes. In Step 1, the multiple correlation was significantly different from zero, $F(2,702)=5.685, \mathrm{p}<.01, \mathrm{R}^{2}=.016$. The regression of affect at school at this stage revealed both a significant gender effect $(\beta=-.085, \mathrm{p}<.05)$ and location effect $(\beta=-.098, \mathrm{p}<.01)$, which remained significant in Step $2\left(\beta_{\text {Gender }}=\right.$ $.074, \mathrm{p}<.05 ; \beta$ Location of Middle School $=-.092, \mathrm{p}<.01)$. When the achievement goal variables were added to the prediction, the change in squared multiple correlation was significant in Step $2, F_{\text {inc }}(4,698)=42.068, \mathrm{p}<.001, \Delta \mathrm{R}^{2}=.191$, but not significant in Step $3, F_{\text {inc }}(6$, $692)=.731, p=.625, \Delta R^{2}=.005$. 
In Step 2, regressing affect at school revealed that mastery approach goals were a positive predictor $(\beta=.306, \mathrm{p}<.001)$, whereas performance avoidance goals were a negative predictor $(\beta=-.204, \mathrm{p}<.001)$.

In Step 3, the regression yielded a significant effect for the overall model but there was no significant change of squared multiple correlation between Step 2 and Step 3. The regression at this stage revealed a significant effect for mastery approach goals ( $\beta$ $=.308, \mathrm{p}<.001)$ and performance avoidance goals $(\beta=-.191, \mathrm{p}<.001)$. No other variables attained significance (see Appendix A: Table A23).

\section{Academic Performance}

Regressing academic performance on the basic model yielded a significant effect for the overall model in college English classes, $F(12,692)=4.790, \mathrm{p}<.001, \mathrm{R}^{2}=.077$, and in advanced mathematics classes, $F(12,692)=4.740, \mathrm{p}<.001, \mathrm{R}^{2}=.076$.

College English classes. In Step 1, the multiple correlation was significantly different from zero, $F(2,702)=6.799, \mathrm{p}<.01, \mathrm{R}^{2}=.019$. This step of regression revealed a significant gender effect on academic performance $(\beta=-.124, p<.01)$, which remained significant in Step $2(\beta=-.115, \mathrm{p}<.01)$ and Step $3(\beta=-.115, \mathrm{p}<.01)$. With the achievement goal variables added to the prediction, the change in squared multiple correlation was siginificant in Step $2, F_{\text {inc }}(4,698)=10.462, \mathrm{p}<.001, \Delta \mathrm{R}^{2}=.074$, but not significant in Step 3, $F_{\text {inc }}(6,692)=.275, \mathrm{p}<.001, \Delta \mathrm{R}^{2}=.002$.

In Step 2, the regression of academic performance revealed that performance approach goals were a positive predictor $(\beta=.190, \mathrm{p}<.001)$, whereas performance avoidance goals were a negative predictors $(\beta=-.206, \mathrm{p}<.001)$. 
In Step 3, there was a significant effect for the overall model, although the change of squared multiple correlation between Step 2 and Step 3 was not significant. The regression at this stage revealed a significant main effect for performance approach goals $(\beta=.182, \mathrm{p}<.001)$ and performance avoidance goals $(\beta=-.209, \mathrm{p}<.001)$. None of the other achievement goal variables attained significance (see Appendix A: Table A22).

Advanced mathematics classes. In Step 1, the multiple correlation was significantly different from zero, $F(2,702)=5.047, \mathrm{p}<.01, \mathrm{R}^{2}=.014$. This step of regression revealed a significant gender effect on academic performance $(\beta=.-.113, p$ $<.01)$, and this gender effect remained significant in Step $2(\beta=-.109, \mathrm{p}<.01)$ and Step $3(\beta=-.110, \mathrm{p}<.01)$. With achievement goal variables added to the prediction, the change in squared multiple correlation was significant in Step $2, F_{\text {inc }}(4,698)=10.448, \mathrm{p}$ $<.001, \Delta \mathrm{R}^{2}=.056$, but not significant in Step $3, F_{\text {inc }}(6,692)=.759, \mathrm{p}=.602, \Delta \mathrm{R}^{2}=.006$.

In Step 2, the regression of academic performance revealed that performance approach goals were a positive predictor $(\beta=.094, \mathrm{p}<.05)$, whereas performance avoidance goals were a negative predictor $(\beta=-.215, \mathrm{p}<.001)$.

In Step 3, although the change of squared multiple correlation between Step 2 and Step 3 was not significant, there was a significant effect for the overall model. The regression at this stage revealed a significant main effect for performance approach goals $(\beta=.094, \mathrm{p}<.05)$, whereas performance avoidance goals were a negative predictor $(\beta=$ $.207, \mathrm{p}<.001$ ). No other achievement goal variables were significant (see Appendix A: Table A23).

SAL Framework and Learning Process and Learning Outcome Variables 
Investigation of the predictive relationship between the SAL framework and learning process and learning outcome variables is also one of the central interests in this study. The same basic regression model was applied to the SAL framework to examine the effect of the deep and surface approaches on metacognitve strategies, perceived academic efficacy, affect at school, and academic performance in both college English classes and advanced mathematics classes.

\section{Metacognitve Strategies}

Regressing metacognitive strategies on the basic model yielded a significant effect for the overall model in college English classes, $F(5,699)=71.904, \mathrm{p}<.001, \mathrm{R}^{2}$ $=.340$, and in advanced mathematics classes, $F(5,699)=86.356, \mathrm{p}<.001, \mathrm{R}^{2}=.382$.

College English classes. In Step 1 the multiple correlation was not significantly different from zero, $F(2,702)=.318, \mathrm{p}=.728, \mathrm{R}^{2}=.001$, indicating the absence of gender and geographical effects on metacognitive strategies. When student approaches to learning terms were added to the prediction, the change in squared multiple correlation was significant in Step 2, $F_{\text {inc }}(2,700)=179.216, \mathrm{p}<.001, \Delta \mathrm{R}^{2}=.339$, but not in Step 3, $F_{\text {inc }}(1,699)=.424, \mathrm{p}=.515, \Delta \mathrm{R}^{2}=.000$.

In Step 2, regressing metacognitive strategies revealed that the deep approach was a positive predictor $(\beta=.564, \mathrm{p}<.001)$, whereas the surface approach was a marginally negative predictor $(\beta=-.057, \mathrm{p}=.76)$.

In Step 3, regressing on the overall model yielded a significant effect, but the change of squared multiple correlation between Step 2 and Step 3 was not significant. The regression of metacognitive strategies at this stage revealed a significant main effect 
for the deep approach $(\beta=.563, \mathrm{p}<.001)$ and marginally significant main effect for the surface approach $(\beta=-.061, p=.063)$. No other variables attained significance (see Appendix A: Table A24).

Advanced Mathematics classes. In Step 1, the multiple correlation was significantly different from zero, $F(2,702)=3.266, \mathrm{p}<.05, \mathrm{R}^{2}=.009$. The regression revealed a significant gender effect on metacognitive strategies $(\beta=-.078, p<.05)$, and this gender effect remained significant in Step $2(\beta=.-.095, \mathrm{p}<.01)$ and in Step $3(\beta=$.$.096, \mathrm{p}<.01)$. With the SAL variables added to the prediction, the change in squared multiple correlation was significant in Step $2, F_{\text {inc }}(2,700)=209.258, \mathrm{p}<.001, \Delta \mathrm{R}^{2}$ $=.371$, but not in Step 3, $F_{\text {inc }}(1,699)=2.151, \mathrm{p}=.143, \Delta \mathrm{R}^{2}=.002$.

In Step 2, regressing metacognitive strategies revealed that the deep approach was a positive predictor $(\beta=.594, \mathrm{p}<.001)$, whereas the surface approach was a marginally negative predictor $(\beta=-.057, \mathrm{p}=-.067)$.

In Step 3, regressing on the overall model yielded a significant effect, although the change of squared multiple correlation between Step 2 and Step 3 was not significant. The regression at this stage revealed a significant positive main effect for the deep $\operatorname{approach}(\beta=.591, \mathrm{p}<.001)$ and a significant negative main effect for the surface approach $(\beta=-.067, p<.05)$. None of the other variables was a significant predictor (see Appendix A: Table A25). 
Perceived Academic Efficacy

Regressing perceived academic efficacy on the basic model yielded a significant effect for the overall model in college English classes, $F(5,699)=31.770, \mathrm{p}<.001, \mathrm{R}^{2}$ $=.185$, and in advanced mathematics classes, $F(5,699)=34.627, \mathrm{p}<.001, \mathrm{R}^{2}=.199$. College English classes. In Step 1, the multiple correlation was significantly different from zero, $F(2,702)=3.190, \mathrm{p}<.05, \mathrm{R}^{2}=.009$. The regression revealed a significant location effect $(\beta=.089, \mathrm{p}<.05)$, which remained significant in both Step 2 and Step $3(\beta=.097, \mathrm{p}<.01)$. The addition of the student approaches to learing terms to the prediction led to a significant change of squared multiple correlation in Step $2, F_{\text {inc }}(2$, $700)=75.586, \mathrm{p}<.001, \Delta \mathrm{R}^{2}=.185$, but not in Step $3, F_{\text {inc }}(1,699)=.139, \mathrm{p}=.710, \Delta \mathrm{R}^{2}$ $=.000$.

In Step 2, regressing perceived academic efficacy revealed that the deep approach was a positive predictor $(\beta=.383, \mathrm{p}<.001)$, whereas the surface approach was a negative predictor $(\beta=-.099, \mathrm{p}<.01)$.

In Step 3, although the change of squared multiple correlation between Step 2 and Step 3 was not significant, the regression on the overall model yielded a significant effect. The regression at this stage revealed a significant positive main effect for the deep $\operatorname{approach}(\beta=.382, \mathrm{p}<.001)$ and a significant negative main effect for the surface approach $(\beta=-.101, p<.01)$. No other variabels attained significance (see Apendix 24).

Advanced mathematics classes. In Step 1, the multiple correlation was not significantly different from zero, $F(2,702)=.048, \mathrm{p}=.954, \mathrm{R}^{2}=.000$, indicating the absence of gender and location effects on perceived academic efficacy. When the SAL 
terms were added to the prediction, the change in squared multiple correlation was significant in Step $2, F_{\text {inc }}(2,700)=85.482, \mathrm{p}<.001, \Delta \mathrm{R}^{2}=.196$, but not in Step $3, F_{\text {inc }}(1$, $699)=1.847, \mathrm{p}=.175, \Delta \mathrm{R}^{2}=.002$.

In Step 2, regressing perceived academic efficacy revealed that the deep approach was a positive predictor $(\beta=.408, \mathrm{p}<.001)$, whereas the surface approach was a negative predictor $(\beta=-.098, \mathrm{p}<.01)$.

In Step 3, the regression on the overall model yieled a significant effect, in spite of an insignificant change of squared multiple correlation between Step 2 and Step 3. The regression at this stage revealed a significant positive main effect for the deep approach $(\beta=.411, \mathrm{p}<.001)$ and a significant negative main effect for the surface approach $(\beta=-$ $.087, \mathrm{p}<.05)$. No other variables attained significance (see Appendix A: Table A25) Affect at School

Regressing affect at school on the basic model yielded a significant effect for the overall model in college English classes, $F(5,699)=42.469, \mathrm{p}<.001, \mathrm{R}^{2}=.233$, and in advanced mathematics classes, $F(5,699)=83.552, \mathrm{p}<.001, \mathrm{R}^{2}=.374$.

College English classes. In Step 1, the multiple correlation was significantly different from zero, $F(2,702)=3.198, \mathrm{p}<.05, \mathrm{R} 2=.009$. The regression indicated a gender effect on affect at school $(\beta=-.091, \mathrm{p}<.05)$, which lost its significance of unique contribution in Step 2 and Step 3. With the SAL terms added, the change of squared multiple correlation was significant in Step $2, F_{\text {inc }}(2,700)=101.158, \mathrm{p}<.001, \Delta \mathrm{R}^{2}$ $=.222$, but not in Step 3, $F_{\text {inc }}(1,699)=1.623, \mathrm{p}=.203, \Delta \mathrm{R}^{2}=.002$. 
In Step 2, regressing affect at school revealed that the deep approach to learning was a positive predictor $(\beta=.333, \mathrm{p}<.001)$, whereas the surface approach to learning was a negative predictor $(\beta=-.259, \mathrm{p}<.001)$.

In Step 3, the regression on the overall model yielded a significant effect, although the change of squared multiple correlation between Step 2 and Step 3 was not significant. The regression at this stage revealed a significant positive main effect for the deep approach $(\beta=.337, \mathrm{p}<.001)$ and a significant negative main effect for the surface approach $(\beta=-.252, p<.001)$. No other variables attained significance (see Appendix A: Table A24).

Advanced mathematics classes. In Step 1, the multiple correlation was significantly different from zero, $F(2,702)=5.685, \mathrm{p}<.01, \mathrm{R}^{2}=.016$. The regression indicated both a significant effect of gender $(\beta=-.085, \mathrm{p}<.05)$ and location $(\beta=-.098, \mathrm{p}$ $<.01)$ on affect at school, but only the gender effect remained significant in Step $2(\beta=-$ $.091, \mathrm{p}<.01)$ and Step $3(\beta=-.090, \mathrm{p}<.01)$. With the SAL terms added, the change of squared multiple correlation was significant in Step $2, F_{i n c}(2,700)=198.017, \mathrm{p}<.001$, $\Delta \mathrm{R}^{2}=.356$, but not in Step 3, $F_{\text {inc }}(1,699)=2.867, \mathrm{p}=.091, \Delta \mathrm{R}^{2}=.003$.

In Step 2, regressing affect at school revealed that the deep approach to learning was a positive predictor $(\beta=.412, \mathrm{p}<.001)$, whereas the surface approach to learning was a negative predictor $(\beta=-.335, \mathrm{p}<.001)$.

In Step 3, the regression on the overall model yielded a significant effect, but the change of squared multiple correlation between Step 2 and Step 3 was not significant. The regression at this stage revealed a positive main effect for the deep approach ( $\beta$ 
$=.415, \mathrm{p}<.001)$ and a negative main effect for the surface approach $(\beta=-.324, \mathrm{p}<.001)$. None of the other variables attained significance (see Appendix A: Table A25).

Academic Performance

Regressing academic performance on the basic model yielded a significant effect for the overall model in college English classes, $F(5,699)=7.883, \mathrm{p}<.001, \mathrm{R}^{2}=.053$, and in advanced mathematics classes, $F(5,699)=9.746, \mathrm{p}<.001, \mathrm{R}^{2}=.065$.

College English classes. In Step 1, the multiple correlation was significantly different from zero, $F(2,702)=6.799, \mathrm{p}<.01, \mathrm{R}^{2}=.019$. The regression indicated a gender effect on academic performance $(\beta=-.124, \mathrm{p}<.01)$, which remained significant in Step $2(\beta=-.101, \mathrm{p}<.01)$ and Step $3(\beta=-.101, \mathrm{p}<.01)$. With the SAL terms added, the change of squared multiple correlation was significant in Step $2, F_{\text {inc }}(2,700)=$ $12.623, \mathrm{p}<.001, \Delta \mathrm{R}^{2}=.034$, but not in Step $3, F_{\text {inc }}(1,699)=.168, \mathrm{p}=.682, \Delta \mathrm{R}^{2}=.000$.

In Step 2, regressing academic performance revealed that the surface approach was a significant negative predictor $(\beta=-.192, \mathrm{p}<.001)$, whereas the deep approach was a marginally significant negative predictor $(\beta=-.067, \mathrm{p}=.081)$.

In Step 3, although the change of squared multiple correlation between Step 2 and Step 3 was not significant, the regression on the overall model yielded a significant effect. The regression at this stage revealed a significant negative effect for the surface approach $(\beta=-.195, p<.001)$ and a maginally significant negative effect for the deep approach $(\beta$ $=-.068, \mathrm{p}=.077$ ). None of the other variables were significant predictors (see Appendix A: Table A24). 
Advanced mathematics classes. In Step 1, the multiple correlation was significantly different from zero, $F(2,702)=5.047, \mathrm{p}<.01, \mathrm{R}^{2}=.014$. The regression indicated a gender effect on academic performance $(\beta=-.113, p<.01)$, which which remained significant in Step $2(\beta=-.113, \mathrm{p}<.01)$ and Step $3(\beta=-.113, \mathrm{p}<.01$. With the SAL terms added, the change of squared multiple was significant in Step 2, $F_{\text {inc }}(2,700)$ $=19.093, \mathrm{p}<.001, \Delta \mathrm{R}^{2}=.051$, but not in Step 3, $F_{\text {inc }}(1,699)=.000, \mathrm{p}=.987, \Delta \mathrm{R}^{2}$ $=.000$.

In Step 2, regressing academic performance revealed that the deep approach was a positive predictor $(\beta=.109, \mathrm{p}<.01)$, whereas the surface approach was a negative predictor $(\beta=-.171, \mathrm{p}<.001)$.

In Step 3, although the change of squared multiple correlation between Step 2 and Step 3 was not significant, the regression on the overall model yielded a significant effect. The regression at this stage revealed a significant positive main effect for the deep approach $(\beta=.109, \mathrm{p}<.01)$ and a negative main effect for the surface approach $(\beta=-.171$, $\mathrm{p}<.001$ ). None of the other variables were significant predictors (see Appendix A: Table A25).

\section{CHC Values and the Goal Orientation Framework}

This part dealt with the way $\mathrm{CHC}$ values and one motivation framework, achievement goal orientations, interacted to impact Chinese students' learning processes and outcomes in an attempt to reveal how Chinese students' attitudes towards $\mathrm{CHC}$ values and their achievement goal orientations may combine to produce different achievement-relevant processes and outcomes and promote optimal motivation. 
Specifically, this part of the regression analysis addressed: (a) how $\mathrm{CHC}$ values and achievement goal orientations contributed their unique predictive utility as main effect terms to metacognitive strategies, perceived academic efficacy, affect at school, and academic performance, (b) whether there was any interaction between $\mathrm{CHC}$ values and each of the 4 goal orientations that contributed a significant unique predictive utility for the aforementioned learning process and outcome variables, and (c) how $\mathrm{CHC}$ values moderated the impact of the goal orientations on relevant learning process and outcome variables in case of a significant interaction.

Apart from students' background information, the independent variables within the regression model tested on each learning process and outcome variable contained: (a) the main effect terms of mastery approach, mastery avoidance, performance approach, performance avoidance goals, and $\mathrm{CHC}$ values, thereby affording a test of their unique predictive utility, and (b) all possible two-way interaction product terms between $\mathrm{CHC}$ values and each of the four goal orientation main effect terms, thereby offering a test of the way $\mathrm{CHC}$ values moderated the influence of goal orientations on learning processes and outcomes.

\section{Metacognitive Strategies}

Regressing metacognitive strategies on the basic model yielded a significant effect for the overall model in college English classes, $F(11,693)=18.649, \mathrm{p}<.001, \mathrm{R}^{2}$ $=.228$, and in advanced mathematics classes, $F(11,693)=31.060, \mathrm{p}<.001, \mathrm{R}^{2}=.330$.

College English classes. In Step 1, the multiple correlation was not significantly different from zero, $F(2,702)=.318, \mathrm{p}=.728, \mathrm{R}^{2}=.001$, indicating a lack of gender or 
location effect. With the addition of $\mathrm{CHC}$ values and goal orientation main effect and interaction effect terms to the model, the change in squared multiple correlation was significant in Step $2, F_{\text {inc }}(5,697)=37.667, \mathrm{p}<.001, \Delta \mathrm{R}^{2}=.213$ and in Step $3, F_{\text {inc }}(4$, $693)=3.360, \mathrm{p}<.05, \Delta \mathrm{R}^{2}=.015$

In Step 2, the regression of metacognitive strategies revealed that mastery avoidance goals $(\beta=.176, \mathrm{p}<.001)$, as well as mastery approach goals $(\beta=.325, \mathrm{p}$ $<.001)$, were significant positive predictors.

In Step 3, regressing metacognitive strategies on the 4 interaction effect terms and the aforementioned 7 main effect terms revealed a significant positive main effect for mastery approach goals $(\beta=.343, \mathrm{p}<.001)$ and mastery avoidance goals $(\beta=.167, \mathrm{p}$ $<.001)$. Although the $\mathrm{CHC}$ was not significant as a main effect term, the regression revealed a significant positive effect for the $\mathrm{Mav} \times \mathrm{CHC}$ value interaction $(\beta=.113, \mathrm{p}$ $<.05)$. Simple slope analysis for the Mav $\times \mathrm{CHC}$ value interaction $\left(\beta_{\mathrm{Mav}}=.215, \mathrm{p}<.001\right.$, $\beta_{\text {CHCvalueLow }}=.123, \mathrm{p}<.01 ; \beta_{\text {Mav }}=.302, \mathrm{p}<.001, \beta_{\text {CHCvalueModerate }}=.123, \mathrm{p}<.01 ; \beta_{\text {Mav }}$ $\left.=.390, \mathrm{p}<.001, \beta_{\mathrm{CHCvalueHigh}}=.123, \mathrm{p}<.01\right)$ revealed that the positive effect of mastery avoidance goals tended to be strengthened with the increase of $\mathrm{CHC}$ values, suggesting that increases in mastery avoidance goals led to large increases in metacognitive strategies when $\mathrm{CHC}$ value measure was high (see Figure 7). None of the other variables were significant predictors (see Appendix A: Table A26).

Figure 7

Mav $\times$ CHC Value Interaction Effect on Metacognitive Strategies in College English Classes Plotted from Simple Regression Equations $\mathrm{Y}=\left(0.250+0.096 \mathrm{Z}_{\mathrm{CHCvalue}}\right) \mathrm{X}_{\mathrm{Mav}}+\left(0.142 \mathrm{Z}_{\mathrm{CHCvalue}}+4.594\right)$ $\mathrm{S}_{\text {Mav }}=1.052, \mathrm{~S}_{\mathrm{CHCvalue}}=0.758$ 
At $Z_{\mathrm{CHCvalueHigh}}=0.758: \quad \mathrm{Y}=0.322 \mathrm{X}_{\mathrm{Mav}}+4.702$

At $Z_{\text {CHCvalueModerate }}=0.000: \quad \mathrm{Y}=0.250 \mathrm{X}_{\mathrm{Mav}}+4.594$

At $Z_{\text {CHCvalueLow }}=-0.758: \quad Y=0.177 X_{\text {Mav }}+4.486$

Simple Regression Analysis of Mav x CHC Value Interaction on Metacognitive Strategies

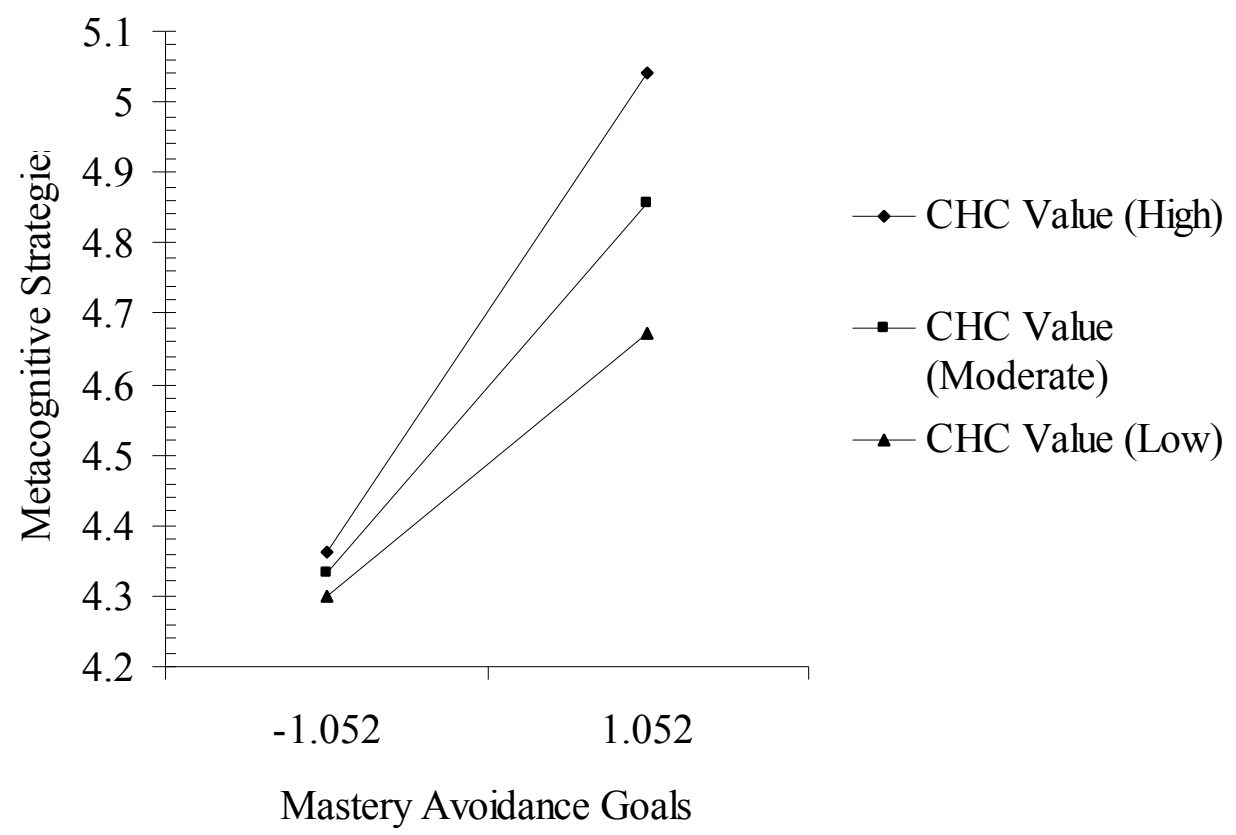

Advanced mathematics classes. In Step 1, the multiple correlation was significantly different from zero, $F(2,702)=3.266, \mathrm{p}<.05, \mathrm{R}^{2}=.009$. The regression indicated a gender effect on metacognitive strategies $(\beta=-.078, p<.05)$, which lost significance in Step $2(\beta=-.047, p=.130)$ and Step $3(\beta=-.049, p=.122)$. When the achievement goal orientation and $\mathrm{CHC}$ value variables were added to the model, the change in squared multiple correlation was significant in Step $2, F_{\text {inc }}(5,697)=66.019, \mathrm{p}$ $<.001, \Delta \mathrm{R}^{2}=.318$, but not significant in Step $3, F_{\text {inc }}(4,693)=.665, \mathrm{p}=.617, \Delta \mathrm{R}^{2}=.003$. 
In Step 2, regressing metacognitive strategies revealed a positive predictive utility of CHC values $(\beta=.081, p<.05)$, mastery approach goals $(\beta=.395, \mathrm{p}<.001)$, and mastery avoidance goals $(\beta=.187, \mathrm{p}<.001)$.

In Step 3, the regression on both main effect and interaction effect terms yielded a significant effect for the overall model, but there was no significant change of squared multiple correlation between Step 2 and Step 3. The three significant predictors in Step 2 retained their unique predictive utility at this stage of regression, $\mathrm{CHC}$ values $(\beta=.080, \mathrm{p}$ $<.05)$, mastery approach goals $(\beta=.388, \mathrm{p}<.001)$, and mastery avoidance goals $(\beta=$ $.192, \mathrm{p}<.001)$. None of the two-way interaction terms or any other variables attained significance (see Appendix A: Table A27)

Perceived Academic Efficacy

Regressing perceived academic efficacy on the basic model yielded a significant effect for the overall model in college English classes, $F(11,693)=14.116, \mathrm{p}<.001, \mathrm{R}^{2}$ $=.183$, and in advanced mathematics classes, $F(11,693)=24.277, \mathrm{p}<.001, \mathrm{R}^{2}=.278$.

College English classes. In Step 1, the multiple correlation was significantly different from zero, $F(2,702)=3.190, \mathrm{p}<.05, \mathrm{R}^{2}=.009$. The regression revealed a significant positive effect of location on perceived academic efficacy $(\beta=.089, \mathrm{p}<.05)$, and this location effect remained significant in Step $2(\beta=.078, \mathrm{p}<.05)$ and Step $3(\beta$ $=.075, \mathrm{p}<.05$ ), indicating that the students with their middle school located at urban areas tended to have higher levels of perceived academic efficacy in college English classes. When $\mathrm{CHC}$ values and goal orientation variables were added to the model, the 
change of squared mulitple correlation was significant in $\operatorname{Step~} 2, F_{\text {inc }}(5,697)=25.835$, p $<.01, \Delta \mathrm{R}^{2}=.155$, and in Step 3, $F_{\text {inc }}(4,693)=4.050, \mathrm{p}<.01, \Delta \mathrm{R}^{2}=.019$.

In Step 2, regressing perceived academic efficacy revealed that $\mathrm{CHC}$ values $(\beta$ $=.101, \mathrm{p}<.05)$, mastery approach goals $(\beta=.245, \mathrm{p}<.001)$, and performance approach goals $(\beta=.090, \mathrm{p}<.05)$ were positive predictors, whereas performance avoidance goals were a negative predictor $(\beta=-.157, \mathrm{p}<.001)$.

In Step 3, the regression on both main effect and interaction effect terms yielded a significant main effect for $\mathrm{CHC}$ values $(\beta=.111, \mathrm{p}<.05)$, mastery approach goals $(\beta$ $=.269, \mathrm{p}<.001)$, performance approach goal $(\beta=.090, \mathrm{p}<.05)$, and performance avoidance goals $(\beta=-.157, \mathrm{p}<.001)$. The regression also revealed a significant positive effect for the Mav $\times \mathrm{CHC}$ value interaction $(\beta=.103, \mathrm{p}<.05)$. Simple slope analysis for the Mav $\times \mathrm{CHC}$ value interaction $\left(\beta_{\text {Mav }}=.063, \mathrm{p}=.220, \beta_{\mathrm{CHCvalueLow}}=.183, \mathrm{p}<.001 ; \beta\right.$ Mav $=.166, \mathrm{p}<.001, \beta_{\text {CHCvalueModerate }}=.183, \mathrm{p}<.001 ; \beta_{\text {Mav }}=.269, \mathrm{p}<.001, \beta_{\text {CHCvalueHigh }}$ $=.183, \mathrm{p}<.001)$ indicated that the positive effect of mastery avoidance goals tended to be weakened with the decrease of $\mathrm{CHC}$ values, suggesting that increases in mastery avoidance goals led to large increases in perceived academic efficacy when $\mathrm{CHC}$ values were high (see Figure 8). None of the other variables attained significance (see Appendix A: Table A26).

Figure 8

Mav $\times$ CHC Value Interaction Effect on Perceived Academic Efficacy in College English Classes Plotted from Simple Regression Equations

$\mathrm{Y}=\left(0.147+0.120 \mathrm{Z}_{\mathrm{CHCvalue}}\right) \mathrm{X}_{\mathrm{Mav}}+\left(0.225 \mathrm{Z}_{\mathrm{CHCvalue}}+5.107\right)$ $\mathrm{S}_{\mathrm{Mav}}=1.052, \mathrm{~S}_{\mathrm{CHCvalue}}=0.758$ At $\mathrm{Z}_{\mathrm{CHCvalueHigh}}=0.758: \quad \mathrm{Y}=0.238 \mathrm{X}_{\mathrm{Mav}}+5.278$ At $Z_{\text {CHCvalueModerate }}=0.000: \quad Y=0.147 \mathrm{X}_{\mathrm{Mav}}+5.107$ 
At $Z_{\text {CHCvalueLow }}=-0.758: \quad Y=0.056 X_{\text {Mav }}+4.936$

Simple Regression Analysis of Mav x CHC Value Interaction on Perceived Academic Efficacy

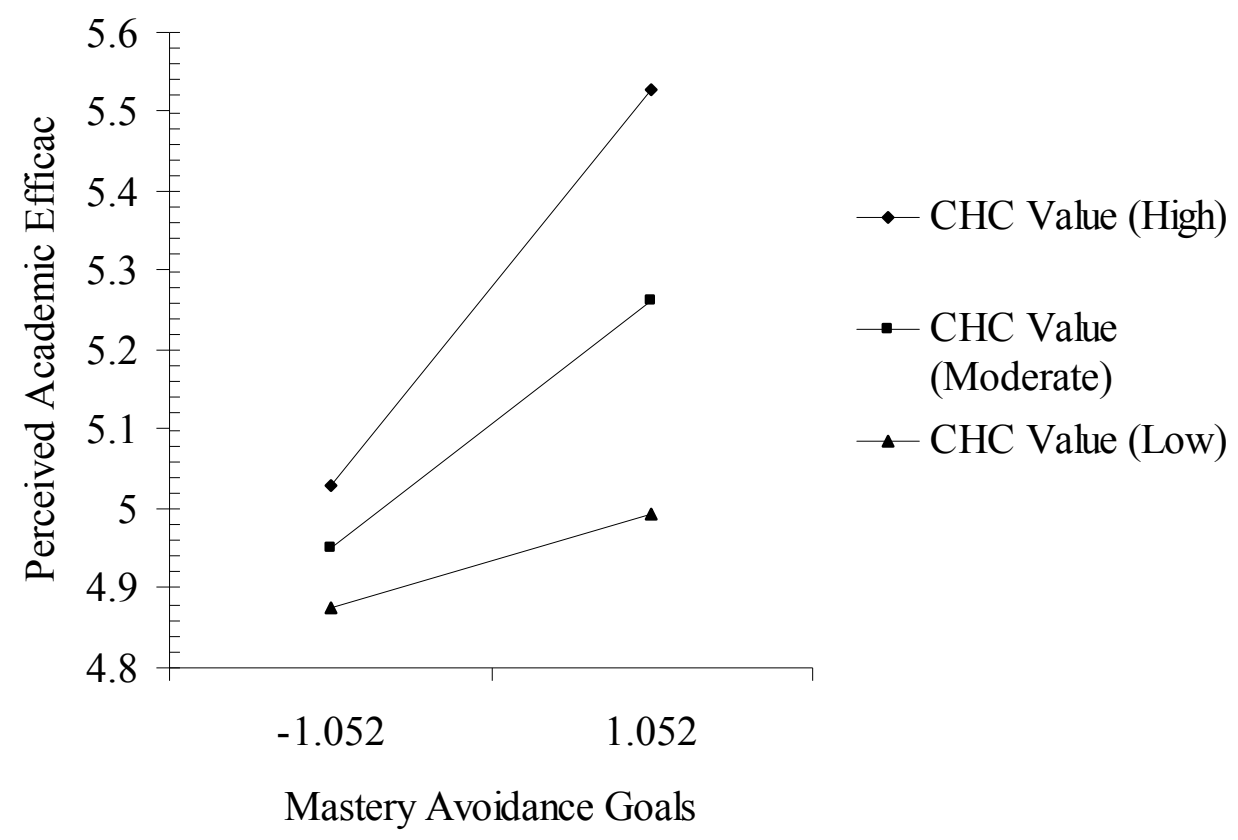

Advanced mathematics classes. In Step 1, the multiple correlation was not significantly different from zero, $F(2,702)=.048, \mathrm{p}=.954, \mathrm{R}^{2}=.000$. The regression indicated the absence of gender or location effect on perceived academic efficacy, and the effect for gender and location remained nonsignifcant in Steps 2 and 3. With the addition of $\mathrm{CHC}$ values and goal orientation variables to the model, the change of squared mulitple correlation was significant in Step $2, F_{\text {inc }}(5,697)=52.459, \mathrm{p}<.001, \Delta \mathrm{R}^{2}=.273$, but not in Step $3, F_{\text {inc }}(4,693)=1.113, \mathrm{p}=.349, \Delta \mathrm{R}^{2}=.005$.

In Step 2, the regression on the main effect terms revealed that $\mathrm{CHC}$ values $(\beta$ $=.164, \mathrm{p}<.001)$, mastery approach goals $(\beta=.295, \mathrm{p}<.001)$, and performance approach 
goals $(\beta=.173, \mathrm{p}<.001)$ positively predicted perceived academic efficacy, whereas performance avoidance goals were a negative predictor $(\beta=-.206, \mathrm{p}<.001)$.

In Step 3, the regression on both main effect and interaction effect yielded a significant effect for the overall model, but there was no significant change of squared multiple correlation between Step 2 and Step 3. The four predictors that demonstrated their unique predictive utility in Step 2 remained significant at this stage of regression, CHC values $(\beta=.163, \mathrm{p}<.001)$, mastery approach goals $(\beta=.291, \mathrm{p}<.001)$, and performance approach goals $(\beta=.176, \mathrm{p}<.001)$, and performance avoidance goals $(\beta=-$ $.217, \mathrm{p}<.001)$. None of the two-way interaction terms or any other variables attained significance (See Appendix A: Table A27).

\section{Affect at School}

Regressing affect at school on the basic model yielded a significant effect for the overall model in college English classes, $F(11,693)=12.646, \mathrm{p}<.001, \mathrm{R}^{2}=.167$, and in advanced mathematics classes, $F(11,693)=18.082, \mathrm{p}<.001, \mathrm{R}^{2}=.223$.

College English classes. In Step 1, the multiple correlation was significantly different from zero, $F(2,702)=3.198, \mathrm{p}<.05, \mathrm{R}^{2}=.009$. The regression of affect at school indicated a significant gender effect, which lost its significance in Step 2 and Step 3. When $\mathrm{CHC}$ values and achievement goal orientation variables were added to the model, the change of squared mulitple correlation was significant in Step $2, F_{\text {inc }}(5,697)=$ $23.051, \mathrm{p}<.001, \Delta \mathrm{R}^{2}=.141$, and in Step $3, F_{\text {inc }}(4,693)=3.647, \mathrm{p}<.01, \Delta \mathrm{R}^{2}=.018$.

In Step 2 , the regression of main effect terms revealed that $\mathrm{CHC}$ values $(\beta=.154$, $\mathrm{p}<.001)$, mastery approach goals $(\beta=.205, \mathrm{p}<.001)$, and mastery avoidance goals $(\beta$ 
$=.094, \mathrm{p}<.05)$ positively predicted affect at school, whereas performance avoidance goals were a negative predictor $(\beta=-.181, \mathrm{p}<.001)$.

In Step 3, regressing affect at school on the overall model yielded a positive main effect for CHC values $(\beta=.163, p<.001)$ and mastery approach goals $(\beta=.236, p$ $<.001)$, a marginally significant positive main effect for mastery avoidance goals ( $\beta$ $=.082, \mathrm{p}=.063)$, and a negative main effect for a performance avoidance goals $(\beta=-$ $.178, \mathrm{p}<.001)$. The regression also revealed that the Map $\times \mathrm{CHC}$ value interaction $(\beta$ $=.090, \mathrm{p}=.069)$ and Pav $\times$ CHC value interaction $(\beta=-.077, \mathrm{p}=.053)$ were marginally significant predictors. Simple slope analysis of the Map $\times \mathrm{CHC}$ value interaction $\left(\beta_{\mathrm{Map}}\right.$ $=.204, \mathrm{p}<.001, \beta_{\text {CHCvalueLow }}=.113, \mathrm{p}<.01 ; \beta_{\text {Map }}=.302, \mathrm{p}<.001, \beta_{\text {CHCvalueModerate }}=.113$, $\left.\mathrm{p}<.01 ; \beta_{\text {Map }}=.401, \mathrm{p}<.001, \beta_{\mathrm{CHCvalueHigh}}=.113, \mathrm{p}<.01\right)$ indicated that the positive effect of mastery approach goals tended to be strengthened with the increase of $\mathrm{CHC}$ values, suggesting that increases in mastery approach goals led to large increases in affect at school when $\mathrm{CHC}$ values were high (see Figure 9). Simple slope analysis of the Pav $\times$ CHC value interaction $\left(\beta_{\text {Pav }}=-.165, \mathrm{p}<.01, \beta_{\text {CHCvalueLow }}=.277, \mathrm{p}<.001 ; \beta_{\text {Pav }}=-.205, \mathrm{p}\right.$ $<.001, \beta_{\text {CHCvalueModerate }}=.277, \mathrm{p}<.001 ; \beta_{\text {Pav }}=-.246, \mathrm{p}<.001, \beta_{\text {CHCvalueHigh }}=.277, \mathrm{p}$ $<.001)$ indicated that the negative effect of performance avoidance goals tended to be strengthened with the increase of $\mathrm{CHC}$ values, suggesting that increases in performance avoidance goals led to large decreases in affect at school when $\mathrm{CHC}$ values were high (see Figure 10). None of the other variables were significant predictors (see Appendix A: Table A26).

Figure 9 
Map $\times$ CHC Value Interaction Effect on Affect at School in College English Classes Plotted from Simple Regression Equations

$$
\begin{aligned}
& \mathrm{Y}=\left(0.320+0.137 \mathrm{Z}_{\text {CHCvalue }}\right) \mathrm{X}_{\text {Map }}+\left(0.151 \mathrm{Z}_{\text {CHCvalue }}+3.875\right) \\
& \mathrm{S}_{\text {Map }}=0.959, \mathrm{~S}_{\mathrm{CHCvalue}}=0.758 \\
& \text { At } Z_{\text {CHCvalueHigh }}=0.758: \quad Y=0.424 X_{\text {Map }}+3.989 \\
& \text { At } Z_{\text {CHCvalueModerate }}=0.000: \quad Y=0.320 X_{\text {Map }}+3.875 \\
& \text { At } Z_{\text {CHCvalueLow }}=-0.758: \quad Y=0.216 X_{\text {Map }}+3.761
\end{aligned}
$$

Simple Regression Analysis of Map x CHC Value Interaction on Affect at School

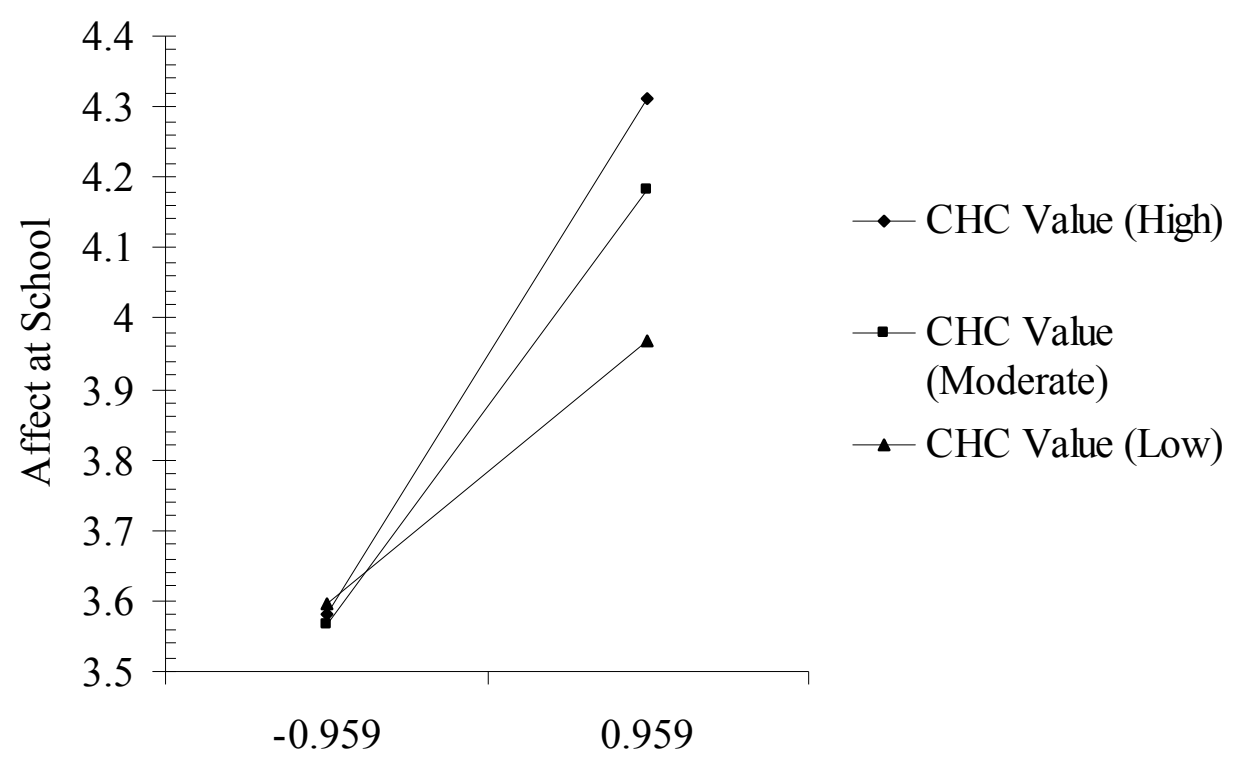

Mastery Approach Goals

Figure 10

Pav $\times$ CHC Value Interaction Effect on Affect at School in College English Classes Plotted from Simple Regression Equations

$\mathrm{Y}=\left(-0.210-0.055 \mathrm{Z}_{\mathrm{CHCvalue}}\right) \mathrm{X}_{\mathrm{Pav}}+\left(0.370 \mathrm{Z}_{\mathrm{CHCvalue}}+3.930\right)$

$\mathrm{S}_{\text {Pav }}=0.990, \mathrm{~S}_{\mathrm{CHCvalue}}=0.758$

At $Z_{\mathrm{CHCvalueHigh}}=0.758: \quad \mathrm{Y}=-0.252 \mathrm{X}_{\mathrm{Pav}}+4.210$

At $Z_{\text {CHCvalueModerate }}=0.000: \quad Y=-0.210 X_{\text {Pav }}+3.930$

At $Z_{\text {CHCvalueLow }}=-0.758: \quad Y=-0.168 X_{\text {Pav }}+3.650$ 
Simple Regression Analysis of Pav x CHC Value Interaction on Affect at School

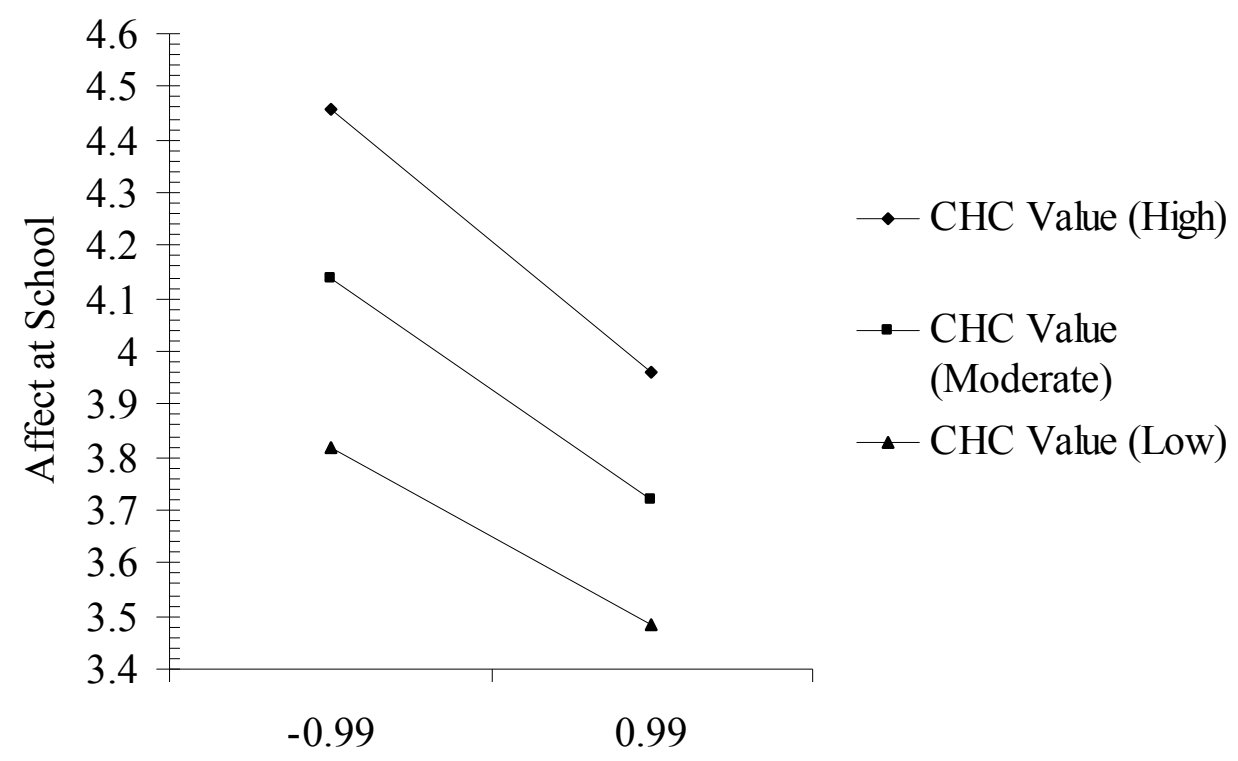

Performance Avoidance Goals

Advanced mathematics classes. In Step 1, the multiple correlation was significantly different from zero, $F(2,702)=5.685, \mathrm{p}<.01, \mathrm{R}^{2}=.016$. The regression indicated a significant effect for gender $(\beta=-.085, \mathrm{p}<.05)$ and location $(\beta=-.098, \mathrm{p}$ $<.01$ ) on affect at school, but only the location effect remained significant in Step 2 and Step 3. With the addition of $\mathrm{CHC}$ values and goal orientation variables added to the model, the change of squared mulitple correlation was significant in Step $2, F_{\text {inc }}(5,697)$ $=36.685, \mathrm{p}<.001, \Delta \mathrm{R}^{2}=.205$, but not in Step 3, $F_{\text {inc }}(4,693)=.457, \mathrm{p}=.767, \Delta \mathrm{R}^{2}$ $=.002$.

In Step 2, the regression on the main effect terms revealed that $\mathrm{CHC}$ values $(\beta$ $=.141, \mathrm{p}<.001)$ and mastery approach goals $(\beta=.273, \mathrm{p}<.001)$ positively predicted 
affect at school, whereas performance avoidance goals were a negative predictor $(\beta=-$ $.217, \mathrm{p}<.001)$

In Step 3, the regression on both main effect and interaction effect terms revealed a significant effect for the overall model, but there was no significant change of squared multiple correlation between Step 2 and Step 3. The three significant predictors in Step 2 retained their unique predictive utility at this stage of regression, $\mathrm{CHC}$ values $(\beta=.139, \mathrm{p}$ $<.01)$, mastery approach goals $(\beta=.276, \mathrm{p}<.001)$, and performance avoidance goals $(\beta$ $=-.217, \mathrm{p}<.001)$. None of the two-way interaction terms or any other variables attained significance (see Appendix A: Table A27).

\section{Academic Performance}

Regressing academic performance on the basic model yielded a significant effect for the overall model in college English classes, $F(11,693)=5.475, \mathrm{p}<.001, \mathrm{R}^{2}=.080$, and in advanced mathematics classes, $F(11,693)=4.863, \mathrm{p}<.001, \mathrm{R}^{2}=.072$.

College English classes. In Step 1, the multiple correlation was significantly different from zero, $F(2,702)=6.799, \mathrm{p}<.01, \mathrm{R}^{2}=.019$. The regression indicated a significant gender effect $(\beta=-.124, \mathrm{p}<.01)$, and this gender effect remained significant in Steps 2 and 3, indicating that women tended to have higher grades in college English classes. When $\mathrm{CHC}$ values and goal orientation variables were added to the model, the change of squared mulitple correlation was significant in Step $2, F_{\text {inc }}(5,697)=8.647$, p $<.001, \Delta \mathrm{R}^{2}=.057$, but not in Step $3, F_{\text {inc }}(4,693)=.688, \mathrm{p}=.600, \Delta \mathrm{R}^{2}=.004$.

In Step 2, regressing academic performance on the main effect terms indicated that performance approach goals positively predicted academic performance $(\beta=.174, p$ 
$<.001)$, whereas performance avoidance goals were a negative predictor $(\beta=-.214, \mathrm{p}$ $<.001)$.

In Step 3, the regression on both the main effect and interaction effect terms yielded a significant effect for the overall model, in spite of no significant change of squared multiple correlation between Step 2 and Step 3. The two significant predictors in Step 2 retained their significant unique predictive utility at this stage, but no two-way interaction terms or any other variables were significant predictors (see Appendix A: Table A26).

Advanced mathematics classes. In Step 1, the multiple correlation was significantly different from zero, $F(2,702)=5.047, \mathrm{p}<.01, \mathrm{R}^{2}=.014$. The regression indicated a significant gender effect $(\beta=-.113, p<.01)$, and this gender effect remained significant in Steps 2 and 3, indicating that women were more likely to obtain higher grades in advanced mathematics classes. With the addition of $\mathrm{CHC}$ values and goal orientation variables to the prediction, the change of squared multiple correlation was significant in Step $2, F_{\text {inc }}(5,697)=8.598, \mathrm{p}<.001, \Delta \mathrm{R}^{2}=.057$, but not in Step $3, F_{\text {inc }}(4$, $693)=.039, \mathrm{p}=.997, \Delta \mathrm{R}^{2}=.000$.

In Step 2, the regression of academic performance on the main effect terms revealed that performance approach goals were a positive predictor $(\beta=.109, \mathrm{p}<.05)$, whereas performance avoidance goals were a negative predictor $(\beta=-.211, \mathrm{p}<.001)$.

In Step 3, although no significant change of squared multiple correlation between Steps 2 and 3, the regression on both the main effect and interaction effect terms yielded a significant effect for the overall model. The two predictors that demonstrated their 
unique predictive utility as main effect terms in Step 2 remained significant at this stage of regression. No two-way interaction or any other variables attained significance (see Appendix A: Table A27).

\section{CHC values and the SAL Framework}

This part deals with the way $\mathrm{CHC}$ values and student approaches to learning interacted to influence Chinese students' learning processes and outcomes in an attempt to reveal whether students' attitude towards $\mathrm{CHC}$ values and their approaches to learning combined to generate different learning processes and outcomes and promote optimal motivation. Specifically, this part of the regression analysis addressed: (a) how CHC values and student approaches to learning contributed their unique predictive utility as main effect terms to metacognitive strategies, perceived academic efficacy, affect at school, and academic performance, (b) whether there was any interaction between CHC values and student approaches to learning that contributed a significant unique predictive utility to the aforementioned learning process and outcome variables, and (c) how $\mathrm{CHC}$ values moderated the impact of student approaches to learning on relevant learning processes and outcomes in case of a significant interaction.

Apart from students' background information, the independent variables within the regression model tested on each learning process and outcome variable contained: (a) the main effect terms of the deep approach to learning, the surface approach to learning, and $\mathrm{CHC}$ values, thereby affording a test of their unique predictive utility, and (b) all the possible two-way interaction product terms between $\mathrm{CHC}$ values and each of the two approaches to learning main effect terms, thereby offering a test of the way $\mathrm{CHC}$ values 
moderated the influence of approaches to learning on learning processes and outcomes in case of significant unique predictive utility.

\section{Metacognitve Strategies}

Regressing metacognitive strategies on the basic model yielded a significant

effect for the overall model in college English classes, $F(7,697)=56.474, \mathrm{p}<.001, \mathrm{R}^{2}$ $=.362$, and in advanced mathematics classes, $F(7,697)=65.316, \mathrm{p}<.001, \mathrm{R}^{2}=.396$.

College English classes. In Step1, the multiple correlation was not significantly different from zero, $F(2,702)=.318, \mathrm{p}=.728, \mathrm{R}^{2}=.001$. The regression indicated the absence of gender or location effect on metacognitive strategies, which remained nonsignificant in Step 2 and Step 3. When student approaches to learning and CHC value variables were added to the model, the change of squared multiple correlation was significant in Step $2, F_{\text {inc }}(3,699)=127.458, \mathrm{p}<.001, \Delta \mathrm{R}^{2}=.353$, and in Step $3, F_{\text {inc }}(2$, $697)=4.218, \mathrm{p}<.05, \Delta \mathrm{R}^{2}=.008$

In Step 2, regressing metacognitive strategies revealed that $\mathrm{CHC}$ values $(\beta=.126$, $\mathrm{p}<.001)$ and the deep approach to learning $(\beta=.539, \mathrm{p}<.001)$ were significant positive predictors, and the surface approach was a marginally significant negative predictor $(\beta=$ $-.059, \mathrm{p}=.064)$

In Step 3, the regression not only yielded a significant main effect for $\mathrm{CHC}$ values $(\beta=.137, \mathrm{p}<.001)$ and the deep approach to learning $(\beta=.525, \mathrm{p}<.001)$, a marginally significant main effect for the surface approach $(\beta=-.062, p=.051)$, but also a significant positive effect for the Dap $\times \mathrm{CHC}$ value interaction $(\beta=.094, \mathrm{p}<.01)$. Simple slope analysis of the Dap $\times \mathrm{CHC}$ value interaction $\left(\beta_{\text {Dap }}=.455, \mathrm{p}<.001, \beta_{\text {CHCvalueLow }}\right.$ 
$=.139, \mathrm{p}<.001 ; \beta_{\text {Dap }}=.537, \mathrm{p}<.001, \beta_{\mathrm{CHCvalueModerate}}=.139, \mathrm{p}<.001 ; \beta_{\text {Dap }}=.618, \mathrm{p}$

$\left.<.001, \beta_{\mathrm{CHCvalueHigh}}=.139, \mathrm{p}<.001\right)$ indicated that the positive effect of the deep approach to learning tended to be strengthened with the increase of $\mathrm{CHC}$ values (see

Figure 11). None of the other variables were significant predictors (see Appendix A:

Table A28).

Figure 11

Dap $\times$ CHC Value Interaction Effect on Metacognitive Strategies in College English Classes Plotted from Simple Regression Equations

$\mathrm{Y}=\left(0.513+0.103 \mathrm{Z}_{\mathrm{CHCvalue}}\right) \mathrm{X}_{\text {Dap }}+\left(0.160 \mathrm{Z}_{\mathrm{CHCvalue}}+4.611\right)$

$\mathrm{S}_{\text {Dap }}=0.911, \mathrm{~S}_{\mathrm{CHC} \text { value }}=0.758$

At $Z_{\text {CHCvalueHigh }}=0.758: \quad Y=0.591 X_{\text {Dap }}+4.732$

At $Z_{\text {CHCvalueModerate }}=0.000: \quad \mathrm{Y}=0.513 \mathrm{X}_{\text {Dap }}+4.611$

At $Z_{\text {CHCvalueLow }}=-0.758: \quad \mathrm{Y}=0.435 \mathrm{X}_{\text {Dap }}+4.490$

Simple Regression Analysis of Dap x CHC Value Interaction on

Metacognitive Strategies

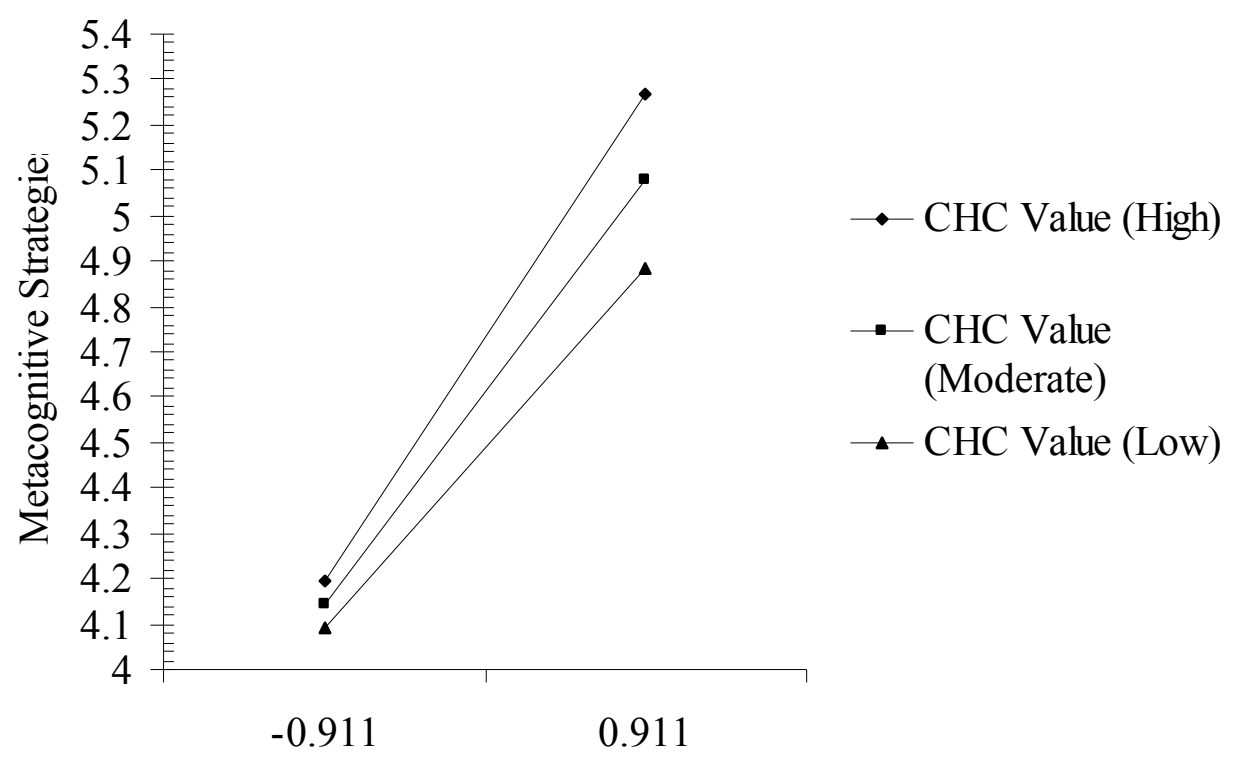

Deep Approaches to Learning 
Advanced mathematics classes. In Step 1, the multiple correlation was significantly different from zero, $F(2,702)=3.266, \mathrm{p}<.05, \mathrm{R}^{2}=.009$. The regression indicated a significant gender effect $(\beta=-.078, p<.05)$, and this gender effect remained significant in Steps 2 and 3, indicating that women tended to adopt higher levels of metacognitive strategies in advanced mathematics classes. When $\mathrm{CHC}$ values and SAL variables were added to the model, the change of squared multiple correlation was significant in Step 2, $F_{\text {inc }}(3,699)=148.061, \mathrm{p}<.001, \Delta \mathrm{R}^{2}=.385$, and but not in Step 3, $F_{\text {inc }}(2,697)=1.119, \mathrm{p}=.327, \Delta \mathrm{R}^{2}=.002$.

In Step 2 , the regression revealed that $\mathrm{CHC}$ values $(\beta=.126, \mathrm{p}<.001)$ and the deep approach $(\beta=.554, \mathrm{p}<.001)$ positively predicted metacognitive strategies, whereas the surface approach was a marginally significant negative predictor $(\beta=-.059, \mathrm{p}=.056)$.

In Step 3, the regression on both main effect and interaction effect terms yielded a significant effect for the overall model, but there was no significant change of squared multiple correlation between Steps 2 and 3. The regression at this stage yielded a significant effect for $\mathrm{CHC}$ values $(\beta=.133, \mathrm{p}<.001)$, the deep approach $(\beta=.550, \mathrm{p}$ $<.001)$, and the surface approach $(\beta=-.065, \mathrm{p}<.05)$. None of the two-way interactions or any other variables were significant predictors (see Appendix A: Table A29). Perceived Academic Efficacy

Regressing perceived academic efficacy on the basic model yielded a significant effect for the overall model in college English classes, $F(7,697)=26.917, \mathrm{p}<.001, \mathrm{R}^{2}$ $=.213$, and in advanced mathematics classes, $F(7,697)=30.999, \mathrm{p}<.001, \mathrm{R}^{2}=.237$. 
College English classes. In Step 1, the multiple correlation was significantly different from zero, $F(2,702)=3.190, \mathrm{p}<.05, \mathrm{R}^{2}=.009$. The regression indicated a significant location effect $(\beta=.089, \mathrm{p}<.05)$, and this location effect remained significant in Steps 2 and 3, indicating that students with their middle schools located in urban areas tended to have higher levels of perceived academic efficacy in college English classes. When $\mathrm{CHC}$ values and SAL variables were added to the model, the change of squared multiple correlation was significant in Step $2, F_{\text {inc }}(3,699)=59.119, \mathrm{p}<.001, \Delta \mathrm{R}^{2}=.201$, but not in Step 3, $F_{\text {inc }}(2,697)=1.435, \mathrm{p}=.239, \Delta \mathrm{R}^{2}=.003$.

In Step 2, the regression revealed that $\mathrm{CHC}$ values $(\beta=.161, \mathrm{p}<.001)$ and the deep approach $(\beta=.350, \mathrm{p}<.001)$ positively predicted perceived academic efficacy, whereas the surface approach $(\beta=-.101, \mathrm{p}<.01)$ was a negative predictor.

In Step 3, the regression on both the main effect and interaction effect terms yielded a significant effect for the overall model, although there was no significant change of squared multiple correlation between Steps 2 and 3. The regression at this stage revealed a significant effect for $\mathrm{CHC}$ values $(\beta=.165, \mathrm{p}<.001)$, the deep approach $(\beta=.346, \mathrm{p}<.001)$, and the surface approach $(\beta=-.100, \mathrm{p}<.01)$. None of the two-way interactions or any other variables attained significance (see Appendix A: Table A28).

Advanced mathematics classes. In Step 1, the multiple correlation was not significantly different from zero, $F(2,702)=.048, \mathrm{p}=.954, \mathrm{R}^{2}=.000$. The regression indicated no gender or location effect on perceived academic efficacy, which remained nonsignificant in Steps 2 and 3. When $\mathrm{CHC}$ values and SAL variables were added to the model, the change of squared multiple correlation was significant in Step $2, F_{\text {inc }}(3,699)$ 
$=72.395, \mathrm{p}<.001, \Delta \mathrm{R}^{2}=.237$, but not in Step $3, F_{\text {inc }}(2,697)=.116, \mathrm{p}=.891, \Delta \mathrm{R}^{2}$ $=.000$.

In Step 2, regressing perceived academic efficacy revealed that $\mathrm{CHC}$ values $(\beta$ $=.214, \mathrm{p}<.001)$ and the deep approach $(\beta=.341, \mathrm{p}<.001)$ were positive predictors, whereas the surface approach was a negative predictor $(\beta=-.101, \mathrm{p}<.01)$.

In Step 3, the regression yielded a significant effect for the overall model, but there was no significant change of squared multiple correlation between Steps 2 and 3. The regression at this stage revealed a significant effect for $\mathrm{CHC}$ values $(\beta=.211, \mathrm{p}$ $<.001)$, the deep approach $(\beta=.343, \mathrm{p}<.001)$, and the surface approach $(\beta=-.100, \mathrm{p}$ $<.01$ ). No two-way interactions or any other variables were significant predictors (see Appendix A: Table A29).

Affect at School

Regressing affect at school on the basic model yielded a significant effect for the overall model in college English classes, $F(7,697)=35.705, \mathrm{p}<.001, \mathrm{R}^{2}=.264$, and in advanced mathematics classes, $F(7,697)=60.396, \mathrm{p}<.001, \mathrm{R}^{2}=.378$.

College English classes. In Step 1, the multiple correlation was significantly different from zero, $F(2,702)=3.198, \mathrm{p}<.05, \mathrm{R}^{2}=.009$. The regression indicated a significant gender effect $(\beta=-.091, \mathrm{p}<.05)$ on affect at school, which lost its significance in Steps 2 and 3. When $\mathrm{CHC}$ values and SAL variables were added to the model, the change of squared multiple correlation was significant in Step 2, $F_{\text {inc }}(3,699)$ $=75.451, \mathrm{p}<.001, \Delta \mathrm{R}^{2}=.242$, and in Step $3, F_{\text {inc }}(2,697)=5.923, \mathrm{p}<.01, \Delta \mathrm{R}^{2}=.013$. 
In Step 2, the regression on the main effect terms revealed that $\mathrm{CHC}$ values $(\beta$ $=.146, \mathrm{p}<.001)$ and the deep approach $(\beta=.304, \mathrm{p}<.001)$ positively predicted affect at school, whereas the surface approach was a negative predictor $(\beta=-.261, \mathrm{p}<.001)$.

In Step 3, regressing affect at school on both the main effect and interaction effect terms yielded a significant main effect for $\mathrm{CHC}$ values $(\beta=.161, \mathrm{p}<.001)$, the deep approach $(\beta=.286, \mathrm{p}<.001)$, and the surface approach $(\beta=-.264, \mathrm{p}<.001)$.

Furthermore, the regression revealed a significant positive effect for the Dap $\times \mathrm{CHC}$ value interaction $(\beta=.119, \mathrm{p}<.01)$, indicating that the moderation of $\mathrm{CHC}$ values on the impact of the deep approach contributed a unique predictive utility to affect at school. Simple slope analysis of the Dap $\times$ CHC value interaction $\left(\beta_{\text {Dap }}=.244, \mathrm{p}<.001\right.$, $\beta_{\text {CHCvalueLow }}=.168, \mathrm{p}<.001 ; \beta_{\text {Dap }}=.351, \mathrm{p}<.001, \beta_{\text {CHCvalueModerate }}=.168, \mathrm{p}<.001 ; \beta_{\text {Dap }}$ $\left.=.457, \mathrm{p}<.001, \beta_{\mathrm{CHC} \text { valueHigh }}=.168, \mathrm{p}<.001\right)$ indicated that the positive effect of the deep approach to learning tended to be strengthened with the increase of $\mathrm{CHC}$ values, suggesting that increases in the deep approach led to large increases in affect at school when $\mathrm{CHC}$ values were high (see Figure 12). No other variables were significant predictors (see Appendix A: Table A28).

Figure 12

Dap $\times$ CHC Value Interaction Effect on Affect at School in College English Classes Plotted from Simple Regression Equations $\mathrm{Y}=\left(0.390+0.157 \mathrm{Z}_{\mathrm{CHCvalue}}\right) \mathrm{X}_{\text {Dap }}+\left(0.225 \mathrm{Z}_{\mathrm{CHCvalue}}+3.898\right)$ $\mathrm{S}_{\text {Dap }}=0.911, \mathrm{~S}_{\mathrm{CHCvalue}}=0.758$ At $Z_{\text {CHCvalueHigh }}=0.758: \quad \mathrm{Y}=0.509 \mathrm{X}_{\text {Dap }}+4.069$ At $Z_{\text {CHCvalueModerate }}=0.000: \quad Y=0.390 X_{\text {Dap }}+3.898$ At $Z_{\text {CHCvalueLow }}=-0.758: \quad Y=0.271 X_{\text {Dap }}+3.727$ 
Simple Regression Analysis of Dap x CHC Value Interaction on Affect at School

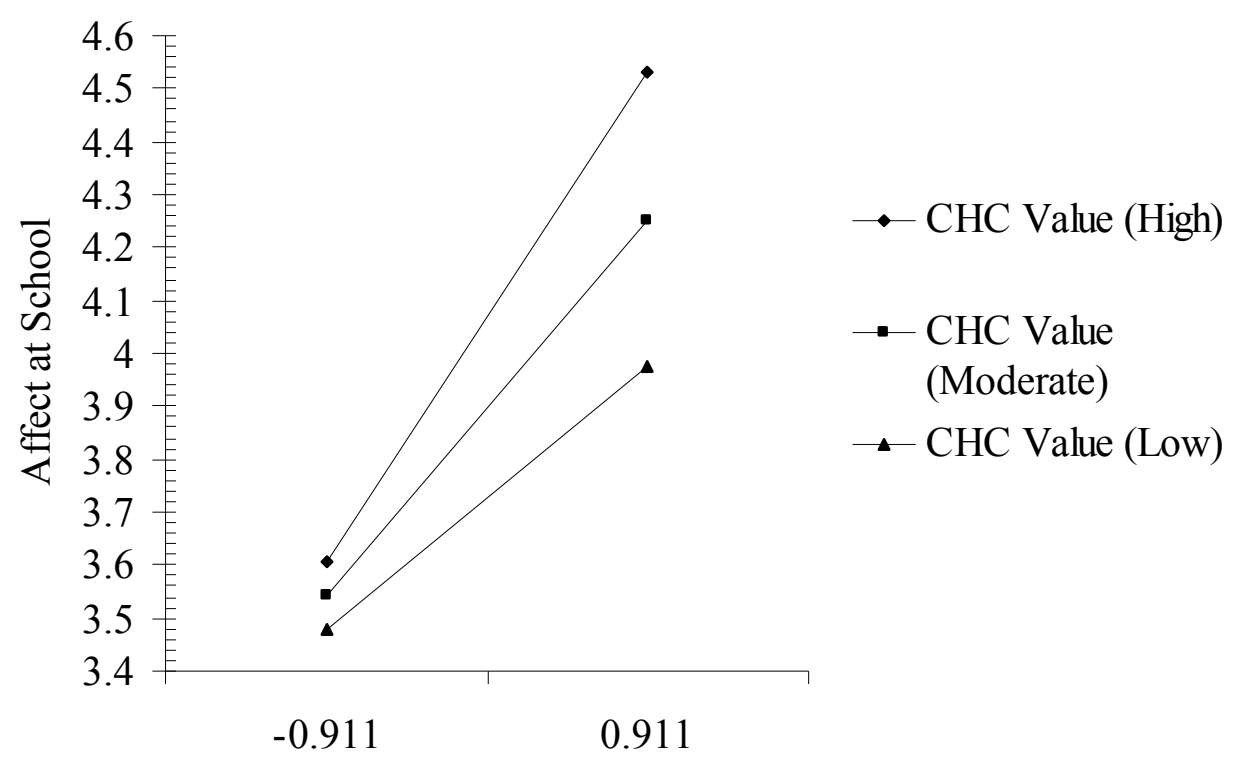

Deep Approaches to Learning

Advanced mathematics classes. In Step 1, the multiple correlation was significantly different from zero, $F(2,702)=5.685, \mathrm{p}<.01, \mathrm{R}^{2}=.016$. The regression indicated a significant gender $(\beta=-.085, \mathrm{p}<.05)$ and location effect $(\beta=-.098, \mathrm{p}<.01)$, but only the former remained significant in Steps 2 and 3. When CHC values and SAL variables were added to the model, the change of squared multiple correlation was significant in Step 2, $F_{\text {inc }}(3,699)=135.351, \mathrm{p}<.001, \Delta \mathrm{R}^{2}=.362$, but not in Step $3, F_{\text {inc }}$ $(2,697)=.011, \mathrm{p}=.989, \Delta \mathrm{R}^{2}=.000$

In Step 2, the regression revealed a positive predictive utility of $\mathrm{CHC}$ values $(\beta$ $=.082, \mathrm{p}<.05)$ and the deep approach $(\beta=.386, \mathrm{p}<.001)$, and a negative predictive effect for the surface approach $(\beta=-.336, p<.001)$. 
In Step 3, the regression on both main effect and interaction effect terms yielded a significant effect for the overall model, although there was no significant change of squared multiple correlation between Steps 2 and 3. The aforementioned three predictors that demonstrated their predictive utility in Step 2 remained significant at this stage of regression. No two-way interactions or any other variables attained significance (see Appendix A: Table A29).

Academic Performance

Regressing academic performance on the basic model yielded a significant effect for the overall model in college English classes, $F(7,697)=6.495, \mathrm{p}<.001, \mathrm{R}^{2}=.061$, and in advanced mathematics classes, $F(7,697)=7.516, \mathrm{p}<.001, \mathrm{R}^{2}=.070$.

College English classes. In Step 1, the multiple correlation was significantly different from zero, $F(2,702)=6.799, \mathrm{p}<.01, \mathrm{R}^{2}=.019$. The regression indicated a significant gender effect $(\beta=-.124, p<.01)$, and this gender effect remained significant in Steps 2 and 3, indicating that women were more likely to obtain higher grades in college English classes. With the addition of $\mathrm{CHC}$ values and SAL variables to the model, the change of squared multiple correlation was significant in Step 2, $F_{\text {inc }}(3,699)=$ $10.384, \mathrm{p}<.001, \Delta \mathrm{R}^{2}=.042$, but not in Step 3, $F_{\text {inc }}(2,697)=.141, \mathrm{p}=.868, \Delta \mathrm{R}^{2}=.000$. In Step 2 , the regression revealed that $\mathrm{CHC}$ values $(\beta=.090, \mathrm{p}<.05)$ positively predicted academic performance, whereas the surface approach $(\beta=-.194, p<.001)$ negatively predicted academic performance. Surprisingly, the regression also revealed that the deep approach was a negative predictor $(\beta=-.085, \mathrm{p}<.05)$. 
In Step 3, the regression yielded a significant effect for the overall model in spite of no significant change of squared multiple correlation between Steps 2 and 3. The regression on both the main effect and interaction effect terms revealed a significant effect for CHC values $(\beta=.093, p<.05)$, the deep approach $(\beta=-.088, p<.05)$, the surface approach $(\beta=-.194, p<.001)$. None of the two-way interactions or any other variables were significant predictors (see Appendix A: Table A28).

Advanced mathematics classes. In Step 1, the multiple correlation was significantly different from zero, $F(2,702)=5.047, \mathrm{p}<.01, \mathrm{R}^{2}=.014$. The regression indicated a gender effect $(\beta=-.113, p<.01)$, and this gender effect remained significant in Steps 2 and 3, indicating that women tended to gain higher grades in advanced mathematics classes. When $\mathrm{CHC}$ values and SAL variables were added to the model, the change of squared multiple correlation was significant in Step $2, F_{\text {inc }}(3,699)=13.106, \mathrm{p}$ $<.001, \Delta \mathrm{R}^{2}=.052$, but not in Step 3, $F_{\text {inc }}(2,697)=1.316, \mathrm{p}=.269, \Delta \mathrm{R}^{2}=.004$.

In Step 2, the regression revealed that the deep approach positively predicted academic performance $(\beta=.121, \mathrm{p}<.01)$, whereas the surface approach was a negative predictor $(\beta=-.170, \mathrm{p}<.001)$.

In Step 3, the regression on both the main effect and interaction effect terms yielded a significant effect for the overall model, although there was no significant change of squared multiple correlation between Steps 2 and 3. The regression at this stage indicated a significant effect for the deep approach $(\beta=.115, \mathrm{p}<.01)$ and the surface approach $(\beta=-.178, \mathrm{p}<.001)$. No two-way interactions or any other variables attained significance (see Appendix A: Table A29). 


\section{CHAPTER 5}

\section{DISCUSSION}

The purpose of this study was: (a) to examine the predictive utility of the achievement goal and SAL frameworks for characterizing Chinese students' motivation and achievement, and (b) to investigate how Confucian-heritage culture (CHC) and achievement goals or SAL may combine to generate different learning processes and outcomes and to promote optimal motivation. This research, on the one hand, contributes to the educational research on CHC students' motivation and learning using both the achievement goal framework and SAL framework. On the other hand, it contributes to both the achievement goal and SAL theoretical frameworks because it introduces the $\mathrm{CHC}$ value construct into achievement motivation research in an attempt to explore the moderating effect of $\mathrm{CHC}$ values on the association between achievement goals and learning processes and outcomes for Chinese students.

In the following sections, research findings are discussed in relation to eight research questions posed in the methodology chapter. Next, implications of this study for educational research on $\mathrm{CHC}$ students and on the two theoretical frameworks are presented. Lastly, limitations of this study and avenues for future research are presented.

To What Extent Do Chinese Students Pursue the CHC Values?

The first research question focused on determining the extent to which a sample of first-year university students in China pursued the $\mathrm{CHC}$ values by endorsing socially oriented goals (family-, peer-, and teacher-oriented goals), following a sense of learning duty, and practicing utility value. 
Given the defining features of Confucian-heritage culture values derived from the literature review (Confucius, 479 B.C.; Ho, 2001; Hong, 2001; Lee, 1996; Salili, 1995, 1996; Salili et al., 2001; Shi et al., 2001; Tweed \& Lehman, 2002; Watkins \& Biggs, 2001), the hypothesis implied that Chinese students would pursue the socially oriented goals (family-, peer-, and teacher-oriented goals), a sense of learning duty, and utility value, all of which would constitute a higher-order unitary $\mathrm{CHC}$ value construct. The EFA and reliability data provided support for the $\mathrm{CHC}$ values as a high-order unitary construct of socially oriented goals, a sense of learning duty, and utility value, when the peer-oriented goals were removed. The peer-oriented goals diverged from the other four cultural value measures in bivariate correlations and factor analyses. Furthermore, the mean for peer-oriented goals was close to the scale midpoint and noticeably lower than the means for the other cultural value indices, evidencing the lower prevalance of this type of goals among these Chinese students. In their research on the influence of culture and context on students' motivational orientation and performance, Salili, Chiu, and Lai have consistently shown that socially oriented goals (family-, teacher-, peer-oriented goals) were more salient for Chinese Canadians and Hong Kong students than for European Canadians and that peer-oriented goals were the least prevalent among the three socially oriented goals for all the three groups of participants. Perhaps the familyoriented goals and teacher-oriented goals direct Chinese students towards cognitive involvement in academic tasks, whereas peer-oriented goals entail a tradeoff between friendship and academic excellence and can operate at the cost of family- and teacheroriented goals that Chinese students value more. 
The EFA results supported the interpretation that a sense of learning duty, socially oriented goals (family- and teacher-oriented goals), and utility value are an integral part of the high-order unitary construct of CHC values, which addresses Chinese students' attitudes toward academic tasks and may influence their motivation and achievement. One implication of this interpretation is that the $\mathrm{CHC}$ values may provide education researchers with a nuanced construct to inform in-depth understanding of the functional relation of achievement goals and SAL to learning for Chinese students. A second implication is that interventions that address students' sense of learning duty, perceived instrumentality of current school success to attainment of personally valued future goals, and group responsibilities and goals may contribute to school-based efforts aimed at enhancing motivation of Chinese students.

To What Extent Do Chinese Students Endorse Achievement Goal Orientations as Postulated by the $2 \times 2$ Conceptualization?

The second research question was concerned with determining the extent to which this sample of Chinese first-year university students pursued achievement goals in agreement with the goal constructs of the $2 \times 2$ framework.

Previous research showed the applicability of the dichotomous and trichotomous goal frameworks to Chinese students (Salili, Chiu, \& Lai, 2001; Shi et al., 2001; Woodrow \& Chapman, 2002) and the potential appropriateness of applying the $2 \times 2$ achievement goal framework to CHC Chinese students (Elliot, 1999; Elliot, Chirkov, Kim, \& Sheldon, 2001; Elliot \& Thrash, 2001; Heine et al., 2001). Thus this hypothesis suggested that Chinese students would pursue mastery approach, mastery avoidance, 
performance approach, and performance avoidance goals as postulated by the $2 \times 2$ framework. The EFA and reliability data in both college English classes and advanced mathematics classes provided support for Chinese students' endorsement of achievement goals consistent with the goal constructs of the $2 \times 2$ conceptualization.

Elliot and McGregor (2001) conducted research with 180 US undergraduate students to investigate the $2 \times 2$ achievement goal framework in general and the mastery avoidance goal construct in particular. They found that mastery avoidance goals, although operative, were less prevalent than the other three forms of goal regulation. However, in the present study with a sample of 714 Chinese first-year undergraduate students, mastery avoidance goals were revealed to be the second most prevalent achievement goals whether in college English classes or in advanced mathematics classes. This higher salience of mastery avoidance goals among Chinese students might be accounted for from the perspective of their characteristic $\mathrm{CHC}$ value endorsement. On the one hand, utility value (DeBacker \& Nelson, 1999; Greene, et al., 1999; Miller, DeBacker, \& Greeet al., 1999) and a sense of learning duty (Hau \& Salili, 1991; Heine et al., 2001; Hess, Chih-Mei, \& McDevitt, 1987; Hong, 2001; Stevenson et al., 1990) tend to evoke mastery goal pursuit; on the other hand, collectivism tends to promote avoidance goal endorsement (Elliot, et al, 2001). This concordance of mastery avoidance goals with the $\mathrm{CHC}$ values makes mastery avoidance goals a priority of our research focus to address the interplay between the $\mathrm{CHC}$ value construct and achievement goals in their influence on achievement-relevant processes and outcomes. 
To What Extent Do Chinese Students Adopt the Approaches to Learning as Posited by the SAL Framework?

The third research question focused on determining the extent to which this sample of Chinese first-year university students adopted the deep and surface approach to learning consistent with the constructs of the revised two-factor SAL framework.

Consistent with the applicability of the revised two-factor SAL framework to a sample of 495 undergraduate students from one university in Hong Kong (Biggs, et al., 2001), the EFA and reliability data in this study supported the Chinese students' adoption of the deep and surface approach to learning, whether in college English classes or in advanced mathematics classes.

One surface strategy item (Item 19) loaded on neither the deep nor the surface approach in college English classes. This item was intended to measure the extent to which Chinese students made use of rote learning in their college English classes, but failed to draw a distinction between rote learning and repetitive learning. The former is a surface strategy that student used to memorize without thought of understanding, whereas the latter is an intermediate strategy used to enhance future recall alongside understanding (Kember, et al., 1999; Watkins \& Biggs, 2001). According to Tweed \& Lehman (2002), Chinese students are frequently misconceived as engaging in surface strategies and rote learning without understanding, when they are engaged in repetitive learning to ensure retention and enhance understanding, and do have deeper, meaningoriented approaches to learning and show high levels of understanding (Watkins \& Biggs, 2001). The reason that Item 19 failed to load on either factor in college English classes 
but loaded on the surface approach in advanced mathematics classes may be that in foreign language classes repetitive learning is often used to enhance retention, develop understanding, and facilitate deep learning, whereas in advanced mathematics classes deep learning and understanding requires organization, elaboration, critical thinking, planning, monitoring, and regulating rather than repetitive learning.

To What Extent Does Chinese Students' Achievement Goal Endorsement Differentially Predict Their Learning Processes and Outcomes?

The fourth research question addressed the extent to which each of the four achievement goals within the $2 \times 2$ framework was linked to a distinct predictive profile for Chinese students' motivation and achievement.

Numerous studies conducted with Western students have demonstrated that achievement goals differentially predict motivational and cognitive processes and outcomes, such as attributional patterns, use of learning strategies, school well-being, and academic achievement (e.g., Elliot \& Church, 1997; Elliot \& McGregor, 2001; Harackiewicz et al., 2002; Kaplan \& Maehr, 1999; Wolters, 2004; also see reviews in Ames, 1992; Dweck \& Leggett, 1988; Kaplan \& Maehr, 2007). Meanwhile, research has revealed the potential applicability of the $2 \times 2$ framework to CHC students (Elliot, 1999; Elliot, et al., 2001; Elliot \& Thrash, 2001; Heine et al., 2001; Salili, et al., 2001; Shi et al., 2001; Woodrow \& Chapman, 2002). In view of these studies, the hypothesis was that each of the goals in the $2 \times 2$ framework would predict a distinct pattern of metacognitive strategies, perceived academic efficacy, affect at school, and academic performance. Results from the regression analyses revealed distinct empirical profiles for each of the 
achievement goals, providing strong support for this hypothesis (see Table 3). Mastery approach goals positively predicted metacognitive strategies, academic efficacy, and affect at school in both college English classes and advanced mathematics classes; mastery avoidance goals positively predicted metacognitive strategies in both classes and affect at school in college English classes; performance approach goals positively predicted academic efficacy and academic performance in both classes; and performance avoidance goals negatively predicted academic efficacy, affect at school, and academic performance in both classes.

Table 3

The Prediction of Achievement Goals for Learning Processes and Outcomes

\begin{tabular}{|c|c|c|c|c|c|c|c|c|}
\hline Outcome & $\begin{array}{r}\text { Meta } \\
\text { sta }\end{array}$ & $\begin{array}{l}\text { nitive } \\
\text { ies }\end{array}$ & & $\begin{array}{l}\operatorname{mic} \\
\text { acy }\end{array}$ & & & $\begin{array}{r}\text { Ac } \\
\text { perf }\end{array}$ & $\begin{array}{l}\text { mic } \\
\text { ance }\end{array}$ \\
\hline Goal Orientation & $\mathrm{CE}$ & $\mathrm{AM}$ & $\mathrm{CE}$ & AM & $\mathrm{CE}$ & AM & $\mathrm{CE}$ & AM \\
\hline Mastery approach & Pos & $\begin{array}{l}\text { Pos } \\
* \text { Neg }\end{array}$ & $\begin{array}{l}\text { Pos } \\
* \text { Pos }\end{array}$ & $\begin{array}{l}\text { Pos } \\
\text { * Neg }\end{array}$ & Pos & Pos & & \\
\hline Mastery avoidance & Pos & $\begin{array}{l}\text { Pos } \\
* \text { Neg }\end{array}$ & * Pos & $\#^{\text {Pos }}$ & Pos & & & \\
\hline $\begin{array}{l}\text { Performance } \\
\text { approach }\end{array}$ & * Pos & & $\begin{array}{l}\text { Pos } \\
\#^{\text {Pos }}\end{array}$ & $\begin{array}{l}\text { Pos } \\
\#^{\text {Pos }}\end{array}$ & & & Pos & Pos \\
\hline $\begin{array}{l}\text { Performance } \\
\text { avoidance }\end{array}$ & * Pos & & $\begin{array}{l}\text { Neg } \\
\#^{\text {Pos }}\end{array}$ & $\begin{array}{l}\text { Neg } \\
* \text { Neg }\end{array}$ & Neg & Neg & Neg & $\mathrm{Neg}$ \\
\hline
\end{tabular}

Note: Pos $=$ positive main effect. Neg $=$ Negative main effect. ${ }^{* P o s}, \#^{\mathrm{Pos}}$, or ${ }^{* \mathrm{Neg}}=$ positive or negative interactive effect between two goals each marked by the same superscript. $\mathrm{CE}=$ College English classes. $\mathrm{AM}=$ Advanced mathematics classes.

Consistent with Elliot and McGregor's findings (2001), the pattern for mastery approach goals was most positive, next was the pattern for mastery avoidance or performance approach goals, and that for performance avoidance goals was the most negative. The pattern for mastery approach goals in this study is consistent with prior research conducted with Western students (e.g., Ames \& Archer, 1988; Dweck \& Leggett, 
1988; Kaplan \& Maehr, 1999; Middleton \& Midgley, 1997; Wolters et al., 1996). One ambiguous issue arose concerning the relation between mastery approach goals and academic performance. Some studies, conducted mainly in K-12 settings, revealed positive associations between mastery approach goals and academic performance (e.g., Kaplan \& Maehr, 1999), whereas other studies, conducted primarily in college settings (Grant \& Dweck, 2003; Harackiewicz, Barron, Carter, Lehto, \& Elliot, 1997) like this study, demonstrated no relations or inconsistent relations between them. Researchers suggested various reasons for these findings concerning the association between mastery approach goals and academic performance. The missing or inconsistent relations found in college settings were suggested to be associated with the difficulty level of the coursework involved (Grant \& Dweck, 2003; Harackiewicz et al., 1997). Grant and Dweck (2003) pointed out that mastery approach goals may facilitate academic performance "when a high degree of challenge is present, when a task is personally important, or when the processing of complex, difficult material is necessary" (p. 550). Similarly, Harackiewicz et al. (1997) indicated that mastery approach goals may benefit academic performance in small, advanced classes where coursework requires deep processing, thoughtful integration of materials, sustained effort, and involvement. In addition to the difficulty level of coursework, Kaplan and Maehr (2007) agreed that the disparity in the findings between K-12 settings and college settings may be related to the assessment method: Mastery approach goals may tend to positively predict academic performance on such tasks as open-ended assignments and projects, but are less likely to do so on multiple-choice tests or problems with one correct answer. This might explain 
no prediction of mastery approach goals for academic performance found in both classes in our study, since in China objective tests are widely used in these two classes.

The pattern for performance approach goals in our study conforms to the findings from previous research conducted with Western students. Although empirical studies with Western students have demonstrated that the pattern for performance approach goals is less consistent than that for mastery approach and performance avoidance goals (Midgley et al., 2001), some variables have been frequently shown to be associated with performance approach goals in a certain way and the pattern for this type of goal is mostly considered positive. For example, academic efficacy (e.g., Skaalvik, 1997; Wolters et al., 1996), persistence and effort expenditure (e.g., Elliot, McGregor, \& Gable, 1999), and academic performance (e.g., Barron \& Harackiewicz, 2001) have been found to demonstrate either a positive or occasionally null relationship to performance approach goals. Deep processing (e.g., Elliot et al., 1999) and intrinsic motivation (e.g., Elliot \& Church, 1997) have been shown to display either a null or occasionally positive association to this type of goal. It is important to note that, in this study, performance approach goals did not show any predictive utility for metacognitive strategies. As Midgley et al. (2001) contended, under performance approach goals, students would be oriented to strategies that aim at enhancing demonstration of ability rather than at learning, and therefore this type of goals might contribute to academic performance but not necessarily to understanding and deep processing.

The pattern for performance avoidance goals was generally consistent with the results from prior research with Western students. This research has shown a negative 
association between performance avoidance goals and a host of motivational and cognitive processes and outcomes, such as academic efficacy (e.g., Skaakvik, 1997), academic performance (e.g., Elliot \& Church, 1997), metacognitive strategies (e.g., Elliot et al., 1999), and interest, enjoyment, and free choice (Rawsthorne \& Elliot, 1999). In contrast with the negative effect on learning strategies in research with Western students, performance avoidance goals in this study of 714 Chinese first-year university students displayed a null relation to metacognitive strategies whether in college English classes or in advanced mathematics classes. Further research is needed to examine this relationship.

The pattern of the associations related to mastery avoidance goals is generally positive in our study. Similar to mastery approach goals and performance approach goals, mastery avoidance goals evoked no negative and deleterious processes in our study, and they demonstrated a positive predictive utility for metacognitive strategies in both classes. In the few published studies that have examined mastery avoidance goals among Western students, however, the profile for this orientation generally seemed not to be positive. This type of goal was found to be negatively related to intrinsic motivation (Cury, Elliot, Da Fonseca, \& Moller, 2006) and to be positively related to disorganized studying and worry (Elliot \& McGregor, 2001). The disparity in predictive pattern between Chinese students and Western students may reflect their different attitude toward avoidance goals: The concordance of avoidance goals with collectivism may make the pattern for mastery avoidance goals less negative for Chinese. Since mastery avoidance goals are a new addition to the literature, their predictive pattern has yet to be clearly established. The 
difference in the pattern for mastery avoidance goals between Western students and Chinese students warrants further research.

To What Extent Do Achievement Goals Combine to Facilitate Learning Processes and Outcomes for Chinese Students?

The fifth research question was concerned with determining the extent to which the multiple goal pursuit was facilitative of Chinese students' learning processes and outcomes.

In contrast to the normative goal theoretical assumption that mastery goals are adaptive and performance goals are maladaptive, characteristic of the dichotomous achievement framework, the revised goal theory (multiple goal theory) perspective advocated by Harackiewicz et al. (1998) asserts that the combination of achievement goals is most adaptive for promoting optimal motivation and achievement (Harackiewicz et al., 1998; Barron \& Harackiewicz, 2001). For these potential multiple goal benefits, three of the four hypotheses suggested by Barron and Harackiewicz (2001) were tested to examine how the multiple goal pursuit promoted achievement outcomes, including : (a) whether the four achievement goals had their own independent, positive effects on a particular learning process and outcome (an additive goal pattern); (b) whether any two of the four achievement goals interacted above and beyond their independent effects in achieving a particular learning process and outcome (an interactive goal pattern); and (c) whether the four achievement goals had specialized effects on different outcomes (a specialized goal pattern). 
Given strong support for the multiple goal perspective among Western students (see Harackiewicz et al., 2002, for review) and the potential multiple goal endorsement for Chinese students, the hypothesis was that Chinese students would pursue multiple goals in an additive goal pattern, an interactive goal pattern, or a specialized goal pattern to promote optimal motivation and achievement. Results from the regression analyses strongly supported this hypothesis (see Table 3).

For use of metacognitive strategies in college English classes, the combination of mastery approach and mastery avoidance goals yielded an additive goal pattern, in which Chinese students with higher levels of both mastery approach and mastery avoidance goals should report more and better use of metacognitive strategies. The combination of performance approach goals and performance avoidance goals generated a positive interaction effect, in which the negative effect of performance avoidance goals was weakened or even reversed with the increase of performance approach goals. Examination of the predicted values presented in Figure 1 indicated that students high in both performance approach and performance avoidance goals reported more use of metacognitive strategies, while those low in performance approach goals but high in performance avoidance goals reported less use of metacognitive strategies. In advanced mathematics classes, mastery approach and mastery avoidance goals worked together to produce a negative interaction effect, in which the positive effect of mastery approach goals was weakened with the increase of mastery avoidance goals. Examination of Figure 2 showed that high mastery avoidance and high mastery approach goal oriented students were engaged in more use of metacognitive strategies. 
For academic efficacy in college English classes, mastery approach goals and performance approach goals combined to yield an additive goal pattern, in which the high mastery approach/ high performance approach combination predicted higher levels of academic efficacy. Mastery approach goals and mastery avoidance goals combined to result in an interactive goal pattern, in which the positive effect of mastery approach goals was strengthened with the increase in mastery avoidance goals. Examination of the predicted values presented in Figure 3 revealed that students with higher levels of both mastery approach and mastery avoidance goals reported higher levels of academic efficacy. The combination of performance approach goals and performance avoidance goals produced a positive interaction effect, in which the negative effect of performance avoidance goals was weakened with the increase in performance approach goals. Examination of the predicted values presented in Figure 4 indicated that students with a combination of high performance approach and low performance avoidance goals reported higher levels of academic efficacy, while those with low performance approach but high performance avoidance goal combination reported lower levels of academic efficacy. In advanced mathematics classes, the combination of mastery approach goals and performance approach goals resulted in an additive goal pattern, in which higher levels of both goals led to higher levels of academic efficacy. Mastery approach goals and performance avoidance goals combined to yield a negative interaction effect, in which the positive effect of mastery approach goals tended to be weakened with the increase in performance avoidance goals. Examination of the predicted value presented in Figure 5 indicated that students with a high mastery approach/low performance 
avoidance combination had higher levels of academic efficacy, while those with a combination of low-mastery-approach/ high-performance-avoidance goal combination had lower levels of academic efficacy. The combination of mastery avoidance goals and performance approach goals yielded a positive interaction effect, in which the positive effect of mastery avoidance goals tended to be strengthened with the increase in performance approach goals. Examination of the predicted value presented in Figure 6 indicated higher levels of both goals led to higher levels of academic efficacy.

For affect at school in college English classes, mastery approach goals and mastery avoidance goals combined to generate an additive goal pattern, in which high levels of both goals were associated with positive affect. In advanced mathematics classes, no additive or interactive goal pattern could be identified that might promote optimal affect at school.

For academic performance in both classes, there appeared no facilitative additive or interactive goal pattern that might benefit academic performance.

By examining metacognitive strategies, academic efficacy, affect at school, and academic performance together as above, strong support was found for positive effects on different outcomes for different goals, which provided evidence for the specialized goal pattern. There was a positive main effect for mastery approach goals or mastery avoidance goals on metacognitive strategies, academic efficacy, and affect at school, and a positive main effect for performance approach goals on affect at school and academic performance. Mastery approach and performance approach goals independently promoted different learning processes and outcomes, as did mastery avoidance and 
performance approach goals. Students adopting either of the two combinations appear to be optimally motivated in this educational context.

Given the findings from the perspective of multiple goal theory, Chinese students with higher levels of both mastery approach and performance approach goals had the most adaptive profile when not only metacongitive strategies and affect at school but also academic efficacy and academic performance are of interest, followed by those high in mastery avoidance and performance approach goals. The combination of mastery approach and mastery avoidance goals was also more adaptive than a single goal pursuit; however, considering that emphasis on performance is culturally inherent in collectivistic values in $\mathrm{CHC}$ countries and that it is far from possible that academic performance is not of major concern for $\mathrm{CHC}$ Chinese students, this mastery goal combination is of less significance than the combination of two approach goals or that of mastery avoidance and performance approach goals.

To What Extent Do Chinese Students' Approaches to Learning Differentially Predict Their Learning Processes and Outcomes?

The sixth research question focused on determining the extent to which the adoption of the deep and surface approach was linked to a distinct set of motivational and cognitive processes and outcomes for Chinese students.

Given the evidenced (e.g., Vermetten, Lodewijks, \& Vermunt, 2001) or potential differential predictive utility of SAL for learning processes and outcomes and the applicability of the revised two-factor SAL framework to CHC students (Biggs, Kember, $\&$ Leung, 2001), the hypothesis was that the adoption of the deep and surface approaches 
would be linked to a distinct predictive profile for Chinese students. It was thought that the deep approach would predict positively use of metacognitive strategies, school wellbeing, and academic performance (when examination procedures demand understanding), whereas the surface approach would be negatively associated with these outcome variables. Results from the regression analyses strongly supported this hypothesis (see Table 4).

Table 4

The Prediction of SAL for Learning Processes and Outcomes

\begin{tabular}{|l|c|c|c|c|c|c|c|c|}
\hline \multirow{2}{*}{ Outcome } & \multicolumn{2}{|c|}{$\begin{array}{c}\text { Metacognitive } \\
\text { stategies }\end{array}$} & \multicolumn{2}{c|}{$\begin{array}{c}\text { Academic } \\
\text { efficacy }\end{array}$} & \multicolumn{2}{c|}{$\begin{array}{c}\text { Affect at } \\
\text { school }\end{array}$} & \multicolumn{2}{c|}{$\begin{array}{c}\text { Academic } \\
\text { performance }\end{array}$} \\
\cline { 2 - 9 } SAL & CE & AM & CE & AM & CE & AM & CE & AM \\
\hline Deep & Pos & Pos & Pos & Pos & Pos & Pos & Neg (Mar) & Pos \\
\hline Surface & Neg (Mar) & Neg & Neg & Neg & Neg & Neg & Neg & Neg \\
\hline
\end{tabular}

Note: Pos = positive main effect. Neg = Negative main effect. Mar = Marginally significant. $\mathrm{CE}=$ College English classes. $\mathrm{AM}=$ Advanced mathematics classes.

The deep approach had beneficial consequences for metacognitive strategies, academic efficacy, and affect at school whether in college English classes or in advanced mathematics classes. In contrast, the surface approach was found to be detrimental for academic efficacy, affect at school, and academic performance in both classes. It also proved inimical for use of metacognitive strategies in advanced mathematics classes, and marginally maladaptive for use of metacognitive strategies in college English classes.

The effect of the deep approach on academic performance in advanced mathematics classes was consistent with the expectation that it would benefit academic performance. In contrast, the adoption of the deep approach had a marginally debilitating effect on academic performance in college English classes in our study. As suggested by 
Diseth and Martinsen (2003), the missing relationship between the deep approach and academic performance might first be attributed to the nature of the curriculum. College English-Band 2, marked by a fixed curriculum, does not necessarily encourage exploration of learning materials that are not included in the curriculum. Moreover, given the prospect of College English test-Band 4 and the far-reaching influence of this test performance on students' career and life, the pressure to achieve in college English classes should be ubiquitous and obvious for Chinese university students, which may dampen students' interest in the subject matter. Finally, the examination procedure should be considered for further understanding of our findings. It is a practice that the college English test before Band 4 is designed separately by each university to measure how well students master the textbook-based course content. If the test demanded less understanding, it can be easily understood why the deep approach might not benefit academic performance in this context.

In addition, Kirby, Silvestri, Allingham, Parrila, and La Fave (2008) found that university students with dyslexia reported significantly greater use of a deep approach, but poor strategies. The suggestion that students' poor reading may make use of the deep approach impossible provides another potential consideration for this lack of relationship between the deep approach and academic performance in college English classes for Chinese university students: English limitations may be a barrier that prevents students from fully employing the deep approach.

To What Extent Do Chinese Students' Attitude Towards CHC Values and Their Achievement Goal Pursuit Interact to Impact Their Learning Processes and Outcomes? 
The seventh research question addressed the extent to which the $\mathrm{CHC}$ value construct and achievement goal endorsement combined to influence achievementrelevant processes and outcomes, such as use of metacognitive strategies, school wellbeing, and academic performance. Given the potential role of $\mathrm{CHC}$ values in promoting achievement goal-oriented learning processes and outcomes, it was hypothesized that $\mathrm{CHC}$ values and achievement goals would contribute to metacognitive strategy use, school well-being, and academic performance either in an additive or interactive pattern. Results from hierarchical-simultaneous regression analyses offered strong support for this hypothesis (see Table 5).

Table 5

The Way CHC Values Combine with Achievement Goals to Influence Leaning Processes and Outcomes

\begin{tabular}{|c|c|c|c|c|c|c|c|c|}
\hline \multirow[b]{2}{*}{$\begin{array}{l}\mathrm{CHC} \text { values } \\
\text { and } \\
\text { Goal Orientations }\end{array}$} & \multicolumn{2}{|c|}{$\begin{array}{c}\text { Meta- } \\
\text { cognitive } \\
\text { stategies }\end{array}$} & \multicolumn{2}{|c|}{$\begin{array}{l}\text { Academic } \\
\text { efficacy }\end{array}$} & \multicolumn{2}{|c|}{ Affect at school } & \multicolumn{2}{|c|}{$\begin{array}{c}\text { Academic } \\
\text { performance }\end{array}$} \\
\hline & $\mathrm{CE}$ & AM & $\mathrm{CE}$ & AM & $\mathrm{CE}$ & $\mathrm{AM}$ & $\mathrm{CE}$ & $\mathrm{AM}$ \\
\hline $\mathrm{CHC}$ values & * Pos & Pos & $\begin{array}{l}\text { Pos } \\
\text { * Pos }\end{array}$ & Pos & $\begin{array}{c}\text { Pos } \\
*^{\mathrm{Pos}}(\mathrm{Mar}) \\
\#^{\mathrm{Neg}}(\mathrm{Mar}) \\
\end{array}$ & Pos & & \\
\hline Mastery approach & Pos & Pos & Pos & Pos & $\begin{array}{c}\text { Pos } \\
\text { *Pos(Mar) }\end{array}$ & Pos & & \\
\hline Mastery avoidance & $\begin{array}{l}\text { Pos } \\
* \text { Pos }\end{array}$ & Pos & * Pos & & Pos (Mar) & & & \\
\hline Performance approach & & & Pos & Pos & & & Pos & Pos \\
\hline $\begin{array}{l}\text { Performance } \\
\text { avoidance }\end{array}$ & & & $\mathrm{Neg}$ & Neg & $\begin{array}{c}\text { Neg } \\
\text { \# }^{\mathrm{Neg}} \text { (Mar) }\end{array}$ & Neg & Neg & Neg \\
\hline
\end{tabular}


Note: Pos $=$ positive main effect. Neg $=$ Negative main effect. $*$ Pos or $\#^{\mathrm{Neg}}=$ positive or negative interactive effect between $\mathrm{CHC}$ values and the achievement goal each marked by the same superscript. Mar = Marginally significant. $\mathrm{CE}=$ College English classes. AM $=$ Advanced mathematics classes.

For use of metacognitive strategies in college English classes, mastery approach goals and mastery avoidance goals had an independent positive effect, with none of the others having a significant effect. Although it had no independent main effect, the CHC value construct combined with mastery avoidance goals to yield a positive interaction effect, in which the positive effect of mastery avoidance goals was strengthened with the increase in $\mathrm{CHC}$ values. Examination of the predicted values presented in Figure 7 indicated that higher levels of mastery avoidance goals and $\mathrm{CHC}$ values led to more reported use of metacognitive strategies. In advanced mathematics classes, CHC values, mastery approach goals, and mastery avoidance goals had an independent positive effect, and no others independently predicted use of metacognitive strategies. With no moderating effect on any goal effects, $\mathrm{CHC}$ values combined with the two goals in an additive pattern to promote use of metacognitive strategies.

For academic efficacy in college English classes, $\mathrm{CHC}$ values, mastery approach and performance approach goals had independent positive effects, while performance avoidance goals had a negative main effect and mastery avoidance goals no main effect. With no moderating effect on mastery approach, performance approach, and performance avoidance goals, $\mathrm{CHC}$ values combined in an additive pattern with one or both of the two approach goals to facilitate academic efficacy, but in the same pattern with performance avoidance goals to yield a debilitating effect. Besides its independent main effect, $\mathrm{CHC}$ values combined with mastery avoidance goals to yield an interaction effect, in which the 
positive effect of mastery avoidance goals tended to be weakened with the decrease of $\mathrm{CHC}$ values. Examination of predicted values in Figure 8 indicated that higher levels of both resulted in higher levels of academic efficacy. In advanced mathematics classes, mastery approach goals, performance approach, and $\mathrm{CHC}$ values each had an independent beneficial effect, while performance avoidance goals had a negative main effect, and mastery avoidance goals had no main effect. With no moderating effect on any goal effect, $\mathrm{CHC}$ values combined with the two approach goals in an additive pattern to facilitate academic efficacy.

For affect at school in college English classes, $\mathrm{CHC}$ values and mastery approach goals had an independent positive consequence, performance avoidance goals a negative main effect, mastery avoidance goals a marginally positive main effect, and performance approach goals no main effect. With no significant moderating effect on any achievement goal effect, $\mathrm{CHC}$ values combined with mastery approach goals in an additive pattern to promote positive affect. It is noteworthy, however, that the interaction between $\mathrm{CHC}$ values and mastery approach goals or performance avoidance goals was marginally significant, in which the positive effect of mastery approach goals or the negative effect of performance avoidance goals tended to be strengthened with the increase of $\mathrm{CHC}$ values. In advanced mathematics classes, $\mathrm{CHC}$ values and mastery approach goals had an independent positive effect, while performance avoidance goals had a negative main effect, and no others had any main effect. With no moderating effect on any achievement goal effect, $\mathrm{CHC}$ values combined with mastery approach goals in an additive pattern to benefit positive affect. 
For academic performance in college English classes, $\mathrm{CHC}$ values exerted no influence on the effect of achievement goals, either as a main effect or in an interaction. In both classes, performance approach goals had an independent positive effect while performance avoidance goals had an independent negative consequence.

In sum, in college English classes, CHC values combined with mastery approach goals, mastery avoidance goals, or performance approach goals either in an additive or interactive pattern to facilitate use of metacognitive strategies, positive affect at school, and perceived academic efficacy. In advanced mathematics classes, $\mathrm{CHC}$ values combined with mastery approach goals, mastery avoidance goals, or performance approach goals in an additive pattern to have a beneficial consequence for use of metacognitive strategies, positive affect at school, and perceived academic efficacy.

Salili et al. (2001), using dichotomous framework, examined the influence of the three socially oriented goals (family-, teacher-, and peer-oriented) on Hong Kong Chinese and Canadian Chinese students' academic achievement. Regressing test anxiety, self-efficacy, effort, mastery (learning) goals, performance goals, and family-, teacher-, and peer-oriented goals on academic achievement revealed that for Hong Kong Chinese performance goals and self-efficacy positively predicted students' achievement, while mastery goals, test anxiety, and strangely effort were negative predictors; for Canadian Chinese, self-efficacy, effort, and family-oriented goals positively predicted achievement, while test anxiety was a negative predictor. In concordance with our findings, $\mathrm{CHC}$ values were not demonstrated to exert any influence on Chinese students' academic achievement. Little research can be identified that has ever investigated how $\mathrm{CHC}$ values 
and achievement goals combine to contribute to metacognitive strategies, academic efficacy, affect at school, and academic performance within the $2 \times 2$ framework.

To What Extent Do Chinese Students' Attitude Towards CHC Values and their Adoption of Approaches to Learning Interact to Affect Their Learning Processes and Outcomes?

The eighth research question was concerned with determining the extent to which $\mathrm{CHC}$ values and SAL combined to influence the achievement-relevant processes and outcomes, such as use of metacognitive strategies, academic efficacy, affect at school, and academic performance. Given the potential influence of $\mathrm{CHC}$ values on the SAL affected learning processes and outcomes, the hypothesis was that $\mathrm{CHC}$ values would facilitate the effect of the deep approach to learning on these learning processes and outcomes either in an additive or interactive pattern. Results from the regression analyses strongly supported this hypothesis (see Table 6).

Table 6

The Way CHC Values Combine with SAL to Influence Leaning Processes and Outcomes

\begin{tabular}{|c|c|c|c|c|c|c|c|c|}
\hline \multirow{2}{*}{$\begin{array}{l}\text { Outcome } \\
\text { and SAL }\end{array}$} & \multicolumn{2}{|c|}{$\begin{array}{l}\text { Metacognitive } \\
\text { stategies }\end{array}$} & \multicolumn{2}{|c|}{$\begin{array}{l}\text { Academic } \\
\text { efficacy }\end{array}$} & \multicolumn{2}{|c|}{$\begin{array}{l}\text { Affect at } \\
\text { school }\end{array}$} & \multicolumn{2}{|c|}{$\begin{array}{c}\text { Academic } \\
\text { performance }\end{array}$} \\
\hline & $\mathrm{CE}$ & $\mathrm{AM}$ & $\mathrm{CE}$ & AM & $\mathrm{CE}$ & $\mathrm{AM}$ & $\mathrm{CE}$ & $\mathrm{AM}$ \\
\hline $\mathrm{CHC}$ values & $\begin{array}{l}\text { Pos } \\
* \text { Pos }\end{array}$ & Pos & Pos & Pos & $\begin{array}{l}\text { Pos } \\
* \text { Pos }\end{array}$ & Pos & Pos & \\
\hline Deep approach & $\begin{array}{l}\text { Pos } \\
* \text { Pos }\end{array}$ & Pos & Pos & Pos & $\begin{array}{l}\text { Pos } \\
* \text { Pos }\end{array}$ & Pos & Neg & Pos \\
\hline Surface approach & $\begin{array}{l}\text { Neg } \\
\text { (Mar) }\end{array}$ & Neg & Neg & Neg & Neg & Neg & Neg & Neg \\
\hline
\end{tabular}

Note: Pos $=$ positive main effect. $\mathrm{Neg}=$ Negative main effect. ${ }^{*}$ Pos $=$ positive interactive effect between $\mathrm{CHC}$ values and SAL each marked by the same superscript. Mar = Marginally significant. $\mathrm{CE}=$ College English classes. $\mathrm{AM}=$ Advanced mathematics classes. 
For use of metacognitive strategies in advanced mathematics classes, academic efficacy in both classes, and affect at school in advanced mathematics classes, both CHC values and the deep approach had independent positive effects, while the surface approach had an independent negative effect. With no moderating effect on the deep approach effect, $\mathrm{CHC}$ values combined with the deep and surface approach in an additive pattern to facilitate these motivational processes and outcomes. With regard to use of metacognitive strategies and affect at school in college English classes, CHC values and the deep approach had independent positive effects and an interactive positive effect, while the surface approach had a marginally negative or negative effect. $\mathrm{CHC}$ values and the deep approach worked together in an interactive pattern to facilitate use of metacognitive strategies and positive affect in college English classes, in which the positive effect of the deep approach to learning tended to be strengthened with the increase of $\mathrm{CHC}$ values.

In disagreement with the expectation that the deep approach would benefit academic performance, the adoption of the deep approach in college English classes impaired academic performance. This might be attributed to the examination procedure, the nature of curriculum, and the pressure to achieve (Diseth, 2003; Diseth \& Martinsen, 2003). Furthermore, as discussed above, Kirby et al.(2008) found that university students with dyslexia reported significantly greater use of a deep approach, but poor strategies, which suggests that students' level of ability in English may be a barrier that prevent students from employing the deep approach.

\section{Research Implications}


Implications for Educational Research on CHC Students

Results from descriptive statistics, correlation analyses, exploratory factor analyses, and regression analyses addressed the role of CHC values in Chinese students' achievement-relevant processes and outcomes. Data were supportive of the reliability, validity, and prevalence of these cultural value constructs among Chinese students, and validated the unitary $\mathrm{CHC}$ values construct composed of a sense of effort, utility value, family-oriented goals, and teacher-oriented goals.

The CHC values have been well researched in prior studies with intent to reveal cultural keys to success in East Asian countries within the SAL theoretical framework (Watkins \& Biggs, 1999). These cultural notions provide a broad setting for the construction of achievement-context schemas, as perceived classroom or school environment does at a specific level (Kaplan \& Maehr, 2007). The latter has been shown to influence achievement goal adoption, which, in turn, directly influences graded performance and intrinsic motivation (e.g., Church, Elliot, \& Gable, 2001). The empirical work on the relationship of culture to achievement goal framework, however, is meager. This line of theory and research on the influence of achievement context on achievement goal framework and SAL framework at different levels is not only of theoretical interest but has practical importance. For example, as Miller et al. (1999) pointed out, motivational interventions, which neglect any attempt to make utility value salient (i.e., by making students perceive current academic activities as instrumental to attaining personally relevant future goals), may fail to enhance motivation and achievement in a particular achievement setting. 


\section{Implications for Achievement Goal Theory and SAL Theory Research}

These findings add to a growing body of empirical work attesting to the conceptual and predictive utility of the $2 \times 2$ framework and the SAL framework for Chinese students. Results from descriptive statistics, correlation analyses, exploratory factor analyses, and regression analyses attest to the applicability of the $2 \times 2$ achievement goal and the revised two-factor SAL frameworks to Chinese students, demonstrating specifically their utility for predicting Chinese students' use of metacognitive strategies, perceived academic efficacy, affect at school, and academic performance. Examination of zero-order correlations and results from these two frameworks reveals a similarity in the motivational pattern between the surface approach and a hybrid of performance avoidance and performance approach goals and between the deep approach and a hybrid of mastery approach, mastery avoidance, and performance approach goals.

Normative goal theory highlights the adaptive nature of mastery (approach) goal pursuit compared to performance goal pursuit and advocates the active shaping of environments to promote adoption of mastery (approach) goals (e.g., Ames, 1992; Dweck $\&$ Leggett, 1988). The results from our study support the generalization from normative goal theory that a mastery (approach) goal orientation is the most adaptive, but in the meanwhile the primary findings are consistent with the revised multiple goals theory perspective advocated by Harackiewicz (1998), in which mastery goals and performance approach goals work together to promote optimal motivation and achievement in an additive, interactive, or specialized pattern (Barron \& Harackiewicz, 2001). Within the 2 
x 2 achievement goal framework, the predictive pattern for each of the goals was generally in line with prior research conducted with Western students, except that the motivation profile associated with the mastery avoidance goal appeared more adaptive for Chinese students. The high-mastery-approach/ high-performance-approach combination proved most beneficial and adaptive in terms of metacognitive strategies, academic efficacy, affect at school, and academic performance as a whole, followed by the pattern for the high-mastery-avoidance/ high-performance-approach combination or the high-mastery-approach/ high-mastery-avoidance combination. From this perspective, students should be encouraged to adopt a mastery approach goal orientation and the classroom should be structured to facilitate and foster a general mastery approach orientation; on the other hand, successful negotiation of many achievement settings marked by competition and social comparison entails the simultaneous adoption of performance approach goals, which promises optimal motivation and achievement for students.

Within the revised two-factor SAL framework, the deep approach predicted positively all the learning processes and outcomes in the study except academic performance in college English classes, whereas the surface approach was negatively associated with all of these learning processes and outcomes except use of metacognitive strategies in college English classes. The findings, consistent with prior research conducted with Western students, support interventions that may facilitate students' adoption of the deep approach. 
Considered from culture and context, $\mathrm{CHC}$ values and achievement goals or SAL combined either in an additive or interactive pattern to facilitate use of metacognitive strategies, academic efficacy, and positive affect. The facilitating role of $\mathrm{CHC}$ values in academic settings for Chinese students encourages attempts to highlight the importance of $\mathrm{CHC}$ values in family or school in the face of the current growing globalization trend.

\section{Limitations and Avenues for Future Research}

Although these results are intriguing and add to our understanding of goal theory and SAL theory in academic settings, a number of limitations need to be addressed in future research, three of which are discussed briefly here.

First, the data were drawn from Chinese first-year university students in college English classes and advanced mathematics classes. These students may have already developed an array of self-regulatory strategies for achieving their academic goals, a pattern that may not be found with younger students who are more diverse in terms of achievement levels, knowledge, value development, and skills. Studies with younger students would address this limitation.

Second, we treated $\mathrm{CHC}$ values as a unitary construct when examining the impact of cultural values on the association between each of the achievement goal framework and SAL framework and achievement-relevant processes and outcomes. This fails to reveal the relative strength of the four components (a sense of learning duty, utility value, family-oriented goals, and teacher-oriented goals) in facilitating these learning processes and outcomes. While the current data suggest the four are closely related, subtle 
differences in the strengths and roles of their contributions could be addressed in future studies.

Third, Harackiewicz et al. (1998) have identified individual differences in need for achievement as an important moderator variable. This personality variable has proven to alter the effect of goal manipulation; mastery goals were more effective in enhancing intrinsic motivation for individuals low in the need for achievement, but performance approach goals enhanced interest for highly achievement-oriented individuals. More attention to moderators like this may introduce a clear insight and comprehensive understanding of students' motivation and achievement in future studies.

In conclusion, the combination of $\mathrm{CHC}$ values and theoretical frameworks shows promise for enhancing our understanding of Chinese learners whose schooling takes place in a cultural context quite different from that of the Western students whose data are typically reported in studies of motivation and learning. 


\section{REFERENCES}

Aiken, L. S., \& West, S. G. (1991). Multiple regression: Testing and interpreting interactions. Newbury Park, CA: Sage.

Ames, C. (1992). Classrooms: Goals, structures, and student motivation. Journal of Educational Psychology, 84, 261-271.

Ames, C., \& Archer, J. (1988). Achievement goals in the classroom: Students' learning strategies and motivational processes. Journal of Educational Psychology, 80, 260-267.

Anderman, E., \& Midgley, E. (1997). Changes in achievement goal orientations, perceived academic competence, and grades across the transition to middle-level schools. Contemporary Educational Psychology, 22, 269-298.

Barron, K. E., \& Harackiewicz, J. M. (2001). Achievement goals and optimal motivation: Testing multiple goal models. Journal of Personality and Social Psychology, 80, 706-722.

Biggs, J. B. (1978). Individual and group differences in study processes. British Journal of Educational Psychology, 48, 274-284.

Biggs, J. B. (1987). Student approaches to learning and studying. Melbourne: Australian Council for Educational Research.

Biggs, J. B. (1993). What do inventories of students' learning process really measure? A theoretical review and clarification. British Journal of Educational Psychology, 63, 3-19. 
Biggs, J. B., Kember, D., \& Leung, D. Y. P. (2001). The revised two-factor study process questionnaire: R-SPQ-2F. British Journal of Educational Psychology, 71, 133149.

Biggs, J.B., \& Kirby, J. (1984). Differentiation of learning processes within ability groups. Educational Psychology, 4, 21-39.

Bouffard, T., Boisvert, J., Vezeau, C., \& Larouche, C. (1995). The impact of goal orientation on self-regulation and performance among college students. British Journal of Educational Psychology, 65, 317-329.

Brickman, S. J., and Miller, R. B. (1998, March). Valuing of future goals and instrumentality as predictors of cognitive engagement. Paper presented at the 6thWorkshop on Achievement and Task Motivation, International Conference on Motivation, Thessaloniki, Greece.

Cacioppo, J. T., \& Petty, R. E. (1982). The need for cognition. Journal of Personality and Social Psychology, 42, 116-131.

Cantwell, R. H., \& Moore, P. J. (1996). The development of measures of individual differences in self-regulatory control and their relationship to academic performance. Contemporary Educational Psychology, 21, 500-517.

Church, M. A., Elliot, A. J., \& Gable, S. L. (2001). Perceptions of classroom environment, achievement goals, and achievement outcomes. Journal of Educational Psychology, 93, 43-54.

Confucius. (1979). The analects (D. C. Lau, Trans.). New York: Penguin Books. (Original work published 479 B.C.) 
Covington, M. V. (1984). The motive for self worth. In R. Ames \& C. Ames (Eds.), Research on motivation in education: Student motivation (Vol. 1, pp. 77-113). San Diego, CA: Academic Press.

Cury, E., Elliot, A. J., Da Fonseca, D., \& Moller, A. C. (2006). The social-cognitive model of achievement motivation and the $2 \times 2$ achievement goal framework. Journal of Personality and Social Psychology, 90, 666-679.

DeBacker,T., and Nelson, R. M. (1999).Variations on an expectancy-value model of motivation in science. Contemporary Educational Psychology, 24, 71-94.

DeVolder, M. L., and Lens, W. (1982). Academic achievement and future time perspective as a cognitive-motivational concept. Journal of Personality and Social Psychology, 42, 566-571.

Diseth, A. (2002). The relationship between intelligence, approaches to learning, and academic achievement. Scandinavian Journal of Educational Research, 46, 219230.

Diseth, A. (2003). Personality and approaches to learning as predictors of academic achievement. European Journal of Personality, 17, 143-155.

Diseth, A., \& Martinsen, O. (2003). Approaches to learning, cognitive style, and motives as predictors of academic achievement. Educational Psychology, 23, 195-207.

Dweck, C. S., \& Leggett, E. L. (1988). A socio-cognitive approach to motivation and personality. Psychological Review, 95, 256-273.

Elliot, A. J. (1999). Approach and avoidance motivation and achievement goals. Educational Psychologist, 34, 169-189. 
Elliot, A. J., Chirkov, V. I., Kim, Y., \& Sheldon, K. M. (2001). A Cross-cultural analysis of avoidance (relative to approach) personal goals. Psychological Science, 12, $505-510$.

Elliot, A., \& Church, M. (1997). A hierarchical model of approach and avoidance achievement motivation. Journal of Personality and Social Psychology, 72, 218232.

Elliot, A. J.,\& Harackiewicz, J. M. (1996). Approach and avoidance achievement goals and intrinsic motivation: A mediational analysis. Journal of Personality \& Social Psychology, 70, 461-475.

Elliot, A., \& McGregor, H. (2001). A 2 x 2 achievement goal framework. Journal of Personality and Social Psychology, 80, 501-519.

Elliot, A. J., McGregor, H. A., \& Gable, S. (1999). Achievement goals, study strategies, and exam performance: A mediational analysis. Journal of Educational Psychology, 3, 549-563.

Elliot, A. J., Shell, M. M., Henry, K. B., Maier, M. A. (2005). Achievement goals, performance contingencies, and performance attainment: An experimental test. Journal of Educational Psychology, 97, 630-640.

Elliot, A. J., \& Thrash, T. M. (2001). Achievement goals and the hierarchical model of achievement motivation. Educational Psychology Review, 13, 139-156.

Entwistle, N.J., \& Ramsden, P. (1983). Understanding student learning. London: Croom Helm. 
Entwistle, N.J., \& Waterston, S. (1988). Approaches to studying and levels of processing in university students. British Journal of Educational Psychology, 58, 258-265.

Evans, C. J., Kirby, J. R., Fabrigar, L. R. (2003). Approaches to learning, need for cognition, and strategic flexibility among university students. British Journal of Educational Psychology, 73, 507-528.

Fabrigar, L. R., Wegener, D. T., MacCallum, R. C., \& Strahan, E. J. (1999). Evaluating the use of exploratory factor analysis in psychological research. Psychological Methods, 4, 272-299.

Fink, S. (2002). How to manage, analyze, and interpret survey data. Thousand Oaks, CA: Sage Publications.

Grant, H., \& Dweck, C. S. (2003). Clarifying achievement goals and their impact. Journal of Personality and Social Psychology, 85, 541-553.

Gray, G., \& Guppy, N. (1999). Successful surveys, research methods and practice ( $2^{\text {nd }}$ Ed.). Toronto, ON: Harcourt Brace \& Company.

Greene, B., DeBacker, T., Ravindran, B., and Krows, A. J. (1999). Goals, values, and beliefs as predictors of achievement and effort in high school mathematics classes. Sex Roles, 40, 421-458.

Harackiewicz, J. M., Barron, K. E., Carter, S. M., Lehto, A. T., Elliot, A. (1997). Predictors and consequences of achievement goals in the college classroom: Maintaining interests and making the grade. Journal of Personality and Social Psychology, 73, 1284-1295. 
Harackiewicz, J. M, Barron, K. E., \& Elliot, A. J. (1998). Rethinking achievement goals: When are they adaptive for college students and why? Educational Psychologist, $33(1), 1-21$.

Harackiewicz, J. M, Barron, K. E., Pintrich, P. R., Elliot, A. J., \& Thrash, T. M. (2002). Revision of achievement goal theory: Necessary and illuminating. Journal of Educational Psychology, 94, 638-645.

Harackiewicz, J. M., Barron, K. E., Tauer, J. M., Carter, S. M., \& Elliot, A. J. (2000). Short-term and long-term consequences of achievement goals in college: Predicting continued interest and performance over time. Journal of Educational Psychology, 92, 316-330.

Harackiewicz, J. M., Barron, K. E., Tauer, J. M., \& Elliot, A. J. (2002). Predicting success in college: A longitudinal study of achievement goals and ability measures as predictors of interest and performance from freshman year through graduation. Journal of Educational Psychology, 94, 562- 575.

Hau, K. T., \& Salili, F. (1991). Structure and semantic differential placement of specific causes: Academic causal attributions by Chinese students in Hong Kong. International Journal of Psychology, 26, 175-193.

Heine, S. J., Kitayama, S., Lehman, D. R., Takata, T., Ide, E., Leung, C., \& Matsumoto, M. (2001). Divergent consequences of success and failure in Japan and North America: An investigation of self-improving motivation and malleable selves. Journal of Personality and Social Psychology, 81, 599-615. 
Hess, R. D., Chih-Mei, C., \& McDevitt, T. M. (1987). Cultural variations in family beliefs about children's performance in mathematics: Comparisons among Peoples's Republic of China, Chinese-American, and Caucasian-American families. Journal of Educational Psychology, 79, 179-188.

Ho, I. T. (2001). Are Chinese teachers authoritarian? In D. A. Watkins \& J. B. Biggs (Eds.), Teaching the Chinese learner: Psychological and pedagogical perspectives (pp. 99-114). Hong Kong: Centre for Comparative Research in Education/Camberwell, Victoria: Australian Council for Educational Research.

Hong, Y. Y. (2001). Chinese students' and teachers' inferences of effort and ability. In F. Salili, C. Y. Chiu, \& Y. Y. Hong (Eds.), Student motivation: The culture and context of learning (pp. 105-120). New York: Kluwer Academic/Plenum Publishers.

Kirby, J. R., Silvestri, R., Allingham, B., Parrila, R. \& La Fave, C. B. (2008). Learning strategies and study approaches of college and university students with dyslexia. Journal of Learning Disabilities, 41, 85-96.

Kaplan, A., \& Maehr, M. (1999). Achievement goals and student well-being. Contemporary Educational Psychology, 24, 330-358.

Kaplan, A., \& Maehr, M. L. (2007). The contributions and prospects of goal orientation theory. Educational Psychology Review, 19, 141-184.

Kaplan, A., \& Midgley, C. (1997). The effect of achievement goals: Does level of perceived academic competence make a difference? Contemporary Educational Psychology, 22, 415-435. 
Kember, D., \& Gow, L. (1990). Cultural specificity of approaches to study. British Journal of Educational Psychology, 60, 356-363.

Kember, D., \& Leung, D.Y.P. (1998). The dimensionality of approaches to learning: An investigation with confirmatory factor analysis on the structure of the SPQ and LPQ. British Journal of Educational Psychology, 68, 395-407.

Lee, W. O. (1999). The cultural context for Chinese learners: Conceptions of learning in the Confucian tradition. In D. A. Watkins \& J. B. Biggs (Eds.), The Chinese learner: Cultural, psychological, and contextual influences (pp. 25-42). Hong Kong: Comparative Education Research Centre.

Marton, F., \& Säljö, R. (1976a). On qualitative differences in learning - I: Outcome and process. British Journal of Educational Psychology, 46, 4-11.

Marton, F., \& Säljö, R. (1976b). On qualitative differences in learning - II: Outcome as a function of the learner's conception of the task. British Journal of Educational Psychology, 46, 115-127.

Meece, J. L., Blumenfeld, P. C., \& Hoyle, R. H. (1988). Students' goal orientations and cognitive engagement in classroom activities. Journal of Educational Psychology, 80, 514- 523.

Meece, J. L., \& Holt, K. (1993). Variations in students' achievement goal patterns. Journal of Educational Psychology, 85, 582-590.

Middleton, M., \& Midgley, C. (1997). Avoiding the demonstration of lack of ability: An underexplored aspect of goal theory. Journal of Educational Psychology, 89, $710-718$. 
Midgley, C., Kaplan, A., \& Middleton, M. (2001). Performance-approach goals: Good for what, for whom, under what circumstances, and at what cost? Journal of Educational Psychology, 93, 77-86.

Midgley, C., Maehr, M. L., \& Urdan, T. (1993). Patterns of adaptive learning survey (PALS). Ann Arbor, MI: University of Michigan.

Miller, R. B., \& Brickman, S. J. (2004). A model of future-oriented motivation and selfregulation. Educational Psychology Review, 16, 9-33.

Miller, R., DeBacker, T., \& Greene, B. (1999). Perceived instrumentality and academics: The link to task valuing. Journal of Instructional Psychology, 26, 250-260.

Miller, R., Greene, B., Montalvo, G., Ravindran, B., \& Nichols, J. (1996). Engagement in academic work: The role of learning goals, future consequences, pleasing others, and perceived ability. Contemporary Educational Psychology, 21, 388-422.

Newble, D., \& Hejka, E.J. (1991). Approaches to learning of medical students and practicing physicians: Some empirical evidence and its implications for medical education. Educational Psychology, 11, 333-342.

Nunnally, J. (1967). Psychometric theory. New York: McGraw-Hill.

Pintrich, P. R. (2000). Multiple goals, multiple pathways: The role of goal orientation in learning and achievement. Journal of Educational Psychology, 92, 544-555.

Pintrich, P. R. (2003). A motivational science perspective on the role of student motivation in learning and teaching contexts. Journal of Educational Psychology, 95, 667-686. 
Pintrich, P. R., \& Garcia, T. (1991). Student goal orientation and self-regulation in the college classroom. In M. L. Maehr \& P. R. Pintrich (Eds.), Advances in motivation and achievement (pp. 371-402). Greenwich, Connecticut: JAI.

Pintrich, P. R., \& Schunk, D. H. (2002). Motivation in education: Theory, research, and application (2nd ed.). Upper Saddle River, NJ: Merill/Prentice Hall.

Rawsthorne, L., \& Elliot, A. J. (1999). Achievement goals and intrinsic motivation: A Meta-analytic review. Personality and Social Psychology Review, 3, 326-344.

Raynor, J. O. (1970). Relationship between achievement-related motives, future orientation, and academic performance. Journal of Personality and Social Psychology, 15, 28-33.

Roeser, R. W., Midgley, C., \& Urdan, T. C. (1996). Perceptions of the school psychological environment and early adolescents' psychological and behavioral functioning in school: The mediating role of goals and belonging. Journal of Educational Psychology, 88, 408-422.

Ryan, A., \& Pintrinch, P. R. (1997). Should I ask for help? The role of motivation and attitude in adults' help seeking in math class. Journal of Educational Psychology, $89,329-341$.

Ryan, A., Pintrinch, P. R., \& Midgley, C. (2001). Avoiding seeking help in the classroom: Who and why? Educational Psychology Reviews, 13, 93-114.

Salant, P., \& Dillman, D. (1994). How to conduct your own survey. New York: John Wiley \& Sons, Inc. 
Salili, F. (1995). Explaining Chinese motivation and achievement. In M. L. Maehr \& P. R. Pintrich (Eds.), Advances in motivation and achievement: Culture, motivation, and achievement (pp. 73-118). Greenwich, CT: JAI.

Salili, F. (1999). Accepting personal responsibility for learning. In D. A. Watkins \& J. B. Biggs (Eds.), The Chinese learner: Cultural, psychological, and contextual influences (pp. 85-105). Hong Kong/ Melbourne: Comparative Education Research Centre, The University of Hong Kong/ Australian Council for Educational Research.

Salili, F., Chiu, C., Lai, S. (2001). The influence of culture and context on students' motivational orientation and performance. In F. Salili, C. Y. Chiu, \& Y. Y. Hong (Eds.), Student motivation: The culture and context of learning (pp. 221-247). New York: Kluwer Academic/Plenum Publishers.

Schoenfeld, A. H. (1987). What's all the fuss about metacognition? In A. H. Schoenfeld (Ed.), Cognitive science and mathematics education (pp. 189-215). Hillsdale, NJ: Lawrence Erlbaum.

Schutz, P. A. (1997). Educational goals, strategies use and the academic performance of high school students. High School Journal, 80, 193-201.

Schutz, P. A., and Lanehart, S. L. (1994). Long-term educational goals, subgoals, learning strategies use and the academic performance of college students. Learning and Individual Differences, 6, 399-412.

Shi, K., Wang, P., Wang, W., Zuo, Y., Liu, D., Maehr, M. L., Mu, X., Linnenbrink, L., \& Hruda, L. (2001). Goals and motivation of Chinese students: Testing the 
adaptive learning model. In F. Salili, C. Y. Chiu, \& Y. Y. Hong (Eds.), Student motivation: The culture and context of learning (pp. 249-270). New York:

Kluwer Academic/Plenum Publishers.

Skaalvik, E. M. (1997). Self-enhancing and self-defeating ego orientation: Relations with task and avoidance orientation, achievement, self-perceptions, and anxiety. Journal of Educational Psychology, 89, 71-81.

Steinberg, L., Dornbusch, S. M., and Brown, B. B. (1992). Ethnic differences in adolescent achievement: An ecological perspective. American Psychologist, 47, $723-729$.

Stevenson, H. W., Lee, S. Y., Chen, C., Stigler, J. W., Hsu, C., \& Kitamura, S. (1990). Context of achievement: A study of American, Chinese, and Japanese children. Monograph of the Society for Research in Child Development, 55 (1-2, Serial No. 221).

Tabachnick, B. G., \& Fidell, L. S. (2007). Using multivariate statistics. Boston, MA: Pearson/Allyn \& Bacon.

Tweed, R. G., \& Lehman, D. R. (2002). Learning considered within a cultural context. American Psychologist, 57(2), 89-99.

Vermetten, Y. J., Lodewijks, H. G., \& Vermunt, J. D. (2001). The role of personality traits and goal orientations in strategy use. Contemporary Educational Psychology, 26, 149-170.

Waternaux, C. (1976). Asymptotic distribution of the sample roots for a non-normal Population. Biometrika, 63 (3), 639-645. 
Watkins, D. A., \& Biggs, J. B. (2001). The paradox of the Chinese learner and beyond. In D. A. Watkins \& J. B. Biggs (Eds.), Teaching the Chinese learner: Psychological and pedagogical perspectives (pp. 3-23). Hong Kong: Centre for Comparative Research in Education/Camberwell, Victoria: Australian Council for Educational Research.

Watkins, D. A. (1999). Learning theories and approaches to research: A cross-cultural perspective. In D. A. Watkins \& J. B. Biggs (Eds.), The Chinese Learners: Cultural, Psychological, and Contextuazl Influences (pp. 3-24). Hong Kong: Comparative Education Research Centre /Camberwell, Victoria: Australian Council for Educational Research.

Weiner, B. (1979). A theory of motivation for some classroom experiences. Journal of Educational Psychology, 71, 3-25.

Winne, P. H. (1995). Inherent details in self-regulated learning. Educational Psychologist, $30,173-187$.

Wolters, C. A. (2004). Advancing achievement goal theory: Using goal structures and goal orientations to predict students' motivation, cognition, and achievement. Journal of Educational Psychology, 96, 236-250.

Wolters, C. A., Yu, S. L., \& Pintrich, P. R. (1996). The relation between goal orientation and students' motivational beliefs and self-regulated learning. Learning and Individual Differences, 8, 211-238. 
Woodrow, L., \& Chapman, E. (2002). Assessing the motivational goal orientations of international English for academic purposes (EAP) students. Current Research in Social Psychology, 7, 1-15.

Yong, M. R. (2005). The motivation effects of the classroom environment in facilitating self-regulated learning. Journal of Marketing Education, 27(1), 25-40. 


\section{APPENDIX A}

\section{Table A1}

Primary and Secondary Factor Loadings for Cultural Value Items (ordered by size of loadings in which variables contribute to factors) and Intercorrelations among Factors

\begin{tabular}{|c|c|c|c|c|c|c|}
\hline \multirow[b]{2}{*}{ CV items and factors } & \multicolumn{5}{|c|}{ Factor } & \multirow[b]{2}{*}{$h^{2}$} \\
\hline & $\begin{array}{c}1 \\
\text { Teacher- } \\
\text { oriented } \\
\text { goal }\end{array}$ & $\begin{array}{c}2 \\
\text { Peer- } \\
\text { oriented } \\
\text { goal }\end{array}$ & $\begin{array}{c}3 \\
\text { Family- } \\
\text { oriented } \\
\text { goal }\end{array}$ & $\begin{array}{c}4 \\
\text { Utility } \\
\text { value }\end{array}$ & $\begin{array}{c}5 \\
\text { Sense of } \\
\text { learning } \\
\text { duty }\end{array}$ & \\
\hline $\begin{array}{l}\text { 22. I want to live up } \\
\text { to my teacher's } \\
\text { expectation in my } \\
\text { school work. }\end{array}$ & [.835] & .046 & .008 & -.009 & -.011 & .686 \\
\hline $\begin{array}{l}\text { 9. I want to make the } \\
\text { teacher feel happy } \\
\text { about my school } \\
\text { work. }\end{array}$ & {$[.831]$} & -.042 & -.018 & -.017 & .017 & .705 \\
\hline $\begin{array}{l}\text { 12. I want to make my } \\
\text { teacher satisfied with } \\
\text { my school work. }\end{array}$ & {$[.810]$} & -.019 & .009 & .019 & -.004 & .653 \\
\hline $\begin{array}{l}25 . \text { I don't want to let } \\
\text { down my teacher in } \\
\text { my school } \\
\text { performance. }\end{array}$ & {$[.718]$} & .026 & -.004 & .037 & .048 & .576 \\
\hline $\begin{array}{l}\text { 6. I want to please my } \\
\text { teacher by doing my } \\
\text { school work. }\end{array}$ & {$[.716]$} & -.005 & -.178 & .011 & -.076 & .637 \\
\hline $\begin{array}{l}\text { 14. I don't want to } \\
\text { excel too much for } \\
\text { fear of losing friends. }\end{array}$ & -.003 & {$[.712]$} & .032 & .052 & .033 & .505 \\
\hline $\begin{array}{l}\text { 3. I do not want to } \\
\text { stand out in my } \\
\text { school work in a way } \\
\text { that would make my }\end{array}$ & -.042 & {$[.618]$} & -.024 & -.037 & -.041 & .388 \\
\hline
\end{tabular}


friends feel we are not the same.

23. Sometimes I'd like to let my school work slip to be accepted by my $\left.\begin{array}{llllll}-.033 & {[.511}\end{array}\right] \quad \begin{array}{llllll}.007 & .102 & -.142 & .281\end{array}$ friends.

18. I'm willing to hide my strengths in order to get accepted by my friends.

$\left.\begin{array}{llllll}.005 & {[.491}\end{array}\right] \quad-.081 \quad 021 \quad .029 \quad .250$

11. I don't want my

friends to feel any

difference between us.

$\left.\begin{array}{lllllll}.090 & {[.367}\end{array}\right] \quad \begin{array}{llllll}.047 & -.079 & .164 & .173\end{array}$

5. I want my family to be proud of me for my school work.

$\begin{array}{lllllll}.000 & -.046 & {\left[\begin{array}{llll}-.874\end{array}\right]} & -.077 & .048 & .759\end{array}$

17. I'd like my parents to be proud of me for my school work.

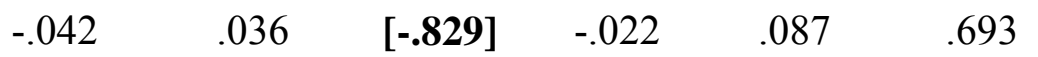

21. I want to bring credit to my family in my school work.

$\begin{array}{llllll}.090 & .006 & {\left[\begin{array}{llll}-.828\end{array}\right]} & .027 & -.068 & .750\end{array}$

1. I want to make my family regard me as a source of their pride and honour for my $\left.\begin{array}{llllll}.016 & 016 & {[-.772}\end{array}\right] \quad-.048 \quad .034 \quad 606$ school work.

19. I want to bring honour to my family in my school work.

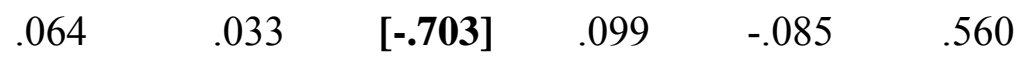

20. I believe that learning the material .054 .039 $.014 \quad[.919] \quad-.058$ .828 
important for

attaining my dreams.

13. I believe that understanding the content taught at school is important .028 .099 for becoming the person I want to be.

16. I believe that learning the content taught at school plays a role in reaching my future goals.

7. I believe that my conscience is clear when working hard.

10. I believe that making efforts to do well gives me a feeling that I am .154

doing the right thing.

15. I believe that regardless of results, studying long hours makes me feel less $\begin{array}{lllllll}-.086 & 056 & -.106 & .022 & \text { [.593 } & .069\end{array}$ guilty.

24. I believe that I will feel guilty if I don't study hard.

8. I believe that my achievement in school work plays a role in reaching my future .03 $\begin{array}{llll}-.126 & -.092 & .095 & .312\end{array}$ goals.

4. I believe that it's a .180 $-.067$ $-.053$ .168 .299 .293 
student's duty to work

hard.

2. I believe that my achievement in school work will be important for $\begin{array}{lllllll}.035 & -.046 & -.049 & .134 & .142 & .078\end{array}$ attaining my dream.

\begin{tabular}{|c|c|c|c|c|c|c|}
\hline Factor & \begin{tabular}{l}
\multicolumn{1}{c}{1} \\
Teacher- \\
oriented \\
goal \\
\multicolumn{1}{c}{2} \\
Peer- \\
oriented \\
goal \\
$\quad 3$ \\
Family- \\
oriented \\
goal \\
$\quad 4$ \\
Utility \\
value \\
$\quad 5$ \\
Sense of \\
learning \\
duty
\end{tabular} & - & .097 & $\begin{array}{r}-.548 \\
.005\end{array}$ & $\begin{array}{l}-.046 \\
-.318 \\
-\end{array}$ & $\begin{array}{l}-.041 \\
-.348 \\
.403 \\
-\end{array}$ \\
\hline
\end{tabular}

Note: $\mathrm{N}=714$. Primary factor loadings are in bold and brackets. $\mathrm{CV}=$ Cultural values. $h^{2}$ $=$ Communality. 


\section{Table A2}

Internal Consistency Reliability Coefficient of Cultural Value Scales (Ordered by size of loadings in which variables contribute to factors)

\begin{tabular}{llc}
\hline \multicolumn{1}{c}{ CV scale } & \multicolumn{1}{c}{ Scale items } & Cronbach's $\alpha$ \\
\hline Teacher-oriented goals & Item 22, 9, 12, 25,6 & .900 \\
Peer-oriented goals & Item 14, 3, 23, 18,11 & .665 \\
Family-oriented goals & Item 5, 17, 21, 1, 19 & .907 \\
Utility value & Item 20, 13, 16 & .689 \\
Sense of learning duty & Item 7, 10, 15, 24 & .718 \\
\hline
\end{tabular}

Note: $\mathrm{N}=714$. $\mathrm{CV}=$ Cultural values. 


\section{Table A3}

Zero-Order Correlations among the Cultural ValueVariables

\begin{tabular}{|l|c|c|c|c|c|}
\hline $\begin{array}{l}\text { Cultural } \\
\text { value } \\
\text { measures }\end{array}$ & 1 & 2 & 3 & 4 & 5 \\
\hline $\begin{array}{c}1 . \text { Teacher- } \\
\text { oriented }\end{array}$ & - & $.547^{* *}$ & $.098^{* *}$ & $.334^{* *}$ & $.429^{* *}$ \\
\hline $\begin{array}{c}2 . \text { Family- } \\
\text { oriented }\end{array}$ & - & .027 & $.302^{* *}$ & $.354^{* *}$ \\
\hline $\begin{array}{c}3 . \text { Peer- } \\
\text { oriented }\end{array}$ & & - & .015 & .029 \\
\hline $\begin{array}{c}\text { 4. Utility } \\
\text { value }\end{array}$ & & & & & $.399^{* *}$ \\
\hline $\begin{array}{c}\text { 5. Sense of } \\
\text { learning } \\
\text { duty }\end{array}$ & & & & & - \\
\hline
\end{tabular}

Note: $\mathrm{N}=714$. $^{* *} \mathrm{P}<.01$. 


\section{Table A4}

Internal Consistency Reliability Coefficient of CHC Value Scale (ordered by size of loadings in which variables contribute to the factor)

\begin{tabular}{lcc}
\hline \multicolumn{1}{c}{ Cultural value measures } & Component & $h^{2}$ \\
Teacher-oriented goals & 1 & .638 \\
Family-oriented goals & {$[.799]$} & .570 \\
Sense of learning duty & {$[.755]$} & .541 \\
Utility value & {$[.735]$} & .440 \\
\hline
\end{tabular}

Note: $\mathrm{N}=714 . h^{2}=$ Communality. 


\section{Table A5}

Primary and Secondary Factor Loadings for Goal Orientation Items in College English Classes (ordered by size of loadings in which variables contribute to factors) and Intercorrelations among Factors

\begin{tabular}{|c|c|c|c|c|c|}
\hline \multirow{3}{*}{ GO items and factors } & \multicolumn{4}{|c|}{ Factor } & \multirow{3}{*}{$h^{2}$} \\
\hline & 1 & 2 & 3 & 4 & \\
\hline & $\begin{array}{c}\text { Mastery } \\
\text { avoidance }\end{array}$ & $\begin{array}{l}\text { Performance } \\
\text { avoidance }\end{array}$ & $\begin{array}{c}\text { Performance } \\
\text { approach }\end{array}$ & $\begin{array}{c}\text { Mastery } \\
\text { approach }\end{array}$ & \\
\hline $\begin{array}{l}\text { 13. I am anxious that } \\
\text { I may not master all } \\
\text { that is supposed to } \\
\text { learn in this class. }\end{array}$ & [.769] & .024 & -.014 & .037 & .639 \\
\hline $\begin{array}{l}\text { 3. I am often } \\
\text { concerned that I may } \\
\text { not learn all that } \\
\text { there is to learn in } \\
\text { this class. }\end{array}$ & [.629] & -.038 & .003 & .130 & .499 \\
\hline $\begin{array}{l}\text { 17. I feel uneasy that } \\
\text { I may not understand } \\
\text { what is to learn in } \\
\text { this class. }\end{array}$ & {$[.416]$} & -.030 & -.049 & -.004 & .186 \\
\hline $\begin{array}{l}15 . \text { I worry that I } \\
\text { may not learn all that } \\
\text { I possibly could in } \\
\text { this class. }\end{array}$ & {$[.416]$} & .154 & -.155 & .126 & .389 \\
\hline $\begin{array}{l}\text { 11. My goal in this } \\
\text { class is to avoid } \\
\text { performing poorly. }\end{array}$ & .050 & {$[.660]$} & -.035 & .047 & .466 \\
\hline $\begin{array}{l}19 . \text { I just want to } \\
\text { avoid doing poorly } \\
\text { in this class. }\end{array}$ & -.092 & {$[.486]$} & .106 & -.283 & .369 \\
\hline $\begin{array}{l}\text { 7. One of my main } \\
\text { goals is to avoid } \\
\text { looking like I can't } \\
\text { do my work. }\end{array}$ & -.080 & [.392] & -.236 & .175 & .279 \\
\hline
\end{tabular}




\begin{tabular}{|c|c|c|c|c|c|}
\hline $\begin{array}{l}\text { 1. My fear of } \\
\text { performing poorly in } \\
\text { this class is often } \\
\text { what motivates me. }\end{array}$ & .320 & [.384] & .056 & .052 & .280 \\
\hline $\begin{array}{l}\text { 5. It's very important } \\
\text { for me that I don't } \\
\text { look stupid in this } \\
\text { class. }\end{array}$ & .047 & [.266] & -.129 & -.062 & .117 \\
\hline $\begin{array}{l}\text { 16. It is important } \\
\text { for me to do well } \\
\text { compared to others } \\
\text { in this class. }\end{array}$ & .089 & -.016 & {$[-.831]$} & -.105 & .693 \\
\hline $\begin{array}{l}\text { 14. It is important } \\
\text { for me to do better } \\
\text { than other students. }\end{array}$ & .074 & .021 & [-.799] & -.055 & .671 \\
\hline $\begin{array}{l}\text { 8. I want to do better } \\
\text { than the other } \\
\text { students in this class. }\end{array}$ & -.097 & -.062 & {$[-.703]$} & .144 & .500 \\
\hline $\begin{array}{l}20 \text {. My goal in this } \\
\text { class is to get a } \\
\text { better grade than } \\
\text { most of the other } \\
\text { students. }\end{array}$ & .008 & .248 & {$[-.457]$} & .005 & .347 \\
\hline $\begin{array}{l}\text { 4. I would feel really } \\
\text { good if I were the } \\
\text { only one who could } \\
\text { answer the teacher's } \\
\text { question in class. }\end{array}$ & .082 & .003 & {$[-.318]$} & .015 & .133 \\
\hline $\begin{array}{l}\text { 12. I do my school } \\
\text { work to get better at } \\
\text { it. }\end{array}$ & .007 & .134 & .121 & [.772] & .548 \\
\hline $\begin{array}{l}\text { 6. I work hard to } \\
\text { learn new things in } \\
\text { this class. }\end{array}$ & .049 & -.100 & .007 & [.624] & .444 \\
\hline $\begin{array}{l}\text { 9. It is important for } \\
\text { me to understand the } \\
\text { content of this }\end{array}$ & .053 & .062 & -.085 & [.543] & .373 \\
\hline
\end{tabular}


course as thoroughly as possible.

18. I desire to completely master the material presented in this .07 class.

2. I want to learn as much as possible from this class.

.195

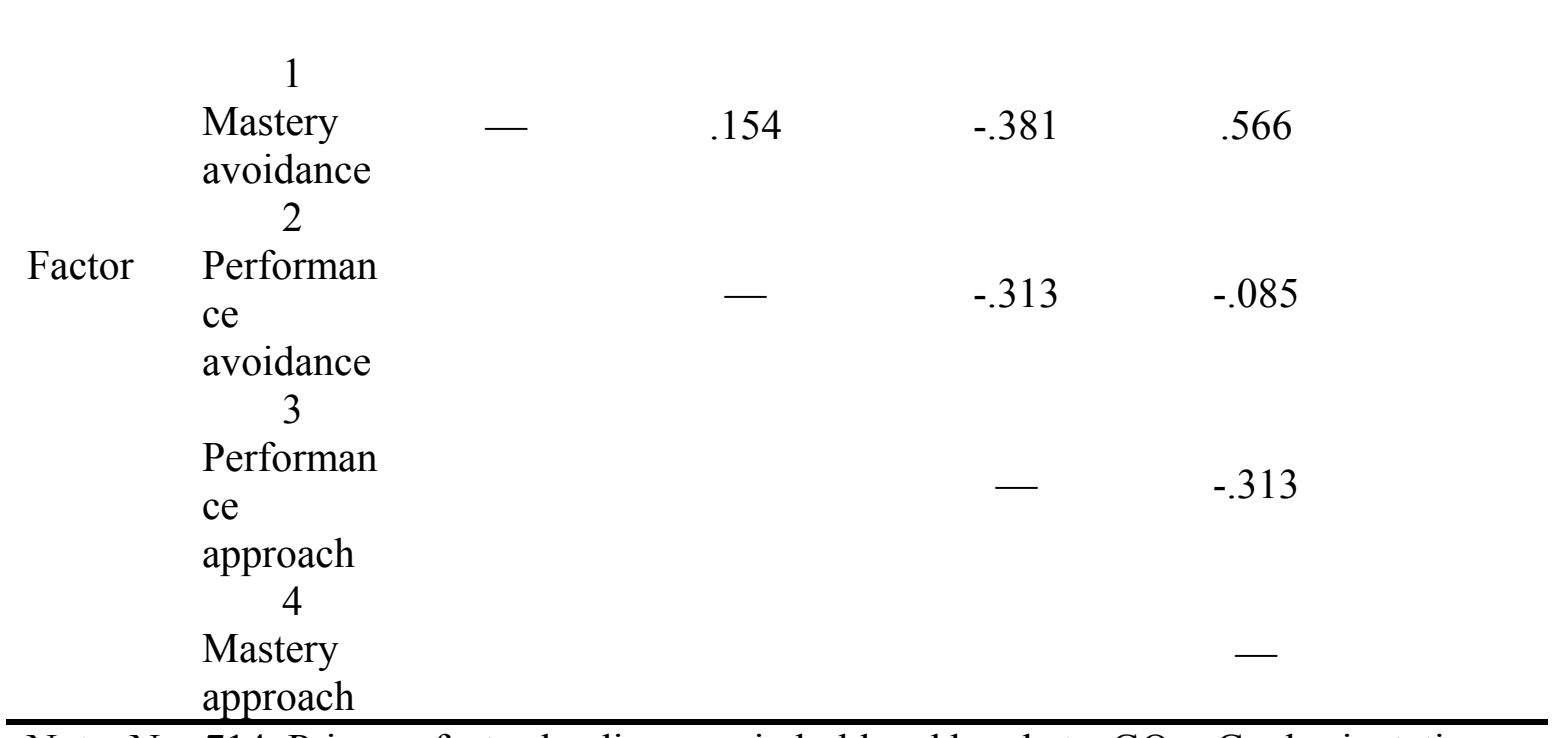

Note: $\mathrm{N}=714$. Primary factor loadings are in bold and brackets. $\mathrm{GO}=$ Goal orientation. $h^{2}=$ Communality. 


\section{Table A6}

Internal Consistency Reliability Coefficient of Goal Orientation Scales (ordered by size of loadings in which variables contribute to factors) in College English Classes

\begin{tabular}{llc}
\hline \multicolumn{1}{c}{ GO scales } & \multicolumn{1}{c}{ Scale items } & Cronbach's $\alpha$ \\
\hline Mastery avoidance & Item $13,3,17,15$ & .713 \\
Performance avoidance & Item $11,19,7,1,5$ & .552 \\
Performance approach & Item $16,14,8,20,4$ & .774 \\
Mastery approach & Item $12,6,9,18,2$ & .785 \\
\hline
\end{tabular}

Note: $\mathrm{N}=714 . \mathrm{GO}=$ Goal orientation. 


\section{Table A7}

Primary and Secondary Factor Loadings for Goal Orientation Items in Advanced Mathematics Classes (ordered by size of loadings in which variables contribute to factors) and Intercorrelations among Factors

\begin{tabular}{|c|c|c|c|c|c|}
\hline \multirow[b]{2}{*}{ GO items and factors } & \multicolumn{4}{|c|}{ Factor } & \multirow[b]{2}{*}{$h^{2}$} \\
\hline & $\begin{array}{c}1 \\
\text { Mastery } \\
\text { avoidance }\end{array}$ & $\begin{array}{c}2 \\
\text { Performance } \\
\text { avoidance }\end{array}$ & $\begin{array}{c}3 \\
\text { Performance } \\
\text { approach }\end{array}$ & $\begin{array}{c}4 \\
\text { Mastery } \\
\text { approach }\end{array}$ & \\
\hline $\begin{array}{l}\text { 13. I am anxious that } \\
\text { I may not master all } \\
\text { that is supposed to } \\
\text { learn in this class. }\end{array}$ & [.776] & .061 & .014 & .082 & .675 \\
\hline $\begin{array}{l}\text { 3. I am often } \\
\text { concerned that I may } \\
\text { not learn all that } \\
\text { there is to learn in } \\
\text { this class. }\end{array}$ & [.633] & -.057 & -.029 & .142 & .533 \\
\hline $\begin{array}{l}15 . \text { I worry that I } \\
\text { may not learn all that } \\
\text { I possibly could in } \\
\text { this class. }\end{array}$ & [.431] & .062 & -.151 & .126 & .352 \\
\hline $\begin{array}{l}\text { 17. I feel uneasy that } \\
\text { I may not understand } \\
\text { what is to learn in } \\
\text { this class. }\end{array}$ & [.332] & .008 & .005 & -.020 & .103 \\
\hline $\begin{array}{l}\text { 11. My goal in this } \\
\text { class is to avoid } \\
\text { performing poorly. }\end{array}$ & .052 & [.733] & -.025 & -.015 & .565 \\
\hline $\begin{array}{l}\text { 7. One of my main } \\
\text { goals is to avoid } \\
\text { looking like I can't } \\
\text { do my work. }\end{array}$ & -.072 & [.608] & -.132 & .118 & .412 \\
\hline $\begin{array}{l}\text { 19. I just want to } \\
\text { avoid doing poorly } \\
\text { in this class. }\end{array}$ & -.141 & [.507] & .119 & -.180 & .364 \\
\hline $\begin{array}{l}\text { 1. My fear of } \\
\text { performing poorly in }\end{array}$ & .264 & [.423] & -.005 & -.002 & .269 \\
\hline
\end{tabular}


this class is often

what motivates me.

5. It's very important

for me that I don't

look stupid in this

[.353]

$-.168$

$-.058$

.223

class.

16. It is important

for me to do well

compared to others

.033

.043

[-.842]

$-.135$

.718

in this class.

14. It is important

for me to do better

.053

.043

$[-.832]$

$-.082$

.727

than other students.

8. I want to do better

than the other

.003

$-.034$

$[-.696]$

.086

.509

students in this class.

20. My goal in this

class is to get a

better grade than

$-.159$

.177

[-.642]

.032

.466

most of the other

students.

4. I would feel really good if I were the only one who could

[-.439]

.080

.262

answer the teacher's

question in class.

12. I do my school

work to get better at

$-.039$

.123

.074

[.797]

.544

it.

6. I work hard to

learn new things in

$-.033$

.020

[.764] $\quad .562$

this class.

2. I want to learn as

much as possible

.052

$-.058$

$-.007$

[.685]

.534

from this class.

18. I desire to

completely master

.163

$-.142$

$-.106$

[.568]

.546

the material 


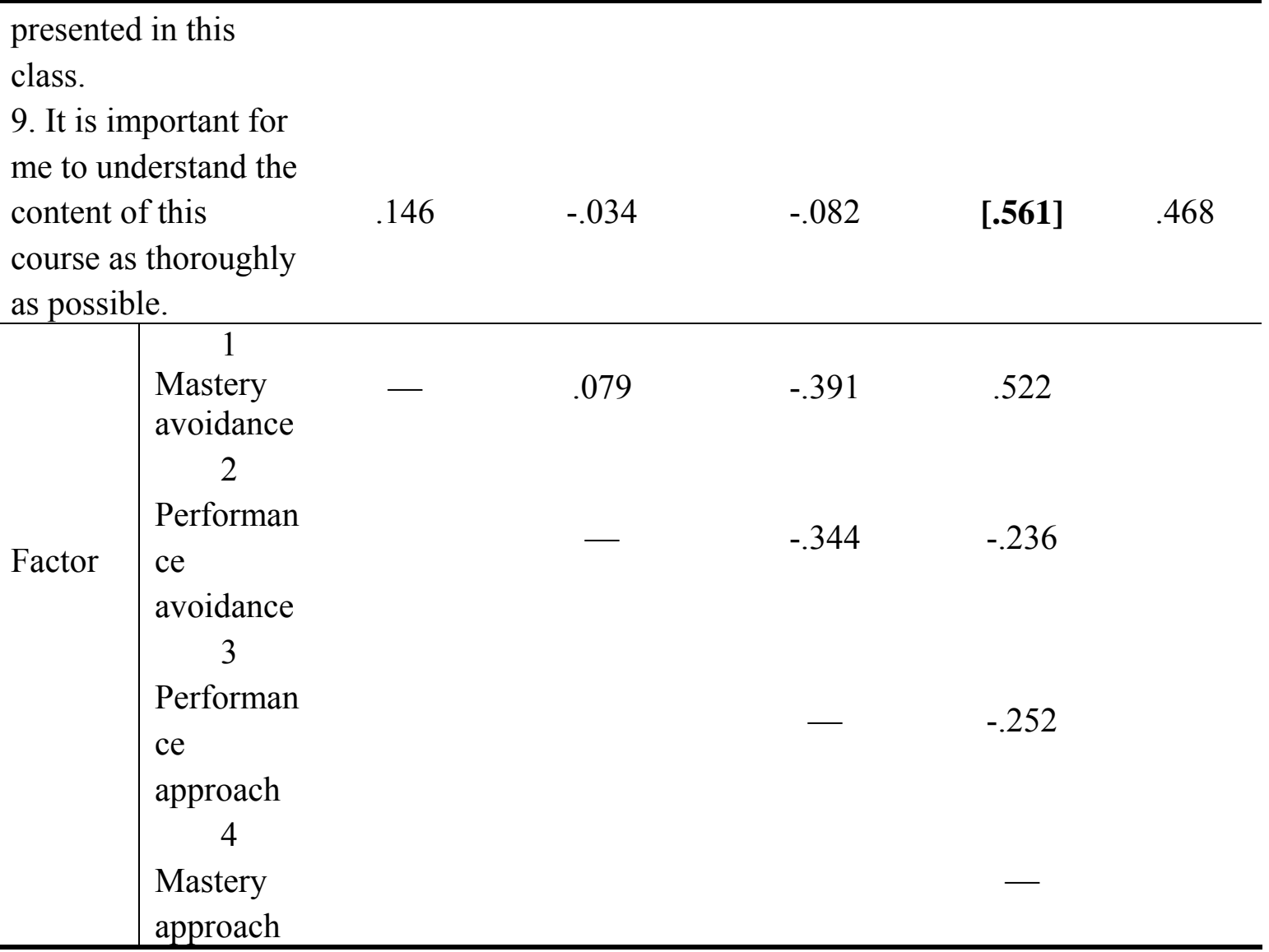

Note: $\mathrm{N}=714$. Primary factor loadings are in bold and brackets. $\mathrm{GO}=$ Goal orientation. $h^{2}=$ Communality. 


\section{Table A8}

Internal Consistency Reliability Coefficient of Goal Orientation Scales (order by size of loadings in which variables contribute to factors) in Advanced Mathematics Classes

\begin{tabular}{llc}
\hline \multicolumn{1}{c}{ GO scales } & \multicolumn{1}{c}{ Scale items } & Cronbach's $\alpha$ \\
\hline Mastery avoidance & Item $13,3,15$ & .741 \\
Performance avoidance & Item $11,7,19,1,5$ & .671 \\
Performance approach & Item $16,14,8,20,4$ & .824 \\
Mastery approach & Item $6,12,2,18,9$ & .841 \\
\hline
\end{tabular}

Note: $\mathrm{N}=714$. $\mathrm{GO}=$ Goal orientation. 


\section{Table A9}

Primary and Secondary Factor Loadings for SAL Items in College English Classes (ordered by size of loadings in which variables contribute to factors)

\begin{tabular}{|c|c|c|c|}
\hline \multirow[b]{2}{*}{ SAL items } & \multicolumn{2}{|c|}{ Factor } & \multirow[b]{2}{*}{$h^{2}$} \\
\hline & $\begin{array}{c}1 \\
\text { Deep } \\
\text { approach } \\
\end{array}$ & $\begin{array}{c}2 \\
\text { Surface } \\
\text { approach } \\
\end{array}$ & \\
\hline $\begin{array}{l}\text { 10. I work hard at my studies } \\
\text { because I find the course } \\
\text { material interesting. }\end{array}$ & {$[.702]$} & -.175 & .524 \\
\hline $\begin{array}{l}\text { 6. I find that studying academic } \\
\text { topics in this course can at times } \\
\text { be as exciting as a good novel or } \\
\text { movie. }\end{array}$ & {$[.662]$} & -.213 & .483 \\
\hline $\begin{array}{l}\text { 18. In this course I come to most } \\
\text { classes with questions in mind } \\
\text { that I want answering. }\end{array}$ & {$[.651]$} & .043 & .425 \\
\hline $\begin{array}{l}\text { 5. I find most new topics } \\
\text { interesting and often spend extra } \\
\text { time trying to obtain more } \\
\text { information about them. }\end{array}$ & [.637] & -.190 & .442 \\
\hline $\begin{array}{l}\text { 13. I spend a lot of my free time } \\
\text { finding out more about } \\
\text { interesting topics which have } \\
\text { been discussed in different } \\
\text { classes. }\end{array}$ & [.591] & -.010 & .350 \\
\hline $\begin{array}{l}\text { 17. I make a point of looking at } \\
\text { most of the suggested readings } \\
\text { that go with the lectures. }\end{array}$ & [.589] & -.050 & .350 \\
\hline $\begin{array}{l}\text { 8. I test myself on important } \\
\text { topics until I understand them } \\
\text { completely. }\end{array}$ & [.562] & .114 & .329 \\
\hline $\begin{array}{l}\text { 14. I feel that virtually any topic } \\
\text { in this course can be highly } \\
\text { interesting once I get into it. }\end{array}$ & {$[.460]$} & -.184 & .245 \\
\hline 2. I find that at times studying & {$[.455]$} & -.062 & .211 \\
\hline
\end{tabular}


this course gives me a feeling of deep personal satisfaction.

1. I find that I have to do enough

work on a topic so that I can

form my own conclusions before

[.324]

I am satisfied.

19. I learn some things by rote, going over and over them until I know them by heart even if I do

not understand them.

3. I generally restrict my study to what is specifically set as I think it is unnecessary to do anything $-.084$

[.671]

extra.

12. I see no point in learning

material which is not likely to be

[.654]

in the examination.

7. I only study seriously what's

given out in class or in the

course outlines.

$-.036$

[.547]

.301

15. I find it is not helpful to study topics in depth. It confuses and wastes time, when all you

need is a passing acquaintance with topics.

4. I do not find my course very interesting so I keep my work to $-.262$

[.540]

the minimum.

16. I find the best way to pass

examinations is to try to

remember answers to likely

[.526]

questions.

11. I believe that lecturers shouldn't expect students to spend significant amounts of $-.008$

time studying material everyone knows won't be examined.

20. My aim is to pass the course $-.173$ 
while doing as little work as

possible.

9. I find I can get by in most

assessments by memorizing key

sections rather than trying to

$-.030$

[.378]

.144

understand them.

Note: $\mathrm{N}=714$. Primary factor loadings are in bold and brackets. $\mathrm{SAL}=$ student approaches to learning. $h^{2}=$ Communality. 


\section{Table A10}

Internal Consistency Reliability Coefficient of SAL Scales (Ordered by size of loadings in which variables contribute to factors) in College English Classes

\begin{tabular}{llc}
\hline \multicolumn{1}{c}{ SAL scales } & \multicolumn{1}{c}{ Scale items } & Cronbach's $\alpha$ \\
\hline Deep approach & Item $10,6,18,5,13,17,8$, & .828 \\
& $14,2,1$ & \\
Surface approach & Item $3,12,7,15,4,16,11$, & .728 \\
& 20,9 & \\
\hline
\end{tabular}

Note: $\mathrm{N}=714$. $\mathrm{SAL}=$ Student approaches to learning. 


\section{Table A11}

Primary and Secondary Factor Loadings for SAL Items in Advanced Mathematics Classes (ordered by size of loadings in which variables contribute to factors)

\begin{tabular}{|c|c|c|c|}
\hline \multirow[b]{2}{*}{ SAL items } & \multicolumn{2}{|c|}{ Factor } & \multirow[b]{2}{*}{$h^{2}$} \\
\hline & $\begin{array}{c}1 \\
\text { Deep } \\
\text { approach } \\
\end{array}$ & $\begin{array}{c}2 \\
\text { Surface } \\
\text { approach } \\
\end{array}$ & \\
\hline 10. I work hard at my studies & & & \\
\hline $\begin{array}{l}\text { because I find the course } \\
\text { material interesting. }\end{array}$ & {$[.776]$} & -.093 & .612 \\
\hline $\begin{array}{l}\text { 6. I find that studying academic } \\
\text { topics in this course can at times } \\
\text { be as exciting as a good novel or } \\
\text { movie. }\end{array}$ & {$[.745]$} & -.115 & .568 \\
\hline $\begin{array}{l}\text { 5. I find most new topics } \\
\text { interesting and often spend extra } \\
\text { time trying to obtain more } \\
\text { information about them. }\end{array}$ & {$[.728]$} & -.147 & .552 \\
\hline $\begin{array}{l}\text { 13. I spend a lot of my free time } \\
\text { finding out more about } \\
\text { interesting topics which have } \\
\text { been discussed in different } \\
\text { classes. }\end{array}$ & [.681] & .049 & .466 \\
\hline $\begin{array}{l}\text { 18. In this course I come to most } \\
\text { classes with questions in mind } \\
\text { that I want answering. }\end{array}$ & {$[.657]$} & -.066 & .436 \\
\hline $\begin{array}{l}\text { 17. I make a point of looking at } \\
\text { most of the suggested readings } \\
\text { that go with the lectures. }\end{array}$ & {$[.616]$} & -.050 & .382 \\
\hline $\begin{array}{l}\text { 14. I feel that virtually any topic } \\
\text { in this course can be highly } \\
\text { interesting once I get into it. }\end{array}$ & [.559] & -.229 & .365 \\
\hline $\begin{array}{l}\text { 8. I test myself on important } \\
\text { topics until I understand them } \\
\text { completely. }\end{array}$ & [.492] & -.040 & .244 \\
\hline $\begin{array}{l}\text { 2. I find that at times studying } \\
\text { this course gives me a feeling of }\end{array}$ & [.399] & -.120 & .173 \\
\hline
\end{tabular}


deep personal satisfaction.

1. I find that I have to do enough

work on a topic so that I can

form my own conclusions before

$[.344]$

$-.228$

.170

I am satisfied.

12. I see no point in learning

material which is not likely to be

$-.100$

[.677]

.469

in the examination.

4. I do not find my course very

interesting so I keep my work to

[.617]

.416

the minimum.

15. I find it is not helpful to

study topics in depth. It confuses

and wastes time, when all you

$-.104$

[.607]

need is a passing acquaintance

with topics.

3. I generally restrict my study to what is specifically set as I think it is unnecessary to do anything

[.585]

extra.

16. I find the best way to pass

examinations is to try to

remember answers to likely

$-.050$

[.576]

.334

questions.

9. I find I can get by in most

assessments by memorizing key

sections rather than trying to

[.500]

understand them.

11. I believe that lecturers

shouldn't expect students to

spend significant amounts of

$-.018$

[.496]

.246

time studying material everyone

knows won't be examined.

20. My aim is to pass the course

while doing as little work as

$-.075$

[.457]

.214

possible.

19. I learn some things by rote, going over and over them until I 
know them by heart even if I do

not understand them.

7. I only study seriously what's

given out in class or in the

$-.160$

[.362]

.157

course outlines.

Note: $\mathrm{N}=714$. Primary factor loadings are in bold and brackets. $\mathrm{SAL}=$ student approaches to learning. $h^{2}=$ Communality. 


\section{Table A12}

Internal Consistency Reliability Coefficient of SAL Scales (ordered by size of loadings in which variables contribute to factors) in Advanced Mathematics Classes

\begin{tabular}{llc}
\hline \multicolumn{1}{c}{ SAL scales } & \multicolumn{1}{c}{ Scale items } & Cronbach's $\alpha$ \\
\hline Deep approach & Item $10,6,5,13,18,17,14$, & .856 \\
& $8,2,1$ & \\
Surface approach & Item $12,4,15,3,16,9,11$, & .795 \\
& $20,19,7$ & \\
\hline
\end{tabular}

Note: $\mathrm{N}=714$. $\mathrm{SAL}=$ Student approaches to learning. 


\section{Table A13}

Factor Loadings for Metacognitive Strategy Items in College English Classes (ordered by size of loadings in which variables contribute to factors)

\begin{tabular}{|c|c|c|}
\hline Metecognitive strategy items & $\begin{array}{c}\text { Component } \\
1 \\
\end{array}$ & $h^{2}$ \\
\hline $\begin{array}{l}\text { 10. I try to determine which concepts I don't } \\
\text { understand well. }\end{array}$ & [.742] & .551 \\
\hline $\begin{array}{l}\text { 16. I set goals for myself in order to direct my study } \\
\text { activities. }\end{array}$ & [.675] & .456 \\
\hline $\begin{array}{l}\text { 4. I skim through the unit to see how it is organized } \\
\text { before I read it thoroughly. }\end{array}$ & [.653] & .427 \\
\hline $\begin{array}{l}\text { 19. I ask myself questions to make sure I understand } \\
\text { the material. }\end{array}$ & {$[.576]$} & .332 \\
\hline $\begin{array}{l}\text { 13. I try to determine the way I study according to } \\
\text { the course requirements and the instructor's teaching } \\
\text { style. }\end{array}$ & [.563] & .316 \\
\hline $\begin{array}{l}\text { 7. If I become confused about something I read, I go } \\
\text { back to my previous notes and sort it out. }\end{array}$ & {$[.536]$} & .288 \\
\hline
\end{tabular}

Note: $\mathrm{N}=714 . h^{2}=$ Communality. 


\section{Table A14}

Factor Loadings for Metacognitive Strategy Items in Advanced Mathematics Classes (ordered by size of loadings in which variables contribute to factors)

\begin{tabular}{|c|c|c|}
\hline Metacognitive strategy items & $\begin{array}{c}\text { Component } \\
1 \\
\end{array}$ & $h^{2}$ \\
\hline $\begin{array}{l}\text { 10. I try to determine which concepts I don't } \\
\text { understand well. }\end{array}$ & {$[.707]$} & .500 \\
\hline $\begin{array}{l}\text { 4. I skim through the unit to see how it is organized } \\
\text { before I read it thoroughly. }\end{array}$ & [.683] & .466 \\
\hline $\begin{array}{l}\text { 16. I set goals for myself in order to direct my study } \\
\text { activities. }\end{array}$ & [.679] & .461 \\
\hline $\begin{array}{l}\text { 19. I ask myself questions to make sure I understand } \\
\text { the material. }\end{array}$ & {$[.668]$} & .446 \\
\hline $\begin{array}{l}\text { 7. If I become confused about something I read, I go } \\
\text { back to my previous notes and sort it out. }\end{array}$ & [.654] & .427 \\
\hline $\begin{array}{l}\text { 13. I try to determine the way I study according to } \\
\text { the course requirements and the instructor's teaching } \\
\text { style. }\end{array}$ & {$[.625]$} & .391 \\
\hline
\end{tabular}

Note: : $\mathrm{N}=714 . h^{2}=$ Communality. 


\section{Table A15}

Factor Loadings for Perceived Academic Efficacy Items in College English Classes (ordered by size of loadings in which variables contribute to factors)

\begin{tabular}{|c|c|c|}
\hline Perceived academic efficacy items & $\begin{array}{c}\text { Component } \\
1\end{array}$ & $h^{2}$ \\
\hline $\begin{array}{l}\text { 17. I'm certain I can figure out how to do the most } \\
\text { difficult school work. }\end{array}$ & {$[.803]$} & .645 \\
\hline 5. I can do even the hardest school work if I try. & [.782] & .612 \\
\hline 15. Even if the work in school is hard, I can learn it. & {$[.738]$} & .545 \\
\hline $\begin{array}{l}\text { 12. I can do almost all the work in school if I don't } \\
\text { give up. }\end{array}$ & {$[.700]$} & .490 \\
\hline $\begin{array}{l}\text { 2. I'm certain I can master the skills taught in school } \\
\text { this year. }\end{array}$ & [.596] & .355 \\
\hline $\begin{array}{l}\text { 9. If I have enough time, I can do a good job on all } \\
\text { my school work. }\end{array}$ & {$[.580]$} & .336 \\
\hline
\end{tabular}

Note: $\mathrm{N}=714 . h^{2}=$ Communality. 


\section{Table A16}

Factor Loadings for Perceived Academic Efficacy Items in Advanced Mathematics Classes (ordered by size of loadings in which variables contribute to factors)

\begin{tabular}{|c|c|c|}
\hline Perceived academic efficacy items & $\begin{array}{c}\text { Component } \\
1 \\
\end{array}$ & $h^{2}$ \\
\hline $\begin{array}{l}\text { 17. I'm certain I can figure out how to do the most } \\
\text { difficult school work. }\end{array}$ & [.839] & .704 \\
\hline 15. Even if the work in school is hard, I can learn it. & [.810] & .656 \\
\hline 5. I can do even the hardest school work if I try. & [.797] & .636 \\
\hline $\begin{array}{l}\text { 12. I can do almost all the work in school if I don't } \\
\text { give up. }\end{array}$ & {$[.790]$} & .624 \\
\hline $\begin{array}{l}\text { 9. If I have enough time, I can do a good job on all } \\
\text { my school work. }\end{array}$ & [.688] & .474 \\
\hline $\begin{array}{l}\text { 2. I'm certain I can master the skills taught in school } \\
\text { this year. }\end{array}$ & [.648] & .420 \\
\hline
\end{tabular}

Note: $\mathrm{N}=714 . h^{2}=$ Communality. 


\section{Table A17}

Factor Loadings for Affect at School Items in College English Classes (ordered by size of loadings in which variables contribute to factors)

\begin{tabular}{lcc}
\hline \multicolumn{1}{c}{ Affect at school items } & Factor & $h^{2}$ \\
14. Most of the time, being in school puts me in a & 1 & .545 \\
good mood. & {$[.738]$} & .435 \\
8. I am often angry when I'm at school. & {$[.660]$} & .430 \\
18. School often makes me feel sad. & {$[.656]$} & .420 \\
3. I like being in school. & {$[.648]$} & .371 \\
1. I often feel bored in school. & {$[.609]$} & .316 \\
6. I am happier when I am at school than when I am & {$[.562]$} & \\
not at school. & & .270 \\
11. I often feel frustrated when I am doing school & {$[.520]$} & \\
work. & &
\end{tabular}

Note: $\mathrm{N}=714 . h^{2}=$ Communality. 


\section{Table A18}

Factor Loadings for Affect at School Items in Advanced Mathematics Classes (ordered by size of loadings in which variables contribute to factors)

\begin{tabular}{|c|c|c|}
\hline Affect at school items & $\begin{array}{c}\text { Factor } \\
1 \\
\end{array}$ & $h^{2}$ \\
\hline $\begin{array}{l}\text { 14. Most of the time, being in school puts me in a } \\
\text { good mood. }\end{array}$ & [.732] & .536 \\
\hline 1. I often feel bored in school. & {$[.715]$} & .511 \\
\hline 18. School often makes me feel sad. & {$[.709]$} & .503 \\
\hline 3. I like being in school. & {$[.701]$} & .491 \\
\hline 8. I am often angry when I'm at school. & [.645] & .415 \\
\hline $\begin{array}{l}\text { 6. I am happier when I am at school than when I am } \\
\text { not at school. }\end{array}$ & [.603] & .364 \\
\hline $\begin{array}{l}\text { 11. I often feel frustrated when I am doing school } \\
\text { work. }\end{array}$ & {$[.550]$} & .302 \\
\hline
\end{tabular}

Note: $\mathrm{N}=714 . h^{2}=$ Communality. 


\section{Table A19}

Internal Consistency Reliability Coefficient of Metacognitive Strategy and School Wellbeing Scales (Ordered by size of loadings in which variables contribute to factors) in College English Classes and Advanced Mathematics Classes

\begin{tabular}{|c|c|c|}
\hline MS scales & Scale items & Cronbach's $\alpha$ \\
\hline \multicolumn{3}{|l|}{ College English } \\
\hline Metacognitive strategy & Item $10,16,4,19,13,7$ & .685 \\
\hline \multicolumn{3}{|l|}{ School well-being } \\
\hline Perceived academic efficacy & Item $17,5,15,12,2,9$ & .791 \\
\hline Affect at school & Item $14,8,18,3,1,6,11$ & .818 \\
\hline \multicolumn{3}{|l|}{ Advanced mathematics } \\
\hline Metacognitive strategy & Item $10,4,16,19,7,13$ & .752 \\
\hline \multicolumn{3}{|l|}{ School well-being } \\
\hline Perceived academic efficacy & Item $17,15,5,12,9,2$ & .855 \\
\hline Affect at school & Item $14,1,18,3,8,6,11$ & .846 \\
\hline
\end{tabular}

Note: $\mathrm{N}=714$. MS $=$ Metacognitive strategy and school well-being. 
Table A20

Descriptive Statistics for All Variables

\begin{tabular}{|c|c|c|c|c|c|c|c|c|}
\hline \multirow[t]{2}{*}{ Variables } & \multirow[t]{2}{*}{$\mathrm{M}$} & \multirow[t]{2}{*}{$\mathrm{SD}$} & \multirow[t]{2}{*}{ Min } & \multirow[t]{2}{*}{$\operatorname{Max}$} & \multicolumn{2}{|c|}{ Skewness } & \multicolumn{2}{|c|}{ Kurtosis } \\
\hline & & & & & $\gamma_{1}$ & $\mathrm{SE}$ & $\gamma_{2}$ & $\mathrm{SE}$ \\
\hline \multicolumn{9}{|l|}{ Cultural values } \\
\hline 1. $\mathrm{CHC}$ values & 5.31 & 0.76 & 2.81 & 7.00 & -.54 & .09 & .18 & .18 \\
\hline \multicolumn{9}{|c|}{ College English Classes } \\
\hline \multicolumn{9}{|c|}{ Achievement goal orientations } \\
\hline 2. Mastery approach & 5.17 & .96 & 1.00 & 7.00 & -.73 & .09 & 1.10 & .18 \\
\hline 3. Mastery avoidance & 4.62 & 1.05 & 1.00 & 7.00 & -.28 & .09 & .08 & .18 \\
\hline 4. Performance approach & 4.51 & 1.10 & 1.20 & 7.00 & -.18 & .09 & -.35 & .18 \\
\hline 5. Performance avoidance & 4.16 & .99 & 1.00 & 6.60 & -.28 & .09 & -.24 & .18 \\
\hline \multicolumn{9}{|l|}{ SAL } \\
\hline 6. Deep approach & 4.13 & .91 & 1.00 & 7.00 & .02 & .09 & .19 & .18 \\
\hline 7. Surface approach & 3.45 & .97 & 1.00 & 6.78 & .22 & .09 & -.05 & .18 \\
\hline \multicolumn{9}{|c|}{ Metacognitive strategy and school well-being } \\
\hline 8.Metacognitve strategy & 4.63 & .87 & 1.33 & 7.00 & -.33 & .09 & .36 & .18 \\
\hline $\begin{array}{l}\text { 9. Perceived academic } \\
\text { efficacy }\end{array}$ & 5.15 & .93 & 2.17 & 7.00 & -.29 & .09 & -.29 & .18 \\
\hline 10. Affect at school & 3.92 & 1.01 & 1.00 & 7.00 & .11 & .09 & .07 & .18 \\
\hline \multicolumn{9}{|l|}{ Academic achievement } \\
\hline 11. Course grades & 61.37 & 9.21 & 27.00 & 87.00 & -.38 & .09 & .36 & .18 \\
\hline
\end{tabular}




\begin{tabular}{|c|c|c|c|c|c|c|c|c|}
\hline \multicolumn{9}{|c|}{ Advanced Mathematics Classes } \\
\hline \multicolumn{9}{|c|}{ Achievement goal orientations } \\
\hline 2. Mastery approach & 5.36 & .98 & 1.40 & 7.00 & -.81 & .09 & .89 & .18 \\
\hline 3. Mastery avoidance & 5.19 & .99 & 1.67 & 7.00 & -.59 & .09 & .32 & .18 \\
\hline 4. Performance approach & 4.62 & 1.16 & 1.00 & 7.00 & -.25 & .09 & -.36 & .18 \\
\hline 5. Performance avoidance & 4.16 & 1.07 & 1.00 & 7.00 & -.25 & .09 & -.26 & .18 \\
\hline \multicolumn{9}{|l|}{ SAL } \\
\hline 6. Deep approach & 4.39 & .93 & 1.60 & 7.00 & .02 & .09 & .02 & .18 \\
\hline 7. Surface approach & 3.54 & .94 & 1.00 & 6.90 & .25 & .09 & -.02 & .18 \\
\hline \multicolumn{9}{|c|}{ Metacognitive strategy and school well-being } \\
\hline 8. Metacognitve strategy & 4.93 & .88 & 1.50 & 7.00 & -.34 & .09 & .29 & .18 \\
\hline $\begin{array}{l}\text { 9. Perceived academic } \\
\text { efficacy }\end{array}$ & 5.42 & .91 & 1.67 & 7.00 & -.42 & .09 & .06 & .18 \\
\hline 10. Affect at school & 4.26 & 1.03 & 1.00 & 7.00 & -.00 & .09 & .04 & .18 \\
\hline \multicolumn{9}{|l|}{ Academic achievement } \\
\hline 11. Course grades & 79.29 & 14.89 & 9.00 & 100.00 & -1.03 & .09 & 1.38 & .18 \\
\hline
\end{tabular}

Note: $\mathrm{N}=714 . \mathrm{SAL}=$ Student approaches to learning. $\gamma_{1}=$ Skewness statistic. $\gamma_{2}=$ Kurtosis statistic. $\mathrm{SE}=\mathrm{Standard}$ error. 


\section{Table A21}

Zero-Order Correlations among the Cultural Value, Achievement Goal Orientation, SAL, Metacognitive Strategy and School Wellbeing, and Achievement Variables

\begin{tabular}{|c|c|c|c|c|c|c|c|c|c|c|c|}
\hline \multicolumn{12}{|c|}{ College English Classes } \\
\hline Measure & 1 & 2 & 3 & 4 & 5 & 6 & 7 & 8 & 9 & 10 & 11 \\
\hline $\begin{array}{l}\text { 1. Confucian-heritage } \\
\text { cultural values }\end{array}$ & - & $.45^{* *}$ & $.41^{* *}$ & $.48^{* *}$ & $.26^{* *}$ & $.20^{* *}$ & -.06 & $.24^{* *}$ & $.24^{* *}$ & $.23^{* *}$ & $.09^{*}$ \\
\hline \multicolumn{12}{|l|}{ Achievement goal orientations } \\
\hline 2. Master approach & & - & $.54^{* *}$ & $.28^{* *}$ & -.03 & $.50^{* *}$ & $-.33^{* *}$ & $.43^{* *}$ & $.36^{* *}$ & $.32^{* *}$ & $.10^{* *}$ \\
\hline 3. Master avoidance & & & - & $.39^{* *}$ & $.20^{* *}$ & $.33^{* *}$ & $-.12^{* *}$ & $.35^{* *}$ & $.24^{* *}$ & $.22^{* *}$ & .05 \\
\hline 4. Performance approach & & & & - & $.34^{* *}$ & $.16^{* *}$ & $.09^{*}$ & $.17^{* *}$ & $.18^{* *}$ & $.08^{*}$ & $.13^{* *}$ \\
\hline 5. Performance avoidance & & & & & - & -.05 & $.44^{* *}$ & -.01 & $-.09^{*}$ & $-.14^{* *}$ & $-.14^{* *}$ \\
\hline \multicolumn{12}{|l|}{ Student approaches to learning } \\
\hline 6. Deep approach & & & & & & - & $-.26^{* *}$ & $.58^{* *}$ & $.41^{* *}$ & $.40^{* *}$ & -.01 \\
\hline 7. Surface approach & & & & & & & - & $-.21^{* *}$ & $-.20^{* *}$ & $-.36^{* *}$ & $-.19^{* *}$ \\
\hline \multicolumn{12}{|c|}{ Metacognitive strategy and school well-being } \\
\hline 8. Metacognitive stratey & & & & & & & & - & $.54^{* *}$ & $.39^{* *}$ & .07 \\
\hline $\begin{array}{l}\text { 9. Perceived academic } \\
\text { efficacy }\end{array}$ & & & & & & & & & - & $.28^{*}$ & .06 \\
\hline $\begin{array}{l}\text { 10. Affect at } \\
\text { school }\end{array}$ & & & & & & & & & & - & .07 \\
\hline 11. Course Grades & & & & & & & & & & & - \\
\hline
\end{tabular}




\begin{tabular}{|c|c|c|c|c|c|c|c|c|c|c|c|}
\hline \multicolumn{12}{|c|}{ Advanced Mathematics Classes } \\
\hline Measures & 1 & 2 & 3 & 4 & 5 & 6 & 7 & 8 & 9 & 10 & 11 \\
\hline $\begin{array}{l}\text { 1. Confucian-heritage } \\
\text { cultural value }\end{array}$ & - & $.37^{* *}$ & $.40^{* *}$ & $.45^{* *}$ & $.18^{* *}$ & $.31^{* *}$ & $-.08^{*}$ & $.32^{* *}$ & $.33^{* *}$ & $.24^{* *}$ & .03 \\
\hline \multicolumn{12}{|l|}{ Achievement goal orientations } \\
\hline 2. Master approach & & - & $.54^{* *}$ & $.22^{* *}$ & $-.17^{* *}$ & $.58^{* *}$ & $-.42^{* *}$ & $.54^{* *}$ & $.46^{* *}$ & $.40^{* *}$ & $.15^{* *}$ \\
\hline 3. Master avoidance & & & - & $.38^{* *}$ & $.11^{* *}$ & $.37^{* *}$ & $-.19^{* *}$ & $.44^{* *}$ & $.31^{* *}$ & $.25^{* *}$ & $.10^{*}$ \\
\hline 4. Performance approach & & & & - & $.35^{* *}$ & $.22^{* *}$ & $.12^{* *}$ & $.21^{* *}$ & $.26^{* *}$ & $.08^{*}$ & .05 \\
\hline 5. Performance avoidance & & & & & - & $-.15^{* *}$ & $.49^{* *}$ & -.04 & $-.16^{* *}$ & $-.23^{* *}$ & $-.18^{* * *}$ \\
\hline \multicolumn{12}{|l|}{ Student approaches to learning } \\
\hline 6. Deep approach & & & & & & - & $-.28^{* *}$ & $.61^{* *}$ & $.43^{* *}$ & $.51^{* *}$ & $.16^{* *}$ \\
\hline 7. Surface approach & & & & & & & - & $-.23^{* *}$ & $-.21^{* *}$ & $-.46^{* *}$ & $-.21^{* *}$ \\
\hline \multicolumn{12}{|c|}{ Metacognitive strategy and school well-being } \\
\hline 8. Metacognitive stratey & & & & & & & & - & $.49^{* *}$ & $.40^{* *}$ & $.20^{* *}$ \\
\hline $\begin{array}{l}\text { 9. Perceived academic } \\
\text { efficacy }\end{array}$ & & & & & & & & & - & $.27^{* *}$ & $.20^{* *}$ \\
\hline 10. Affect at school & & & & & & & & & & - & $.21^{* *}$ \\
\hline 11. Course Grades & & & & & & & & & & & - \\
\hline
\end{tabular}

Note: $\mathrm{N}=714 . \mathrm{CE}=$ College English. $\mathrm{AM}=$ Advanced mathematics. ${ }^{*} \mathrm{P}<.05 .{ }^{* *} \mathrm{P}<.01$. 


\section{Table A22}

Summary of Hierarchical and Simultaneous Regression Analysis for Achievement Goal Variables Predicting Metacognitive Strategies, Perceived Academic Efficacy, Affect at School, and Academic Performance in College English Classes

\begin{tabular}{|c|c|c|c|c|}
\hline \multirow[t]{2}{*}{ Variables } & $\begin{array}{l}\text { Metacognitive } \\
\text { strategies }\end{array}$ & $\begin{array}{l}\text { Perceived } \\
\text { academic } \\
\text { efficacy }\end{array}$ & $\begin{array}{l}\text { Affect } \\
\text { at } \\
\text { school }\end{array}$ & $\begin{array}{c}\text { Academic } \\
\text { performance }\end{array}$ \\
\hline & $\beta_{1}$ & $\beta_{2}$ & $\beta_{3}$ & $\beta_{4}$ \\
\hline \multicolumn{5}{|l|}{ Step 1} \\
\hline Gender & -.014 & -.027 & $-.091^{*}$ & $-.124^{* *}$ \\
\hline $\begin{array}{l}\text { Location of middle } \\
\text { school }\end{array}$ & .026 & $.089^{*}$ & -.033 & .053 \\
\hline \multicolumn{5}{|l|}{ Step 2} \\
\hline Gender & .051 & .020 & -.047 & $-.115^{* *}$ \\
\hline $\begin{array}{l}\text { Location of middle } \\
\text { school }\end{array}$ & .019 & $.076^{*}$ & -.043 & .039 \\
\hline Master approach & $.335^{* * *}$ & $.276^{* * *}$ & $.253^{* * *}$ & .032 \\
\hline Mastery avoidance & $.179^{* * *}$ & $.074 \#$ & $.108^{*}$ & -.012 \\
\hline $\begin{array}{l}\text { Performance } \\
\text { approach }\end{array}$ & .025 & $.121^{* *}$ & .014 & $.190^{* * *}$ \\
\hline $\begin{array}{l}\text { Performance } \\
\text { avoidance }\end{array}$ & -.046 & $-.142^{* * *}$ & $-.159^{* * *}$ & $-.206^{* * *}$ \\
\hline \multicolumn{5}{|l|}{ Step 3} \\
\hline Gender & .048 & .018 & -.046 & $-.115^{* *}$ \\
\hline $\begin{array}{l}\text { Location of middle } \\
\text { school }\end{array}$ & .017 & $.072^{*}$ & -.050 & .039 \\
\hline Master approach & $.354^{* * *}$ & $.313^{* * *}$ & $.290^{* * *}$ & .030 \\
\hline Mastery avoidance & $.168^{* * *}$ & .056 & $.102^{*}$ & -.007 \\
\hline $\begin{array}{l}\text { Performance } \\
\text { approach }\end{array}$ & .035 & $.140^{* *}$ & .011 & $.182^{* * *}$ \\
\hline $\begin{array}{l}\text { Performance } \\
\text { avoidance }\end{array}$ & -.044 & $-.138^{* * *}$ & $-.162^{* * *}$ & $-.209^{* * *}$ \\
\hline $\begin{array}{l}\text { Mastery approach } \\
\quad \times \\
\text { mastery avoidance } \\
\text { Mastery approach }\end{array}$ & .072 & $.149^{* *}$ & .065 & -.027 \\
\hline $\begin{array}{l}\times \\
\text { performance approach } \\
\text { Mastery approach }\end{array}$ & .028 & .015 & .039 & .001 \\
\hline $\begin{array}{c}\times \\
\text { performance avoidance }\end{array}$ & -.005 & -.064 & .012 & .042 \\
\hline Mastery avoidance & -.053 & $-.079^{\#}$ & .013 & .027 \\
\hline
\end{tabular}




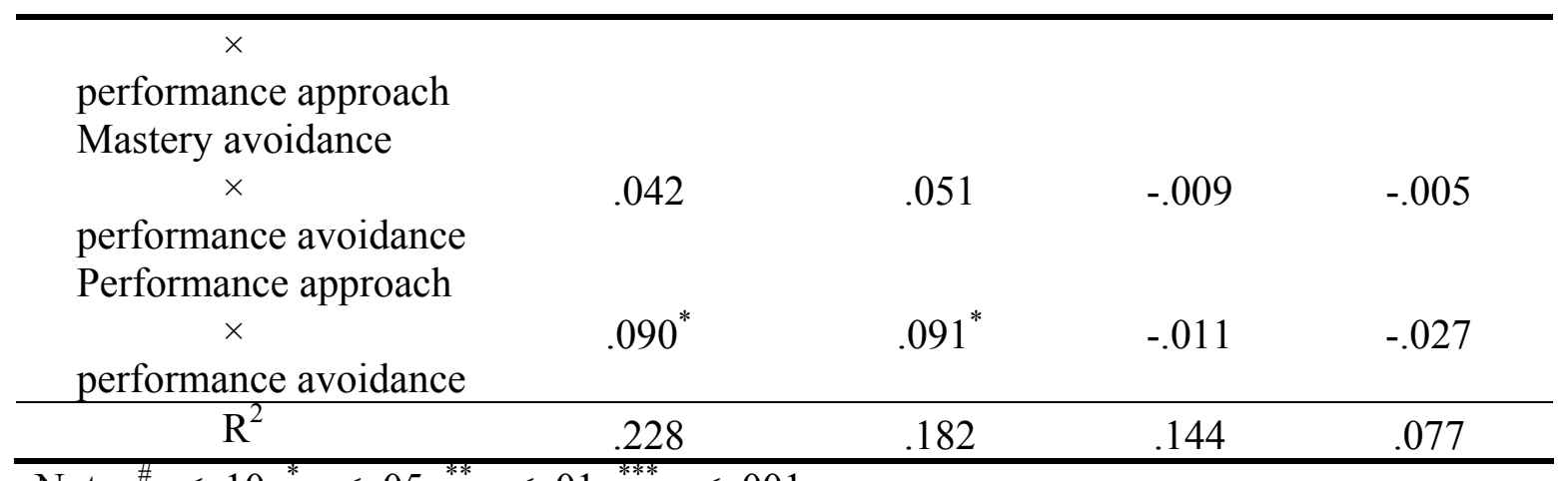

Note: ${ }^{\#} p<.10 .{ }^{*} p<.05 .{ }^{* * *} p<.01 .{ }^{* * *} p<.001$. 


\section{Table A23}

Summary of Hierarchical and Simultaneous Regression Analysis for Achievement Goal Variables Predicting Metacognitive Strategies, Perceived Academic Efficacy, Affect at School, and Academic Performance in Advanced Mathematics Classes

\begin{tabular}{|c|c|c|c|c|}
\hline \multirow[t]{2}{*}{ Variables } & $\begin{array}{l}\text { Metacognitive } \\
\text { strategies }\end{array}$ & $\begin{array}{l}\text { Perceived } \\
\text { academic } \\
\text { efficacy }\end{array}$ & $\begin{array}{l}\text { Affect } \\
\text { at } \\
\text { school }\end{array}$ & $\begin{array}{c}\text { Academic } \\
\text { performance }\end{array}$ \\
\hline & $\beta_{1}$ & $\beta_{2}$ & $\beta_{3}$ & $\beta_{4}$ \\
\hline \multicolumn{5}{|l|}{ Step 1} \\
\hline Gender & $-.078^{*}$ & .005 & $-.085^{*}$ & $-.113^{* *}$ \\
\hline $\begin{array}{l}\text { Location of middle } \\
\text { school }\end{array}$ & -.061 & .011 & $-.098^{* *}$ & -.045 \\
\hline \multicolumn{5}{|l|}{ Step 2} \\
\hline Gender & $-.054^{\#}$ & .025 & $-.074^{*}$ & $-.109^{* *}$ \\
\hline $\begin{array}{l}\text { Location of middle } \\
\text { school }\end{array}$ & $-.055^{\#}$ & .013 & $-.092^{* *}$ & -.043 \\
\hline Master approach & $.414^{* * *}$ & $.334^{* * *}$ & $.306^{* * *}$ & .048 \\
\hline Mastery avoidance & $.199^{* * *}$ & .060 & $.081^{\#}$ & .052 \\
\hline $\begin{array}{l}\text { Performance } \\
\text { approach }\end{array}$ & .041 & $.224^{* * *}$ & .043 & $.094^{*}$ \\
\hline $\begin{array}{l}\text { Performance } \\
\text { avoidance }\end{array}$ & -.009 & $-.191^{* * *}$ & $-.204^{* * *}$ & $-.215^{* * *}$ \\
\hline \multicolumn{5}{|l|}{ Step 3} \\
\hline Gender & -.050 & .024 & $-.073^{*}$ & $-.110^{* *}$ \\
\hline $\begin{array}{l}\text { Location of middle } \\
\text { school }\end{array}$ & $-.061^{\#}$ & .012 & $-.093^{* *}$ & -.044 \\
\hline Master approach & $.388^{* * *}$ & $.321^{* * *}$ & $.308^{* * *}$ & .041 \\
\hline Mastery avoidance & $.194^{* * *}$ & .076 & .065 & .050 \\
\hline $\begin{array}{l}\text { Performance } \\
\text { approach }\end{array}$ & $.068^{\#}$ & $.238^{* * *}$ & .051 & $.094^{*}$ \\
\hline $\begin{array}{l}\text { Performance } \\
\text { avoidance }\end{array}$ & .002 & $-.181^{* * *}$ & $-.191^{* * *}$ & $-.207^{* * *}$ \\
\hline$\underset{\times}{\text { Mastery approach }}$ & $-.100^{* *}$ & -.009 & $-.067^{\#}$ & -.063 \\
\hline $\begin{array}{l}\text { mastery avoidance } \\
\text { Mastery approach }\end{array}$ & & & & \\
\hline $\begin{array}{l}\quad \times \\
\text { performance approach } \\
\text { Mastery approach }\end{array}$ & .036 & -.010 & .012 & -.016 \\
\hline performance avoidance & $-.079^{\#}$ & $-.099^{*}$ & -.003 & -.002 \\
\hline Mastery avoidance & -.034 & $.114^{*}$ & .021 & .057 \\
\hline
\end{tabular}




\begin{tabular}{lllll}
\hline $\begin{array}{l}\times \\
\text { performance approach } \\
\text { Mastery avoidance } \\
\times\end{array}$ & & & & \\
\\
$\begin{array}{l}\text { performance avoidance } \\
\text { Performance approach } \\
\times\end{array}$ \\
$\begin{array}{l}\text { performance avoidance } \\
\mathrm{R}^{2}\end{array}$
\end{tabular}

Note: ${ }^{\#} p<.10 .{ }^{*} p<.05 .{ }^{* *} p<.01 .^{* * *} p<.001$. 


\section{Table A24}

Summary of Hierarchical and Simultaneous Regression Analysis for SAL Variables Predicting Metacognitive Strategies, Perceived Academic Efficacy, Affect at School, and Academic Performance in College English Classes

\begin{tabular}{|c|c|c|c|c|}
\hline \multirow[t]{2}{*}{ Variables } & $\begin{array}{c}\text { Metacognitive } \\
\text { strategies }\end{array}$ & $\begin{array}{c}\text { Perceived } \\
\text { academic } \\
\text { efficacy }\end{array}$ & $\begin{array}{c}\text { Affect } \\
\text { at } \\
\text { school }\end{array}$ & $\begin{array}{c}\text { Academic } \\
\text { performance }\end{array}$ \\
\hline & $\beta_{1}$ & $\beta_{2}$ & $\beta_{3}$ & $\beta_{4}$ \\
\hline \multicolumn{5}{|l|}{ Step 1} \\
\hline Gender & -.014 & -.027 & $-.091^{*}$ & $-.124^{* *}$ \\
\hline $\begin{array}{l}\text { Location of middle } \\
\text { school }\end{array}$ & .026 & $.089^{*}$ & -.033 & .053 \\
\hline \multicolumn{5}{|l|}{ Step 2} \\
\hline Gender & .005 & -.007 & -.051 & $-.101^{* *}$ \\
\hline $\begin{array}{l}\text { Location of middle } \\
\text { school }\end{array}$ & .036 & $.097^{* *}$ & -.022 & .055 \\
\hline Deep approach & $.564^{* * *}$ & $.383^{* * *}$ & $.333^{* * *}$ & $-.067^{\#}$ \\
\hline Surface approach & $-.057^{\#}$ & $-.099^{* *}$ & $-.259^{* * *}$ & $-.192^{* * *}$ \\
\hline \multicolumn{5}{|l|}{ Step 3} \\
\hline Gender & .004 & -.007 & -.050 & $-.101^{* *}$ \\
\hline $\begin{array}{l}\text { Location of middle } \\
\text { school }\end{array}$ & .036 & $.097^{* *}$ & -.021 & .055 \\
\hline Deep approach & $.563^{* * *}$ & $.382^{* * *}$ & $.337^{* * *}$ & $-.068^{\#}$ \\
\hline Surface approach & $-.061^{\#}$ & $-.101^{* *}$ & $-.252^{* * *}$ & $-.195^{* * *}$ \\
\hline \multicolumn{5}{|l|}{ Deep approach } \\
\hline$\times$ & .020 & .013 & -.043 & .015 \\
\hline \multicolumn{5}{|l|}{ Surface approach } \\
\hline $\mathrm{R}^{2}$ & .340 & .185 & .233 & .053 \\
\hline
\end{tabular}

Note: ${ }^{\#} p<.10 .{ }^{*} p<.05 .{ }^{* *} p<.01 .{ }^{* * *} p<.001$. 


\section{Table A25}

Summary of Hierarchical and Simultaneous Regression Analysis for SAL Variables Predicting Metacognitive Strategies, Perceived Academic Efficacy, Affect at School, and Academic Performance in Advanced Mathematics Classes

\begin{tabular}{|c|c|c|c|c|}
\hline \multirow[t]{2}{*}{ Variables } & $\begin{array}{c}\text { Metacognitive } \\
\text { strategies }\end{array}$ & $\begin{array}{c}\text { Perceived } \\
\text { academic } \\
\text { efficacy }\end{array}$ & $\begin{array}{c}\text { Affect } \\
\text { at } \\
\text { school }\end{array}$ & $\begin{array}{c}\text { Academic } \\
\text { performance }\end{array}$ \\
\hline & $\beta_{1}$ & $\beta_{2}$ & $\beta_{3}$ & $\beta_{4}$ \\
\hline \multicolumn{5}{|l|}{ Step 1} \\
\hline Gender & $-.078^{*}$ & .005 & $-.085^{*}$ & $-.113^{* *}$ \\
\hline $\begin{array}{l}\text { Location of middle } \\
\text { school }\end{array}$ & -.061 & .011 & -.098 & -.045 \\
\hline \multicolumn{5}{|l|}{ Step 2} \\
\hline Gender & $-.095^{* *}$ & -.006 & $-.091^{* *}$ & $-.113^{* *}$ \\
\hline $\begin{array}{l}\text { Location of middle } \\
\text { school }\end{array}$ & -.003 & .053 & -.047 & -.028 \\
\hline Deep approach & $.594^{* * *}$ & $.408^{* * *}$ & $.412^{* * *}$ & $.109^{* *}$ \\
\hline Surface approach & $-.057^{\#}$ & $-.098^{* *}$ & $-.335^{* * *}$ & $-.171^{* * *}$ \\
\hline \multicolumn{5}{|l|}{ Step 3} \\
\hline Gender & $-.096^{* *}$ & -.005 & $-.090^{* *}$ & $-.113^{* *}$ \\
\hline $\begin{array}{l}\text { Location of middle } \\
\text { school }\end{array}$ & -.004 & .054 & -.046 & -.028 \\
\hline Deep approach & $.591^{* * *}$ & $.411^{* * *}$ & $.415^{* * *}$ & $.109^{* *}$ \\
\hline Surface approach & $-.067^{*}$ & $-.087^{*}$ & $-.324^{* * *}$ & $-.171^{* * *}$ \\
\hline \multicolumn{5}{|l|}{ Deep approach } \\
\hline$\times$ & .045 & -.047 & $-.052^{\#}$ & .000 \\
\hline \multicolumn{5}{|l|}{ Surface approach } \\
\hline $\mathrm{R}^{2}$ & .382 & .199 & .374 & .065 \\
\hline
\end{tabular}

Note: ${ }^{\#} p<.10 .{ }^{*} p<.05 .{ }^{* *} p<.01 .{ }^{* * * *} p<.001$. 


\section{Table A26}

Summary of Hierarchical and Simultaneous Regression Analysis for CHC Values and Goal Orientation Variables Predicting Metacognitive Strategies, Perceived Academic Efficacy, Affect at School, and Academic Performance in College English Classes

\begin{tabular}{|c|c|c|c|c|}
\hline \multirow[t]{2}{*}{ Variables } & $\begin{array}{l}\text { Metacognitive } \\
\text { strategies }\end{array}$ & $\begin{array}{c}\text { Perceived } \\
\text { academic } \\
\text { efficacy }\end{array}$ & $\begin{array}{l}\text { Affect } \\
\text { at } \\
\text { school }\end{array}$ & $\begin{array}{c}\text { Academic } \\
\text { performanc } \\
\mathrm{e}\end{array}$ \\
\hline & $\beta_{1}$ & $\beta_{2}$ & $\beta_{3}$ & $\beta_{4}$ \\
\hline \multicolumn{5}{|l|}{ Step 1} \\
\hline Gender & -.014 & -.027 & $-.091^{*}$ & $-.124^{* *}$ \\
\hline $\begin{array}{l}\text { Location of middle } \\
\text { school }\end{array}$ & .026 & $.089^{*}$ & -.033 & .053 \\
\hline \multicolumn{5}{|l|}{ Step 2} \\
\hline Gender & .053 & .025 & -.040 & $-.113^{* *}$ \\
\hline $\begin{array}{l}\text { Location of middle } \\
\text { school }\end{array}$ & .020 & $.078^{*}$ & -.038 & .041 \\
\hline $\mathrm{CHC}$ values & .030 & $.101^{*}$ & $.154^{* * * *}$ & .053 \\
\hline Master approach & $.325^{* * *}$ & $.245^{* * *}$ & $.205^{* * *}$ & .016 \\
\hline Mastery avoidance & $.176^{* * *}$ & .065 & $.094^{*}$ & -.017 \\
\hline $\begin{array}{l}\text { Performance } \\
\text { approach }\end{array}$ & .015 & $.090^{*}$ & -.033 & $.174^{* * *}$ \\
\hline $\begin{array}{l}\text { Performance } \\
\text { avoidance }\end{array}$ & -.050 & $-.157^{* * *}$ & $-.181^{* * *}$ & $-.214^{* * *}$ \\
\hline \multicolumn{5}{|l|}{ Step 3} \\
\hline Gender & .052 & .026 & -.039 & $-.111^{* *}$ \\
\hline $\begin{array}{l}\text { Location of middle } \\
\text { school }\end{array}$ & .017 & $.075^{*}$ & -.037 & .043 \\
\hline $\mathrm{CHC}$ values & .039 & $.111^{*}$ & $.163^{* * *}$ & .056 \\
\hline Master approach & $.343^{* * *}$ & $.269^{* * *}$ & $.236^{* * * *}$ & .023 \\
\hline Mastery avoidance & $.167^{* * *}$ & .055 & $.082^{\#}$ & -.017 \\
\hline $\begin{array}{l}\text { Performance } \\
\text { approach }\end{array}$ & .014 & $.090^{*}$ & -.033 & $.175^{* * *}$ \\
\hline $\begin{array}{l}\text { Performance } \\
\text { avoidance }\end{array}$ & -.048 & $-.157^{* * *}$ & $-.178^{* * *}$ & $-.218^{* * *}$ \\
\hline Mastery approach & & & & \\
\hline $\begin{array}{c}\times \\
\mathrm{CHC} \text { values }\end{array}$ & .007 & .047 & $.090^{\#}$ & .073 \\
\hline $\begin{array}{l}\text { Mastery avoidance } \\
\times \\
\mathrm{CHC} \text { values }\end{array}$ & $.113^{*}$ & $.103^{*}$ & .016 & -.081 \\
\hline$\underset{\times}{\text { Performance approach }}$ & .018 & .006 & .046 & .006 \\
\hline
\end{tabular}




\begin{tabular}{lllll}
\hline $\begin{array}{l}\text { CHC values } \\
\text { Performance avoidance } \\
\times\end{array}$ & & & & \\
$\begin{array}{c}\times \\
\text { CHC values }\end{array}$ & -.030 & -.022 & $-.077^{\#}$ & .010 \\
\hline $\mathrm{R}^{2}$ & .228 & .183 & .167 & .080 \\
\hline
\end{tabular}

Note: ${ }^{\#} p<.10 .{ }^{*} p<.05 .{ }^{* *} p<.01 .{ }^{* * *} p<.001$. 


\section{Table A27}

Summary of Hierarchical and Simultaneous Regression Analysis for CHC Values and Goal Orientation Variables Predicting Metacognitive Strategies, Perceived Academic Efficacy, Affect at School, and Academic Performance in Advanced Mathematics Classes

\begin{tabular}{|c|c|c|c|c|}
\hline \multirow[t]{2}{*}{ Variables } & $\begin{array}{l}\text { Metacognitive } \\
\text { strategies }\end{array}$ & $\begin{array}{c}\text { Perceived } \\
\text { academic } \\
\text { efficacy }\end{array}$ & $\begin{array}{l}\text { Affect } \\
\text { at } \\
\text { school }\end{array}$ & $\begin{array}{c}\text { Academic } \\
\text { performance }\end{array}$ \\
\hline & $\beta_{1}$ & $\beta_{2}$ & $\beta_{3}$ & $\beta_{4}$ \\
\hline \multicolumn{5}{|l|}{ Step 1} \\
\hline Gender & $-.078^{*}$ & .005 & $-.085^{*}$ & $-.113^{* *}$ \\
\hline $\begin{array}{l}\text { Location of middle } \\
\text { school }\end{array}$ & $-.061^{\#}$ & .011 & $-.098^{* *}$ & -.045 \\
\hline \multicolumn{5}{|l|}{ Step 2} \\
\hline Gender & -.047 & .038 & $-.063^{\#}$ & $-.113^{* *}$ \\
\hline $\begin{array}{l}\text { Location of middle } \\
\text { school }\end{array}$ & $-.053^{\#}$ & .017 & $-.088^{* *}$ & -.044 \\
\hline $\mathrm{CHC}$ values & $.081^{*}$ & $.164^{* * *}$ & $.141^{* * *}$ & -.048 \\
\hline Master approach & $.395^{* * *}$ & $.295^{* * *}$ & $.273^{* * *}$ & .060 \\
\hline Mastery avoidance & $.187^{* * *}$ & .037 & .062 & .059 \\
\hline $\begin{array}{l}\text { Performance } \\
\text { approach }\end{array}$ & .016 & $.173^{* * *}$ & .000 & $.109^{*}$ \\
\hline $\begin{array}{l}\text { Performance } \\
\text { avoidance }\end{array}$ & -.016 & $-.206^{* * *}$ & $-.217^{* * *}$ & $-.211^{* * *}$ \\
\hline \multicolumn{5}{|l|}{ Step 3} \\
\hline Gender & -.049 & .038 & $-.063^{\#}$ & $-.114^{* *}$ \\
\hline $\begin{array}{l}\text { Location of middle } \\
\text { school }\end{array}$ & $-.055^{\#}$ & .014 & $-.087^{*}$ & -.045 \\
\hline $\mathrm{CHC}$ values & $.080^{*}$ & $.163^{* * *}$ & $.139^{* *}$ & -.046 \\
\hline Master approach & $.388^{* * *}$ & $.291^{* * *}$ & $.276^{* * *}$ & .056 \\
\hline Mastery avoidance & $.192^{* * *}$ & .042 & .064 & .060 \\
\hline $\begin{array}{l}\text { Performance } \\
\text { approach }\end{array}$ & .014 & $.176^{* * *}$ & .000 & $.108^{*}$ \\
\hline $\begin{array}{l}\text { Performance } \\
\text { avoidance }\end{array}$ & -.012 & $-.217^{* * *}$ & $-.217^{* * *}$ & $-.213^{* * *}$ \\
\hline Mastery approach & & & & \\
\hline $\begin{array}{c}\times \\
\mathrm{CHC} \text { values }\end{array}$ & -.062 & .029 & .015 & -.011 \\
\hline Mastery avoidance & & & & \\
\hline $\begin{array}{c}\times \\
\mathrm{CHC} \text { values }\end{array}$ & .071 & .044 & .041 & .013 \\
\hline$\underset{\times}{\operatorname{Performance} \text { approach }}$ & -.017 & -.063 & -.031 & .000 \\
\hline
\end{tabular}




\begin{tabular}{lllll}
\hline $\begin{array}{l}\text { CHC values } \\
\text { Performance avoidance } \\
\times\end{array}$ & & & & \\
$\begin{array}{c}\times \\
\text { CHC values }\end{array}$ & -.004 & .057 & .005 & .009 \\
\hline $\mathrm{R}^{2}$ & .330 & .278 & .223 & .072 \\
\hline
\end{tabular}

Note: ${ }^{\#} p<.10 .{ }^{*} p<.05 .{ }^{* *} p<.01 .{ }^{* * *} p<.001$. 


\section{Table A28}

Summary of Hierarchical and Simultaneous Regression Analysis for CHC Values and SAL Predicting Metacognitive Strategies, Perceived Academic Efficacy, Affect at School, and Academic Performance in College English Classes

\begin{tabular}{|c|c|c|c|c|}
\hline \multirow[t]{2}{*}{ Variables } & $\begin{array}{c}\text { Metacognitive } \\
\text { strategies }\end{array}$ & $\begin{array}{l}\text { Perceived } \\
\text { academic } \\
\text { efficacy }\end{array}$ & $\begin{array}{c}\text { Affect } \\
\text { at } \\
\text { school }\end{array}$ & $\begin{array}{c}\text { Academic } \\
\text { performance }\end{array}$ \\
\hline & $\beta_{1}$ & $\beta_{2}$ & $\beta_{3}$ & $\beta_{4}$ \\
\hline \multicolumn{5}{|l|}{ Step 1} \\
\hline Gender & -.014 & -.027 & $-.091^{*}$ & $-.124^{* *}$ \\
\hline $\begin{array}{l}\text { Location of middle } \\
\text { school }\end{array}$ & .026 & $.089^{*}$ & -.033 & .053 \\
\hline \multicolumn{5}{|l|}{ Step 2} \\
\hline Gender & 018 & .011 & -.035 & $-.091^{*}$ \\
\hline $\begin{array}{l}\text { Location of middle } \\
\text { school }\end{array}$ & .038 & $.100^{* *}$ & -.020 & .057 \\
\hline $\mathrm{CHC}$ values & $.126^{* * *}$ & $.161^{* * *}$ & $.146^{* * *}$ & $.090^{*}$ \\
\hline Deep approach & $.539^{* * *}$ & $.350^{* * *}$ & $.304^{* * *}$ & $-.085^{*}$ \\
\hline Surface approach & $-.059^{\#}$ & $-.101^{* *}$ & $-.261^{* * *}$ & $-.194^{* * *}$ \\
\hline \multicolumn{5}{|l|}{ Step 3} \\
\hline Gender & .018 & .014 & -.034 & $-.090^{*}$ \\
\hline $\begin{array}{l}\text { Location of middle } \\
\text { school }\end{array}$ & .032 & $.101^{* *}$ & -.027 & .056 \\
\hline $\mathrm{CHC}$ values & $.137^{* * *}$ & $.165^{* * *}$ & $.161^{* * *}$ & $.093^{*}$ \\
\hline Deep approach & $.525^{* * *}$ & $.346^{* * *}$ & $.286^{* * *}$ & $-.088^{*}$ \\
\hline Surface approach & $-.062^{\#}$ & $-.100^{* *}$ & $-.264^{* * *}$ & $-.194^{* * *}$ \\
\hline $\begin{array}{c}\text { Deep approach } \\
\times \\
\text { CHC values }\end{array}$ & $.094^{* *}$ & .027 & $.119^{* *}$ & .019 \\
\hline $\begin{array}{c}\text { Surface approach } \\
\times \\
\text { CHC values }\end{array}$ & .039 & -.043 & .020 & -.001 \\
\hline $\mathrm{R}^{2}$ & .362 & .213 & .264 & .061 \\
\hline
\end{tabular}

Note: ${ }^{\#} p<.10 .{ }^{*} p<.05 .{ }^{* *} p<.01 .{ }^{* * *} p<.001$. 


\section{Table A29}

Summary of Hierarchical and Simultaneous Regression Analysis for CHC Values and SAL Predicting Metacognitive Strategies, Perceived Academic Efficacy, Affect at School, and Academic Performance in Advanced Mathematics Classes

\begin{tabular}{|c|c|c|c|c|}
\hline Variables & $\begin{array}{c}\text { Metacognitive } \\
\text { strategies }\end{array}$ & $\begin{array}{c}\text { Perceived } \\
\text { academic } \\
\text { efficacy }\end{array}$ & $\begin{array}{c}\text { Affect } \\
\text { at } \\
\text { school }\end{array}$ & $\begin{array}{c}\text { Academic } \\
\text { performance }\end{array}$ \\
\hline & $\beta_{1}$ & $\beta_{2}$ & $\beta_{3}$ & $\beta_{4}$ \\
\hline \multicolumn{5}{|l|}{ Step 1} \\
\hline Gender & $-.078^{*}$ & .005 & $-.085^{*}$ & $-.113^{* *}$ \\
\hline $\begin{array}{l}\text { Location of middle } \\
\text { school }\end{array}$ & -.061 & .011 & $-.098^{* *}$ & -.045 \\
\hline \multicolumn{5}{|l|}{ Step 2} \\
\hline Gender & $-.080^{* *}$ & .020 & $-.081^{* *}$ & $-.118^{* *}$ \\
\hline $\begin{array}{l}\text { Location of middle } \\
\text { school }\end{array}$ & -.004 & .051 & -.048 & -.028 \\
\hline $\mathrm{CHC}$ values & $.126^{* * *}$ & $.214^{* * *}$ & $.082^{*}$ & -.041 \\
\hline Deep approach & $.554^{* * *}$ & $.341^{* * *}$ & $.386^{* * *}$ & $.121^{* *}$ \\
\hline Surface approach & $-.059^{\#}$ & $-.101^{* *}$ & $-.336^{* * *}$ & $-.170^{* * *}$ \\
\hline \multicolumn{5}{|l|}{ Step 3} \\
\hline Gender & $-.080^{* *}$ & .020 & $-.081^{* *}$ & $-.118^{* *}$ \\
\hline $\begin{array}{l}\text { Location of middle } \\
\text { school }\end{array}$ & -.008 & .052 & -.047 & -.032 \\
\hline $\mathrm{CHC}$ values & $.133^{* * *}$ & $.211^{* * *}$ & $.082^{*}$ & -.032 \\
\hline Deep approach & $.550^{* * *}$ & $.343^{* * *}$ & $.386^{* * *}$ & $.115^{* *}$ \\
\hline Surface approach & $-.065^{*}$ & $-.100^{* *}$ & $-.336^{* * *}$ & $-.178^{* * *}$ \\
\hline Deep approach & & & & \\
\hline$\times$ & .019 & -.016 & .002 & .034 \\
\hline $\begin{array}{l}\text { CHC values } \\
\text { Surface approach }\end{array}$ & & & & \\
\hline $\begin{array}{c}\times \\
\text { CHC values }\end{array}$ & .047 & -.009 & -.004 & .061 \\
\hline $\mathrm{R}^{2}$ & .396 & .237 & .378 & .070 \\
\hline
\end{tabular}

Note: ${ }^{\#} p<.10 .{ }^{*} p<.05 .{ }^{* *} p<.01 .{ }^{* * *} p<.001$. 


\section{APPENDIX B}

\section{SCALES AND ITEMS}

Goal Orientation Scales (revised Elliot \& Mcgregor, 2001)

Mastery Approach: 2, 6, 9, 12, 18

Mastery Avoidance: 3, 10, 13, 15, 17

Performance Approach: 4, 8, 14, 16, 20

Performance Avoidance: 1, 5, 7, 11, 19

1. My fear of performing poorly in this class is often what motivates me.

2. I want to learn as much as possible from this class.

3. I am often concerned that I may not learn all that there is to learn in this class.

4. I would feel really good if I were the only one who could answer the teacher's question in class.

5. It's very important for me that I don't look stupid in this class.

6. I work hard to learn new things in this class.

7. One of my main goals is to avoid looking like I can't do my work.

8. I want to do better than the other students in this class.

9. It is important for me to understand the content of this course as thoroughly as possible.

10. Sometimes I'm afraid that I may not understand the content of this class as thoroughly as I'd like.

11. My goal in this class is to avoid performing poorly.

12. I do my school work to get better at it.

13. I am anxious that I may not master all that is supposed to learn in this class.

14. It is important for me to do better than other students.

15. I worry that I may not learn all that I possibly could in this class.

16. It is important for me to do well compared to others in this class.

17. I feel uneasy that I may not understand what is to learn in this class.

18. I desire to completely master the material presented in this class.

19. I just want to avoid doing poorly in this class.

20. My goal in this class is to get a better grade than most of the other students.

\section{Culture Value Scales}

Sense of Learning Duty (self-made): 4, 7, 10, 15, 24

Utility Value (Miller, DeBacker \& Greene, 1999; $N=5, \alpha=.91): 2,8,13,16,20$

Group Goals (Self-made based on Salili, Chiu, \& Lai, 2001)

- Family-oriented goals: 1, 5, 17, 19, 21

- Peer-oriented goals: 3, 11, 14, 18, 23

- Teacher-oriented goals: 6, 9, 12, 22, 25

1. I work to make my family regard me as their pride and honour.

2. I do the work assigned in this class because my achievement is important for attaining my dream.

3. I don't want to stand out too much because it will make my friends feel we are not the 
same.

4. I work hard because learning is a student's duty.

5. I work hard in school so that my family will be proud of me.

6. An important reason that I do my school work is to please my teacher.

7. I just follow my conscience to work hard.

8. I do the work assigned in this class because my achievement plays a role in reaching my future goals.

9. I do my work because I want the teacher to like me.

10. I make efforts to do well because it gives me a feeling that I am doing the right thing.

11. I sometimes pretend to do worse because I want my friends to feel no difference between us.

12. I want to get better at school in order to make my teacher satisfied.

13. I do the work assigned in this class because understanding this content is important for becoming the person I want to be.

14. I don't want to excel too much for fear of losing friends.

15. Regardless of results, to study long hours makes me feel less guilty.

16. I do the work assigned in this class because learning the content plays a role in reaching my future goals.

17. I make efforts because good performance will make my parents proud of me.

18. To get accepted by my friends I will purposefully make our differences unrecognizable.

19. I do my school work to bring honour to my family

20. I do the work assigned in this class because learning this material is important for attaining my dreams.

21. An important reason why I do my school work is that I want to be a credit to my family.

22. I do my work because I want to live up to my teacher's expectation.

23. To be accepted by my friends I sometimes let my school work slip.

24. I will feel guilty if I don't study hard.

25. I work hard because I don't want to let down my teacher.

Deep Approach

Student Approaches to Learning (SAL) Scales (Biggs et al., 2001)

- Deep motive $(\alpha=.62): 2,6,10,14,18$

- Deep Strategy $(\alpha=.63): 1,5,8,13,17$

Surface Approach

- Surface motive $(\alpha=.72): 4,9,12,15,20$

- $\quad$ Surface strategy $(\alpha=.57): 3,7,11,16,19$

1. I find that I have to do enough work on a topic so that I can form my own conclusions before I am satisfied.

2. I find that at times studying this course gives me a feeling of deep personal satisfaction.

3. I generally restrict my study to what is specifically set as I think it is unnecessary to do anything extra. 
4. I do not find my course very interesting so I keep my work to the minimum.

5. I find most new topics interesting and often spend extra time trying to obtain more information about them.

6. I find that studying academic topics in this course can at times be as exciting as a good novel or movie.

7. I only study seriously what's given out in class or in the course outlines.

8. I test myself on important topics until I understand them completely.

9. I find I can get by in most assessments by memorizing key sections rather than trying to understand them.

10. I work hard at my studies because I find the course material interesting.

11. I believe that lecturers shouldn't expect students to spend significant amounts of time studying material everyone knows won't be examined.

12. I see no point in learning material which is not likely to be in the examination.

13. I spend a lot of my free time finding out more about interesting topics which have been discussed in different classes.

14. I feel that virtually any topic in this course can be highly interesting once I get into it.

15. I find it is not helpful to study topics in depth. It confuses and wastes time, when all you need is a passing acquaintance with topics.

16. I find the best way to pass examinations is to try to remember answers to likely questions.

17. I make a point of looking at most of the suggested readings that go with the lectures.

18. In this course I come to most classes with questions in mind that I want answering.

19. I learn some things by rote, going over and over them until I know them by heart even if I do not understand them.

20. My aim is to pass the course while doing as little work as possible.

Metacognitive Strategy and School Well-being Scales

Metacognitive strategies (Yong, 2005): 4, 7, 10, 13, 16, 19

School Well-being (Kaplan \& Maehr, 1999)

- Affect at school $(N=7, \alpha=.82): 1,3,6,8,11,14,18$

- Perceived academic efficacy $(N=6, \alpha=.84): 2,5,9,12,15,17$

1. I often feel bored in school. (reversed)

2. I'm certain I can master the skills taught in school this year.

3. I like being in school.

4. I skim through the unit to see how it is organized before I read it thoroughly.

5. I can do even the hardest school work if I try.

6. I am happier when I am at school than when I am not at school.

7. If I become confused about something I read, I go back to my previous notes and sort it out.

8. I am often angry when I'm at school. (reversed)

9. If I have enough time, I can do a good job on all my school work.

10. I try to determine which concepts I don't understand well.

11. I often feel frustrated when I am doing school work. (reversed)

12. I can do almost all the work in school if I don't give up. 
13. I try to determine the way I study according to the course requirements and the instructor's teaching style.

14. Most of the time, being in school puts me in a good mood.

15. Even if the work in school is hard, I can learn it.

16. I set goals for myself in order to direct my study activities.

17. I'm certain I can figure out how to do the most difficult school work.

18. School often makes me feel sad. (reversed)

19. I ask myself questions to make sure I understand the material. 


\section{APPENDIX C \\ QUESTIONNAIRE}

(English Version)

\section{A Questionnaire on Motivation, Cultural Values, Learning Processes, and Learning in Chinese Students}

Participant's Demographic Information

1. Gender:

2. Major:

3. Location of Middle School: Rural __ (Y/N) Urban __ (Y/N)

4. Student Number: 


\section{Part One: Cultural Values}

This part is to find out your attitudes towards three cultural values: the perception of learning as a primary and moral duty, utility value or perceived instrumentality of current school success to personally valued future goals, and group goals.

Please indicate the degree to which you agree with each of the statements by circling the response:

1: Strongly Disagree (SD)

2: Disagree (D)

3: Somewhat Disagree (SOD)

4: Undecided (U)

5: Somewhat Agree (SOA)

6: Agree (A)

7: Strongly Agree (SA)

\begin{tabular}{|l|c|c|c|c|c|c|c|}
\hline \multicolumn{1}{|r|}{ Degree of Agreement } & SD & D & SOD & U & SOA & A & SA \\
\hline $\begin{array}{l}\text { 1. I want to make my family regard me } \\
\text { as a source of their pride and honour } \\
\text { for my school work. }\end{array}$ & 1 & 2 & 3 & 4 & 5 & 6 & 7 \\
\hline $\begin{array}{l}\text { 2. I believe that my achievement in } \\
\text { school work will be important for } \\
\text { attaining my dream. }\end{array}$ & 1 & 2 & 3 & 4 & 5 & 6 & 7 \\
\hline $\begin{array}{l}\text { 3. I do not want to stand out in my } \\
\text { school work in a way that would } \\
\text { make my friends feel we are not the } \\
\text { same. }\end{array}$ & 1 & 2 & 3 & 4 & 5 & 6 & 7 \\
\hline $\begin{array}{l}\text { 4. I believe that it's a student's duty to } \\
\text { work hard. }\end{array}$ & 1 & 2 & 3 & 4 & 5 & 6 & 7 \\
\hline $\begin{array}{l}\text { 5. I want my family to be proud of me } \\
\text { for my school work. }\end{array}$ & 1 & 2 & 3 & 4 & 5 & 6 & 7 \\
\hline $\begin{array}{l}\text { 6. I want to please my teacher by doing } \\
\text { my school work. }\end{array}$ & 1 & 2 & 3 & 4 & 5 & 6 & 7 \\
\hline $\begin{array}{l}\text { 7. I believe that my conscience is clear } \\
\text { when working hard. }\end{array}$ & 1 & 2 & 3 & 4 & 5 & 6 & 7 \\
\hline $\begin{array}{l}\text { 8. I believe that my achievement in } \\
\text { school work plays a role in reaching } \\
\text { my future goals. }\end{array}$ & 1 & 2 & 3 & 4 & 5 & 6 & 7 \\
\hline $\begin{array}{l}\text { 9. I want to make the teacher feel } \\
\text { happy about my school work. }\end{array}$ & 1 & 2 & 3 & 4 & 5 & 6 & 7 \\
\hline $\begin{array}{l}\text { 10. I believe that making efforts to do } \\
\text { well gives me a feeling that I am } \\
\text { doing the right thing. }\end{array}$ & 1 & 2 & 3 & 4 & 5 & 6 & 7 \\
\hline
\end{tabular}




\begin{tabular}{|c|c|c|c|c|c|c|c|}
\hline $\begin{array}{l}\text { 11. I don't want my friends to feel any } \\
\text { difference between us. }\end{array}$ & 1 & 2 & 3 & 4 & 5 & 6 & 7 \\
\hline $\begin{array}{l}\text { 12. I want to make my teacher satisfied } \\
\text { with my school work. }\end{array}$ & 1 & 2 & 3 & 4 & 5 & 6 & 7 \\
\hline $\begin{array}{l}\text { 13. I believe that understanding the } \\
\text { content taught at school is important } \\
\text { for becoming the person I want to } \\
\text { be. }\end{array}$ & 1 & 2 & 3 & 4 & 5 & 6 & 7 \\
\hline $\begin{array}{l}\text { 14. I don't want to excel too much for } \\
\text { fear of losing friends. }\end{array}$ & 1 & 2 & 3 & 4 & 5 & 6 & 7 \\
\hline $\begin{array}{l}\text { 15. I believe that regardless of results, } \\
\text { studying long hours makes me feel } \\
\text { less guilty. }\end{array}$ & 1 & 2 & 3 & 4 & 5 & 6 & 7 \\
\hline $\begin{array}{l}\text { 16. I believe that learning the content } \\
\text { taught at school plays a role in } \\
\text { reaching my future goals. }\end{array}$ & 1 & 2 & 3 & 4 & 5 & 6 & 7 \\
\hline $\begin{array}{l}\text { 17. I'd like my parents to be proud of } \\
\text { me for my school work. }\end{array}$ & 1 & 2 & 3 & 4 & 5 & 6 & 7 \\
\hline $\begin{array}{l}\text { 18. I'm willing to hide my strengths in } \\
\text { order to get accepted by my friends. }\end{array}$ & 1 & 2 & 3 & 4 & 5 & 6 & 7 \\
\hline $\begin{array}{l}\text { 19. I want to bring honour to my family } \\
\text { in my school work. }\end{array}$ & 1 & 2 & 3 & 4 & 5 & 6 & 7 \\
\hline $\begin{array}{l}\text { 20. I believe that learning the material } \\
\text { taught at school is important for } \\
\text { attaining my dreams. }\end{array}$ & 1 & 2 & 3 & 4 & 5 & 6 & 7 \\
\hline $\begin{array}{l}\text { 21. I want to bring credit to my family } \\
\text { in my school work. }\end{array}$ & 1 & 2 & 3 & 4 & 5 & 6 & 7 \\
\hline $\begin{array}{l}\text { 22. I want to live up to my teacher's } \\
\text { expectation in my school work. }\end{array}$ & 1 & 2 & 3 & 4 & 5 & 6 & 7 \\
\hline $\begin{array}{l}\text { 23. Sometimes I'd like to let my school } \\
\text { work slip to be accepted by my } \\
\text { friends. }\end{array}$ & 1 & 2 & 3 & 4 & 5 & 6 & 7 \\
\hline $\begin{array}{l}\text { 24. I believe that I will feel guilty if I } \\
\text { don't study hard. }\end{array}$ & 1 & 2 & 3 & 4 & 5 & 6 & 7 \\
\hline $\begin{array}{l}\text { 25. I don't want to let down my teacher } \\
\text { in my school performance. }\end{array}$ & 1 & 2 & 3 & 4 & 5 & 6 & 7 \\
\hline
\end{tabular}




\section{Part Two: Motivation and Learning in the College English Course}

Section A: Achievement Goal Orientations in the College English Course

This section is to find out your reasons of studying hard in the college English course.

Please indicate the degree to which you agree with each of the statements by circling the response:

1: Strongly Disagree (SD)

2: Disagree (D)

3: Somewhat Disagree (SOD)

4: Undecided (U)

5: Somewhat Agree (SOA)

6: Agree (A)

7: Strongly Agree (SA)

\begin{tabular}{|c|c|c|c|c|c|c|c|}
\hline $\begin{array}{l}\text { Degree of Agreement } \\
\text { Achievement Goal } \\
\text { Orientations }\end{array}$ & SD & D & SOD & U & SOA & A & SA \\
\hline $\begin{array}{l}\text { 1. My fear of performing poorly in this } \\
\text { class is often what motivates me. }\end{array}$ & 1 & 2 & 3 & 4 & 5 & 6 & 7 \\
\hline $\begin{array}{l}\text { 2. I want to learn as much as possible } \\
\text { from this class. }\end{array}$ & 1 & 2 & 3 & 4 & 5 & 6 & 7 \\
\hline $\begin{array}{l}\text { 3. I am often concerned that I may not } \\
\text { learn all that there is to learn in this } \\
\text { class. }\end{array}$ & 1 & 2 & 3 & 4 & 5 & 6 & 7 \\
\hline $\begin{array}{l}\text { 4. I would feel really good if I were the } \\
\text { only one who could answer the } \\
\text { teacher's question in class. }\end{array}$ & 1 & 2 & 3 & 4 & 5 & 6 & 7 \\
\hline $\begin{array}{l}\text { 5. It's very important for me that I } \\
\text { don't look stupid in this class. }\end{array}$ & 1 & 2 & 3 & 4 & 5 & 6 & 7 \\
\hline $\begin{array}{l}\text { 6. I work hard to learn new things in } \\
\text { this class. }\end{array}$ & 1 & 2 & 3 & 4 & 5 & 6 & 7 \\
\hline $\begin{array}{l}\text { 7. One of my main goals is to avoid } \\
\text { looking like I can't do my work. }\end{array}$ & 1 & 2 & 3 & 4 & 5 & 6 & 7 \\
\hline $\begin{array}{l}\text { 8. I want to do better than the other } \\
\text { students in this class. }\end{array}$ & 1 & 2 & 3 & 4 & 5 & 6 & 7 \\
\hline $\begin{array}{l}\text { 9. It is important for me to understand } \\
\text { the content of this course as } \\
\text { thoroughly as possible. }\end{array}$ & 1 & 2 & 3 & 4 & 5 & 6 & 7 \\
\hline $\begin{array}{l}\text { 10. Sometimes I'm afraid that I may not } \\
\text { understand the content of this class } \\
\text { as thoroughly as I'd like. }\end{array}$ & 1 & 2 & 3 & 4 & 5 & 6 & 7 \\
\hline $\begin{array}{l}\text { 11. My goal in this class is to avoid } \\
\text { performing poorly. }\end{array}$ & 1 & 2 & 3 & 4 & 5 & 6 & 7 \\
\hline
\end{tabular}




\begin{tabular}{|l|l|l|l|l|l|l|l|}
\hline $\begin{array}{l}\text { 12. I do my school work to get better at } \\
\text { it. }\end{array}$ & 1 & 2 & 3 & 4 & 5 & 6 & 7 \\
\hline $\begin{array}{l}\text { 13. I am anxious that I may not master } \\
\text { all that is supposed to learn in this } \\
\text { class. }\end{array}$ & 1 & 2 & 3 & 4 & 5 & 6 & 7 \\
\hline $\begin{array}{l}\text { 14. It is important for me to do better } \\
\text { than other students. }\end{array}$ & 1 & 2 & 3 & 4 & 5 & 6 & 7 \\
\hline $\begin{array}{l}\text { 15. I worry that I may not learn all that I } \\
\text { possibly could in this class. }\end{array}$ & 1 & 2 & 3 & 4 & 5 & 6 & 7 \\
\hline $\begin{array}{l}\text { 16. It is important for me to do well } \\
\text { compared to others in this class. }\end{array}$ & 1 & 2 & 3 & 4 & 5 & 6 & 7 \\
\hline $\begin{array}{l}\text { 17. I feel uneasy that I may not } \\
\text { understand what is to learn in this } \\
\text { class. }\end{array}$ & 1 & 2 & 3 & 4 & 5 & 6 & 7 \\
\hline $\begin{array}{l}\text { 18. I desire to completely master the } \\
\text { material presented in this class. }\end{array}$ & 1 & 2 & 3 & 4 & 5 & 6 & 7 \\
\hline $\begin{array}{l}\text { 19. I just want to avoid doing poorly in } \\
\text { this class. }\end{array}$ & 1 & 2 & 3 & 4 & 5 & 6 & 7 \\
\hline $\begin{array}{l}\text { 20. My goal in this class is to get a } \\
\text { better grade than most of the other } \\
\text { students. }\end{array}$ & 1 & 2 & 3 & 4 & 5 & 6 & 7 \\
\hline
\end{tabular}

Section B: Student Approaches to Learning (SAL) in the College English Course This section is to find out your motivation for the college English course and the strategies involved in your learning of this course.

Please indicate the degree to which you agree with each of the statements by circling the response:

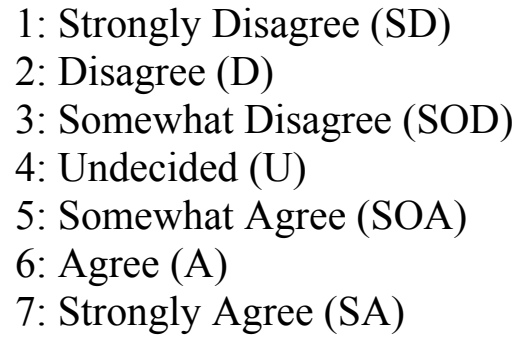

\begin{tabular}{|l|c|c|c|c|c|c|c|}
\hline $\begin{array}{l}\text { Degree of Agreement } \\
\begin{array}{l}\text { Student Approaches } \\
\text { to Learning }\end{array}\end{array}$ & SD & D & SOD & U & SOA & A & SA \\
\hline $\begin{array}{l}\text { 1. I find that I have to do enough work } \\
\text { on a topic so that I can form my own } \\
\text { conclusions before I am satisfied. }\end{array}$ & 1 & 2 & 3 & 4 & 5 & 6 & 7 \\
\hline 2. I find that at times studying this & 1 & 2 & 3 & 4 & 5 & 6 & 7 \\
\hline
\end{tabular}




\begin{tabular}{|l|l|l|l|l|l|l|l|}
\hline $\begin{array}{l}\text { course gives me a feeling of deep } \\
\text { personal satisfaction. }\end{array}$ & & & & & & & \\
\hline $\begin{array}{l}\text { 3. I generally restrict my study to what } \\
\text { is specifically set as I think it is } \\
\text { unnecessary to do anything extra. }\end{array}$ & 1 & 2 & 3 & 4 & 5 & 6 & 7 \\
\hline $\begin{array}{l}\text { 4. I do not find my course very } \\
\text { interesting so I keep my work to the } \\
\text { minimum. }\end{array}$ & 1 & 2 & 3 & 4 & 5 & 6 & 7 \\
\hline $\begin{array}{l}\text { 5. I find most new topics interesting } \\
\text { and often spend extra time trying to } \\
\text { obtain more information about them. }\end{array}$ & 1 & 2 & 3 & 4 & 5 & 6 & 7 \\
\hline $\begin{array}{l}\text { 6. I find that studying academic topics } \\
\text { in this course can at times be as } \\
\text { exciting as a good novel or movie. }\end{array}$ & 1 & 2 & 3 & 4 & 5 & 6 & 7 \\
\hline $\begin{array}{l}\text { 7. I only study seriously what's given } \\
\text { out in class or in the course outlines. }\end{array}$ & 1 & 2 & 3 & 4 & 5 & 6 & 7 \\
\hline $\begin{array}{l}\text { 8. I test myself on important topics } \\
\text { until I understand them completely. }\end{array}$ & 1 & 2 & 3 & 4 & 5 & 6 & 7 \\
\hline $\begin{array}{l}\text { 9. I find I can get by in most } \\
\text { assessments by memorizing key } \\
\text { sections rather than trying to } \\
\text { understand them. }\end{array}$ & 1 & 2 & 3 & 4 & 5 & 6 & 7 \\
\hline $\begin{array}{l}\text { 10. I work hard at my studies because I } \\
\text { find the course material interesting. }\end{array}$ & 1 & 2 & 3 & 4 & 5 & 6 & 7 \\
\hline $\begin{array}{l}\text { 11. I believe that lecturers shouldn't } \\
\text { expect students to spend significant } \\
\text { amounts of time studying material } \\
\text { everyone knows won't be examined. }\end{array}$ & 1 & 2 & 3 & 4 & 5 & 6 & 7 \\
\hline $\begin{array}{l}\text { 12. I see no point in learning material } \\
\text { which is not likely to be in the } \\
\text { examination. }\end{array}$ & 1 & 2 & 3 & 4 & 5 & 6 & 7 \\
\hline $\begin{array}{l}\text { 13. I spend a lot of my free time finding } \\
\text { out more about interesting topics } \\
\text { which have been discussed in } \\
\text { different classes. }\end{array}$ & 1 & 2 & 3 & 4 & 5 & 6 & 7 \\
\hline $\begin{array}{l}\text { 14. I feel that virtually any topic in this } \\
\text { course can be highly interesting once } \\
\text { I get into it. }\end{array}$ & 1 & 2 & 3 & 4 & 5 & 6 & 7 \\
\hline $\begin{array}{l}\text { 15. I find it is not helpful to study topics } \\
\text { in depth. It confuses and wastes } \\
\text { time, when all you need is a passing } \\
\text { acquaintance with topics. }\end{array}$ & 1 & 2 & 3 & 4 & 5 & 6 & 7 \\
\hline $\begin{array}{l}\text { 16. I find the best way to pass } \\
\text { examinations is to try to remember } \\
\text { answers to likely questions. }\end{array}$ & 1 & 2 & 3 & 4 & 5 & 6 & 7 \\
\hline 17. I make a point of looking at most of & 1 & 2 & 3 & 4 & 5 & 6 & 7 \\
\hline
\end{tabular}




\begin{tabular}{|l|l|l|l|l|l|l|l|}
\hline $\begin{array}{l}\text { the suggested readings that go with } \\
\text { the lectures. }\end{array}$ & & & & & & & \\
\hline $\begin{array}{l}\text { 18. In this course I come to most classes } \\
\text { with questions in mind that I want } \\
\text { answering. }\end{array}$ & 1 & 2 & 3 & 4 & 5 & 6 & 7 \\
\hline $\begin{array}{l}\text { 19. I learn some things by rote, going } \\
\text { over and over them until I know } \\
\text { them by heart even if I do not } \\
\text { understand them. }\end{array}$ & 1 & 2 & 3 & 4 & 5 & 6 & 7 \\
\hline $\begin{array}{l}\text { 20. My aim is to pass the course while } \\
\text { doing as little work as possible. }\end{array}$ & 1 & 2 & 3 & 4 & 5 & 6 & 7 \\
\hline
\end{tabular}

Section C: Metacognitive Strategy and School Well-being in the College English Course This section is to find out your use of metacognitive strategies in the college English course and your school well-being.

Please indicate the degree to which you agree with each of the statements by circling the response:
1: Strongly Disagree (SD)
2: Disagree (D)
3: Somewhat Disagree (SOD)
4: Undecided (U)
5: Somewhat Agree (SOA)
6: Agree (A)
7: Strongly Agree (SA)

\begin{tabular}{|c|c|c|c|c|c|c|c|}
\hline $\begin{array}{l}\text { Meta- } \\
\text { Cognitive } \\
\text { Strategies and } \\
\text { School Well-being }\end{array}$ & SD & $\mathrm{D}$ & SOD & $\mathrm{U}$ & SOA & A & SA \\
\hline 1. I often feel bored in school. & 1 & 2 & 3 & 4 & 5 & 6 & 7 \\
\hline $\begin{array}{l}\text { 2. I'm certain I can master the skills } \\
\text { taught in school this year. }\end{array}$ & 1 & 2 & 3 & 4 & 5 & 6 & 7 \\
\hline 3. I like being in school. & 1 & 2 & 3 & 4 & 5 & 6 & 7 \\
\hline $\begin{array}{l}\text { 4. I skim through the unit to see how it } \\
\text { is organized before I read it } \\
\text { thoroughly. }\end{array}$ & 1 & 2 & 3 & 4 & 5 & 6 & 7 \\
\hline $\begin{array}{l}\text { 5. I can do even the hardest school } \\
\text { work if I try. }\end{array}$ & 1 & 2 & 3 & 4 & 5 & 6 & 7 \\
\hline $\begin{array}{l}\text { 6. I am happier when I am at school } \\
\text { than when I am not at school. }\end{array}$ & 1 & 2 & 3 & 4 & 5 & 6 & 7 \\
\hline
\end{tabular}




\begin{tabular}{|l|c|c|c|c|c|c|c|}
\hline $\begin{array}{l}\text { 7. If I become confused about } \\
\text { something I read, I go back to my } \\
\text { previous notes and sort it out. }\end{array}$ & 1 & 2 & 3 & 4 & 5 & 6 & 7 \\
\hline 8. I am often angry when I'm at school. & 1 & 2 & 3 & 4 & 5 & 6 & 7 \\
\hline $\begin{array}{l}\text { 9. If I have enough time, I can do a } \\
\text { good job on all my school work. }\end{array}$ & 1 & 2 & 3 & 4 & 5 & 6 & 7 \\
\hline $\begin{array}{l}\text { 10. I try to determine which concepts I } \\
\text { don't understand well. }\end{array}$ & 1 & 2 & 3 & 4 & 5 & 6 & 7 \\
\hline $\begin{array}{l}\text { 11. I often feel frustrated when I am } \\
\text { doing school work. }\end{array}$ & 1 & 2 & 3 & 4 & 5 & 6 & 7 \\
\hline $\begin{array}{l}\text { 12. I can do almost all the work in } \\
\text { school if I don't give up. }\end{array}$ & 1 & 2 & 3 & 4 & 5 & 6 & 7 \\
\hline $\begin{array}{l}\text { 13. I try to determine the way I study } \\
\text { according to the course requirements } \\
\text { and the instructor's teaching style. }\end{array}$ & 1 & 2 & 3 & 4 & 5 & 6 & 7 \\
\hline $\begin{array}{l}\text { 14. Most of the time, being in school } \\
\text { puts me in a good mood. }\end{array}$ & 1 & 2 & 3 & 4 & 5 & 6 & 7 \\
\hline $\begin{array}{l}\text { 15. Even if the work in school is hard, I } \\
\text { can learn it. }\end{array}$ & 1 & 2 & 3 & 4 & 5 & 6 & 7 \\
\hline $\begin{array}{l}\text { 16. I set goals for myself in order to } \\
\text { direct my study activities. }\end{array}$ & 1 & 2 & 3 & 4 & 5 & 6 & 7 \\
\hline $\begin{array}{l}\text { 17. I'm certain I can figure out how to } \\
\text { do the most difficult school work. }\end{array}$ & 1 & 2 & 3 & 4 & 5 & 6 & 7 \\
\hline 18. School often makes me feel sad. & 1 & 2 & 3 & 4 & 5 & 6 & 7 \\
\hline $\begin{array}{l}\text { 19. I ask myself questions to make sure I } \\
\text { understand the material. }\end{array}$ & 1 & 2 & 3 & 4 & 5 & 6 & 7 \\
\hline
\end{tabular}




\section{Part Three: Motivation and Learning in Advanced Mathematics}

Section A: Achievement Goal Orientations in the Advanced Mathematics course This section is to find out your reasons of studying hard in the advanced mathematics course.

Please indicate the degree to which you agree with each of the statements by circling the response:
1: Strongly Disagree (SD)
2: Disagree (D)
3: Somewhat Disagree (SOD)
4: Undecided (U)
5: Somewhat Agree (SOA)
6: Agree (A)
7: Strongly Agree (SA)

\begin{tabular}{|c|c|c|c|c|c|c|c|}
\hline $\begin{array}{l}\text { Degree of Agreement } \\
\text { Orientations }\end{array}$ & $\mathrm{SD}$ & D & SOD & $\mathrm{U}$ & SOA & A & $\mathrm{SA}$ \\
\hline $\begin{array}{l}\text { 1. My fear of performing poorly in this } \\
\text { class is often what motivates me. }\end{array}$ & 1 & 2 & 3 & 4 & 5 & 6 & 7 \\
\hline $\begin{array}{l}\text { 2. I want to learn as much as possible } \\
\text { from this class. }\end{array}$ & 1 & 2 & 3 & 4 & 5 & 6 & 7 \\
\hline $\begin{array}{l}\text { 3. I am often concerned that I may not } \\
\text { learn all that there is to learn in this } \\
\text { class. }\end{array}$ & 1 & 2 & 3 & 4 & 5 & 6 & 7 \\
\hline $\begin{array}{l}\text { 4. I would feel really good if I were the } \\
\text { only one who could answer the } \\
\text { teacher's question in class. }\end{array}$ & 1 & 2 & 3 & 4 & 5 & 6 & 7 \\
\hline $\begin{array}{l}\text { 5. It's very important for me that I } \\
\text { don't look stupid in this class. }\end{array}$ & 1 & 2 & 3 & 4 & 5 & 6 & 7 \\
\hline $\begin{array}{l}\text { 6. I work hard to learn new things in } \\
\text { this class. }\end{array}$ & 1 & 2 & 3 & 4 & 5 & 6 & 7 \\
\hline $\begin{array}{l}\text { 7. One of my main goals is to avoid } \\
\text { looking like I can't do my work. }\end{array}$ & 1 & 2 & 3 & 4 & 5 & 6 & 7 \\
\hline $\begin{array}{l}\text { 8. I want to do better than the other } \\
\text { students in this class. }\end{array}$ & 1 & 2 & 3 & 4 & 5 & 6 & 7 \\
\hline $\begin{array}{l}\text { 9. It is important for me to understand } \\
\text { the content of this course as } \\
\text { thoroughly as possible. }\end{array}$ & 1 & 2 & 3 & 4 & 5 & 6 & 7 \\
\hline $\begin{array}{l}\text { 10. Sometimes I'm afraid that I may not } \\
\text { understand the content of this class } \\
\text { as thoroughly as I'd like. }\end{array}$ & 1 & 2 & 3 & 4 & 5 & 6 & 7 \\
\hline 11. My goal in this class is to avoid & 1 & 2 & 3 & 4 & 5 & 6 & 7 \\
\hline
\end{tabular}




\begin{tabular}{|l|l|l|l|l|l|l|l|}
\hline performing poorly. & & & & & & & \\
\hline $\begin{array}{l}\text { 12. I do my school work to get better at } \\
\text { it. }\end{array}$ & 1 & 2 & 3 & 4 & 5 & 6 & 7 \\
\hline $\begin{array}{l}\text { 13. I am anxious that I may not master } \\
\text { all that is supposed to learn in this } \\
\text { class. }\end{array}$ & 1 & 2 & 3 & 4 & 5 & 6 & 7 \\
\hline $\begin{array}{l}\text { 14. It is important for me to do better } \\
\text { than other students. }\end{array}$ & 1 & 2 & 3 & 4 & 5 & 6 & 7 \\
\hline $\begin{array}{l}\text { 15. I worry that I may not learn all that I } \\
\text { possibly could in this class. }\end{array}$ & 1 & 2 & 3 & 4 & 5 & 6 & 7 \\
\hline $\begin{array}{l}\text { 16. It is important for me to do well } \\
\text { compared to others in this class. }\end{array}$ & 1 & 2 & 3 & 4 & 5 & 6 & 7 \\
\hline $\begin{array}{l}\text { 17. I feel uneasy that I may not } \\
\text { understand what is to learn in this } \\
\text { class. }\end{array}$ & 1 & 2 & 3 & 4 & 5 & 6 & 7 \\
\hline $\begin{array}{l}\text { 18. I desire to completely master the } \\
\text { material presented in this class. }\end{array}$ & 1 & 2 & 3 & 4 & 5 & 6 & 7 \\
\hline $\begin{array}{l}\text { 19. I just want to avoid doing poorly in } \\
\text { this class. }\end{array}$ & 1 & 2 & 3 & 4 & 5 & 6 & 7 \\
\hline $\begin{array}{l}\text { 20. My goal in this class is to get a } \\
\text { better grade than most of the other } \\
\text { students. }\end{array}$ & 1 & 2 & 3 & 4 & 5 & 6 & 7 \\
\hline
\end{tabular}

Section B: Student Approaches to Learning (SAL) in the Advanced Mathematics course This section is to find out your motivation for the advanced mathematics course and the strategies involved in your learning of this course.

Please indicate the degree to which you agree with each of the statements by circling the response:
1: Strongly Disagree (SD)
2: Disagree (D)
3: Somewhat Disagree (SOD)
4: Undecided (U)
5: Somewhat Agree (SOA)
6: Agree (A)
7: Strongly Agree (SA)

\begin{tabular}{|l|c|c|c|c|c|c|c|}
\hline $\begin{array}{l}\text { Degree of Agreement } \\
\text { Student Approaches } \\
\text { to Learning }\end{array}$ & SD & D & SOD & U & SOA & A & SA \\
\hline $\begin{array}{l}\text { 1. I find that I have to do enough work } \\
\text { on a topic so that I can form my own } \\
\text { conclusions before I am satisfied. }\end{array}$ & 1 & 2 & 3 & 4 & 5 & 6 & 7 \\
\hline
\end{tabular}




\begin{tabular}{|c|c|c|c|c|c|c|c|}
\hline $\begin{array}{l}\text { 2. I find that at times studying this } \\
\text { course gives me a feeling of deep } \\
\text { personal satisfaction. }\end{array}$ & 1 & 2 & 3 & 4 & 5 & 6 & 7 \\
\hline $\begin{array}{l}\text { 3. I generally restrict my study to what } \\
\text { is specifically set as I think it is } \\
\text { unnecessary to do anything extra. }\end{array}$ & 1 & 2 & 3 & 4 & 5 & 6 & 7 \\
\hline $\begin{array}{l}\text { 4. I do not find my course very } \\
\text { interesting so I keep my work to the } \\
\text { minimum. }\end{array}$ & 1 & 2 & 3 & 4 & 5 & 6 & 7 \\
\hline $\begin{array}{l}\text { 5. I find most new topics interesting } \\
\text { and often spend extra time trying to } \\
\text { obtain more information about them. }\end{array}$ & 1 & 2 & 3 & 4 & 5 & 6 & 7 \\
\hline $\begin{array}{l}\text { 6. I find that studying academic topics } \\
\text { in this course can at times be as } \\
\text { exciting as a good novel or movie. }\end{array}$ & 1 & 2 & 3 & 4 & 5 & 6 & 7 \\
\hline $\begin{array}{l}\text { 7. I only study seriously what's given } \\
\text { out in class or in the course outlines. }\end{array}$ & 1 & 2 & 3 & 4 & 5 & 6 & 7 \\
\hline $\begin{array}{l}\text { 8. I test myself on important topics } \\
\text { until I understand them completely. }\end{array}$ & 1 & 2 & 3 & 4 & 5 & 6 & 7 \\
\hline $\begin{array}{l}\text { 9. I find I can get by in most } \\
\text { assessments by memorizing key } \\
\text { sections rather than trying to } \\
\text { understand them. }\end{array}$ & 1 & 2 & 3 & 4 & 5 & 6 & 7 \\
\hline $\begin{array}{l}\text { 10. I work hard at my studies because I } \\
\text { find the course material interesting. }\end{array}$ & 1 & 2 & 3 & 4 & 5 & 6 & 7 \\
\hline $\begin{array}{l}\text { 11. I believe that lecturers shouldn't } \\
\text { expect students to spend significant } \\
\text { amounts of time studying material } \\
\text { everyone knows won't be examined. }\end{array}$ & 1 & 2 & 3 & 4 & 5 & 6 & 7 \\
\hline $\begin{array}{l}\text { 12. I see no point in learning material } \\
\text { which is not likely to be in the } \\
\text { examination. }\end{array}$ & 1 & 2 & 3 & 4 & 5 & 6 & 7 \\
\hline $\begin{array}{l}\text { 13. I spend a lot of my free time finding } \\
\text { out more about interesting topics } \\
\text { which have been discussed in } \\
\text { different classes. }\end{array}$ & 1 & 2 & 3 & 4 & 5 & 6 & 7 \\
\hline $\begin{array}{l}\text { 14. I feel that virtually any topic in this } \\
\text { course can be highly interesting once } \\
\text { I get into it. }\end{array}$ & 1 & 2 & 3 & 4 & 5 & 6 & 7 \\
\hline $\begin{array}{l}\text { 15. I find it is not helpful to study topics } \\
\text { in depth. It confuses and wastes } \\
\text { time, when all you need is a passing } \\
\text { acquaintance with topics. }\end{array}$ & 1 & 2 & 3 & 4 & 5 & 6 & 7 \\
\hline $\begin{array}{l}\text { 16. I find the best way to pass } \\
\text { examinations is to try to remember } \\
\text { answers to likely questions. }\end{array}$ & 1 & 2 & 3 & 4 & 5 & 6 & 7 \\
\hline
\end{tabular}




\begin{tabular}{|l|l|l|l|l|l|l|l|}
\hline $\begin{array}{l}\text { 17. I make a point of looking at most of } \\
\text { the suggested readings that go with } \\
\text { the lectures. }\end{array}$ & 1 & 2 & 3 & 4 & 5 & 6 & 7 \\
\hline $\begin{array}{l}\text { 18. In this course I come to most classes } \\
\text { with questions in mind that I want } \\
\text { answering. }\end{array}$ & 1 & 2 & 3 & 4 & 5 & 6 & 7 \\
\hline $\begin{array}{l}\text { 19. I learn some things by rote, going } \\
\text { over and over them until I know } \\
\text { them by heart even if I do not } \\
\text { understand them. }\end{array}$ & 1 & 2 & 3 & 4 & 5 & 6 & 7 \\
\hline $\begin{array}{l}\text { 20. My aim is to pass the course while } \\
\text { doing as little work as possible. }\end{array}$ & 1 & 2 & 3 & 4 & 5 & 6 & 7 \\
\hline
\end{tabular}

Section C: Metacognitive Strategy and School Well-being in the Advanced Mathematics course

This section is to find out your use of metacognitive strategies in the advanced mathematics course and your school well-being.

Please indicate the degree to which you agree with each of the statements by circling the response:

1: Strongly Disagree (SD)

2: Disagree (D)

3: Somewhat Disagree (SOD)

4: Undecided (U)

5: Somewhat Agree (SOA)

6: Agree (A)

7: Strongly Agree (SA)

\begin{tabular}{|l|c|c|c|c|c|c|c|}
\hline \multicolumn{1}{|l|}{ Degree of Agreement } \\
$\begin{array}{l}\text { Cognitive } \\
\text { Strategies and } \\
\text { School Well-being }\end{array}$ & SD & D & SOD & U & SOA & A & SA \\
\hline 1. I often feel bored in school. & 1 & 2 & 3 & 4 & 5 & 6 & 7 \\
\hline $\begin{array}{l}\text { 2. I'm certain I can master the skills } \\
\text { taught in school this year. }\end{array}$ & 1 & 2 & 3 & 4 & 5 & 6 & 7 \\
\hline 3. I like being in school. & 1 & 2 & 3 & 4 & 5 & 6 & 7 \\
\hline $\begin{array}{l}\text { 4. I skim through the unit to see how it } \\
\text { is organized before I read it } \\
\text { thoroughly. }\end{array}$ & 1 & 2 & 3 & 4 & 5 & 6 & 7 \\
\hline $\begin{array}{l}\text { 5. I can do even the hardest school } \\
\text { work if I try. }\end{array}$ & 1 & 2 & 3 & 4 & 5 & 6 & 7 \\
\hline
\end{tabular}




\begin{tabular}{|l|c|c|c|c|c|c|c|}
\hline $\begin{array}{l}\text { 6. I am happier when I am at school } \\
\text { than when I am not at school. }\end{array}$ & 1 & 2 & 3 & 4 & 5 & 6 & 7 \\
\hline $\begin{array}{l}\text { 7. If I become confused about } \\
\text { something I read, I go back to my } \\
\text { previous notes and sort it out. }\end{array}$ & 1 & 2 & 3 & 4 & 5 & 6 & 7 \\
\hline 8. I am often angry when I'm at school. & 1 & 2 & 3 & 4 & 5 & 6 & 7 \\
\hline $\begin{array}{l}\text { 9. If I have enough time, I can do a } \\
\text { good job on all my school work. }\end{array}$ & 1 & 2 & 3 & 4 & 5 & 6 & 7 \\
\hline $\begin{array}{l}\text { 10. I try to determine which concepts I } \\
\text { don't understand well. }\end{array}$ & 1 & 2 & 3 & 4 & 5 & 6 & 7 \\
\hline $\begin{array}{l}\text { 11. I often feel frustrated when I am } \\
\text { doing school work. }\end{array}$ & 1 & 2 & 3 & 4 & 5 & 6 & 7 \\
\hline $\begin{array}{l}\text { 12. I can do almost all the work in } \\
\text { school if I don't give up. }\end{array}$ & 1 & 2 & 3 & 4 & 5 & 6 & 7 \\
\hline $\begin{array}{l}\text { 13. I try to determine the way I study } \\
\text { according to the course requirements } \\
\text { and the instructor's teaching style. }\end{array}$ & 1 & 2 & 3 & 4 & 5 & 6 & 7 \\
\hline $\begin{array}{l}\text { 14. Most of the time, being in school } \\
\text { puts me in a good mood. }\end{array}$ & 1 & 2 & 3 & 4 & 5 & 6 & 7 \\
\hline $\begin{array}{l}\text { 15. Even if the work in school is hard, I } \\
\text { can learn it. }\end{array}$ & 1 & 2 & 3 & 4 & 5 & 6 & 7 \\
\hline $\begin{array}{l}\text { 16. I set goals for myself in order to } \\
\text { direct my study activities. }\end{array}$ & 1 & 2 & 3 & 4 & 5 & 6 & 7 \\
\hline $\begin{array}{l}\text { 17. I'm certain I can figure out how to } \\
\text { do the most difficult school work. }\end{array}$ & 1 & 2 & 3 & 4 & 5 & 6 & 7 \\
\hline 18. School often makes me feel sad. & 1 & 2 & 3 & 4 & 5 & 6 & 7 \\
\hline $\begin{array}{l}\text { 19. I ask myself questions to make sure I } \\
\text { understand the material. }\end{array}$ & 1 & 2 & 3 & 4 & 5 & 6 & 7 \\
\hline
\end{tabular}

\section{Thank You For Your Participation!}

(If you are interested in receiving a copy of the research findings, please provide us with your email address 


\section{Questionnaire}

(Chinese Version)

\section{中国学生学习动机、文化价值观、学习过程、以及 \\ 学习成绩的问卷调查}

个人信息

5. 性别:

6. 专业:

7. 中学所在地: 乡村 (是/否) 城镇 (是/否)

8. 学号: 


\section{第一部分: 文化价值观}

您对三种文化价值观念的态度 (这三种文化价值观念包括: 1、学习职责观, 即是 否把学习看作是学生的主要责任; 2、实用价值观, 即是否认为当前的学业成绩的 好坏会影响个人重要的前途目标; 3、群体职责观, 即是否认同以家庭、朋友、老 师为导向的群体目标）

请用圆圈标示出您对下列每个问题的看法:

\begin{tabular}{|c|c|c|c|c|c|c|c|}
\hline 文化价值观念 & $\begin{array}{l}\text { 非 } \\
\text { 常 } \\
\text { 不 } \\
\text { 同 } \\
\text { 意 }\end{array}$ & $\begin{array}{l}\text { 不 } \\
\text { 同 } \\
\text { 意 }\end{array}$ & $\begin{array}{l}\text { 有 } \\
\text { 些 } \\
\text { 不 } \\
\text { 同 } \\
\text { 意 }\end{array}$ & $\begin{array}{l}\text { 说 } \\
\text { 不 } \\
\text { 清 }\end{array}$ & $\begin{array}{l}\text { 有 } \\
\text { 些 } \\
\text { 同 } \\
\text { 意 }\end{array}$ & $\begin{array}{l}\text { 同 } \\
\text { 意 }\end{array}$ & $\begin{array}{l}\text { 非 } \\
\text { 常 } \\
\text { 同 } \\
\text { 意 }\end{array}$ \\
\hline $\begin{array}{l}\text { 1. 我希望家人为我的学业而感到骄傲 } \\
\text { 和自豪。 }\end{array}$ & 1 & 2 & 3 & 4 & 5 & 6 & 7 \\
\hline $\begin{array}{l}\text { 2. 我认为, 学习成绩对于我实现梦想 } \\
\text { 而言并非无足轻重。 }\end{array}$ & 1 & 2 & 3 & 4 & 5 & 6 & 7 \\
\hline $\begin{array}{l}\text { 3. 我不愿意在学业方面表现得过于与 } \\
\text { 众不同, 这会让朋友觉得我们不是 } \\
\text { 同类人。 }\end{array}$ & 1 & 2 & 3 & 4 & 5 & 6 & 7 \\
\hline 4. 我认为, 努力学习是学生的职责。 & 1 & 2 & 3 & 4 & 5 & 6 & 7 \\
\hline $\begin{array}{l}\text { 5. 我想让家人为我的学业而感到自 } \\
\text { 豪。 }\end{array}$ & 1 & 2 & 3 & 4 & 5 & 6 & 7 \\
\hline $\begin{array}{l}\text { 6. 我希望老师为我的学业而感到高 } \\
\text { 兴。 }\end{array}$ & 1 & 2 & 3 & 4 & 5 & 6 & 7 \\
\hline $\begin{array}{l}\text { 7. 我认为, 我努力学习的时候会感到 } \\
\text { 内心坦然。 }\end{array}$ & 1 & 2 & 3 & 4 & 5 & 6 & 7 \\
\hline $\begin{array}{l}\text { 8. 我认为, 学习成绩对于实现我的未 } \\
\text { 来目标具有一定的作用。 }\end{array}$ & 1 & 2 & 3 & 4 & 5 & 6 & 7 \\
\hline $\begin{array}{l}\text { 9. 我希望老师为我的学业表现而感到 } \\
\text { 欣慰。 }\end{array}$ & 1 & 2 & 3 & 4 & 5 & 6 & 7 \\
\hline $\begin{array}{l}\text { 10. 我认为, 付出努力好好学习会让我 } \\
\text { 感觉到自己做的是一件正确的、应 } \\
\text { 该的事情。 }\end{array}$ & 1 & 2 & 3 & 4 & 5 & 6 & 7 \\
\hline $\begin{array}{l}\text { 11. 我不想让朋友觉得我们之间有差 } \\
\text { 距。 }\end{array}$ & 1 & 2 & 3 & 4 & 5 & 6 & 7 \\
\hline $\begin{array}{l}\text { 12. 我希望能够让老师对我的学业感到 } \\
\text { 满意。 }\end{array}$ & 1 & 2 & 3 & 4 & 5 & 6 & 7 \\
\hline 13. 我认为, 掌握理解学校的授课内容 & 1 & 2 & 3 & 4 & 5 & 6 & 7 \\
\hline
\end{tabular}




\begin{tabular}{|c|c|c|c|c|c|c|c|}
\hline $\begin{array}{l}\text { 对于实现我的人生目标而言相当重 } \\
\text { 要。 }\end{array}$ & & & & & & & \\
\hline $\begin{array}{l}\text { 14. 我不想显得过于鹤立鸡群, 因为担 } \\
\text { 心这样会让我失去朋友。 }\end{array}$ & 1 & 2 & 3 & 4 & 5 & 6 & 7 \\
\hline $\begin{array}{l}\text { 15. 我认为, 不管结果如何, 努力学习 } \\
\text { 会让我感到内心更加坦然一些。 }\end{array}$ & 1 & 2 & 3 & 4 & 5 & 6 & 7 \\
\hline $\begin{array}{l}\text { 16. 我认为, 学习课业知识对于实现我 } \\
\text { 的未来目标具有一定作用。 }\end{array}$ & 1 & 2 & 3 & 4 & 5 & 6 & 7 \\
\hline $\begin{array}{l}\text { 17. 我想让父母为我的学业表现感到自 } \\
\text { 豪。 }\end{array}$ & 1 & 2 & 3 & 4 & 5 & 6 & 7 \\
\hline $\begin{array}{l}\text { 18. 为了能够融于朋友之中, 我会故意 } \\
\text { 地掩饰我们之间的差距。 }\end{array}$ & 1 & 2 & 3 & 4 & 5 & 6 & 7 \\
\hline $\begin{array}{l}\text { 19. 我希望自己的学业能够为家人带来 } \\
\text { 荣耀。 }\end{array}$ & 1 & 2 & 3 & 4 & 5 & 6 & 7 \\
\hline $\begin{array}{l}\text { 20. 我认为, 掌握学校的授课知识对于 } \\
\text { 我实现梦想而言很重要。 }\end{array}$ & 1 & 2 & 3 & 4 & 5 & 6 & 7 \\
\hline $\begin{array}{l}\text { 21. 我希望家人为我的学业而感到光 } \\
\text { 荣。 }\end{array}$ & 1 & 2 & 3 & 4 & 5 & 6 & 7 \\
\hline $\begin{array}{l}\text { 22. 我不想喜负老师的对我学业的期 } \\
\text { 望。 }\end{array}$ & 1 & 2 & 3 & 4 & 5 & 6 & 7 \\
\hline $\begin{array}{l}\text { 23. 为了能够融于朋友之中, 我有时会 } \\
\text { 在功课上故意表现得差一些。 }\end{array}$ & 1 & 2 & 3 & 4 & 5 & 6 & 7 \\
\hline $\begin{array}{l}\text { 24. 我认为, 不努力学习会让我有负罪 } \\
\text { 而于心不安。 }\end{array}$ & 1 & 2 & 3 & 4 & 5 & 6 & 7 \\
\hline $\begin{array}{l}\text { 25. 我不想让老师为我的学业表现而感 } \\
\text { 到失望。 }\end{array}$ & 1 & 2 & 3 & 4 & 5 & 6 & 7 \\
\hline
\end{tabular}




\section{第二部分: 大学英语课程的学习与动机}

A 组问题: 大学英语课程的学习目标定向

下列问题旨在揭示您努力学习大学英语课程的原因。

请用圆圈标示出您对下列每个问题的看法:

\begin{tabular}{|c|c|c|c|c|c|c|c|}
\hline 学习目标定向 & $\begin{array}{l}\text { 非 } \\
\text { 常 } \\
\text { 不 } \\
\text { 同 } \\
\text { 意 }\end{array}$ & $\begin{array}{l}\text { 不 } \\
\text { 同 } \\
\text { 意 }\end{array}$ & $\begin{array}{l}\text { 有 } \\
\text { 些 } \\
\text { 不 } \\
\text { 同 } \\
\text { 意 }\end{array}$ & $\begin{array}{l}\text { 说 } \\
\text { 不 } \\
\text { 清 }\end{array}$ & $\begin{array}{l}\text { 有 } \\
\text { 些 } \\
\text { 同 } \\
\text { 意 }\end{array}$ & $\begin{array}{l}\text { 同 } \\
\text { 意 }\end{array}$ & $\begin{array}{l}\text { 非 } \\
\text { 常 } \\
\text { 同 } \\
\text { 意 }\end{array}$ \\
\hline $\begin{array}{l}\text { 1. 害怕这门课的成绩不好常常会促使 } \\
\text { 我努力学习。 }\end{array}$ & 1 & 2 & 3 & 4 & 5 & 6 & 7 \\
\hline $\begin{array}{l}\text { 2. 我想从这门课中尽可能地学到更多 } \\
\text { 的知识。 }\end{array}$ & 1 & 2 & 3 & 4 & 5 & 6 & 7 \\
\hline $\begin{array}{l}\text { 3. 如果没有学会这门课中应该学会的 } \\
\text { 知识内容, 我常会放心不下。 }\end{array}$ & 1 & 2 & 3 & 4 & 5 & 6 & 7 \\
\hline $\begin{array}{l}\text { 4. 如果在课堂上只有我一个人能回答 } \\
\text { 得出老师的问题, 我会感觉很好。 }\end{array}$ & 1 & 2 & 3 & 4 & 5 & 6 & 7 \\
\hline $\begin{array}{l}\text { 5. 在课堂上不要献丑露拙, 这一点对 } \\
\text { 我而言比较重要。 }\end{array}$ & 1 & 2 & 3 & 4 & 5 & 6 & 7 \\
\hline $\begin{array}{l}\text { 6. 在这门课中我努力学习的目的是要 } \\
\text { 掌握新知识。 }\end{array}$ & 1 & 2 & 3 & 4 & 5 & 6 & 7 \\
\hline $\begin{array}{l}\text { 7. 我不愿意让别人感觉我的学习能力 } \\
\text { 很差, 这是我努力学习的主要原因 } \\
\text { 之一。 }\end{array}$ & 1 & 2 & 3 & 4 & 5 & 6 & 7 \\
\hline $\begin{array}{l}\text { 8. 我想要比班里的其他人学习成绩 } \\
\text { 好。 }\end{array}$ & 1 & 2 & 3 & 4 & 5 & 6 & 7 \\
\hline $\begin{array}{l}\text { 9. 我认为, 尽可能透彻地理解课程的 } \\
\text { 内容相当重要。 }\end{array}$ & 1 & 2 & 3 & 4 & 5 & 6 & 7 \\
\hline $\begin{array}{l}\text { 10. 有时我害怕自己可能并没有一像自 } \\
\text { 己希望地那样一透彻理解学习的内 } \\
\text { 容。 }\end{array}$ & 1 & 2 & 3 & 4 & 5 & 6 & 7 \\
\hline $\begin{array}{l}\text { 11. 在这门课上, 我之所以努力学习是 } \\
\text { 因为不愿意学习成绩很差。 }\end{array}$ & 1 & 2 & 3 & 4 & 5 & 6 & 7 \\
\hline $\begin{array}{l}\text { 12. 我努力学习的目的在于更好地理解 } \\
\text { 学到的知识。 }\end{array}$ & 1 & 2 & 3 & 4 & 5 & 6 & 7 \\
\hline $\begin{array}{l}\text { 13. 如果没有掌握这门课上所有应该学 } \\
\text { 到的知识内容, 我会为此感到担 }\end{array}$ & 1 & 2 & 3 & 4 & 5 & 6 & 7 \\
\hline
\end{tabular}




\begin{tabular}{|l|l|l|l|l|l|l|l|}
\hline 心。 & & & & & & & \\
\hline $\begin{array}{l}\text { 14. 我很重视是否能够比别人学习成绩 } \\
\text { 好。 }\end{array}$ & 1 & 2 & 3 & 4 & 5 & 6 & 7 \\
\hline $\begin{array}{l}\text { 15. 在这门课上, 我会害怕自己也许并 } \\
\text { 没有学会力所能及范围以内的知识 } \\
\text { 内容。 }\end{array}$ & 1 & 2 & 3 & 4 & 5 & 6 & 7 \\
\hline $\begin{array}{l}\text { 16. 我很看重是否比其他的同学学得更 } \\
\text { 好。 }\end{array}$ & 1 & 2 & 3 & 4 & 5 & 6 & 7 \\
\hline $\begin{array}{l}\text { 17. 在这门课上, 如果没有理解应该掌 } \\
\text { 握的学习内容, 我不会感到心安理 } \\
\text { 得。 }\end{array}$ & 1 & 2 & 3 & 4 & 5 & 6 & 7 \\
\hline $\begin{array}{l}\text { 18. 我希望透彻地掌握这门课的学习内 } \\
\text { 容。 }\end{array}$ & 1 & 2 & 3 & 4 & 5 & 6 & 7 \\
\hline $\begin{array}{l}\text { 19. 在这门课上, 我只是期望学习成绩 } \\
\text { 不要很差。 }\end{array}$ & 1 & 2 & 3 & 4 & 5 & 6 & 7 \\
\hline 20. 在这门课上, 我努力学习是为了取 \\
得比大多数人更加优异的成绩。
\end{tabular}

$B$ 组问题: 大学英语课程的学习方法

下列问题旨在揭示您大学英语课程的学习动机以及学习策略

请用圆圈标示出您对下列每个问题的看法:

\begin{tabular}{|c|c|c|c|c|c|c|c|}
\hline 认可程度 & $\begin{array}{l}\text { 非 } \\
\text { 常 } \\
\text { 不 } \\
\text { 同 } \\
\text { 意 }\end{array}$ & $\begin{array}{l}\text { 不 } \\
\text { 同 } \\
\text { 意 }\end{array}$ & $\begin{array}{l}\text { 有 } \\
\text { 些 } \\
\text { 不 } \\
\text { 同 } \\
\text { 意 }\end{array}$ & $\begin{array}{l}\text { 说 } \\
\text { 不 } \\
\text { 清 }\end{array}$ & $\begin{array}{l}\text { 有 } \\
\text { 些 } \\
\text { 同 } \\
\text { 意 }\end{array}$ & $\begin{array}{l}\text { 同 } \\
\text { 意 }\end{array}$ & $\begin{array}{l}\text { 非 } \\
\text { 常 } \\
\text { 同 } \\
\text { 意 }\end{array}$ \\
\hline $\begin{array}{l}\text { 1. 我发觉必须下足功夫好好学习新内 } \\
\text { 容新知识, 才能对之形成自己的见 } \\
\text { 解和认识, 只有这样才会让自己满 } \\
\text { 意。 }\end{array}$ & 1 & 2 & 3 & 4 & 5 & 6 & 7 \\
\hline $\begin{array}{l}\text { 2. 我感觉在学习这门课的时候, 有时 } \\
\text { 会产生一种强烈的自我满足之感。 }\end{array}$ & 1 & 2 & 3 & 4 & 5 & 6 & 7 \\
\hline $\begin{array}{l}\text { 3. 一般而言, 我只会对明确规定的课 } \\
\text { 程内容下功夫, 因为我认为没有必 } \\
\text { 要学习额外知识。 }\end{array}$ & 1 & 2 & 3 & 4 & 5 & 6 & 7 \\
\hline $\begin{array}{l}\text { 4. 我觉得这门课并不是很有意思, 所 } \\
\text { 以在功课学习上我所花的精力是少 }\end{array}$ & 1 & 2 & 3 & 4 & 5 & 6 & 7 \\
\hline
\end{tabular}




\begin{tabular}{|c|c|c|c|c|c|c|c|}
\hline 之又少。 & & & & & & & \\
\hline $\begin{array}{l}\text { 5. 我发觉大多数的新内容都很有趣, } \\
\text { 常常花额外的精力努力学习与之相 } \\
\text { 关的东西。 }\end{array}$ & 1 & 2 & 3 & 4 & 5 & 6 & 7 \\
\hline $\begin{array}{l}\text { 6. 我发觉这门课的学习有时就象一部 } \\
\text { 好的小说或电影一样令人兴奋。 }\end{array}$ & 1 & 2 & 3 & 4 & 5 & 6 & 7 \\
\hline $\begin{array}{l}\text { 7. 我只把学习的精力认真地用在课堂 } \\
\text { 内容或课程大纲所列的内容上。 }\end{array}$ & 1 & 2 & 3 & 4 & 5 & 6 & 7 \\
\hline $\begin{array}{l}\text { 8. 对重点知识点我会进行自我测试直 } \\
\text { 到完全理解。 }\end{array}$ & 1 & 2 & 3 & 4 & 5 & 6 & 7 \\
\hline $\begin{array}{l}\text { 9. 我发觉只要进行重点记忆而不需努 } \\
\text { 力理解内容就能应付大多数检查和 } \\
\text { 测试。 }\end{array}$ & 1 & 2 & 3 & 4 & 5 & 6 & 7 \\
\hline $\begin{array}{l}\text { 10. 我努力学习, 因为我发觉课程内容 } \\
\text { 很有趣。 }\end{array}$ & 1 & 2 & 3 & 4 & 5 & 6 & 7 \\
\hline $\begin{array}{l}\text { 11. 任课教师期望学生花大量的时间学 } \\
\text { 习考试范围以外的内容, 我认为这 } \\
\text { 是不合理的。 }\end{array}$ & 1 & 2 & 3 & 4 & 5 & 6 & 7 \\
\hline $\begin{array}{l}\text { 12. 有些内容在考试中只不过是 “小概 } \\
\text { 率事件” , 我认为学习掌握这些内 } \\
\text { 容毫无意义。 }\end{array}$ & 1 & 2 & 3 & 4 & 5 & 6 & 7 \\
\hline $\begin{array}{l}\text { 13. 针对每次上课中讨论到的有趣内 } \\
\text { 容, 我都会花大量课外时间找到更 } \\
\text { 多与之相关的材料。 }\end{array}$ & 1 & 2 & 3 & 4 & 5 & 6 & 7 \\
\hline $\begin{array}{l}\text { 14. 一旦我投入其中, 我感觉实际上这 } \\
\text { 门课的任何内容都很有趣。 }\end{array}$ & 1 & 2 & 3 & 4 & 5 & 6 & 7 \\
\hline $\begin{array}{l}\text { 15. 我发觉深入学习并无裨益。如果你 } \\
\text { 只需要对内容一带而过, 深入学习 } \\
\text { 会让人头军胛涨, 浪费时间。 }\end{array}$ & 1 & 2 & 3 & 4 & 5 & 6 & 7 \\
\hline $\begin{array}{l}\text { 16. 我感觉通过考试的最好办法就是努 } \\
\text { 力记住在考试中可能出现的问题的 } \\
\text { 答案。 }\end{array}$ & 1 & 2 & 3 & 4 & 5 & 6 & 7 \\
\hline $\begin{array}{l}\text { 17. 和课堂内容相关联的推荐阅读资 } \\
\text { 料, 其中的大部分我都会努力地读 } \\
\text { 一读。 }\end{array}$ & 1 & 2 & 3 & 4 & 5 & 6 & 7 \\
\hline $\begin{array}{l}\text { 18. 在这门课中, 大多数情况下我都是 } \\
\text { 带着问题、抱着想要寻找到问题答 } \\
\text { 案的态度去上课的。 } \\
\end{array}$ & 1 & 2 & 3 & 4 & 5 & 6 & 7 \\
\hline $\begin{array}{l}\text { 19. 有些知识的学习我要靠死记硬背, } \\
\text { 哪怕并不理解, 我会一遍遍的重复 } \\
\text { 直到牢牢记住。 }\end{array}$ & 1 & 2 & 3 & 4 & 5 & 6 & 7 \\
\hline
\end{tabular}




\begin{tabular}{|c|c|c|c|c|c|c|c|}
\hline $\begin{array}{c}\text { 20. 尽可能少地付出努力却能通过该门 } \\
\text { 课程, 这是我所向往追求的结果。 }\end{array}$ & 1 & 2 & 3 & 4 & 5 & 6 & 7 \\
\hline
\end{tabular}

C 组问题: 大学英语课程的元认知策略及学校心理健康状况

下列问题目的在于揭示您在学习大学英语课程过程中所应用的元认知策略及学校心 理健康状况

请用圆圈标示出您对下列每个问题的看法:

\begin{tabular}{|c|c|c|c|c|c|c|c|}
\hline $\begin{array}{l}\text { 元认知策略及 } \\
\text { 学校心理健康状况 }\end{array}$ & $\begin{array}{l}\text { 非 } \\
\text { 常 } \\
\text { 不 } \\
\text { 同 } \\
\text { 意 }\end{array}$ & $\begin{array}{l}\text { 不 } \\
\text { 同 } \\
\text { 意 }\end{array}$ & $\begin{array}{l}\text { 有 } \\
\text { 些 } \\
\text { 不 } \\
\text { 同 } \\
\text { 意 }\end{array}$ & $\begin{array}{l}\text { 说 } \\
\text { 不 } \\
\text { 清 }\end{array}$ & $\begin{array}{l}\text { 有 } \\
\text { 些 } \\
\text { 同 } \\
\text { 意 }\end{array}$ & $\begin{array}{l}\text { 同 } \\
\text { 意 }\end{array}$ & $\begin{array}{l}\text { 非 } \\
\text { 常 } \\
\text { 同 } \\
\text { 意 }\end{array}$ \\
\hline 1. 我常常感到学校课堂很无聊。 & 1 & 2 & 3 & 4 & 5 & 6 & 7 \\
\hline $\begin{array}{l}\text { 2. 我确信自己能够掌握本学年的学业 } \\
\text { 知识技能。 }\end{array}$ & 1 & 2 & 3 & 4 & 5 & 6 & 7 \\
\hline 3. 我喜欢学校课堂。 & 1 & 2 & 3 & 4 & 5 & 6 & 7 \\
\hline $\begin{array}{l}\text { 4. 在透彻地阅读章节内容之前, 我会 } \\
\text { 快速汶览一下该章节了解其结构框 } \\
\text { 架。 }\end{array}$ & 1 & 2 & 3 & 4 & 5 & 6 & 7 \\
\hline $\begin{array}{l}\text { 5. 只要我努力, 即使是再难的学业功 } \\
\text { 课问题我都能够攻克解决。 }\end{array}$ & 1 & 2 & 3 & 4 & 5 & 6 & 7 \\
\hline $\begin{array}{l}\text { 6. 跟在校外相比, 我在学校课堂里时 } \\
\text { 感到更开心。 }\end{array}$ & 1 & 2 & 3 & 4 & 5 & 6 & 7 \\
\hline $\begin{array}{l}\text { 7. 当我读到的内容让我感到迷惑不解 } \\
\text { 的时候, 我会翻查以前的笔记来解 } \\
\text { 决问题。 }\end{array}$ & 1 & 2 & 3 & 4 & 5 & 6 & 7 \\
\hline $\begin{array}{l}\text { 8. 在学校课堂里, 我常常会感到心情 } \\
\text { 不悦。 }\end{array}$ & 1 & 2 & 3 & 4 & 5 & 6 & 7 \\
\hline $\begin{array}{l}\text { 9. 如果我有充分的时间, 所有的学业 } \\
\text { 功课我都会做得很好。 }\end{array}$ & 1 & 2 & 3 & 4 & 5 & 6 & 7 \\
\hline $\begin{array}{l}\text { 10. 我会努力弄清楚有哪些概念我还没 } \\
\text { 有理解透彻。 }\end{array}$ & 1 & 2 & 3 & 4 & 5 & 6 & 7 \\
\hline $\begin{array}{l}\text { 11. 功课学习的时候, 我常常会感到心 } \\
\text { 情郁闪。 }\end{array}$ & 1 & 2 & 3 & 4 & 5 & 6 & 7 \\
\hline $\begin{array}{l}\text { 12. 只要坚持不放弃, 我就能做好几乎 } \\
\text { 所有的功课。 }\end{array}$ & 1 & 2 & 3 & 4 & 5 & 6 & 7 \\
\hline
\end{tabular}




\begin{tabular}{|l|l|l|l|l|l|l|l|}
\hline $\begin{array}{l}\text { 13. 我会根据课程需要以及授课教师的 } \\
\text { 讲课特点来决定自己的学习方法。 }\end{array}$ & 1 & 2 & 3 & 4 & 5 & 6 & 7 \\
\hline $\begin{array}{l}\text { 14. 大多数时候, 学校课堂会让我心情 } \\
\text { 愉快。 }\end{array}$ & 1 & 2 & 3 & 4 & 5 & 6 & 7 \\
\hline $\begin{array}{l}\text { 15. 即使学业功课有难度, 我也能够掌 } \\
\text { 握。 }\end{array}$ & 1 & 2 & 3 & 4 & 5 & 6 & 7 \\
\hline $\begin{array}{l}\text { 16. 我会为自己设定目标来指导学习任 } \\
\text { 务。 }\end{array}$ & 1 & 2 & 3 & 4 & 5 & 6 & 7 \\
\hline $\begin{array}{l}\text { 17. 即使是难度最大的学习任务, 我也 } \\
\text { 很确信自己能够设法解决。 }\end{array}$ & 1 & 2 & 3 & 4 & 5 & 6 & 7 \\
\hline $\begin{array}{l}\text { 18. 学校课堂常常会让我感到情绪低 } \\
\text { 落。 }\end{array}$ & 1 & 2 & 3 & 4 & 5 & 6 & 7 \\
\hline $\begin{array}{l}\text { 19. 我会自问自答来看看自己是否理解 } \\
\text { 了学习内容。 }\end{array}$ & 1 & 2 & 3 & 4 & 5 & 6 & 7 \\
\hline
\end{tabular}




\section{第三部分: 高等数学的学习与动机}

$\mathrm{A}$ 组问题: 高等数学课程的学习目标定向

下列问题旨在揭示您努力学习高等数学课程的原因。

请用圆圈标示出您对下列每个问题的看法:

\begin{tabular}{|c|c|c|c|c|c|c|c|}
\hline 认可程度 & $\begin{array}{l}\text { 非 } \\
\text { 常 } \\
\text { 不 } \\
\text { 同 } \\
\text { 意 }\end{array}$ & $\begin{array}{l}\text { 不 } \\
\text { 同 } \\
\text { 意 }\end{array}$ & $\begin{array}{l}\text { 有 } \\
\text { 些 } \\
\text { 不 } \\
\text { 同 } \\
\text { 意 }\end{array}$ & $\begin{array}{l}\text { 说 } \\
\text { 不 } \\
\text { 清 }\end{array}$ & $\begin{array}{l}\text { 有 } \\
\text { 些 } \\
\text { 同 } \\
\text { 意 }\end{array}$ & $\begin{array}{l}\text { 同 } \\
\text { 意 }\end{array}$ & $\begin{array}{l}\text { 非 } \\
\text { 常 } \\
\text { 同 } \\
\text { 意 }\end{array}$ \\
\hline $\begin{array}{l}\text { 1. 害怕这门课的成绩不好常常会促使 } \\
\text { 我努力学习。 }\end{array}$ & 1 & 2 & 3 & 4 & 5 & 6 & 7 \\
\hline $\begin{array}{l}\text { 2. 我想从这门课中尽可能地学到更多 } \\
\text { 的知识。 }\end{array}$ & 1 & 2 & 3 & 4 & 5 & 6 & 7 \\
\hline $\begin{array}{l}\text { 3. 如果没有学会这门课中应该学会的 } \\
\text { 知识内容, 我常会放心不下。 }\end{array}$ & 1 & 2 & 3 & 4 & 5 & 6 & 7 \\
\hline $\begin{array}{l}\text { 4. 如果在课堂上只有我一个人能回答 } \\
\text { 得出老师的问题, 我会感觉很好。 } \\
\end{array}$ & 1 & 2 & 3 & 4 & 5 & 6 & 7 \\
\hline $\begin{array}{l}\text { 5. 在课堂上不要献丑露拙, 这一点对 } \\
\text { 我而言比较重要。 }\end{array}$ & 1 & 2 & 3 & 4 & 5 & 6 & 7 \\
\hline $\begin{array}{l}6 . \text { 在这门课中我努力学习的目的是要 } \\
\text { 掌握新知识。 }\end{array}$ & 1 & 2 & 3 & 4 & 5 & 6 & 7 \\
\hline $\begin{array}{l}\text { 7. 我不愿意让别人感觉我的学习能力 } \\
\text { 很差, 这是我努力学习的主要原因 } \\
\text { 之一。 }\end{array}$ & 1 & 2 & 3 & 4 & 5 & 6 & 7 \\
\hline $\begin{array}{l}\text { 8. 我想要比班里的其他人学习成绩 } \\
\text { 好。 }\end{array}$ & 1 & 2 & 3 & 4 & 5 & 6 & 7 \\
\hline $\begin{array}{l}\text { 9. 我认为, 尽可能透彻地理解课程的 } \\
\text { 内容相当重要。 }\end{array}$ & 1 & 2 & 3 & 4 & 5 & 6 & 7 \\
\hline $\begin{array}{l}\text { 10. 有时我害怕自己可能并没有一像自 } \\
\text { 己希望地那样一透彻理解学习的内 } \\
\text { 容。 }\end{array}$ & 1 & 2 & 3 & 4 & 5 & 6 & 7 \\
\hline $\begin{array}{l}\text { 11. 在这门课上, 我之所以努力学习是 } \\
\text { 因为不愿意学习成绩很差。 }\end{array}$ & 1 & 2 & 3 & 4 & 5 & 6 & 7 \\
\hline $\begin{array}{l}\text { 12. 我努力学习的目的在于更好地理解 } \\
\text { 学到的知识。 }\end{array}$ & 1 & 2 & 3 & 4 & 5 & 6 & 7 \\
\hline 13. 如果没有掌握这门课上所有应该学 & 1 & 2 & 3 & 4 & 5 & 6 & 7 \\
\hline
\end{tabular}




\begin{tabular}{|c|c|c|c|c|c|c|c|}
\hline $\begin{array}{l}\text { 到的知识内容, 我会为此感到担 } \\
\text { 心。 }\end{array}$ & & & & & & & \\
\hline $\begin{array}{l}\text { 14. 我很重视是否能够比别人学习成绩 } \\
\text { 好。 }\end{array}$ & 1 & 2 & 3 & 4 & 5 & 6 & 7 \\
\hline $\begin{array}{l}\text { 15. 在这门课上, 我会害怕自己也许并 } \\
\text { 没有学会力所能及范围以内的知识 } \\
\text { 内容。 }\end{array}$ & 1 & 2 & 3 & 4 & 5 & 6 & 7 \\
\hline $\begin{array}{l}\text { 16. 我很看重是否比其他的同学学得更 } \\
\text { 好。 }\end{array}$ & 1 & 2 & 3 & 4 & 5 & 6 & 7 \\
\hline $\begin{array}{l}\text { 17. 在这门课上, 如果没有理解应该掌 } \\
\text { 握的学习内容, 我不会感到心安理 } \\
\text { 得。 }\end{array}$ & 1 & 2 & 3 & 4 & 5 & 6 & 7 \\
\hline $\begin{array}{l}\text { 18. 我希望透彻地掌握这门课的学习内 } \\
\text { 容。 }\end{array}$ & 1 & 2 & 3 & 4 & 5 & 6 & 7 \\
\hline $\begin{array}{l}\text { 19. 在这门课上, 我只是期望学习成绩 } \\
\text { 不要很差。 }\end{array}$ & 1 & 2 & 3 & 4 & 5 & 6 & 7 \\
\hline $\begin{array}{l}\text { 20. 在这门课上, 我努力学习是为了取 } \\
\text { 得比大多数人更加优异的成绩。 }\end{array}$ & 1 & 2 & 3 & 4 & 5 & 6 & 7 \\
\hline
\end{tabular}

$B$ 组问题：高等数学课程的学习方法

下列问题旨在揭示您高等数学课程的学习动机以及学习策略

请用圆圈标示出您对下列每个问题的看法:

\begin{tabular}{|l|c|c|c|c|c|c|c|}
\hline 认可程度 & $\begin{array}{c}\text { 非 } \\
\text { 常 } \\
\text { 不 } \\
\text { 同 }\end{array}$ & $\begin{array}{c}\text { 不 } \\
\text { 同 } \\
\text { 意 }\end{array}$ & $\begin{array}{c}\text { 有 } \\
\text { 些 } \\
\text { 不 } \\
\text { 同 } \\
\text { 意习方法及策略 }\end{array}$ & $\begin{array}{c}\text { 不 } \\
\text { 清 }\end{array}$ & $\begin{array}{c}\text { 有 } \\
\text { 些 } \\
\text { 同 } \\
\text { 意 }\end{array}$ & $\begin{array}{c}\text { 同 } \\
\text { 意 }\end{array}$ & $\begin{array}{c}\text { 非 } \\
\text { 常 } \\
\text { 同 } \\
\text { 意 }\end{array}$ \\
\hline $\begin{array}{l}\text { 1. 我发觉必须下足功夫好好学习新内 } \\
\text { 容新知识, 才能对之形成自己的见 } \\
\text { 解和认识, 只有这样才会让自己满 } \\
\text { 意。 }\end{array}$ & 1 & 2 & 3 & 4 & 5 & 6 & 7 \\
\hline 2. 我感觉在学习这门课的时候, 有时 & 1 & 2 & 3 & 4 & 5 & 6 & 7 \\
会产生一种强烈的自我满足之感。 & & & & & & & \\
\hline 3. 一般而言, 我只会对明确规定的课 & 1 & 2 & 3 & 4 & 5 & 6 & 7 \\
程内容下功夫, 因为我认为没有必 \\
要学习额外知识。
\end{tabular}




\begin{tabular}{|c|c|c|c|c|c|c|c|}
\hline $\begin{array}{l}\text { 以在功课学习上我所花的精力是少 } \\
\text { 之又少。 }\end{array}$ & & & & & & & \\
\hline $\begin{array}{l}\text { 5. 我发觉大多数的新内容都很有趣, } \\
\text { 常常花额外的精力努力学习与之相 } \\
\text { 关的东西。 }\end{array}$ & 1 & 2 & 3 & 4 & 5 & 6 & 7 \\
\hline $\begin{array}{l}\text { 6. 我发觉这门课的学习有时就象一部 } \\
\text { 好的小说或电影一样令人兴奋。 }\end{array}$ & 1 & 2 & 3 & 4 & 5 & 6 & 7 \\
\hline $\begin{array}{l}\text { 7. 我只把学习的精力认真地用在课堂 } \\
\text { 内容或课程大纲所列的内容上。 }\end{array}$ & 1 & 2 & 3 & 4 & 5 & 6 & 7 \\
\hline $\begin{array}{l}\text { 8. 对重点知识点我会进行自我测试直 } \\
\text { 到完全理解。 }\end{array}$ & 1 & 2 & 3 & 4 & 5 & 6 & 7 \\
\hline $\begin{array}{l}\text { 9. 我发觉只要进行重点记忆而不需努 } \\
\text { 力理解内容就能应付大多数检查和 } \\
\text { 测试。 }\end{array}$ & 1 & 2 & 3 & 4 & 5 & 6 & 7 \\
\hline $\begin{array}{l}\text { 10. 我努力学习, 因为我发觉课程内容 } \\
\text { 很有趣。 }\end{array}$ & 1 & 2 & 3 & 4 & 5 & 6 & 7 \\
\hline $\begin{array}{l}\text { 11. 任课教师期望学生花大量的时间学 } \\
\text { 习考试范围以外的内容, 我认为这 } \\
\text { 是不合理的。 }\end{array}$ & 1 & 2 & 3 & 4 & 5 & 6 & 7 \\
\hline $\begin{array}{l}\text { 12. 有些内容在考试中只不过是 “小概 } \\
\text { 率事件” , 我认为学习掌握这些内 } \\
\text { 容毫无意义。 }\end{array}$ & 1 & 2 & 3 & 4 & 5 & 6 & 7 \\
\hline $\begin{array}{l}\text { 13. 针对每次上课中讨论到的有趣内 } \\
\text { 容, 我都会花大量课外时间找到更 } \\
\text { 多与之相关的材料。 }\end{array}$ & 1 & 2 & 3 & 4 & 5 & 6 & 7 \\
\hline $\begin{array}{l}\text { 14. 一旦我投入其中, 我感觉实际上这 } \\
\text { 门课的任何内容都很有趣。 }\end{array}$ & 1 & 2 & 3 & 4 & 5 & 6 & 7 \\
\hline $\begin{array}{l}\text { 15. 我发觉深入学习并无禆益。如果你 } \\
\text { 只需要对内容一带而过, 深入学习 } \\
\text { 会让人头军脑涨, 浪费时间。 }\end{array}$ & 1 & 2 & 3 & 4 & 5 & 6 & 7 \\
\hline $\begin{array}{l}\text { 16. 我感觉通过考试的最好办法就是努 } \\
\text { 力记住在考试中可能出现的问题的 } \\
\text { 答案。 }\end{array}$ & 1 & 2 & 3 & 4 & 5 & 6 & 7 \\
\hline $\begin{array}{l}\text { 17. 和课堂内容相关联的推荐阅读资 } \\
\text { 料, 其中的大部分我都会努力地读 } \\
\text { 一读。 }\end{array}$ & 1 & 2 & 3 & 4 & 5 & 6 & 7 \\
\hline $\begin{array}{l}\text { 18. 在这门课中, 大多数情况下我都是 } \\
\text { 带着问题、抱着想要寻找到问题答 } \\
\text { 案的态度去上课的。 }\end{array}$ & 1 & 2 & 3 & 4 & 5 & 6 & 7 \\
\hline $\begin{array}{l}\text { 19. 有些知识的学习我要靠死记硬背, } \\
\text { 哪怕并不理解, 我会一遍遍的重复 }\end{array}$ & 1 & 2 & 3 & 4 & 5 & 6 & 7 \\
\hline
\end{tabular}




\begin{tabular}{|c|l|l|l|l|l|l|l|}
\hline 直到牢牢记住。 & & & & & & & \\
\hline $\begin{array}{c}\text { 20. 尽可能少地付出努力却能通过该门 } \\
\text { 课程, 这是我所向往追求的结果。 }\end{array}$ & 1 & 2 & 3 & 4 & 5 & 6 & 7 \\
\hline
\end{tabular}

C 组问题: 高等数学课程的元认知策略及学校心理健康状况

下列问题目的在于揭示您在学习高等数学课程过程中所应用的元认知策略及学校心 理健康状况

请用圆圈标示出您对下列每个问题的看法:

\begin{tabular}{|c|c|c|c|c|c|c|c|}
\hline $\begin{array}{l}\text { 元认知策略及 } \\
\text { 学校心理健康状况 }\end{array}$ & $\begin{array}{l}\text { 非 } \\
\text { 常 } \\
\text { 不 } \\
\text { 同 } \\
\text { 意 }\end{array}$ & $\begin{array}{l}\text { 不 } \\
\text { 同 } \\
\text { 意 }\end{array}$ & $\begin{array}{l}\text { 有 } \\
\text { 些 } \\
\text { 不 } \\
\text { 同 } \\
\text { 意 }\end{array}$ & $\begin{array}{l}\text { 说 } \\
\text { 不 } \\
\text { 清 }\end{array}$ & $\begin{array}{l}\text { 有 } \\
\text { 些 } \\
\text { 同 } \\
\text { 意 }\end{array}$ & $\begin{array}{l}\text { 同 } \\
\text { 意 }\end{array}$ & $\begin{array}{l}\text { 非 } \\
\text { 常 } \\
\text { 同 } \\
\text { 意 }\end{array}$ \\
\hline 1. 我常常感到学校课堂很无聊。 & 1 & 2 & 3 & 4 & 5 & 6 & 7 \\
\hline $\begin{array}{l}\text { 2. 我确信自己能够掌握本学年的学业 } \\
\text { 知识技能。 }\end{array}$ & 1 & 2 & 3 & 4 & 5 & 6 & 7 \\
\hline 3. 我喜欢学校课堂。 & 1 & 2 & 3 & 4 & 5 & 6 & 7 \\
\hline $\begin{array}{l}\text { 4. 在透彻地阅读章节内容之前, 我会 } \\
\text { 快速浏览一下该章节了解其结构框 } \\
\text { 架。 }\end{array}$ & 1 & 2 & 3 & 4 & 5 & 6 & 7 \\
\hline $\begin{array}{l}\text { 5. 只要我努力, 即使是再难的学业功 } \\
\text { 课问题我都能够攻克解决。 }\end{array}$ & 1 & 2 & 3 & 4 & 5 & 6 & 7 \\
\hline $\begin{array}{l}\text { 6. 跟在校外相比, 我在学校课堂里时 } \\
\text { 感到更开心。 }\end{array}$ & 1 & 2 & 3 & 4 & 5 & 6 & 7 \\
\hline $\begin{array}{l}\text { 7. 当我读到的内容让我感到迷惑不解 } \\
\text { 的时候, 我会翻查以前的笔记来解 } \\
\text { 决问题。 }\end{array}$ & 1 & 2 & 3 & 4 & 5 & 6 & 7 \\
\hline $\begin{array}{l}\text { 8. 在学校课堂里, 我常常会感到心情 } \\
\text { 不悦。 }\end{array}$ & 1 & 2 & 3 & 4 & 5 & 6 & 7 \\
\hline $\begin{array}{l}\text { 9. 如果我有充分的时间, 所有的学业 } \\
\text { 功课我都会做得很好。 }\end{array}$ & 1 & 2 & 3 & 4 & 5 & 6 & 7 \\
\hline $\begin{array}{l}\text { 10. 我会努力弄清楚有哪些概念我还没 } \\
\text { 有理解透彻。 }\end{array}$ & 1 & 2 & 3 & 4 & 5 & 6 & 7 \\
\hline $\begin{array}{l}\text { 11. 功课学习的时候, 我常常会感到心 } \\
\text { 情郁闷。 }\end{array}$ & 1 & 2 & 3 & 4 & 5 & 6 & 7 \\
\hline 12. 只要坚持不放弃, 我就能做好几乎 & 1 & 2 & 3 & 4 & 5 & 6 & 7 \\
\hline
\end{tabular}




\begin{tabular}{|c|c|c|c|c|c|c|c|}
\hline 所有的功课。 & & & & & & & \\
\hline $\begin{array}{l}\text { 13. 我会根据课程需要以及授课教师的 } \\
\text { 讲课特点来决定自己的学习方法。 }\end{array}$ & 1 & 2 & 3 & 4 & 5 & 6 & 7 \\
\hline $\begin{array}{l}\text { 14. 大多数时候, 学校课堂会让我心情 } \\
\text { 愉快。 }\end{array}$ & 1 & 2 & 3 & 4 & 5 & 6 & 7 \\
\hline $\begin{array}{l}\text { 15. 即使学业功课有难度, 我也能够掌 } \\
\text { 握。 }\end{array}$ & 1 & 2 & 3 & 4 & 5 & 6 & 7 \\
\hline $\begin{array}{l}\text { 16. 我会为自己设定目标来指导学习任 } \\
\text { 务。 }\end{array}$ & 1 & 2 & 3 & 4 & 5 & 6 & 7 \\
\hline $\begin{array}{l}\text { 17. 即使是难度最大的学习任务, 我也 } \\
\text { 很确信自己能够设法解决。 }\end{array}$ & 1 & 2 & 3 & 4 & 5 & 6 & 7 \\
\hline $\begin{array}{l}\text { 18. 学校课堂常常会让我感到情绪低 } \\
\text { 落。 }\end{array}$ & 1 & 2 & 3 & 4 & 5 & 6 & 7 \\
\hline $\begin{array}{l}\text { 19. 我会自问自答来看看自己是否理解 } \\
\text { 了学习内谷。 }\end{array}$ & 1 & 2 & 3 & 4 & 5 & 6 & 7 \\
\hline
\end{tabular}

\section{非常感谢您的参与及配合!}

(如果您对我们的研究结果感兴趣并希望收到一份研究结果报告, 请提供您的电子 邮件联系地址 


\section{APPENDIX D}

\section{LETTER OF INFORMATION}

The letter is written to request your participation in a questionnaire study aimed at exploring Chinese students' motivation and learning. This research is being conducted by Li Ouyang under the supervision of Dr. Nancy Hutchinson at the Faculty of Education, Queen's University in Kingston, Ontario, Canada as partial fulfillment of the graduate study program. The topic that is being researched is entitled Motivation, Cultural Values, Learning Processes, and Learning in Chinese Students. Basically, the study is being conducted to examine the applicability of the $2 \times 2$ goal orientation framework to Chinese university students and investigate the relationship found between each of the 2 x 2 goal orientation framework and the Student Approaches to Learning framework and these students' attitudes toward Confucian-heritage cultural $(\mathrm{CHC})$ values. The information obtained from this questionnaire will hopefully shed light on the role of culture and context on students' motivational and cognitive processes and outcomes.

As a part of the research, a questionnaire will be administered to inquire about: (a) your demographic information such as major, gender, location of middle school (urban or rural), and student number that offers the permission that your final examination grades in college English or advanced mathematics can be used for the research purpose, (b) your attitude towards the specified cultural values that are supposed to impact CHC students' motivation and achievement, and (c) your achievement goal orientations, approaches to learning (motive and strategy), school well-being, and use of metacognitive strategies.

If you consent to participate in the study by completing the questionnaire, then you will also be asked to provide (on the questionnaire) your student ID number, needed in order to obtain achievement data. It will take you approximately 50 minutes to complete the questionnaire. You are not obliged to answer any question that you find objectionable or that makes you feel uncomfortable. There are no known physical, psychological, economic, or social risks associated with this research. Your participation is completely voluntary. You are free to withdraw from this study at any point of time for any reason you may deem fit without any consequence to your academic standing at the university, and you may request removal of all or part of your data. To do this you could send email to me-be sure to include your student number - and your data will be removed once you confirm that you want to withdraw from the study.

The confidentiality shall be protected to the extent possible, and the information in the form of raw data on completed questionnaires shall be kept safe in a locked cabinet in the Graduate Student Facility at the Faculty of Education, Queen's University. You are assured that no information collected will be reported to anyone who is in authority over you, and the people who have access to the information are my supervisory committee and me. The research findings will be based on the analysis of aggregate participant data 
and may be reported in scholarly journals or conferences. Completed questionnaires and data will be destroyed following publication of the research.

If you are interested in receiving a copy of the research findings, please provide your email address in the space provided at the end of the questionnaire.

For any questions about this study, please feel free to contact me, Li Ouyang at 1-613533-6000 ext. 75952, email51o1@qlink.queensu.ca, or my supervisor Dr. Nancy L. Hutchinson at 1-613-533-3025, email hutchinn@educ.queensu.ca. For queries, concerns or complaints about the research ethics of this study, please contact the Dean of the Faculty of Education, Dr. Rosa Bruno-Jofré, at 1-613-533-6210, email brunojor@educ.queensu.ca, or the Chair of the Queen's University General Research Ethics Board, Dr. Stephen Leighton, at 1-613-533-6000 ext. 77034, email greb.chair@queensu.ca.

Thank you for your cooperation!

Yours sincerely,

Li Ouyang

M. Ed. Candidate

Faculty of Education, Queen's University 


\section{APPENDIX E}

\section{RECRUITMENT SCRIPT}

Hello, my name is Li Ouyang. I am a Master's student at the Faculty of Education, Queen's University in Canada. I am currently working on my Master's thesis with Dr. Nancy Hutchinson. I am studying motivation, cultural values, learning processes, and learning in Chinese students. There are two theories which may help us to understand better what motivates Chinese university students to learn. One theory has been primarily used to understand what motivates students in North America. It is called the $2 \mathrm{x} 2$ theory of goal orientations. Another theory has been used to study western and Chinese students. It is called Student Approaches to Learning (SAL). Basically, the study is being conducted to examine the applicability of the $2 \times 2$ goal orientation framework to Chinese university students. The second purpose is to investigate the relationship found between each of the 2 × 2 goal orientation framework and the Student Approaches to Learning framework and the students' attitudes toward Confucian-heritage cultural (CHC) values. This research will hopefully lead to a greater understanding of the role of culture and context on students' motivational and cognitive processes and outcomes.

If you consent to participate in the study by completing the questionnaire, then you will also be asked to provide (on the questionnaire) your student ID number, needed in order to obtain achievement data. The questionnaire will be administered to inquire about:

firstly, your demographic information such as major, gender, location of middle school (urban or rural), and student number that indicates that you permit your final examination grades in college English or advanced mathematics to be used for the research purpose; secondly your attitude towards the specified cultural values that are supposed to impact CHC students' motivation and achievement, and thirdly your achievement goal orientations, approaches to learning (motive and strategy), school well-being, and use of metacognitive strategies. It will take you approximately 50 minutes to complete the questionnaire. You will be presented first with the questions concerning your attitude towards the cultural values, and then with the questions concerning your motivation and learning for your college English course and for your advanced mathematics course respectively.

I would like to assure you that this study has been reviewed and received ethics clearance through the Research Ethics Board at Queen's University. Your participation is completely voluntary, and you are free to withdraw from this study at any point of time for any reason you may deem fit without any consequence to your academic standing at the university. To do this you could send email to me- - be sure to include your student number-and your data will be removed once you confirm that you want to withdraw from the study.

The confidentiality shall be protected to the extent possible. You are assured that no information collected will be reported to anyone who is in authority over you, and the people who have access to the information are my supervisory committee and me. The 
research findings will be based on the analysis of aggregate participant data and may be reported in scholarly journals or conferences. Completed questionnaires and data will be destroyed following publication of the research.

If you are interested in receiving a copy of the research findings, please provide your email address in the space provided at the end of the questionnaire.

When you complete the questionnaire, please put the questionnaire into the envelope labeled "Questionnaire." I will go to your seat and collect them.

If you have any questions or concerns, please do not hesitate to contact me at 5lo1@qlink.queensu.ca, or my supervisor Dr. Nancy L. Hutchinson at 1-613-533-3025, email hutchinn@educ.queensu.ca. For queries, concerns or complaints about the research ethics of this study, please contact the Dean of the Faculty of Education, Dr. Rosa BrunoJofré, at 1-613-533-6210, email brunojor@educ.queensu.ca, or the Chair of the Queen's University General Research Ethics Board, Dr. Stephen Leighton, at 1-613-533-6000 ext. 77034, email greb.chair@queensu.ca. 